\title{
A Proposed Path Forward for Transportation of High- Assay Low-Enriched Uranium
}

Josh Jarrell

September 27, 2018

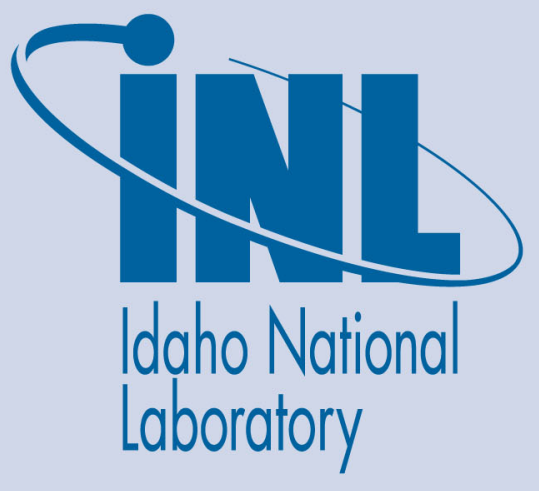

The INL is a U.S. Department of Energy National Laboratory operated by Battelle Energy Alliance 


\section{DISCLAIMER}

This information was prepared as an account of work sponsored by an agency of the U.S. Government. Neither the U.S. Government nor any agency thereof, nor any of their employees, makes any warranty, expressed or implied, or assumes any legal liability or responsibility for the accuracy, completeness, or usefulness, of any information, apparatus, product, or process disclosed, or represents that its use would not infringe privately owned rights. References herein to any specific commercial product, process, or service by trade name, trade mark, manufacturer, or otherwise, does not necessarily constitute or imply its endorsement, recommendation, or favoring by the U.S. Government or any agency thereof. The views and opinions of authors expressed herein do not necessarily state or reflect those of the U.S. Government or any agency thereof. 
INL/EXT-18-51518

Revision 0

\title{
A Proposed Path Forward for Transportation of High- Assay Low-Enriched Uranium
}

\author{
Josh Jarrell
}

September 2018

Idaho National Laboratory Idaho Falls, Idaho 83415

http://www.inl.gov

Prepared for the

U.S. Department of Energy

Office of Nuclear Energy

Under DOE Idaho Operations Office

Contract DE-AC07-05ID14517 



\section{SUMMARY}

Many of the advanced reactors currently being designed will use high-assay low-enriched uranium (HALEU) as the reactor fuel. HALEU is fuel that is enriched to 5-20\% uranium-235. With the change to higher enriched material, the industry will have new challenges regarding the development and regulatory approval of enrichment and fuel fabrication facilities and suitable transportation packages to support the economic use of HALEU materials. One area of concern relates to ensuring sub-criticality of the material during transportation as identified by the Nuclear Energy Institute (NEI). To evaluate the relevant work, expertise, and industry perspectives on HALEU, a workshop was organized to share relevant experience and insights into HALEU transportation, handling, and management.

At the workshop, held August 30 and 31, 2018, NEI and industry provided the following recommendations to the Department of Energy (DOE) and the national lab complex.

- DOE and the lab complex should communicate and educate the Nuclear Regulatory Commission (NRC) on criticality issues related to HALEU.

- Idaho National Laboratory (INL) should support work needed to certify package design(s) for the transportation of HALEU.

- An amendment of the Certificate of Compliance of an existing package could be used for the shipment of commercial quantities.

- DOE could provide funding to package designer(s) for analysis and engineering work for a package to be submitted to NRC for approval.

- INL should provide the expected amount of impurities (either a specific number or a range) that will be present in recycled naval fuel.

- In the longer term, DOE and the lab complex should increase the availability of criticality benchmark data to further reduce conservatism in package design.

In addition, a couple of key takeaways were identified, including the following:

- Although the labs can provide additional criticality experiments, industry has enough data to license facilities, overpacks, and cylinders. Validation from additional critical experiments to establish less uncertainty in the benchmarks will be helpful.

- A collective effort from industry is needed to express consistency on how much information exists or is needed related to criticality.

Based on interactions with industry, DOE, and national laboratories, largevolume transportation of fresh HALEU appears to be feasible from a criticality perspective. Specifically, an initial review of applicable criticality benchmark 
experiments identified numerous applicable experiments. However, a more thorough review of a realistic transportation package design is suggested.

Therefore, the following next steps are proposed:

1. Evaluate a large-volume package with uranium dioxide enriched to $20 \%$. The GNF-A NPC package was specifically proposed as a potentially viable option.

2. Based on the results of (1), determine if additional package designs and fuel material should be evaluated.

3. Based on the results of (1), determine if additional criticality experiments would be beneficial to improve the margins for criticality due to uncertainties.

4. Determine DOE transportation needs (packages sizes, shielding requirements, handling/operational requirements, and timing of availability) related to HALEU.

5. Continue to interface with NEI and interested industry companies to determine the appropriate time to engage the NRC. 


\section{CONTENTS}

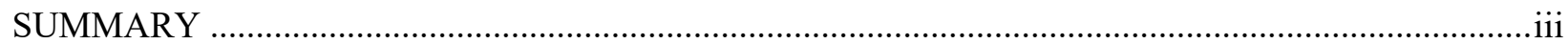

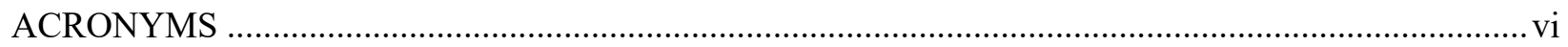

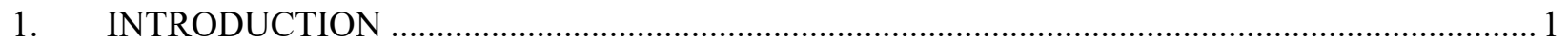

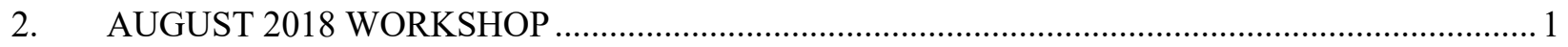

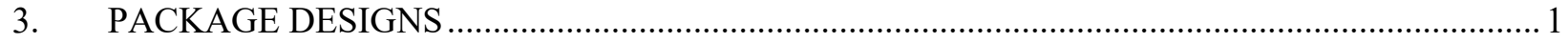

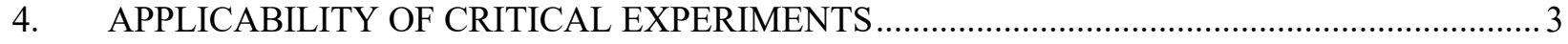

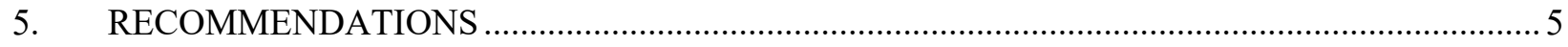

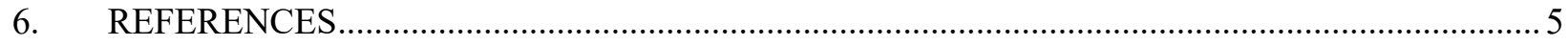

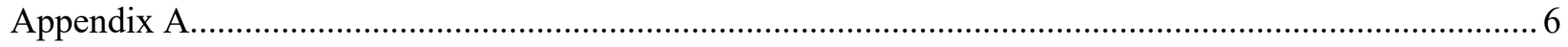

FIGURES

Figure 1. Example of Model 30B UF6 Cylinder [Appendix A] ............................................................2

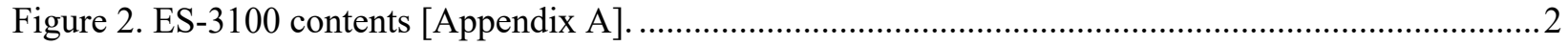

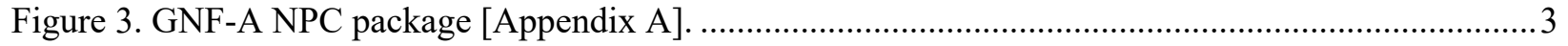

Figure 4. DAHER-TLI conceptual design of the 30B-20 cylinder for UF 6 [Appendix A] ........................ 3

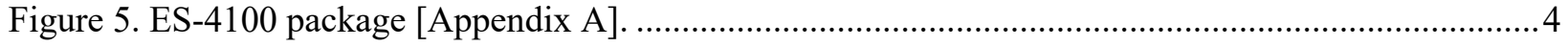

Figure 6. Plot of ck when comparing criticality experiments with the ES-4100 package with 20\% enriched $\mathrm{UF}_{6}$ [Appendix A]. 


\section{ACRONYMS}

DOE Department of Energy

HALEU high-assay low-enriched uranium

HEU highly-enriched uranium

INL Idaho National Laboratory

LEU low-enriched uranium

NE Office of Nuclear Energy

NEI Nuclear Energy Institute

NRC Nuclear Regulatory Commission

ORNL Oak Ridge National Laboratory 


\section{A Proposed Path Forward for Transportation of High- Assay Low-Enriched Uranium \\ 1. INTRODUCTION}

Many of the advanced reactors currently being designed will use high-assay low-enriched uranium (HALEU) as the reactor fuel [NEI 2018b]. HALEU is fuel that is enriched to 5-20\% uranium-235. With the change to higher enriched material, the industry will face new challenges regarding the development and regulatory approval of enrichment and fuel fabrication facilities and suitable transportation packages to support the economic use of HALEU materials. One area of concern relates to ensuring sub-criticality of the material during transportation as identified by the Nuclear Energy Institute (NEI) [NEI 2018a].

To evaluate the relevant work, expertise, and industry perspectives on HALEU, a workshop was organized to share relevant experience and insights into HALEU transportation, handling, and management.

\section{AUGUST 2018 WORKSHOP}

The Idaho National Laboratory (INL)/NEI Invitation-Only Technical Workshop on Transportation of High-Assay Low-Enriched Uranium was hosted at NEI in Washington, D.C. August 30 and 31, 2018. It brought together a range of industry participants, national laboratories, and Department of Energy (DOE) representatives. The primary objective of this workshop was to advise DOE on the gaps related to transportation of HALEU and licensing support activities. The fundamental goal was to ensure that transportation and handling of HALEU at associated fuel cycle facilities does not delay the deployment of advanced reactors. A summary of the workshop is included in Appendix A. Of particular interest are the recommendations from NEI and industry participants for DOE/INL:

- DOE and the lab complex should communicate and educate the NRC on criticality issues related to HALEU.

- INL should support work needed to certify package design for the transportation of HALEU.

- An amendment of the COC of an existing package could be used for the shipment of commercial quantities.

- $\quad$ DOE could provide funding to package designer(s) for analysis and engineering work for a package to be submitted to NRC for approval.

- INL should provide the expected amount of impurities (either a specific number or a range) that will be present in recycled naval fuel.

- In the longer term, DOE and the lab complex should increase the availability of criticality benchmark data (i.e., by performing, sponsoring, or data mining additional criticality benchmarks) to further reduce conservatism in package design.

\section{PACKAGE DESIGNS}

Current package designs are generally divided into two groups: (1) large packages designed for less than 5\% enriched material or (2) smaller packages designed for up to $100 \%$ enriched material. For example, $2,277 \mathrm{~kg}$ of $\mathrm{UF}_{6}$ currently can be transported in Type 30B packages at up to $5 \%$ enrichment (as illustrated in Figure 1), while only $24.9 \mathrm{~kg}$ of $\mathrm{UF}_{6}$ can be transported in Type 5A/B packages at up to $100 \%$ enrichment [ANSI 2012]. 


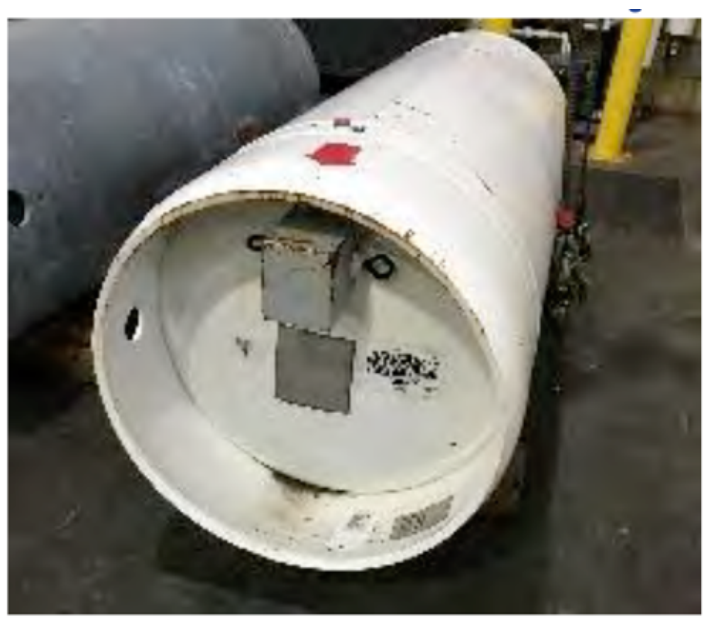

Figure 1. Example of Model 30B UF6 Cylinder [Appendix A].

Another example is the DOE-certified ES-3100 package, which has been design to hold $24 \mathrm{~kg}$ of $\mathrm{UO}_{2}$ as illustrated in Figure 2.

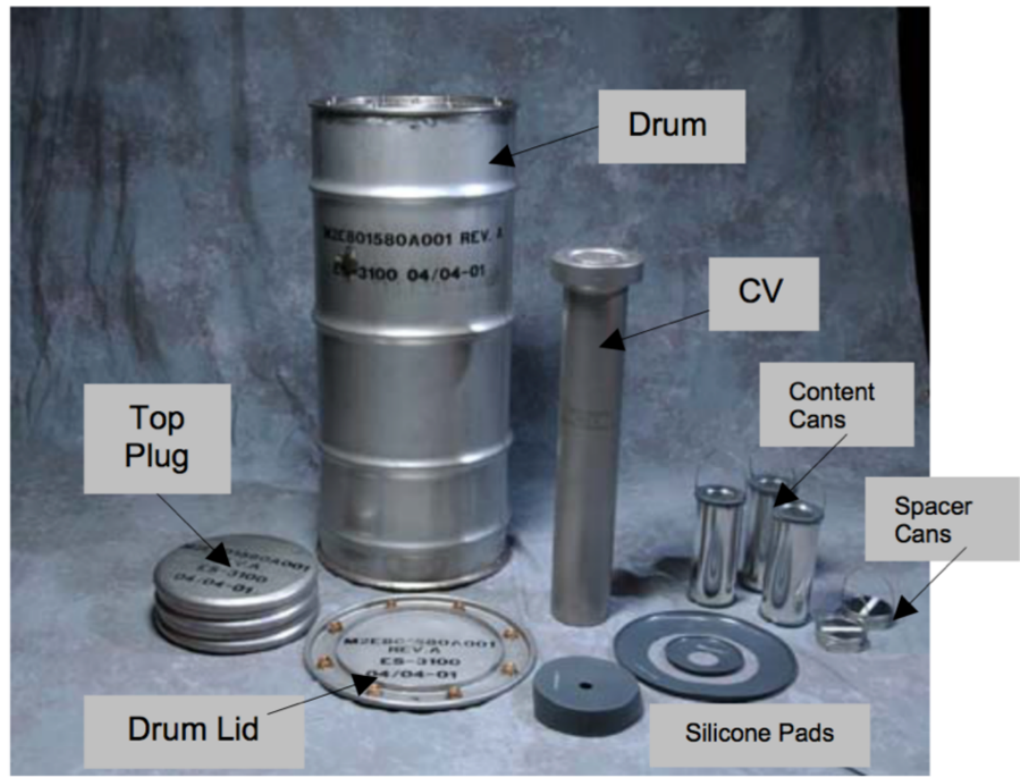

Figure 2. ES-3100 contents [Appendix A].

For fresh fuel packaging, GNF has a package, the GNF-A NPC, currently designed to move 5\% enriched $\mathrm{UO}_{2}, \mathrm{U}_{3} \mathrm{O}_{8}, \mathrm{UO}_{\mathrm{x}}$, and other uranium materials as shown in Figure 3. 


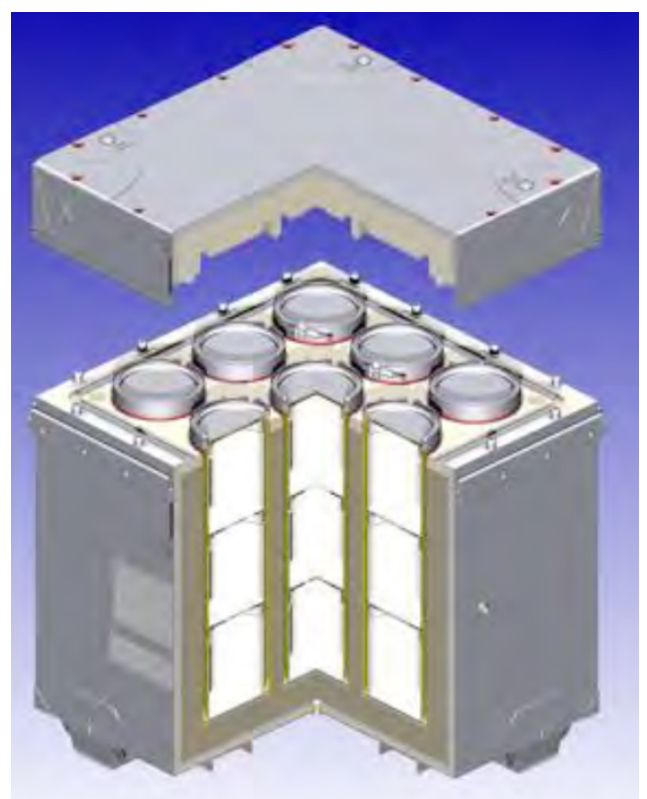

Figure 3. GNF-A NPC package [Appendix A].

In addition, Daher-TLI is in the process of developing a package based on the 30B package. It could accommodate $20 \%$ enriched $\mathrm{UF}_{6}$ and is called the $30 \mathrm{~B}-20$. It is being developed with a goal to transport up to $1,600 \mathrm{~kg}$ of $\mathrm{UF}_{6}$ enriched to $20 \%$ as illustrated in Figure 4.

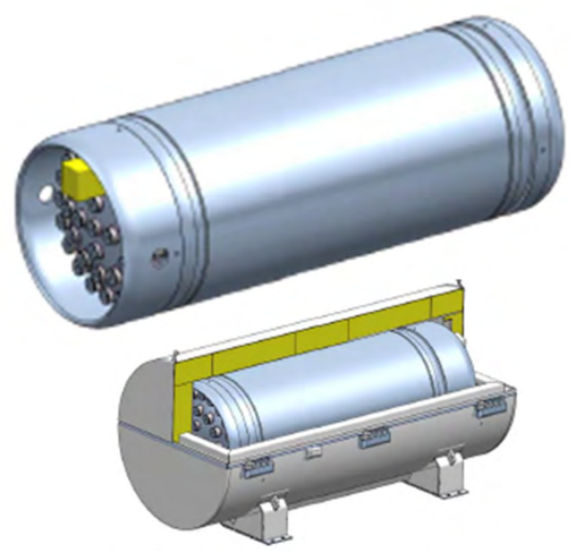

Figure 4. DAHER-TLI conceptual design of the 30B-20 cylinder for UF 6 [Appendix A].

\section{APPLICABILITY OF CRITICAL EXPERIMENTS}

To date, there have been over 5,000 approved International Criticality Safety Benchmark Evaluation Project (ICSBEP) criticality benchmarks, though most uranium experiments are done with less than 5\% enriched or greater than $20 \%$ enriched material. This potential lack of experiments in the $5-20 \%$ enriched range may increase the needed conservatism in package design. As such, Oak Ridge National Laboratory (ORNL) performed a set of initial analyses to explore the number of applicable experiments and found 376 ICSBEP experiments using uranium with 5-25\% enrichment.

The applicability of experiments is not solely dependent on enrichment, but must also take materials, configuration, and design into account. To determine how similar the application and the critical 
experiment models are, sensitivity/uncertainty tools in the TSUNAMI/SCALE software package were used to compare each application/experiment pair. This approach produced a correlation coefficient (ck) for each application pair, which ranged from 0 to 1 . A high ck value (near 1) for an application pair indicates that both models have similar sensitivities to the same nuclear data and, consequently, should have similar biases. Conversely, a low ck value (near 0) indicates that the two systems differ significantly and may have significantly different biases.

For the initial analysis, the ES-4100 package was evaluated with $20 \%$ enriched UF6. This package allows $1 \mathrm{~kg}$ of $\mathrm{U}-235$ in each of the four containment vessels and has a $\mathrm{B}_{4} \mathrm{C}$ poison element in the central location as illustrated in Figure 5.

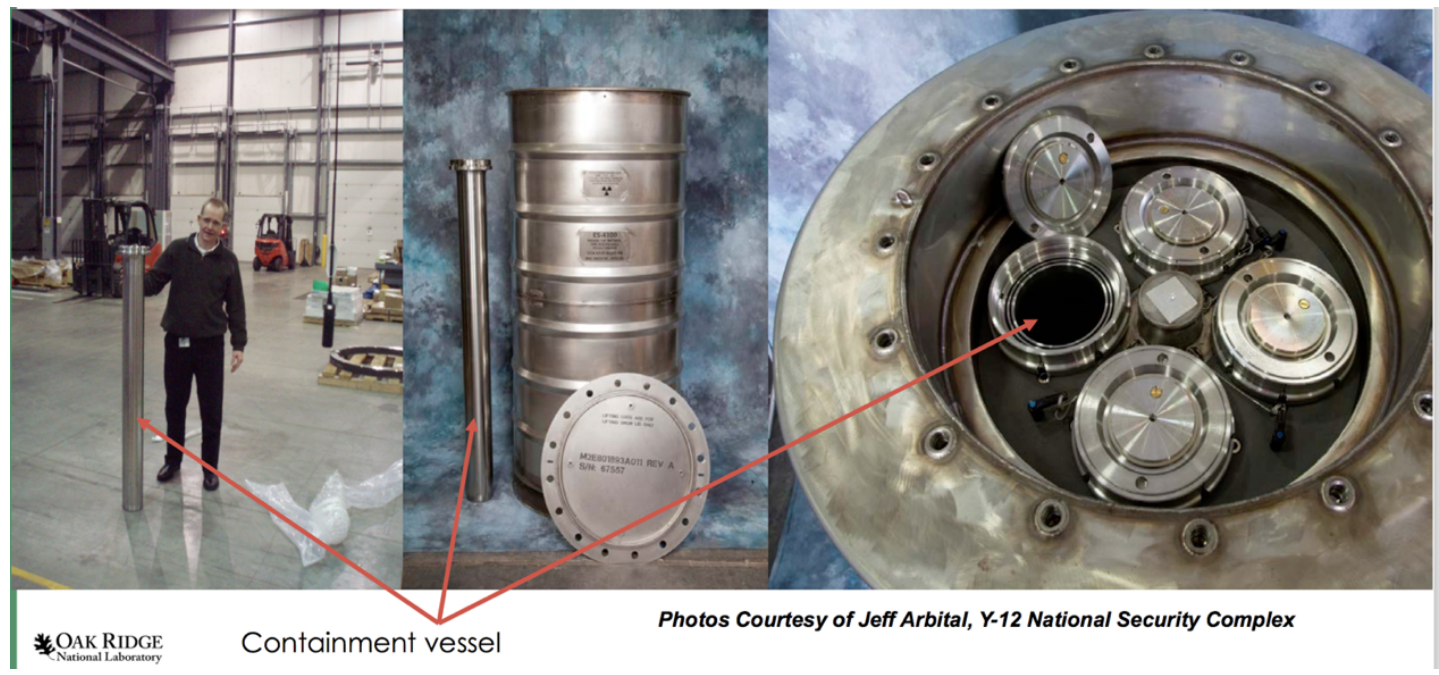

Figure 5. ES-4100 package [Appendix A].

The initial results indicated a large number of applicable experiments as illustrated in Figure 6.

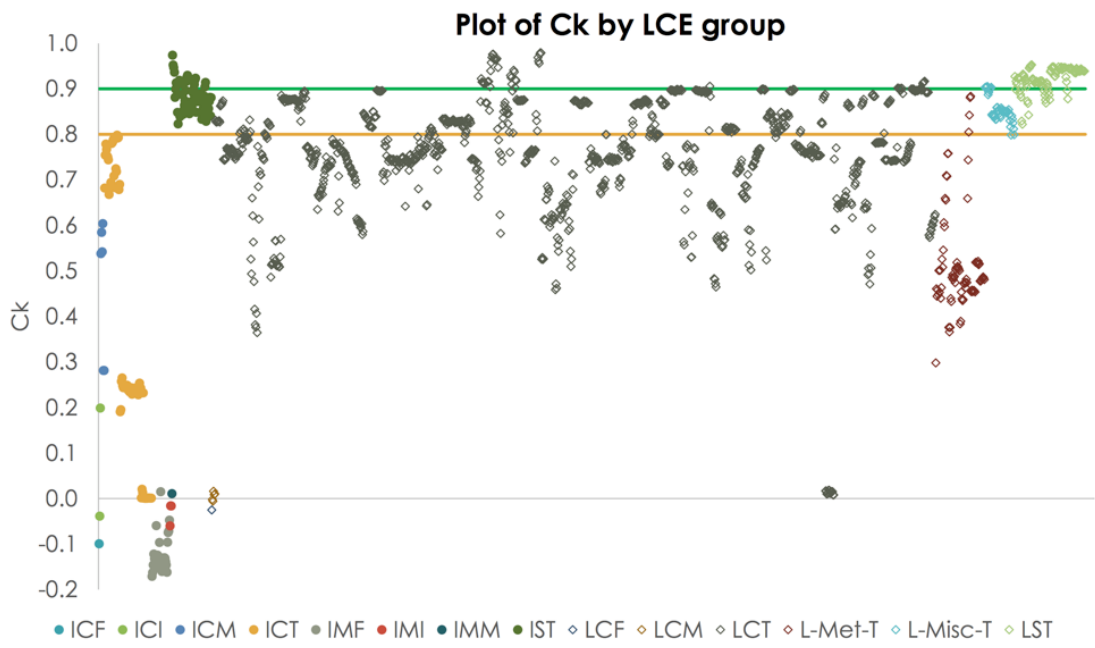

Figure 6. Plot of ck when comparing criticality experiments with the ES-4100 package with $20 \%$ enriched $\mathrm{UF}_{6}[$ Appendix A]. 
Of the 1,584 evaluated experiments, 173 had ck above 0.9 and 698 had ck above 0.8 . Therefore, initial results imply that a significant number of experiments will be applicable to a transportation package with HALEU. However, there are some questions that will need to be confirmed, including:

- Do larger-volume packages with more reactive configurations have similar numbers of applicable benchmarks?

- Do other fuel forms (e.g., $\mathrm{UO}_{2}, \mathrm{U}_{3} \mathrm{O}_{8}$, TRISO-based fuels, and metallic fuels) have similar numbers of applicable benchmarks?

- For larger packages, what are the biases and uncertainties due to nuclear data?

\section{RECOMMENDATIONS}

Based on communication with industry, DOE, and national laboratories, large-volume transportation of fresh HALEU appears to be feasible from a criticality perspective. Specifically, an initial review of applicable criticality benchmark experiments identified numerous applicable experiments. In fact, the handling requirements driven by the material characteristics may be a more pressing concern than the transportation issues. However, for completeness, a more thorough review of a realistic transportation package design is suggested. Therefore, the following next steps related to the transportation of HALEU are proposed:

1. Evaluate a large-volume package with uranium dioxide enriched to $20 \%$. The GNF-A NPC package was specifically proposed as a potentially viable option.

2. Based on the results of (1), determine if additional package designs and fuel material should be evaluated.

3. Based on the results of (1), determine if additional criticality experiments would be beneficial to improve the margins for criticality due to uncertainties.

4. Determine DOE transportation needs (packages sizes, shielding requirements, handling/operational requirements, and timing of availability) related to HALEU.

5. Continue to interface with NEI and interested industry companies to determine the appropriate time to engage the NRC.

\section{REFERENCES}

ANSI 2012

NEI 2018a

NEI 2018b
ANSI N14.1: Packaging of Uranium Hexafluoride for Transport, American National Standards Institute, 2012.

Addressing the Challenges with Establishing the Infrastructure for the front-end of the Fuel Cycle for Advanced Reactors, NEI White Paper, January 2018. https://www.nei.org/CorporateSite/media/filefolder/resources/reports-andbriefs/white-paper-advanced-fuel-cycle-infrastructure-201801.pdf

NEI February 22, 2018 Statement on HALEU https://www.nei.org/news/2018/revamp-of-fuel-industry-support-advancedreactors 
Appendix A 


\section{Meeting Summary}

SUBJECT: INL-NEI Invitation-Only Technical Workshop on Transportation of High Assay LowEnriched Uranium

\section{ORGANIZER: INL and NEI}

AUTHOR: Gordon Petersen (INL)

DATE: August $30^{\text {th }}$ and August $31^{\text {st }}$

PURPOSE: The primary objective of this workshop will be to advise DOE on the gaps related to transportation of HALEU and licensing support activities. The goal is to ensure that transportation and handling of HALEU at associated fuel cycle facilities does not delay the ability of advanced reactors to be deployed.

OVERVIEW: The meeting started with lunch provided by NEI. Everett Redmond from NEI then began the meeting by announcing safety procedures and letting all the attendees introduce themselves. He then went over the mission statement of the NEI Fuels Task Force and the letter sent to Secretary Perry by NEI specifiying the amount of HALEU needed over the next ten years. Josh Jarrell from INL took over and introduced the goals of the meeting and reiterated some of the questions Everett proposed. Over the next day, presentations were given by industry, national laboratories, and the NRC. Each presentation concluded with time to ask questions and have discussions. The first day concluded with a discussion in preparation for the NRC visit led by Nima Ashkeboussi. The second day was led off with a presentation from the NRC followed by discussion. Next the labs and industry continued presenting topics related to the capabilities and needs related to HALEU management. The second day concluded with a DOE perspective given by John Herczeg, industry/NEI recommendations for DOE led by Nima, and a wrap up of action items led by Josh. The following notes provide a short overview of the presentations given.

Industry provided information from an enrichment, licensing, and transportation perspective:

1. Capabilities exist for enrichment up to $20 \%$ (Melissa Mann/URENCO)

a. Imperative to develop fuel cycle with consortium (fabricators, convertors, enrichers, reactor operators, transporters, etc.) approach for licensing framework

b. Questions remain concerning transforming Cat III facility into Cat II facility and transportation off site

c. Suggests engaging NRC and ANSI/ASTM standards now

2. Experience in licensing facilities with enrichments greater than $5.0 \mathrm{wt} . \% \mathrm{U}^{235}$ and have transportation packages that can be amended for HALEU (Lon Paulson/GNF)

a. GNFA Wilmington fuel fabrication facility

b. Model RAJ-II Type B fissile package will require SAR update to transport HALEU

c. Model NPC Type A fissile package will require SAR update to transport HALEU

d. Licensing a new package takes 42 weeks minimum for NRC review, but start to finish takes $\sim 5$ years

3. Packages for shipping 20\% enriched materials (Andy Langston/DAHER-TLI)

a. Majority of DOE $20 \%$ enriched fuel shipped in drum type packages (Versa-Pac)

b. Currently Versa-Pac is under NRC amendment application for $1 \mathrm{~S} / 2 \mathrm{~S}$ cylinder

c. $30 \mathrm{~B}$ cylinder design up to $20 \% \mathrm{UF}_{6}$ enrichment currently under development

i. $1600 \mathrm{~kg}$

ii. $30 \mathrm{~B}-20$ can be operated and handled in same way as 30B cylinder 
iii. Licensing overpack and cylinder with French, German, and NRC.

d. Package for $5 \mathrm{~B} / \mathrm{A}$ cylinders under development

i. VP-55XL is an enhanced version of the TLI's NRC approved VP-55

4. Licensing transport overpacks and packages with NRC (Rick Migliore/TN Americas)

a. Little concern in ability to license/certify package

b. Industry is not in position to create criticalitybenchmarks

c. More concerned with licensing and packaging on the SNF side after the fuel is removed from the reactor

The labs presented on the following capabilities:

1. Nuclear Data and Benchmarking Program (Brad Rearden/ORNL)

a. High uncertainties in cross sections with-in intermediate and high energy ranges

b. Cross cutting program can support the needs of advance reactors

i. Use correlation coefficients in trending analyses to determine cross section sensitivities

ii. Perform gap analyses for non LWRs

c. Mine existing experiments to determine similarities

2. INL could bridge material gap for 10 years (Monica Regalbuto/INL)

a. Naval reactor fuel, EBR-II, and ZPPR plates can be available for downblending

b. Issues may exist with uncertainties and dose of U-234

3. Nuclear Criticality Safety Program (Doug Bowen/ORNL)

a. National Criticality Experiments Research Center (NCERC) best for 20\% enrichment experiments

b. Experiments are expensive and time consuming to setup and perform

i. $\quad$ Cost $\rightarrow \$ 425 \mathrm{k}-\$ 2.1 \mathrm{M}$

ii. Time frame $\rightarrow 24-54$ months

4. Validation discussion (John Scaglione/ORNL)

a. Some techniques do not need experiments but can instead use physics-based solution

b. Criticality validation process for ES-4100 package

i. Requires detailed knowledge of the application system

ii. Used similarity assessment to find how similar experiments were to target $(\mathrm{Ck}$ value)

iii. Over 175 relevant experiments with $\mathrm{C}_{\mathrm{k}}$ over 0.9 and just under 700 with $\mathrm{Ck}$ over 0.8 , when considering HALEU $\mathrm{UF}_{6}$ in the ES-4100 package. Therefore, optimism that experiments exist to defend future package designs for HALEU transport.

The NRC's also gave a short presentation followed by a discussion (Drew Barto/NRC)

1. Stressed the lack of information from $>5 \% \mathrm{x}<19.75 \%$ enrichment

2. Explained difficulty in changing existing regulation, especially regarding moderator exclusion for $>5 \%$ enriched $\mathrm{UF}_{6}$.

3. Gave timeline for expected review

a. Complete entire process from day of acceptace of application to certifying in 7.4 months for $80 \%$ of transportation reviews and 2 years for all transportation reviews

\section{ACTION ITEMS/IMPORTANT TAKE-AWAYS}

1. DOE is committed to transportation of material regardless of form, and NEI will be be the focal point for prioritization of different strategies.

2. Although the labs can provide additional criticality experiments, industry has enough data to license facilities, overpacks, and cylinders. Validation to find more critical experiments to establish less uncertainty in the benchmarks will be helpful. 
3. A collective effort from industry is needed to express consistency on how much information exists or is needed in regards to criticality.

4. NEI will change HALEU white paper concerning criticality.

5. NRC needs to validate methodology is applicable at $>5 \%$ enriched.

6. NRC already has group that meets bi-weekly concerning HALEU.

a. It will be very difficult and time-consuming to change $\mathrm{NRC}$ regulations

\section{INDUSTRIES REQUEST FOR NEI, DOE, LAB COMPLEXES}

1. DOE and the lab complex should communicate and educate the NRC on criticality issues related to HALEU.

2. INL should support work needed to certify package design for the transportation of HALEU.

a. Suggest amending the COC of an existing package used for the shipment of commercial quantities.

b. Suggest DOE provide funding to package designer(s) for analysis and engineering work for a package to be submitted to NRC for approval.

3. INL should provide specific, or a range, on the expected impurities that will be present in recycled naval fuel.

4. In the longer term, DOE and the lab complex should increase the availabilitiy of criticality benchmark data (i.e., by performing, sponsoring, or data mining additional criticality benchmarks) to further reduce conservatism in package design.

\section{ATTACHMENTS}

- Part I: Agenda

- Part II: Attendee List

- Part III: Presentations 


\section{Agenda \\ August 30-31, 2018 \\ Nuclear Energy Institute, \\ 1201 F Street NW, Suite 1100 \\ Washington, DC 20004 \\ Room Clean Air A-B}

INL-NEI Technical Workshop on Transportation of High Assay Low-Enriched Uranium

\begin{tabular}{|c|c|}
\hline \multicolumn{2}{|r|}{ August 30} \\
\hline 12:00 pm & $\begin{array}{l}\text { Lunch / Introductions / Goals of Meeting - Josh Jarrell, INL and } \\
\text { Everett Redmond, NEI }\end{array}$ \\
\hline 1:00 pm & $\begin{array}{l}\text { Validation and role of critical experiments and nuclear data - Brad Rearden, } \\
\text { ORNL }\end{array}$ \\
\hline 1:45 pm & $\begin{array}{l}\text { Potential for material recovery and form/dose/isotope concerns - Monica } \\
\text { Regalbuto, INL }\end{array}$ \\
\hline 2:15 pm & Potential for enrichment up to $20 \%$ - Melissa Mann, URENCO \\
\hline 2:45 pm & Break \\
\hline 3:00 pm & Evaluation of HALEU fabrication issues - Lon Paulson, GEH/GNF \\
\hline 3:30 pm & HALEU UF6 transportation issues - Andy Langston, DAHER-TLI \\
\hline 4:00 pm & Cask supplier perspective - Rick Migliore, TN Americas \\
\hline 4:15 pm & Criticality sensitivity analysis - Brad Rearden, ORNL \\
\hline 4:45 pm & Discussion and preparation for NRC Visit - Nima Ashkeboussi, NEI \\
\hline $5: 15$ pm & Adjourn \\
\hline
\end{tabular}




\section{8:30 am}

9:30 am

9:40 am

10:10 am

10:30 am

11:00 am

11:10 am

11:40 am

12:00 pm

\section{August 31}

NRC perspective - Drew Barto, NRC

Break

Criticality facilities and cost and process for new criticality experiments Doug Bowen (ORNL)

Validation discussion: How important are material forms to establishing applicability of criticality experiments? Is there "common ground"? If not, what forms should be the focus? - John Scaglione, ORNL

Example validation process: How important is the application model (e.g., transportation package design, fuel form, and materials) and how are the criticality experiments used to establish appropriate bias and uncertainty? - John Scaglione, ORNL

DOE perspective - John Herczeg, DOE

Industry/NEI Needs and Recommendations for DOE - Nima Ashkeboussi, NEI Wrap up /Action Items - Josh Jarrell, INL

Adjourn 


\section{Part II}

\section{HALEU Tech Workshop}

Thursday Aug. 30 and 31, 2018

\section{2:00PM- 5:00PM 8:00AM-1:00PM}

\begin{tabular}{|c|c|c|}
\hline Last Name & First Name & Company \\
\hline Blanton & Paul & SRNL \\
\hline Bowen & Doug & ORNL \\
\hline Bowers & Harlan & X-Energy \\
\hline Caponiti & Alice & DOE \\
\hline Carmichael & Ben & Southern Nuclear \\
\hline Cummings & Kris & Curtiss Wright \\
\hline Duskas & Andrea & DOE \\
\hline Gillespie & Mary & DOE \\
\hline Gresham & Jim & Westinghouse \\
\hline Griffith & Andy & DOE \\
\hline Hackett & Micah & Kairos \\
\hline Herczeg & John & DOE \\
\hline \begin{tabular}{|l|} 
Jarrell \\
\end{tabular} & Josh & INL \\
\hline Kliewer & Rod & Framatome \\
\hline Knauf & Florie & Centrus \\
\hline Krich & Rod & X-Energy \\
\hline Kucukboyaci & Vefa & Westinghouse \\
\hline Lane & Carol & X-Energy \\
\hline Langston & Andy & Daher-TLI \\
\hline Lell & Richard & ANL \\
\hline Lutchenkov & Dmitiri & MPR \\
\hline Mann & Melissa & URENCO \\
\hline Migliore & Rick & Orano \\
\hline Moss-Herman & Cheryl & DOE \\
\hline Pappano & Pete & X-Energy \\
\hline Paulson & Lon & GNF \\
\hline Petersen & Gordon & INL \\
\hline Rearden & Brad & ORNL \\
\hline Regalbuto & Monica & INL \\
\hline Scaglione & John & ORNL \\
\hline Schilthelm & Steve & BWXT \\
\hline Scott & C. Tyler & Westinghouse \\
\hline Stucker & Dave & Westinghouse \\
\hline Tweardy & Matt & NNSA \\
\hline Waud & Brian & NNSA \\
\hline Welling & Craig & DOE \\
\hline
\end{tabular}




\section{Part III}


Everett Redmond, Ph.D. Nuclear Energy Institute

\section{HALEU WORKSHOP}




\section{NEI FUELS TASK FORCE}

- Mission: Lead industry efforts in identifying and resolving regulatory and policy issues for the development of the nuclear fuel supply chain for advanced reactors with an emphasis on challenges related to the utilization of high assay low enriched uranium. 
- Values in MTU

- Current fleet uses about 2000 MTU/year

- Letter to Secretary Perry July 5, 2018

- Data from eight companies

- Not all ARs or advanced fuels need HALEU

\begin{tabular}{|c|c|c|}
\hline Year & Total & Cumulative \\
\hline 2018 & 0.026 & 0.026 \\
\hline 2019 & 1.506 & 1.532 \\
\hline 2020 & 2.21 & 3.7 \\
\hline 2021 & 4.2 & 7.9 \\
\hline 2022 & 3.7 & 11.6 \\
\hline 2023 & 18.8 & 30.4 \\
\hline 2024 & 10.3 & 40.7 \\
\hline 2025 & 12.4 & 53.1 \\
\hline 2026 & 57.4 & 110.5 \\
\hline 2027 & 73.6 & 184.1 \\
\hline 2028 & 108.1 & 292.2 \\
\hline 2029 & 111.8 & 404.0 \\
\hline 2030 & 185.5 & 589.5 \\
\hline
\end{tabular}




\section{QUESTIONS TO CONSIDER}

- Will the fuel cycle process be similar to current fleet?

Mining $\Rightarrow$ Conversion $\Rightarrow$ Enrich $\Rightarrow$ Fab $\Rightarrow$ Reactor
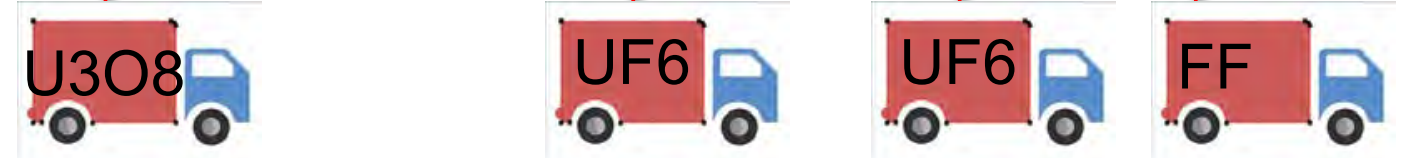

- What differences might exist - material form, etc.?

- Should the task force engage publicly with NRC on the issues from this workshop?

- What other topics should the task force tackle? 


\section{Transportation of HALEU Workshop - Introduction and Background}

Josh Jarrell

Used Fuel Relationship Manager, INL

Josh.Jarrell@inl.gov

208-526-1614

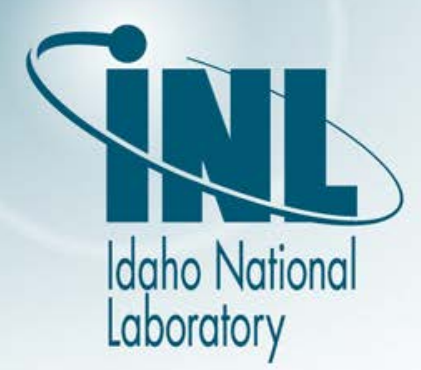




\section{Purpose of this workshop}

- Develop and collect industry input and recommendations for future HALEU transportation needs

- Avoid transportation delaying deployment of advanced reactors/fuels

- Focus is on large volume shipments of materials

- Criticality is expected to be most challenging design aspect

- Applicable to handling and storage of material at other facilities

- INL will be providing a "path forward" report to DOE by the end of September

- Recommendations from this workshop will be included in this report
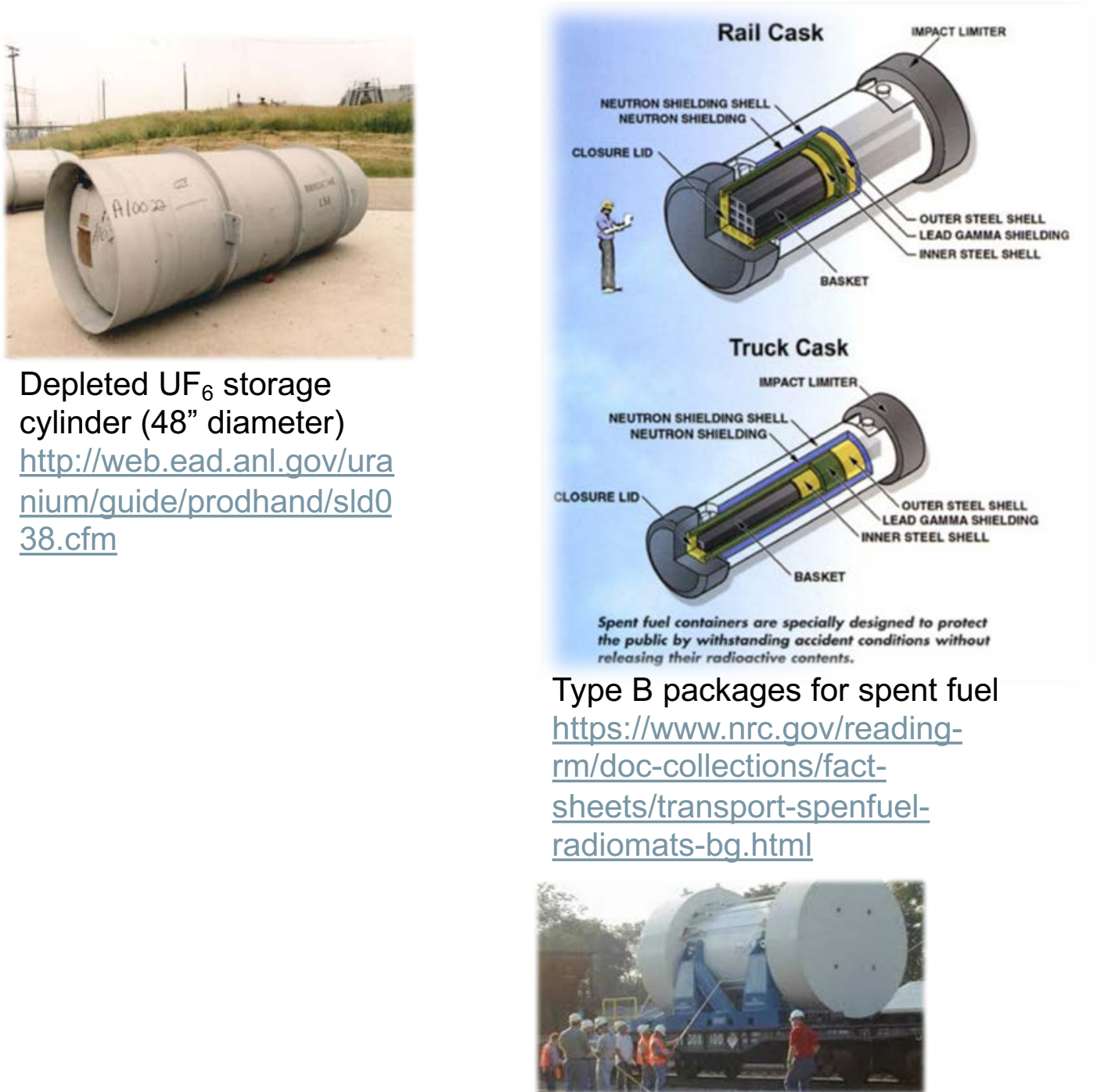


\section{Agenda}

\section{$12: 00 \mathrm{pm}$}

$1: 00 \mathrm{pm}$

$1: 45 \mathrm{pm}$

2:15 pm

2:45 pm

3:00 pm

$3: 30 \mathrm{pm}$

4:00 pm

4:15 pm

4:45 pm

5:15 pm

\section{August 30}

Lunch / Introductions / Goals of Meeting - Josh Jarrell, INL and Everett Redmond, NEI

Validation and role of critical experiments and nuclear data - Brad Rearden, ORNL

Potential for material recovery and form/dose/isotope concerns - Monica Regalbuto, INL

Potential for enrichment up to $20 \%$ - Melissa Mann, URENCO

Break

Evaluation of HALEU fabrication issues - Lon Paulson, GEH/GNF

HALEU UF6 transportation issues - Andy Langston, DAHER-TLI

Cask supplier perspective - Rick Migliore, TN Americas

Criticality sensitivity analysis - Brad Rearden, ORNL

Discussion and preparation for NRC Visit - Nima Ashkeboussi, NEI

Adjourn
11:00 am
August 31

NRC perspective - Drew Barto, NRC

Break

Criticality facilities and cost and process for new criticality experiments Doug Bowen (ORNL)

Validation discussion: How important are material forms to establishing applicability of criticality experiments? Is there "common ground"? If not, what forms should be the focus? - John Scaglione, ORNL

Example validation process: How important is the application model (e.g. transportation package design, fuel form, and materials) and how are the criticality experiments used to establish appropriate bias and uncertainty? - John Scaglione, ORNL

DOE perspective - John Herczeg, DOE

Industry/NEI Needs and Recommendations for DOE - Nima Ashkeboussi, NEI

Wrap up /Action Items - Josh Jarrell, INL

Adjourn 


\section{Fuel Cycle Infrastructure for Advanced Reactors}

- High assay low enriched uranium (HALEU) feed stock

- Develop a domestic capability to enrich Uranium between $5 \%$ and $20 \%$

- Downblending current and/or recovered HEU in the federal complex

- HALEU Fuel Fabrication

- Multiple fuel form options (metallic, oxide, nitride, etc.)

- HALEU Transportation

- HALEU as $U_{6}$ to fuel fabrication facility

- HALEU fuel to reactor facility
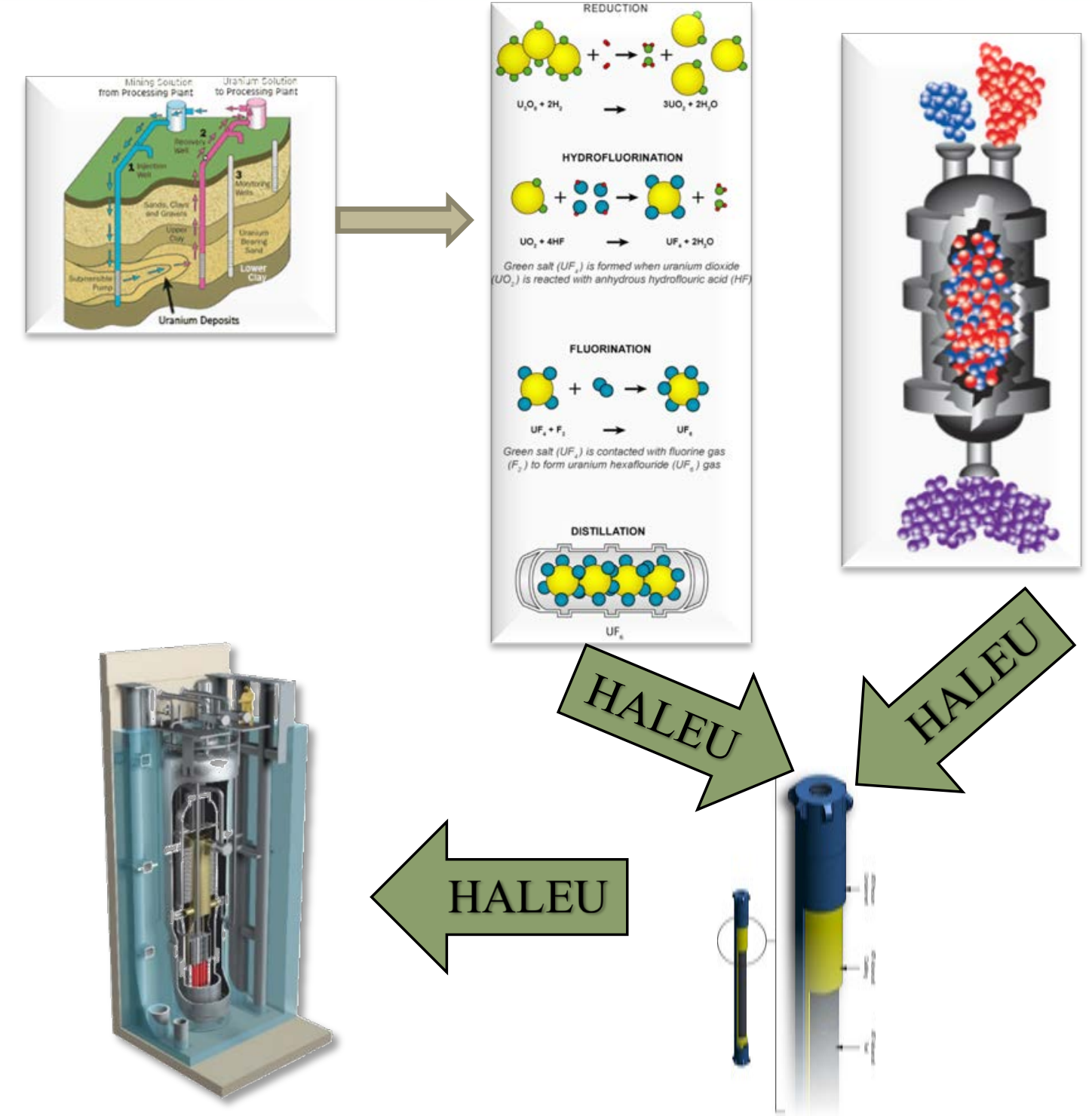


\section{Large volume shipments are anticipated}

- By 2023, almost 20 MTUs of HALEU may be needed (NEI July 5 , 2018 letter to Secretary of Energy)

- Current $\mathrm{UF}_{6}$ package (5A or $5 \mathrm{~B}$ ) hold $\sim \mathbf{2 4 . 9} \mathbf{~ k g}$ of $\mathrm{UF}_{6}$ or $\sim 16.8 \mathrm{~kg}$ of $20 \%$ enriched uranium

- Current $\mathrm{UF}_{6}$ packages for $5 \%$ enriched (30B) hold $\sim 2277 \mathbf{~ k g}$ of $\mathrm{UF}_{6}$

- DOE certified package (ES-3100) holds $\sim 24 \mathbf{~ k g}$ of $\mathrm{UO}_{2}$ or $\sim 21 \mathrm{~kg}$ of $20 \%$ enriched uranium

- 20 MTUs of $\mathrm{UF}_{6}$ HALEU would require:

- $11915 \mathrm{~A}$ package shipments

- 13 30B packages shipments (assuming 20\% enriched was allowable)

- 20 MTUs of $\mathrm{UO}_{2} \mathrm{HALEU}$ would require:

- 953 ES-3100 package shipments

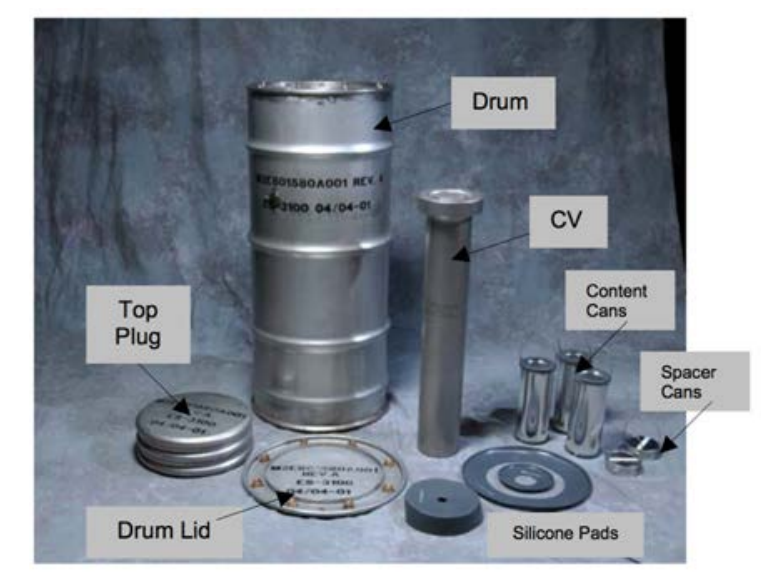

Figure 1. ES-3100 Container

ES-3100 Container

Deployment and Operation of the ES-3100 Type

B Shipping Container, PVP2006-ICPVT-11, July

https://www.osti.gov/servlets/pur//974250

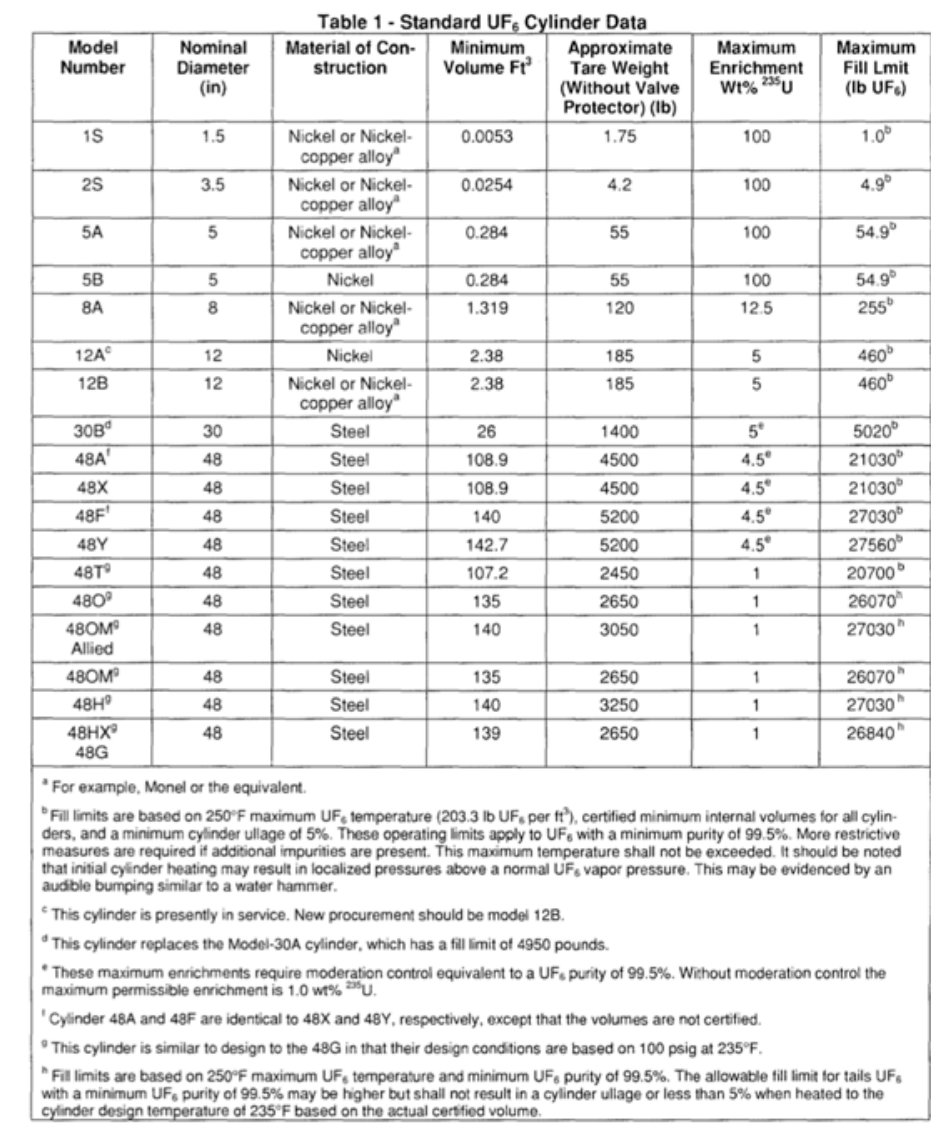




\section{Consider these questions:}

1. What form(s) of HALEU should be considered in this scope (e.g., UF , oxide, metal)?

- How important are the forms to additional criticality experiments? Is there "common ground" regardless of HALEU form?

- What are the potential material pathways and transportation needs of (a) sources to (b) finished forms that need to be scoped out? E.g., HALEU UF ${ }_{6}$ transported to a fuel fabrication facility, converted to metal fuel, which is subsequently transported to reactor site.

2. For a given form, what does an economic transportation package design look like? Truck cask? Rail cask? Amount of material? Construction materials? Absorber materials?

- Are there licensed/certified packages that are suitable (domestic and international packages)?

- Are there licensed/certified/designed packages that could be the basis for an economic HALEU package? 


\section{Consider these questions:}

3. Are the current criticality benchmark experiments sufficient to justify certification of packages and licensing of facilities by the NRC?

- If so, how much conservatism in the calculations do the current experiments cause? Can we quantify the volume-reduction / cost implications of this conservatism?

- If not, what experiments should be proposed?

- Can the existing critical experiment facilities perform the necessary benchmarks?

- What changes to the existing safety bases need to be made, how long will that take, and how long is it good for?

4. What are the roles and responsibilities of the nuclear utilities, fuel fabricators, reactor developers, transportation package vendors, DOE, and the DOE laboratory complex? 


\section{Validation and Role of Critical Experiments and Nuclear Data}

\section{Presented by:}

Bradley T. Rearden, Ph.D. National Technical Director

Nuclear Data and Benchmarking Program

\section{Presented to:}

Technical Workshop on Transportation of High Assay Low-Enriched Uranium August 30-31, 2018

Nuclear Energy Institute

August 30, 2018 


\section{Nuclear Data and Benchmarking Program}

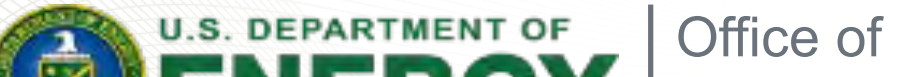 ENERGY Fanerand}

- New Nuclear Energy Enabling Technology (NEET) Crosscutting Program

- Partner with industry, NRC, and other programs to:

- Identify priority needs for nuclear data and benchmarking

- Perform new data measurements and evaluations

- Support integral experiments and handbooks

- Participate in application benchmark studies

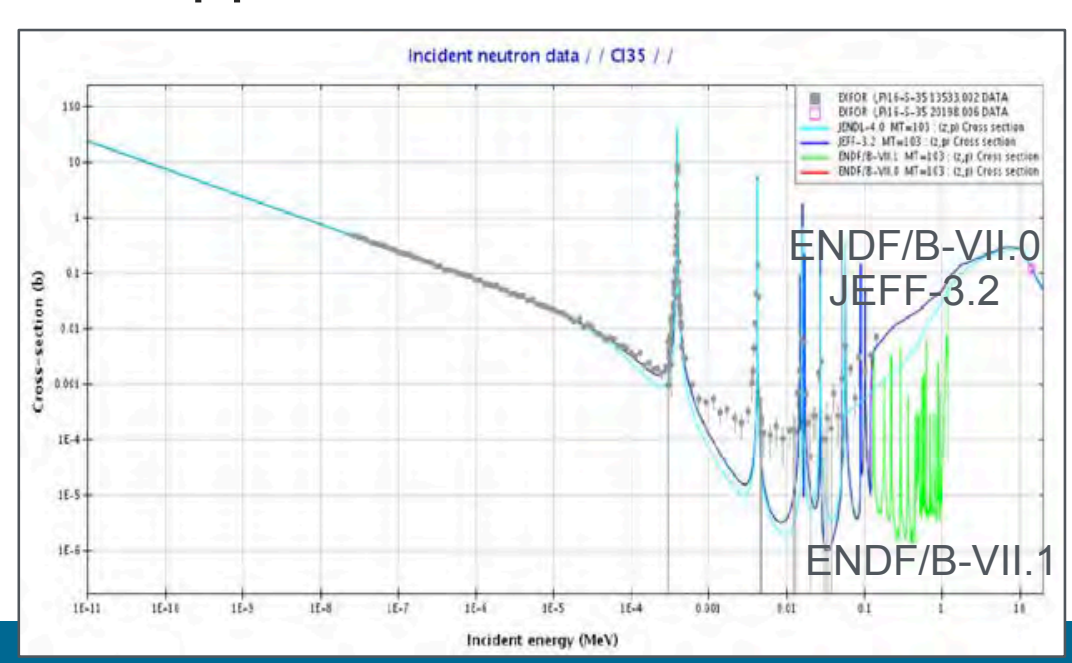

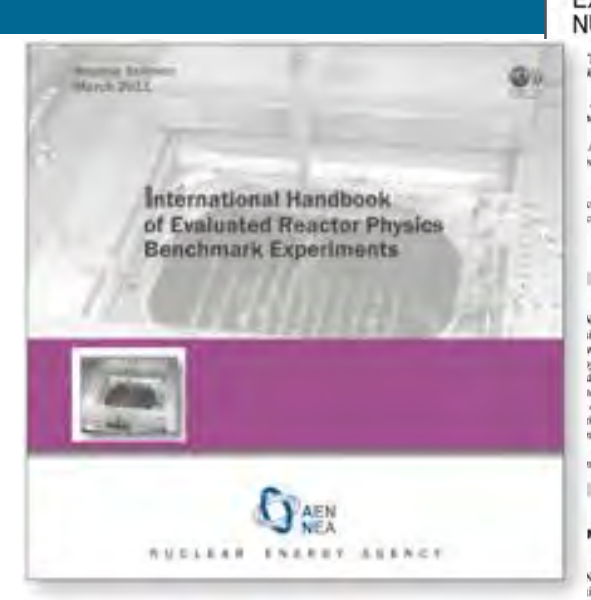

USE OF SENSITIVITY AND DIGN OF REACLOSINTHE CRITICALITY BENCHMARK NUCLEAR FUEL

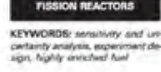

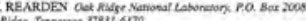

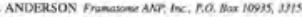

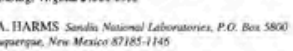

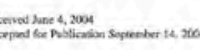
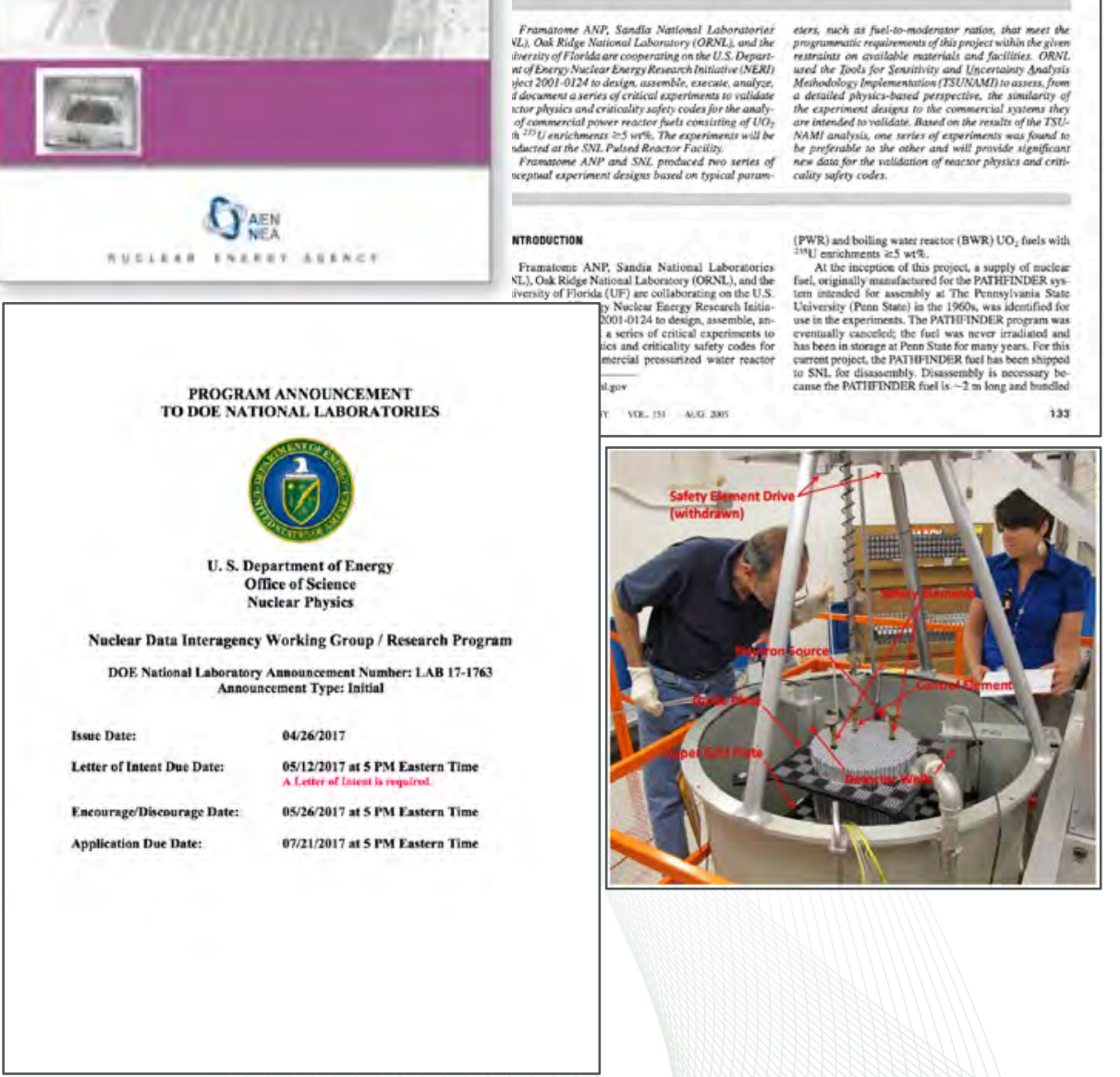


\section{Abbreviated advanced reactor technology matrix (1/2)}

\begin{tabular}{|c|c|c|c|c|c|c|c|c|c|c|}
\hline $\begin{array}{c}\text { Reactor } \\
\text { Type }\end{array}$ & $\begin{array}{c}\text { Companies } \\
\text { Red = NRC Priority }\end{array}$ & $\begin{array}{l}\text { Licensing } \\
\text { action } \\
\text { expected }\end{array}$ & $\begin{array}{c}\text { Fuel / } \\
\text { Enrichment }\end{array}$ & $\begin{array}{l}\text { Thermal } \\
\text { spectrum }\end{array}$ & $\begin{array}{c}\text { Fast } \\
\text { Spectrum }\end{array}$ & Coolant & $\begin{array}{c}\text { Radial } \\
\text { core } \\
\text { expansion }\end{array}$ & $\begin{array}{c}\text { Flowing } \\
\text { Fuel }\end{array}$ & $\begin{array}{l}\text { Fuel } \\
\text { Form }\end{array}$ & $\begin{array}{l}\text { Control } \\
\text { elements }\end{array}$ \\
\hline \multirow[b]{2}{*}{ HPR } & Oklo & 2019 & $\sim 20 \%$ & & $\checkmark$ & $\begin{array}{c}\text { Sodium } \\
\text { heat pipes }\end{array}$ & $\checkmark$ & & $\begin{array}{l}\text { Metallic } \\
\text { Castings }\end{array}$ & $\begin{array}{l}\text { External } \\
\text { drums }\end{array}$ \\
\hline & $\begin{array}{l}\text { Westinghouse } \\
\text { (eVinci) }\end{array}$ & 2019 & $19.75 \%$ & $\begin{array}{l}\text { Thermal/ } \\
\text { Epithermal }\end{array}$ & & $\begin{array}{c}\text { Sodium } \\
\text { heat pipes } \\
\text { (dual } \\
\text { condenser) }\end{array}$ & & & Oxide & $\begin{array}{l}\text { External } \\
\text { drums }\end{array}$ \\
\hline \multirow{2}{*}{ SFR } & $\begin{array}{l}\text { TerraPower } \\
\text { (TWR) }\end{array}$ & & $\sim 20 \%$ & & $\checkmark$ & Sodium & $\checkmark$ & & $\begin{array}{l}\text { Metallic } \\
\text { Rods }\end{array}$ & Internal rods \\
\hline & GE PRISM & & $\sim 20 \%$ & & $\checkmark$ & Sodium & $\checkmark$ & & $\begin{array}{l}\text { Metallic } \\
\text { Rods }\end{array}$ & Internal rods \\
\hline LFR & Westinghouse & & $15-20 \%$ & & $\checkmark$ & Lead & $\checkmark$ & & $\begin{array}{l}\text { Oxide/ } \\
\text { Nitride }\end{array}$ & Internal rods \\
\hline \multirow{2}{*}{ HTGR } & $\begin{array}{l}\text { X-energy (Xe- } \\
100)\end{array}$ & $2020 s$ & $15.5 \%$ & $\checkmark$ & & Helium & & Pebbles & TRISO & $\begin{array}{l}\text { External } \\
\text { rods }\end{array}$ \\
\hline & $\begin{array}{l}\text { Areva (SC- } \\
\text { HTGR) }\end{array}$ & & $\sim 20 \%$ & $\checkmark$ & & Helium & & & TRISO & Internal rods \\
\hline FHR & Kairos & $2020 s$ & $\sim 17 \%$ & $\checkmark$ & & FLiBe & & Pebbles & TRISO & $\begin{array}{l}\text { External } \\
\text { rods }\end{array}$ \\
\hline
\end{tabular}




\section{Abbreviated advanced reactor technology matrix (2/2)}

\begin{tabular}{|l|l|c|c|c|c|c|c|c|c|c|}
$\begin{array}{c}\text { Reactor } \\
\text { Type }\end{array}$ & $\begin{array}{c}\text { Companies } \\
\text { Red = NRC } \\
\text { Priority }\end{array}$ & $\begin{array}{c}\text { Licensing } \\
\text { action } \\
\text { expected }\end{array}$ & $\begin{array}{c}\text { Fuel } / \\
\text { Enrichment }\end{array}$ & $\begin{array}{c}\text { Thermal } \\
\text { spectrum }\end{array}$ & $\begin{array}{c}\text { Fast } \\
\text { Spectrum }\end{array}$ & $\begin{array}{c}\text { Radial } \\
\text { Coolant } \\
\text { core } \\
\text { expansion }\end{array}$ & $\begin{array}{c}\text { Flowing } \\
\text { Fuel }\end{array}$ \\
\hline \\
\hline
\end{tabular}

Send updates to Brad - reardenb@ornl.gov 
Nuclear data is of fundamental importance in nuclear science and engineering

Neutronics calculations rely on nuclear data for criticality, reactivity, power distributions, depletion, decay heat, and more.
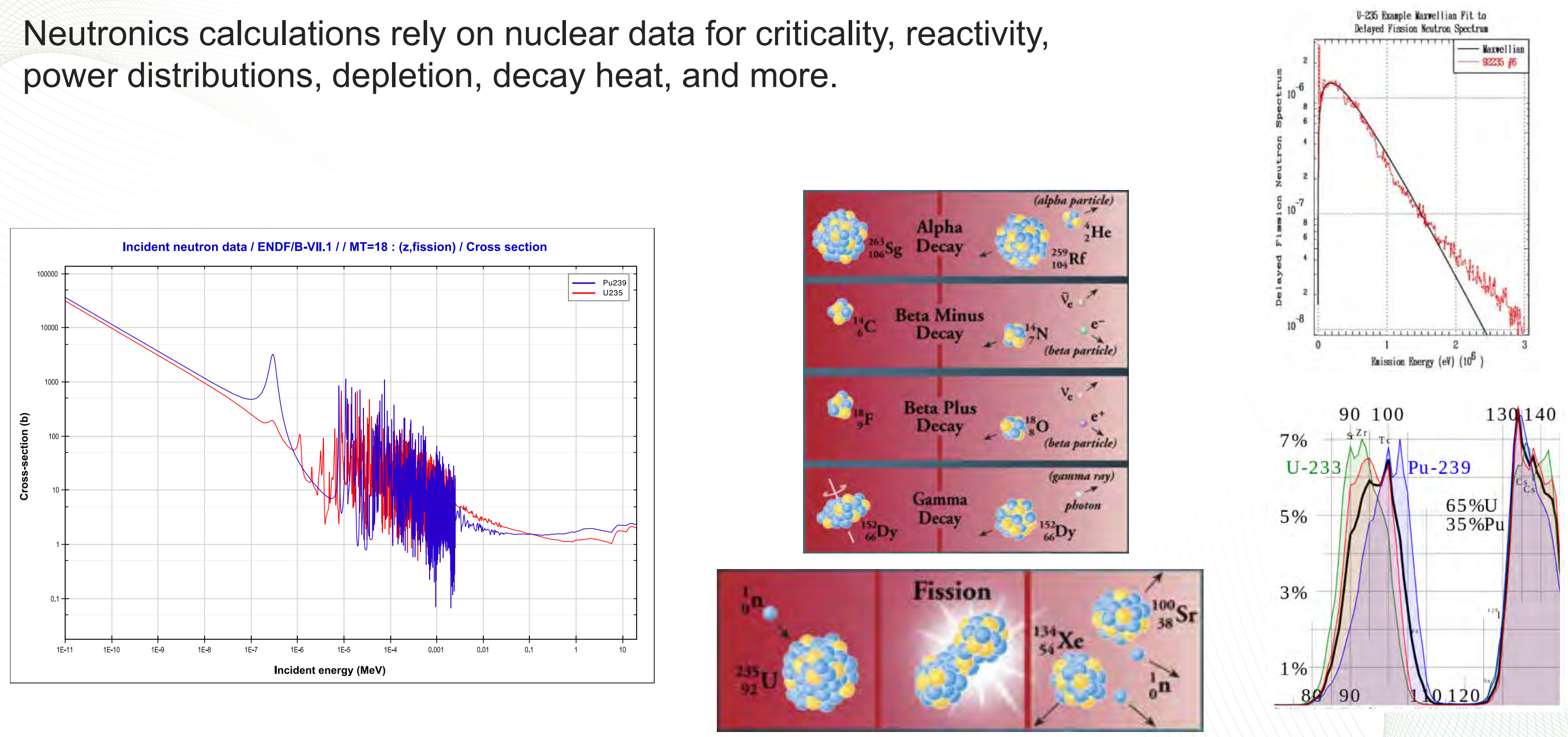


\section{Different reactor designs have different nuclear data needs}
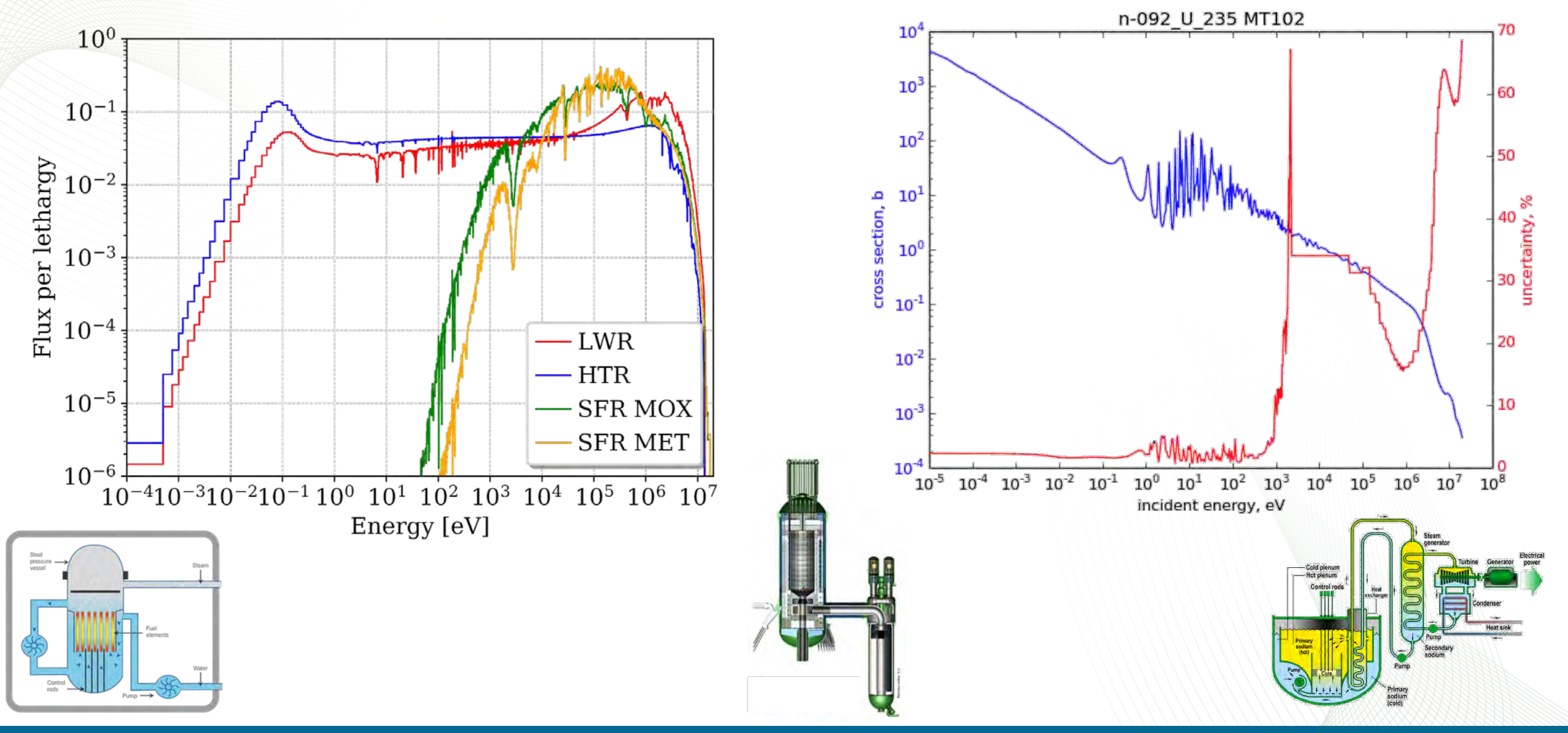


\section{Nuclear data lifecycle}

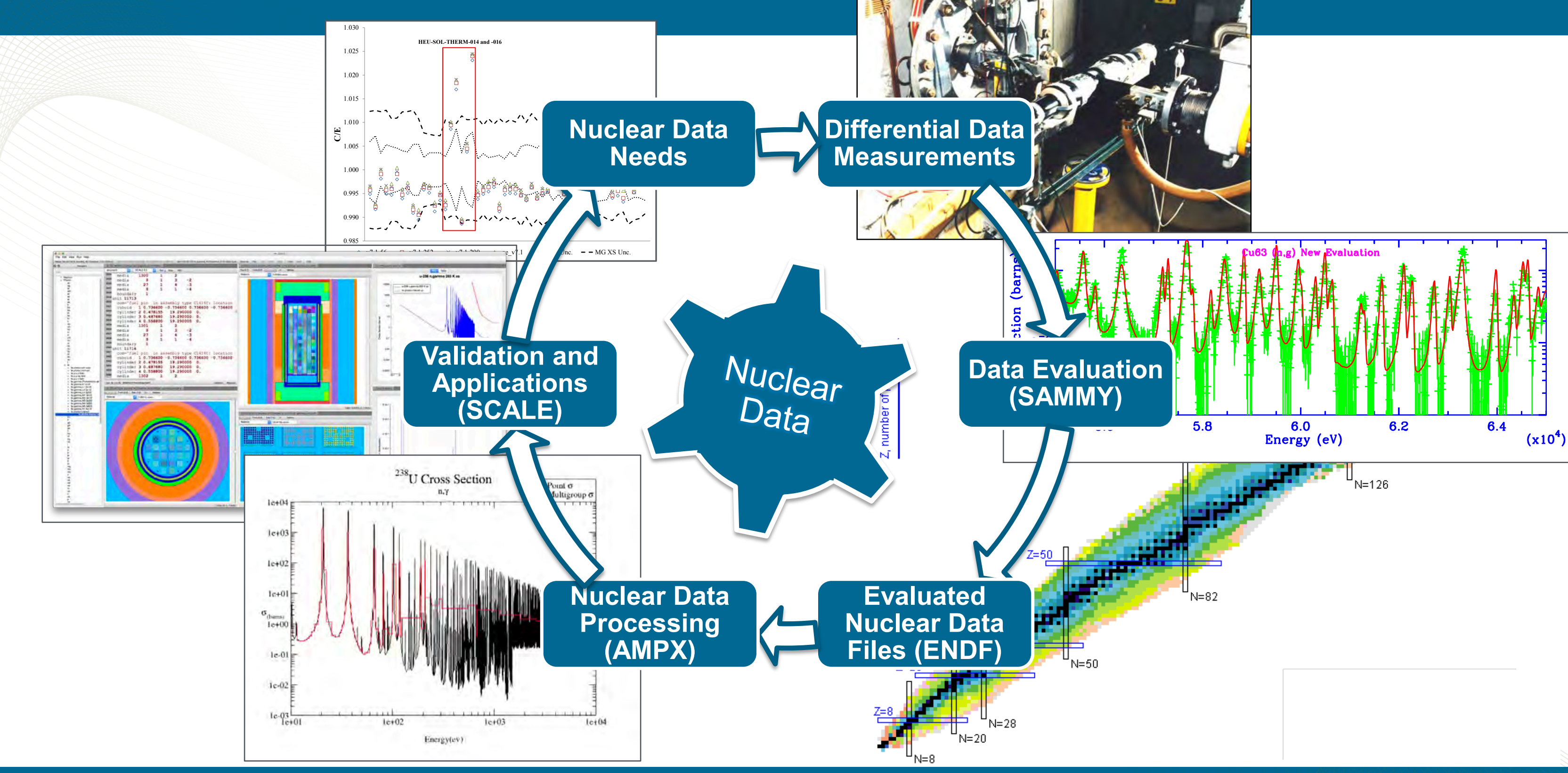


Cross section components:

Typically generated separately, then combined for distribution

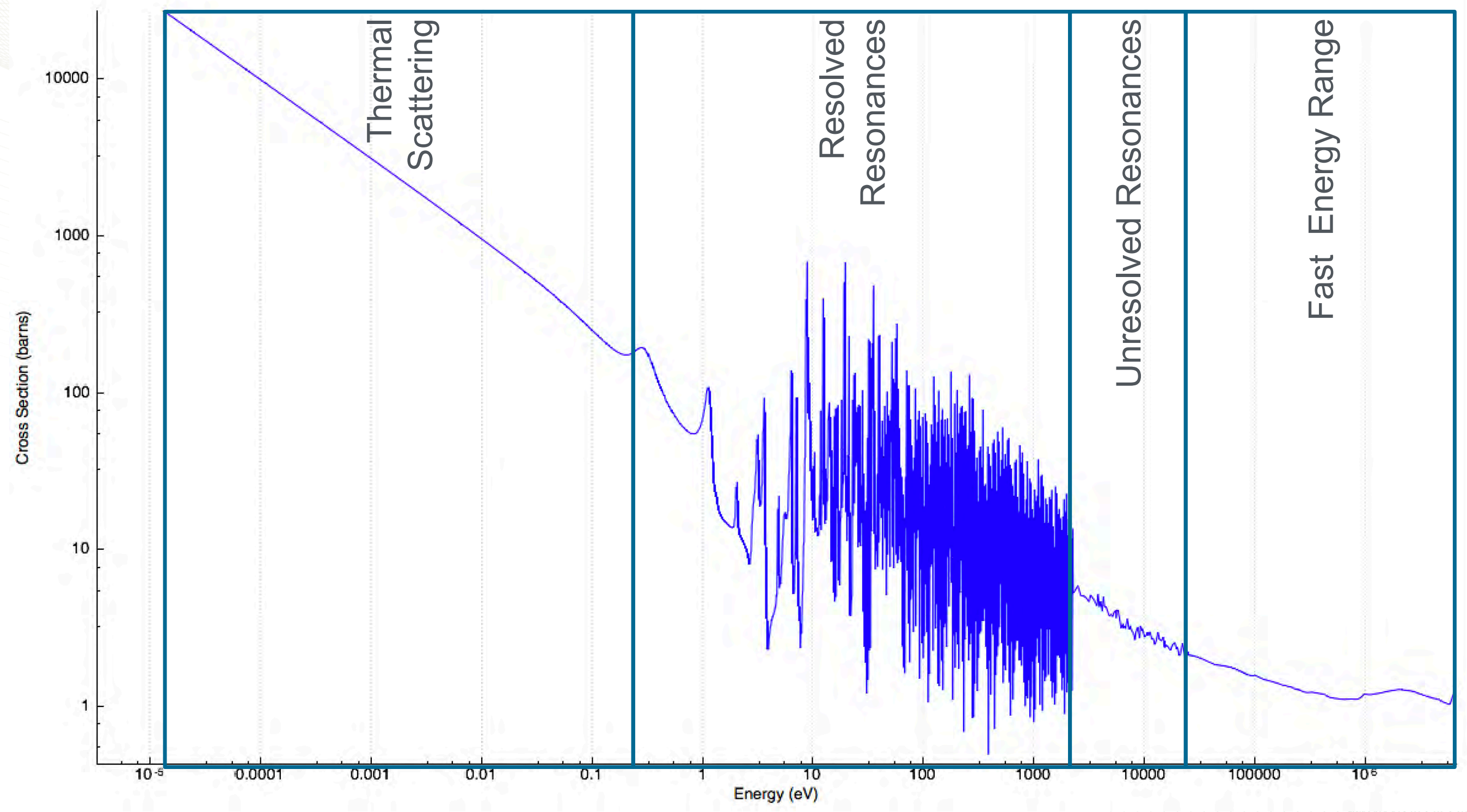




\section{How are these "general purpose" libraries generated?}

- A specific program (DOE-SC, NNSA/NCSP, NNSA/NA-22, DOD, international participant) funds an update in a nuclear data evaluation

- New differential physics experiments

- Data processing

- Comparison to and optimization with applications in their interest

- National Nuclear Data Center - Cross Section Evaluation Working Group (CSEWG)

- Updates are exchanged through a beta repository for ENDF and reviewed by a global team

- Meets twice annually, with participation from IAEA, OECD/NEA, and others to review proposed updates

- If changes benefit, or do not disrupt, applications of interest to these teams, the new evaluation is approved

- Until now, no official representation for Nuclear Energy applications 


\section{Compensating Errors in the Jezebel $k_{\text {eff }}$}

- Eric Bauge ${ }^{*}$ reported on an analysis where components of the Bruyères-le-Châtel (BRC) ${ }^{239} \mathrm{Pu}$ evaluation were replaced with those from ENDF/B-VII.1. At each step in the replacement process, $\mathrm{k}_{\mathrm{fff}}$ of the Jezebel critical assembly was computed. While both the BRC and ENDF/B-VII.1 give the same $k_{\text {ff }}$ for Jezebel, they do so for very different reasons. This replacement study shows how different parts of the evaluation substantially shift the reactivity of Jezebel. We do not know if either evaluation is "correct" but both get the "correct" answer.
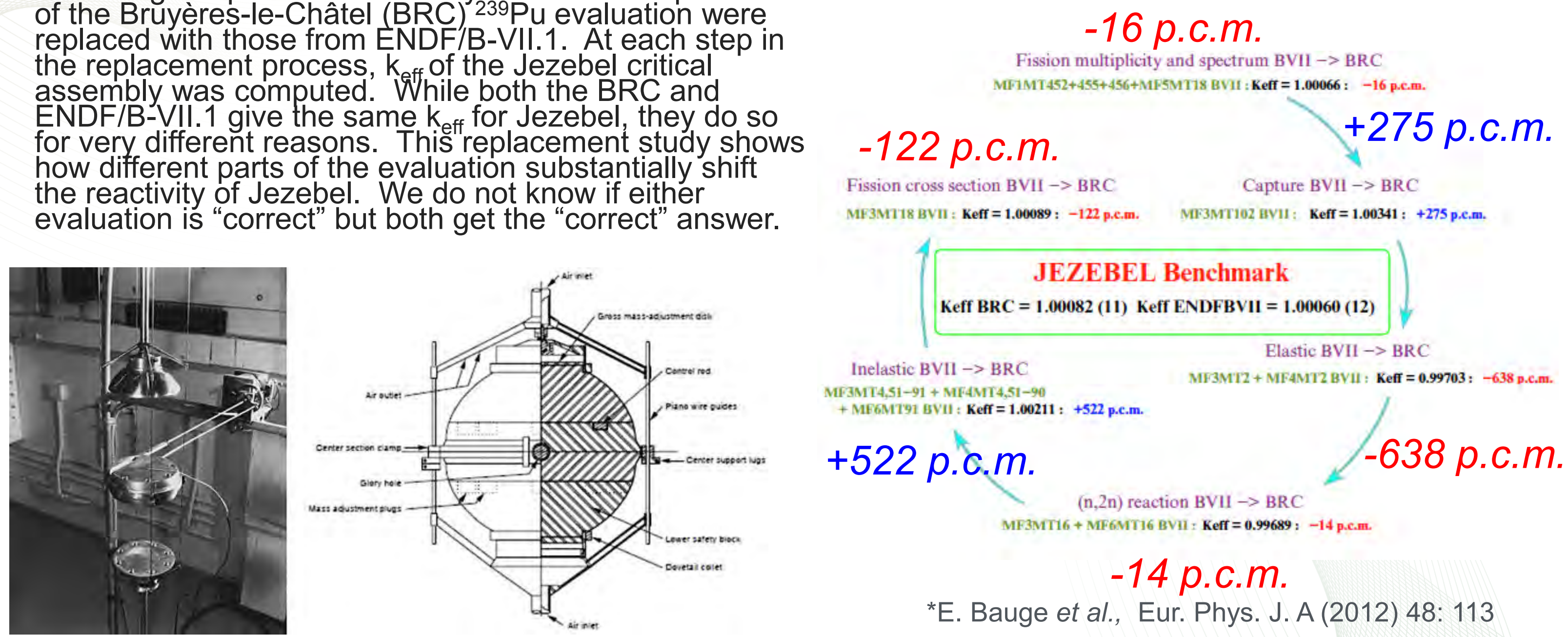

We do not know if either evaluation is "correct" but both get the "correct" answer. 


\section{Nuclear data for activation, depletion, and decay}

\section{- Decay data}

- ENDF/B-VII.1

- Natural isotopic abundances (NIST database)

- ICRP 72 inhalation dose coefficients, EPA Report 12 on external exposure

- Neutron reaction cross section data

- JEFF 3.1/A special purpose activation file

- ENDF/B-VII.0, -VII.1

- Fission product yields: ENDF/B-VII.0

- Photon emission line-energy data

- Evaluated Nuclear Structure Data Files (ENSDF)

- ENDF/B-VII.1

- Neutron emission libraries

- SOURCES 4C code

- Spontaneous fission decay and delayed neutron data

- Alpha stopping powers, $(\alpha, n)$ cross sections, excitation levels
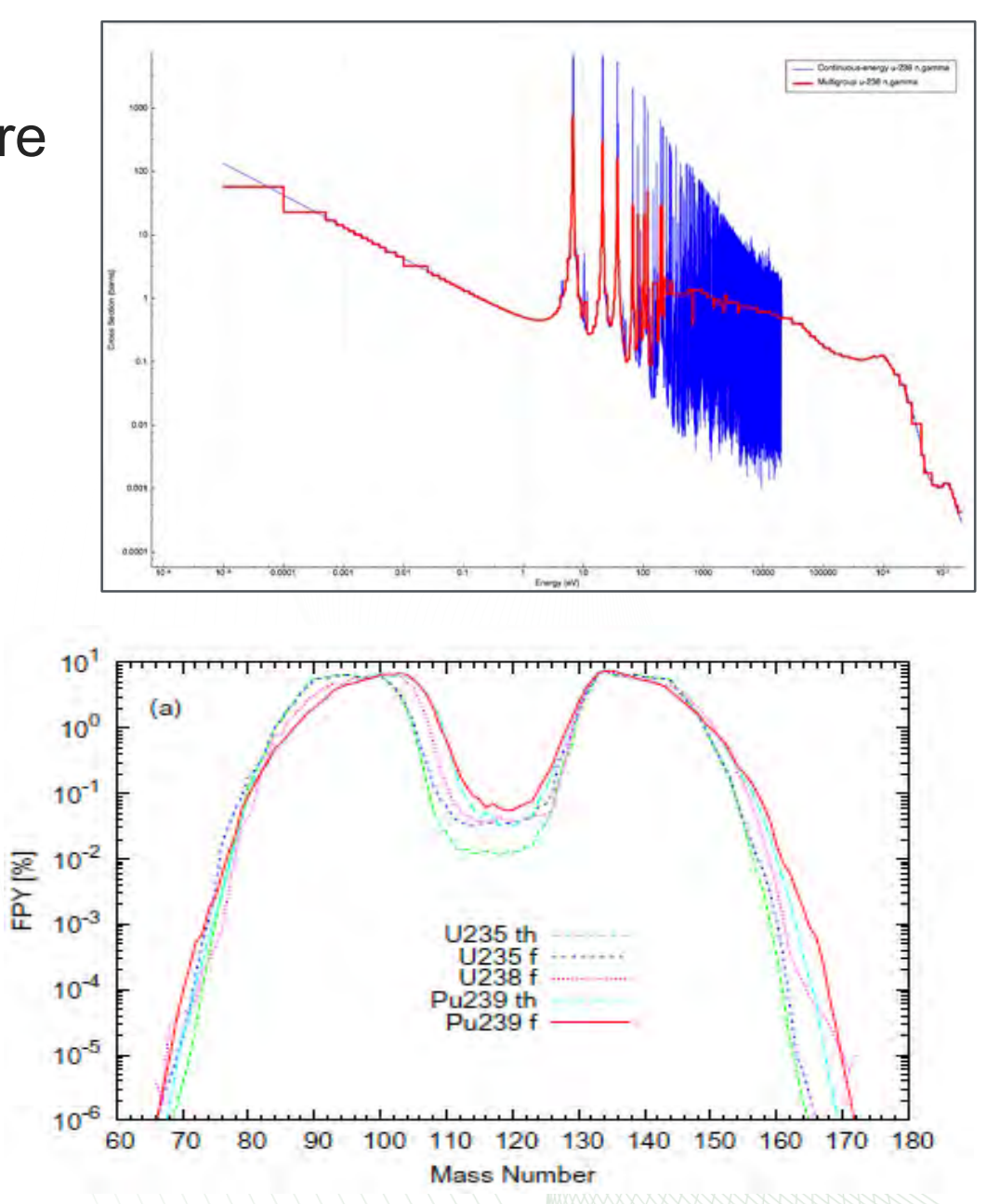


\section{U inelastic scattering cross section uncertainty differences between international libraries}

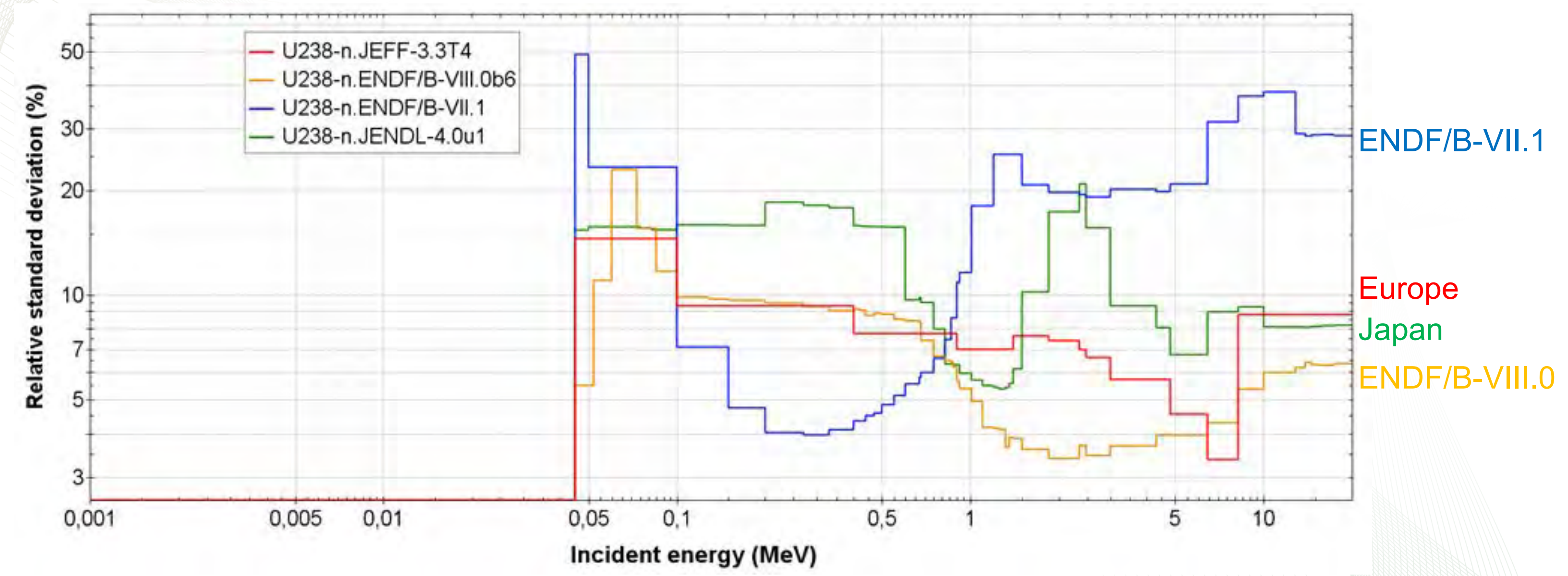



sodium fast reactor study with ENDF/B-VII.1 uncertainties

CE TSUNAMI: nominal values and uncertainties

\begin{tabular}{l|cc|cc}
\hline & \multicolumn{2}{|c|}{ MET1000 } & \multicolumn{2}{c}{ MOX3600 } \\
\hline & nominal & uncertainty & nominal & uncertainty \\
Eigenvalue & $1.0841(1)$ & $1.49(1) \%$ & $1.0771(1)$ & $1.52(1) \%$ \\
CR worth & $12081(11) \mathrm{pcm}$ & $2.81(1) \%$ & $4973(11) \mathrm{pcm}$ & $2.67(1) \%$ \\
\hline
\end{tabular}

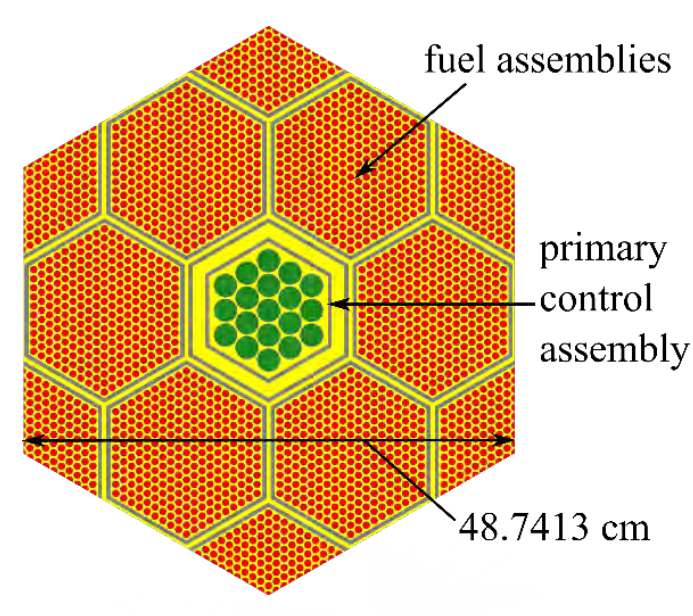

MET1000

CE TSUNAMI: Top 3 contributors

\begin{tabular}{cc|cc}
\hline \multicolumn{2}{c|}{ MET1000 } & \multicolumn{2}{c}{ MOX3600 } \\
\hline Eigenvalue & CR worth & Eigenvalue & CR worth \\
\hline U-238 inel. & U-238 inel. & U-238 inel. & U-238 inel. \\
Fe-56 inel. & Fe-56 inel. & U-238 cap. & Na-23 el. \\
Na-23 el. & Na-23 el. & Pu-239 cap. & U-238 chi \\
\hline
\end{tabular}

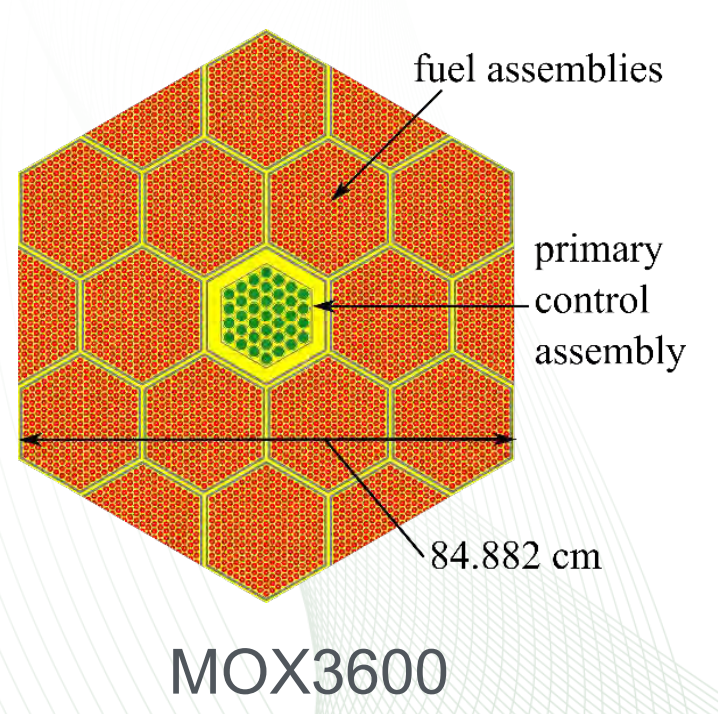

energy.gov/ne 
Recent nuclear data developments of interest to the advanced reactor community 


\section{HTR-10 pebble: KENO-VI eigenvalue comparison}

\begin{tabular}{ccccc}
\hline Library & Code & XS lib & $\mathbf{k}_{\infty}$ & $\boldsymbol{\Delta} \mathbf{k}(\mathbf{p c m})$ \\
\hline ENDF/B-VII.1 & KENO & CE & $1.6770(4)$ & $($ ref $)$ \\
ENDF/B-VIII.0 & KENO & CE & $1.6722(4)$ & $-438(57)$ \\
\hline
\end{tabular}

Note: The $1 \sigma$ statistical uncertainties are given in parentheses.

Replace individual nuclides in ENDF/B-VII.1 calculation by ENDF/B-VIII.0 data:

\begin{tabular}{lc}
\hline Basis: ENDF 7.1 & $\Delta \mathbf{k}$ to all ENDF 7.1 $(\mathbf{p c m})$ \\
\hline But: graphite from ENDF 8.0 & -7 \\
But: ${ }^{235}$ U from ENDF 8.0 & -702 \\
But: ${ }^{238}$ U from ENDF 8.0 & 239 \\
All ENDF 8.0 & -438 \\
\hline
\end{tabular}

- Differences between ENDF/B-VII.0 and VII.1: carbon capture

HTR-10 fuel pebble

- Differences between ENDF/B-VII.1 and VIII.0: ${ }^{235} \mathrm{U}$ and ${ }^{238} \mathrm{U}$ 


\section{Changes in ${ }^{35} \mathrm{Cl}(n, p)$ cross section from ENDF/B-VII.0 to VII.1}

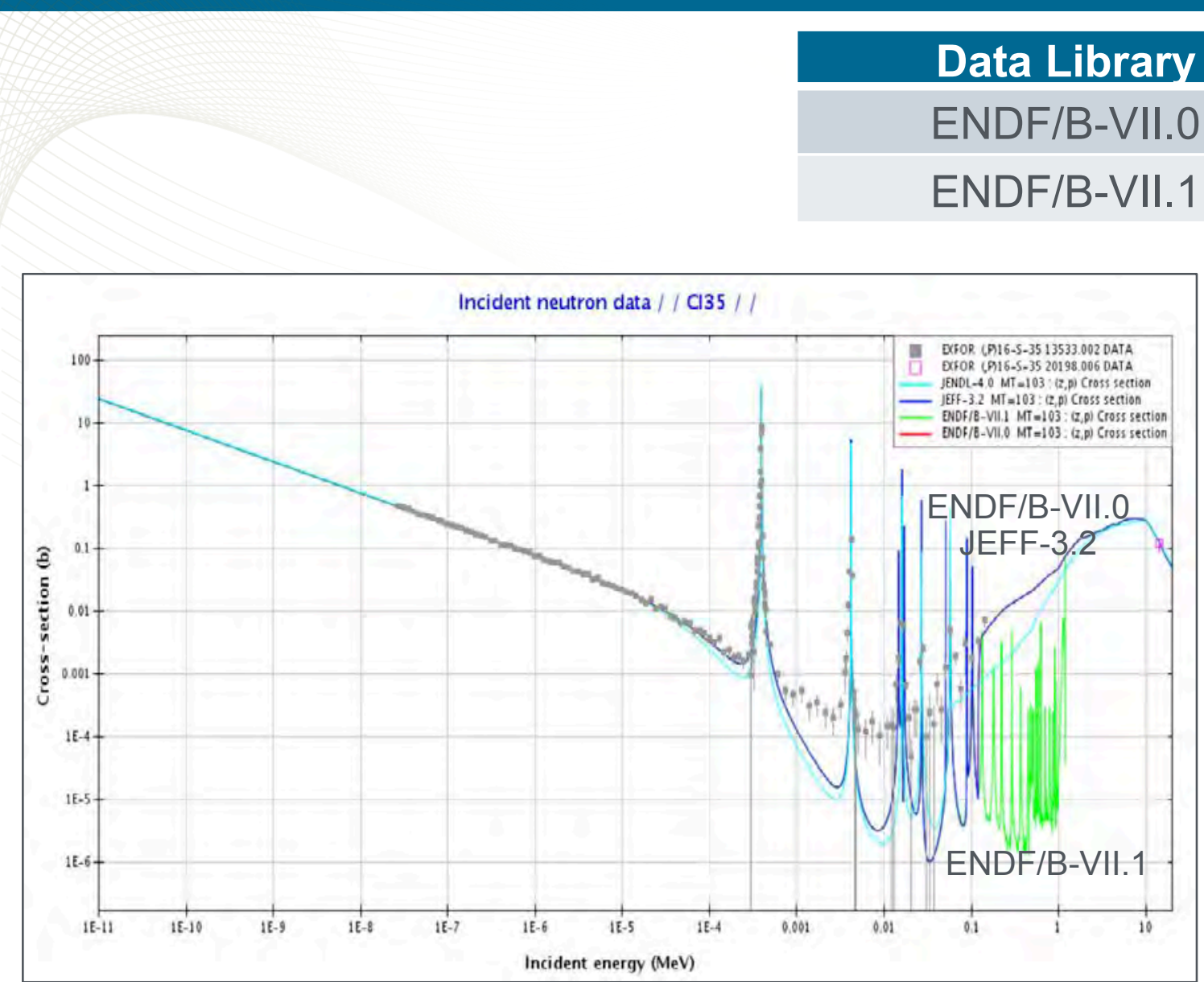

No data for FLiBe / FLiNaK thermal scattering

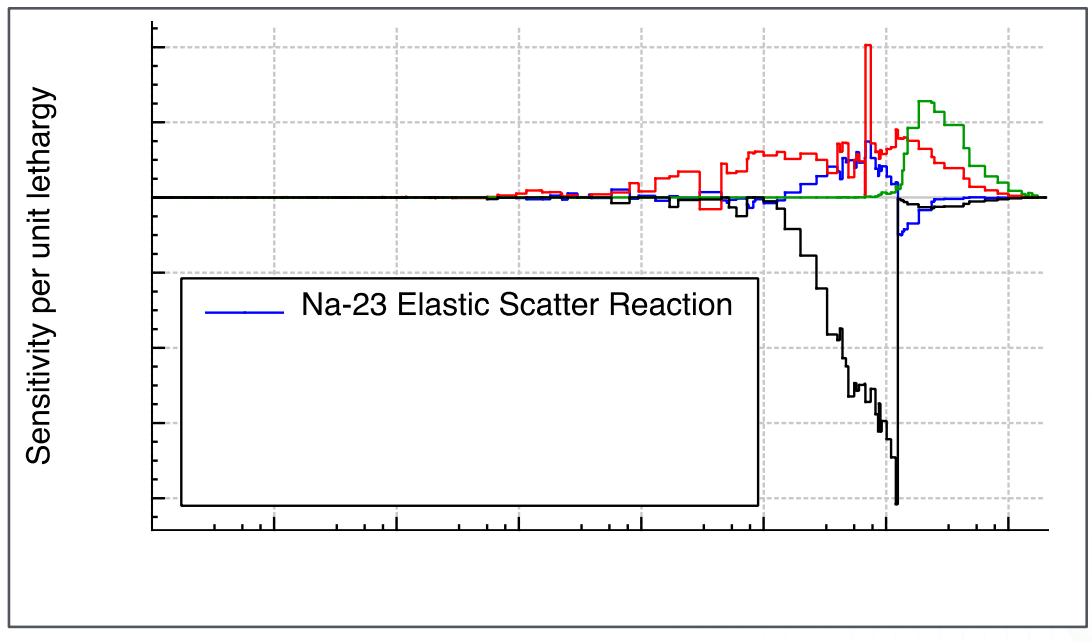

$1.02993 \pm 0.00002$

$1.04924 \pm 0.00002$

\begin{tabular}{|c|c|}
\hline Reaction & Sensitivity \\
\hline Cl-35 (n,p) Capture Reaction & -0.958 \\
\hline Pu-239 Nu-bar & 0.603 \\
\hline U-238 Nu-bar & 0.281 \\
\hline Na-23 Elastic Scatter Reaction & 0.114 \\
\hline
\end{tabular}




\section{Validation of methods and nuclear data for advanced applications}




\section{International benchmark evaluation projects}

- Programmatic support for US leadership of the following projects:

- International Criticality Safety Benchmark Evaluation Project (ICSBEP)

- International Reactor Physics Benchmark Evaluation Project (IRPhEP)

- Handbooks generated by these projects provide thousands of benchmark experiments from dozens of countries with an assessment of data integrity, quantification of experimental uncertainties, and thorough technical review with established deployment process

- Strong collaborations have been implemented with the Organisation for Economic Cooperation and Development (OECD) Nuclear Energy Agency (NEA)

ICSBEP

- 22 contributing Countries

- $\quad 69,000$ pages

- >5,000 approved benchmarks
IRPhEP

- 21 contributing countries

- 50 reactor facilities

- 147 approved benchmarks
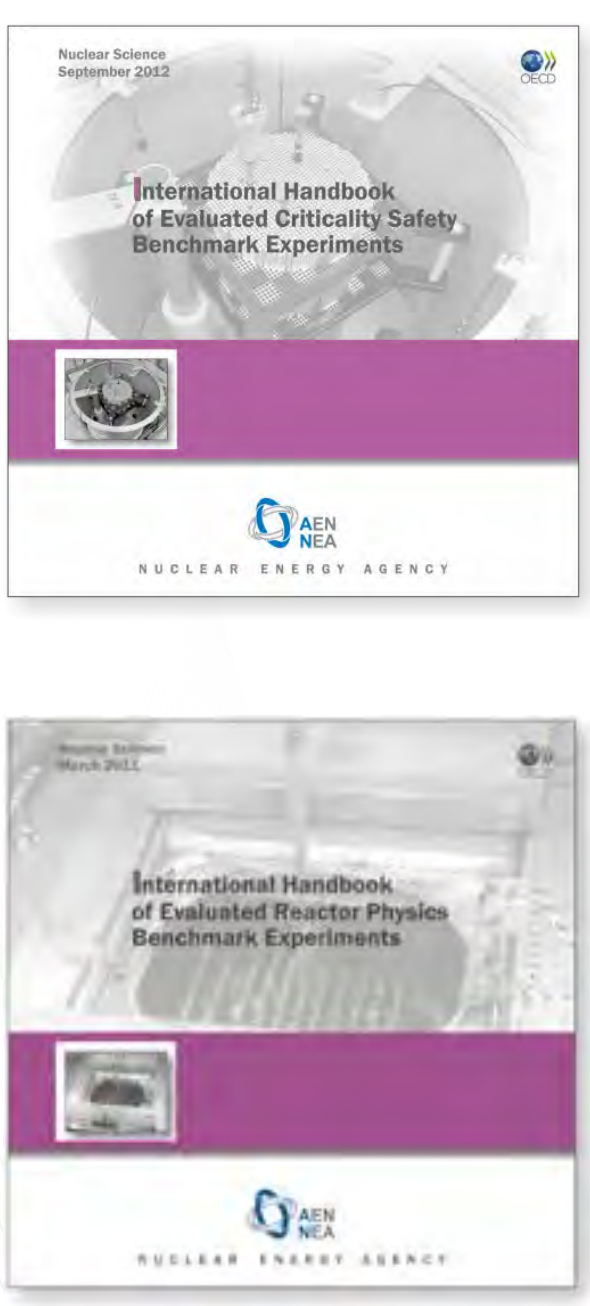


\section{Computational bias for critical benchmarks}
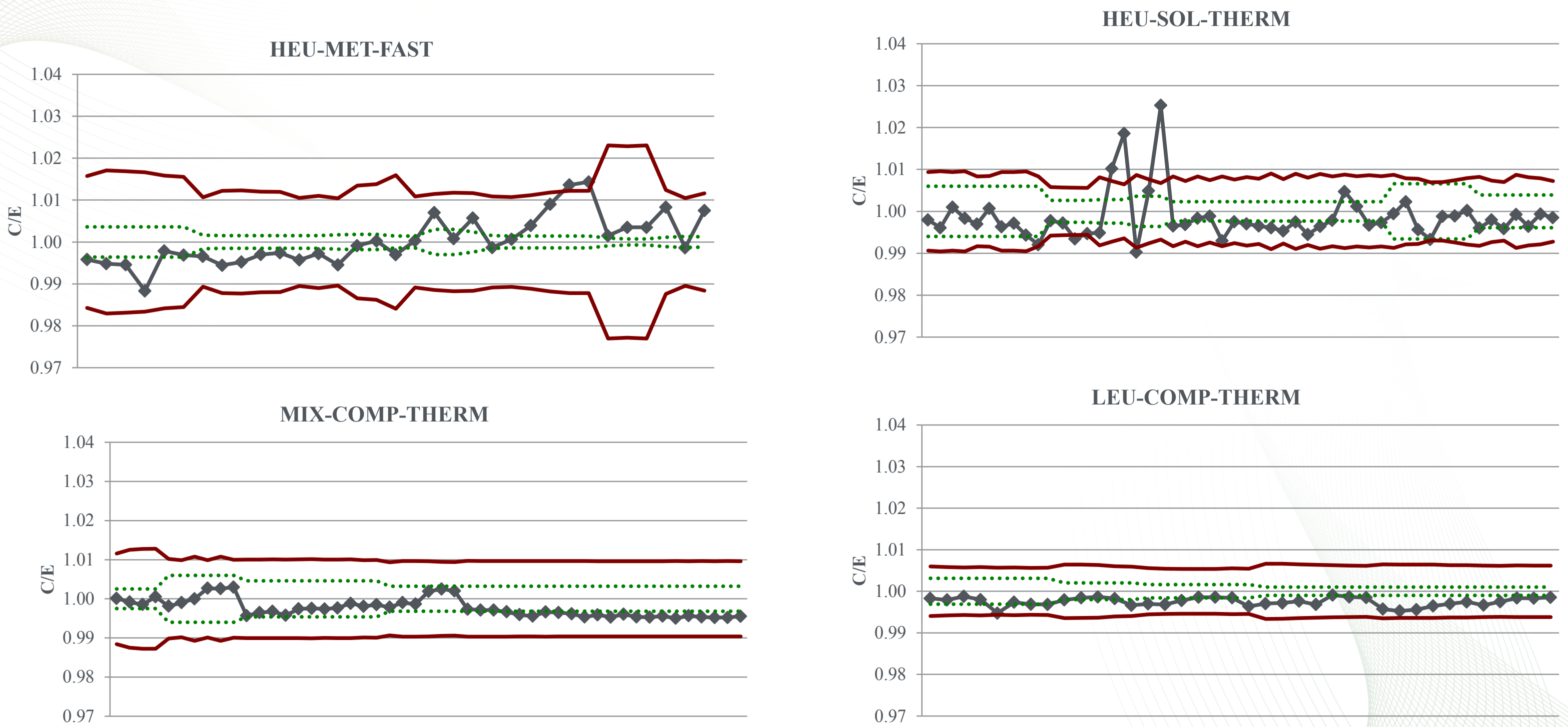


\section{International Spent Nuclear Fuel Database SFCOMPO 2.0 provides a central repository of destructive assay data}

Modern database of measured fuel compositions was expanded as part of a multi-year international collaboration. ORNL has coordinated this effort through the OECD/NEA Expert Group on Assay Data for Spent Fuel since 2009.

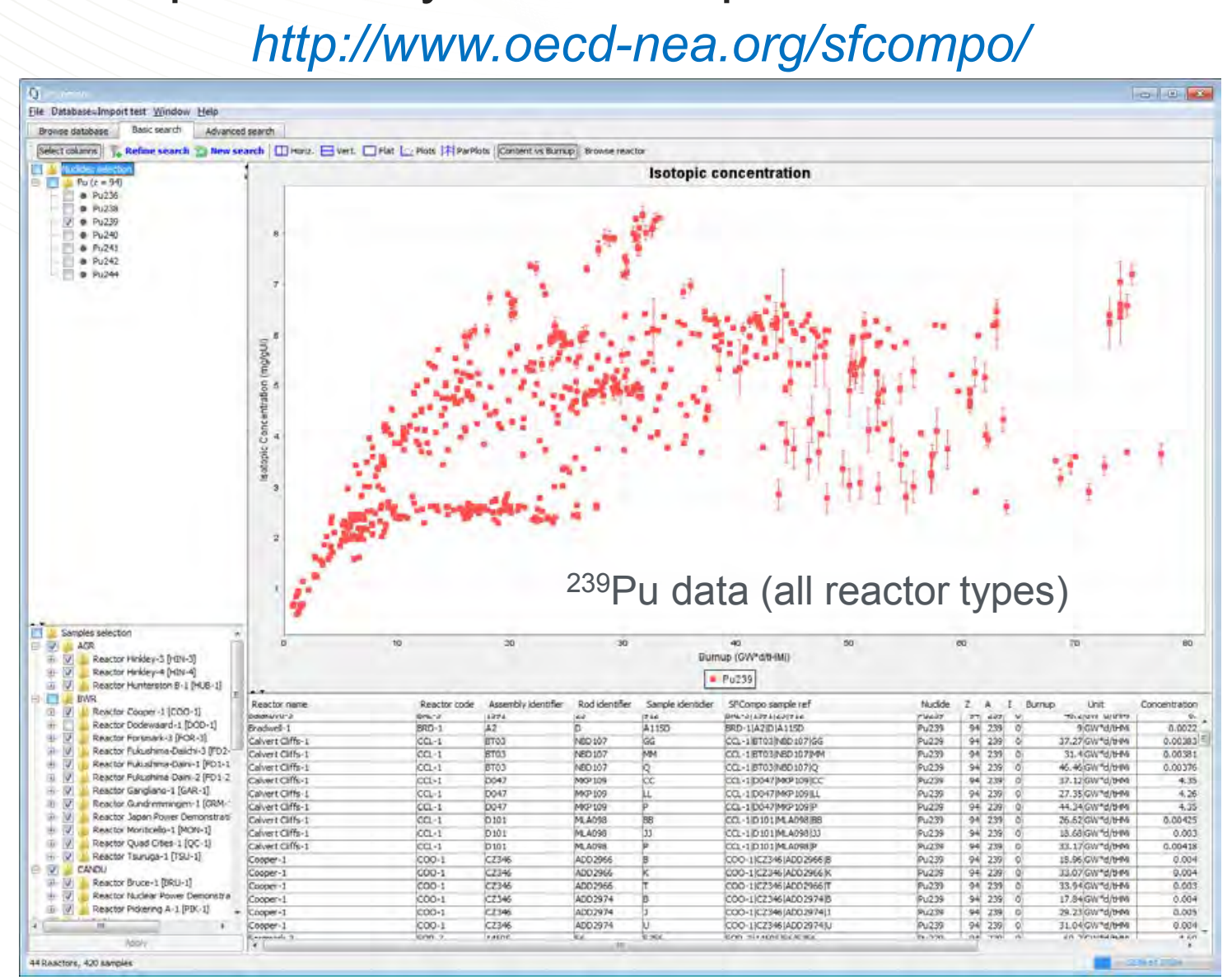

Databases maintained by OECD Nuclear Energy Agency Data Bank include:

- ICSBEP (Criticality safety database)

- IRPhEP (Reactor physics database)

- SFCOMPO (Spent fuel composition and decay heat database)

- Data for PWR, BWR, AGR, MAGNOX, CANDU, RBMK, VVER-440, VVER-1000 fuels

- 44 reactors, 118 assemblies, 91 isotopes important to fuel cycle safety and WM

- 750 samples > 22,000 measurements

- Data essential for code validation and uncertainty analysis, integral nuclear data testing -- Energy and Security applications 
$5 \%<$ Hi-assay LEU $<20 \%$ 


\section{NRC/NMSS perspectives on high assay fuel}

\section{$>$ 5.0 Weight Percent QU.NRR}

\section{Code Validation:}

$0 \%$

LEU powder /

pellet

packages,

$\mathrm{UF}_{6}$,

$\mathrm{UO}_{2}\left(\mathrm{NO}_{3}\right)_{2}$,

fresh fuel

assemblies,

spent fuel

assemblies
$5 \%$

Longer

irradiation

cycles, ATF

Advanced reactor fuel (MSR, SFR, HTGR)
$20 \% \backslash 93 \%$

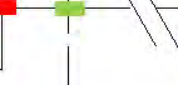

Research

reactor

fuel,

fresh or

spent

(TRIGA,

MTR

etc.)

\section{Some}

research

reactor fuel,

fresh or

spent, HEU

powder I

pellet / metal

packages

\section{U.S.NRC}

Prokctiting Prophe

NRC Regulatory Perspective on Criticality Safety in Fissile
Material Transportation and Spent Fuel Storage

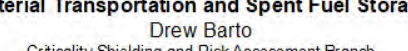

Criticality Shielding and Risk Assessment Branch
Division of Spent fuel Management
US NRC

American Nuclear Society Winter Meeting Washington, DC
October 30,2017

\section{Part $71 / 72$ Interface U.S.NRC}

High- Capacity PWR Cask Criticality Safety Criteria:

Storage:

- $<5.0 \%$ Initial enrichment

- Minimum soluble boron during loading

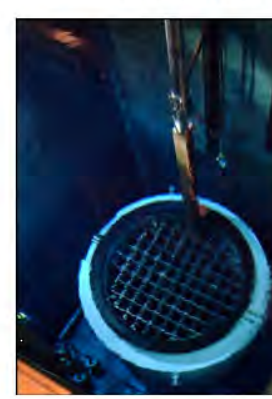

Transportation:

- $<5.0 \%$ Initial enrichment

- $>45 \mathrm{GWd} / \mathrm{MTU}$ burnup

- Cooling time

- Limits on irradiation parameters:

- Soluble boron

- Specific power

- Moderator temp.

- Fuel temp. 


\section{Example criticality validation process using the ES-4100 package}

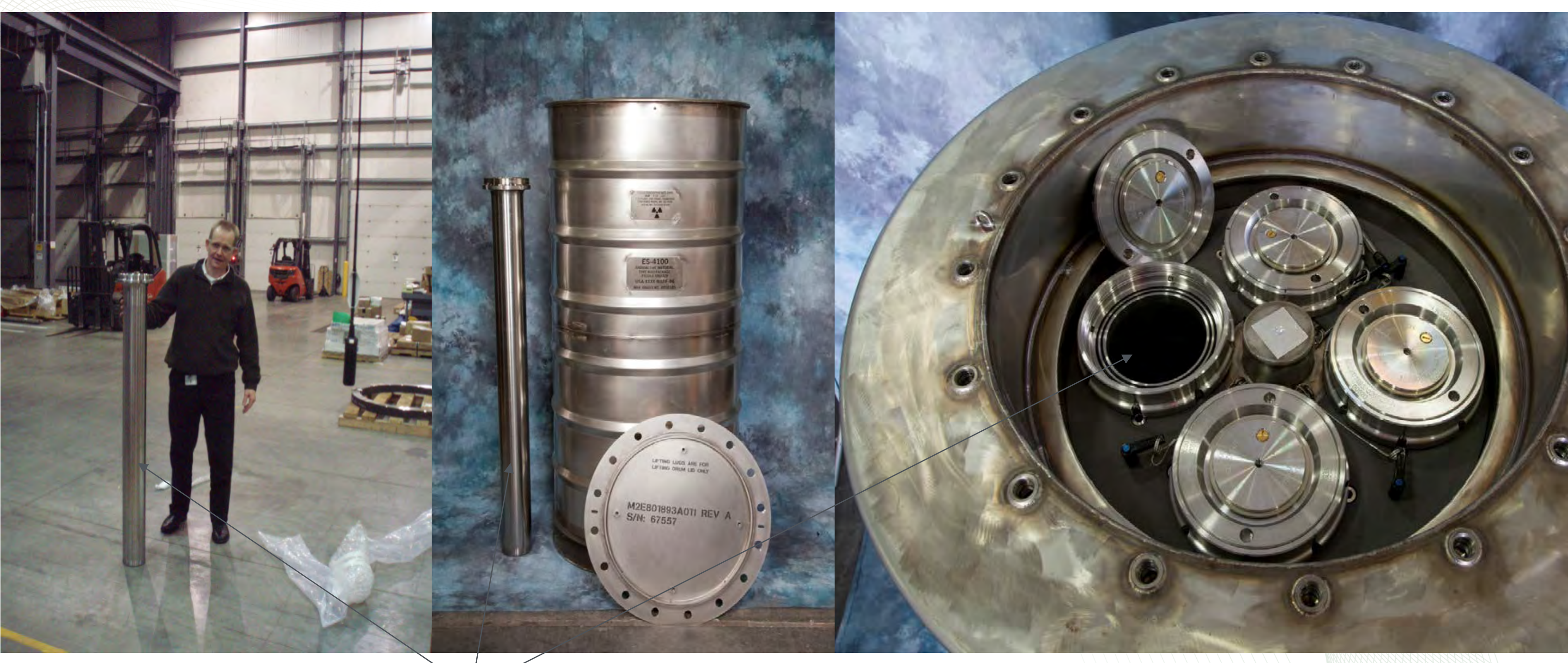




\section{ES-4100 w/ 20 w/o UF 6 study:}

Counteracting errors in ENDF/B-VII.1 - ENDF/B-VIII.0

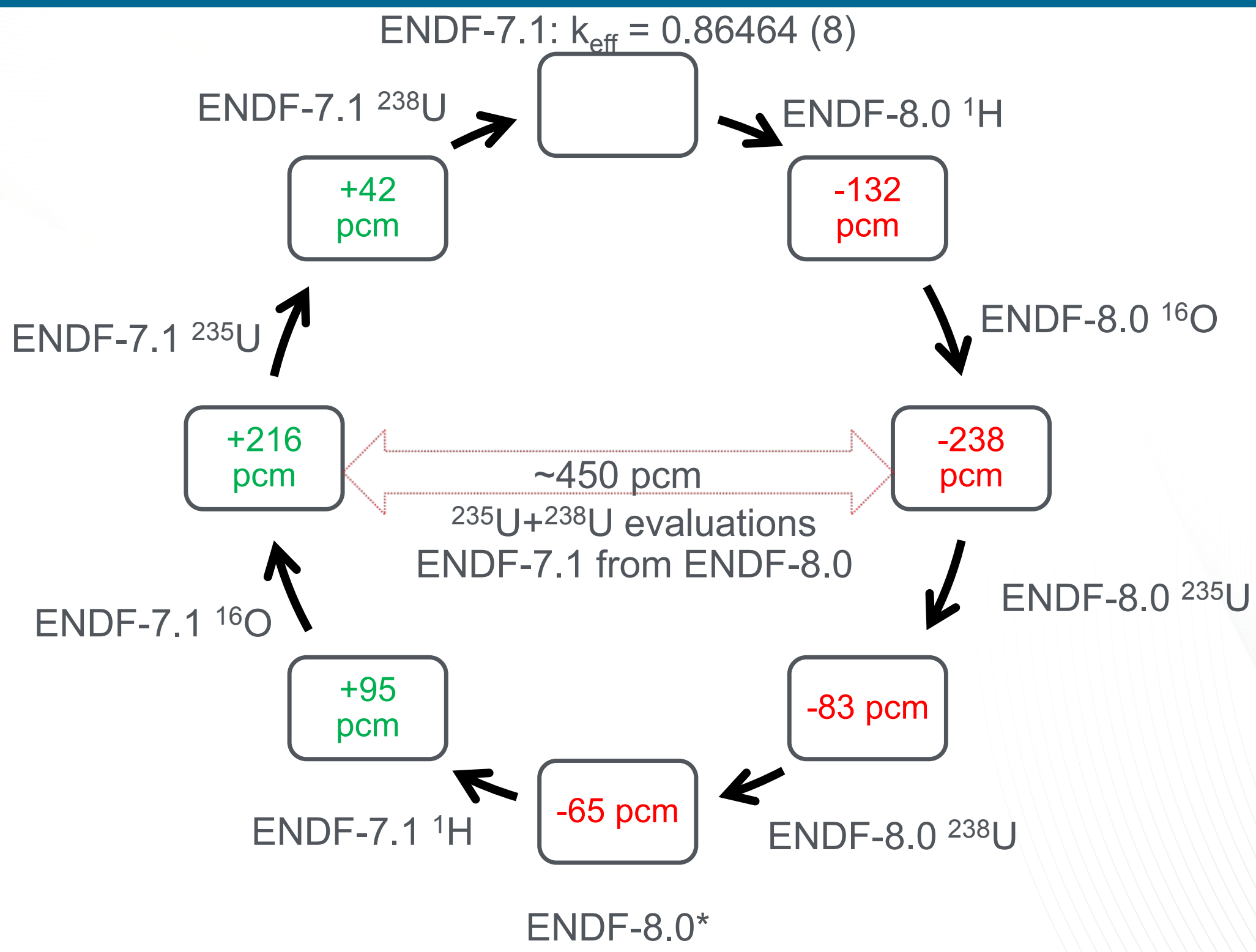


Sensitivity of $k_{\text {eff }}$ to nuclear data quantifies how important each cross section is for application of interest

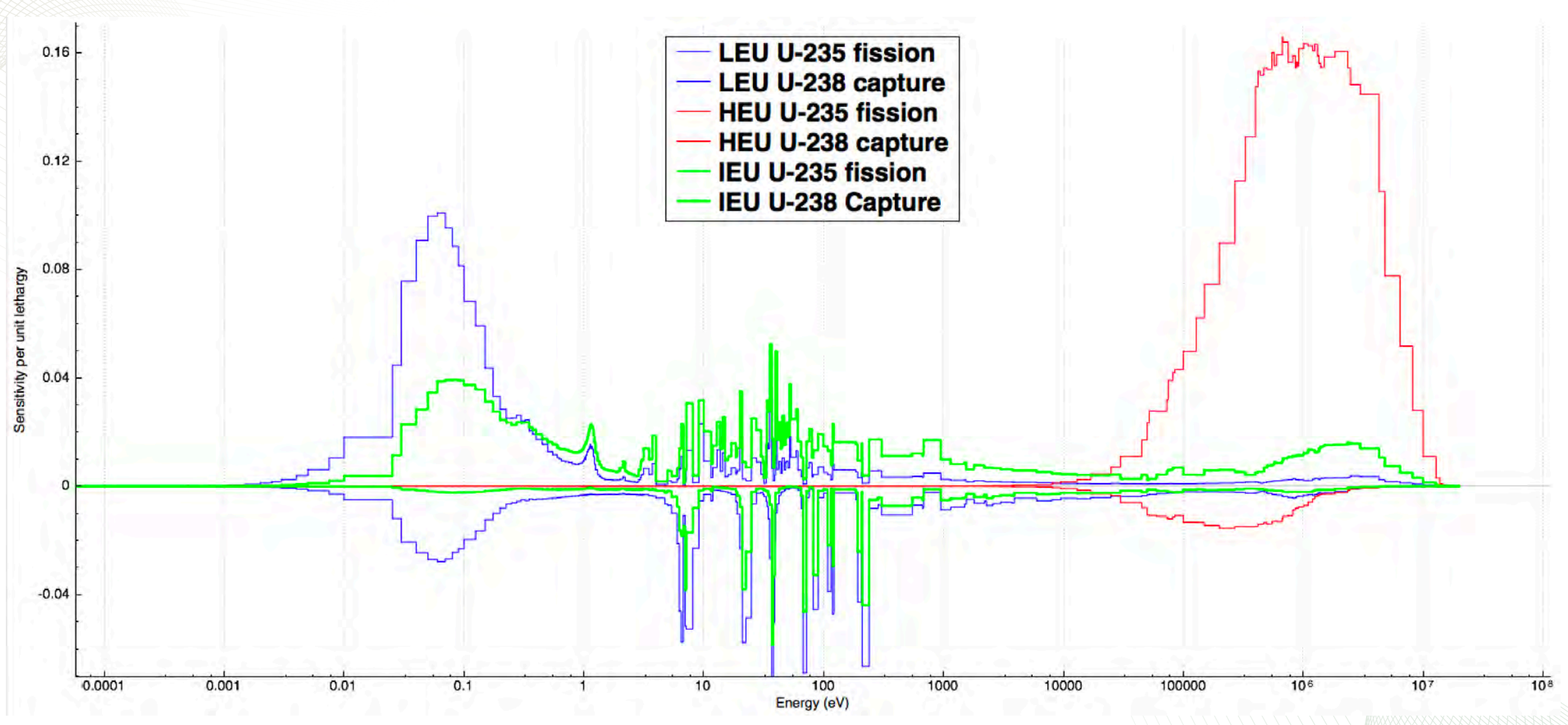




\section{Role of Sensitivity and Uncertainty Analysis in Validation}

- Clearly identifies processes that are important to validate

- Materials, Nuclides, Reactions, Energy

- Assists with challenging areas of applicability where few or no similar experiments are available

- Premise of S/U-based validation

- Computational biases are primarily caused by errors in the cross-section data

- Errors are bounded by cross-section uncertainties represented in covariance data 
Example application of S/U methods: Safety assessment for transportation of burned nuclear fuel

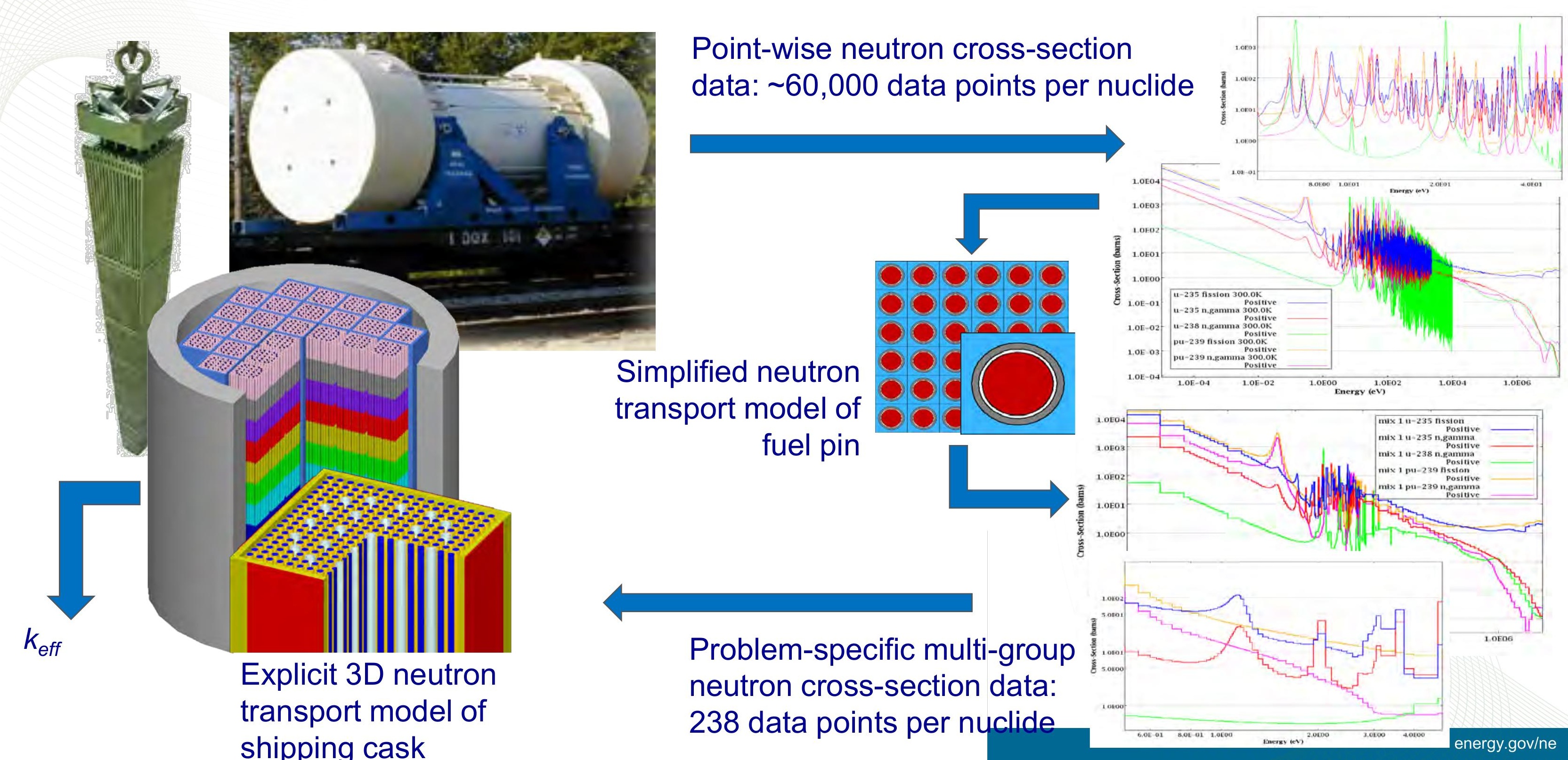




\section{Sensitivities of $k_{\text {eff }}$ of a shipping cask to cross section data}
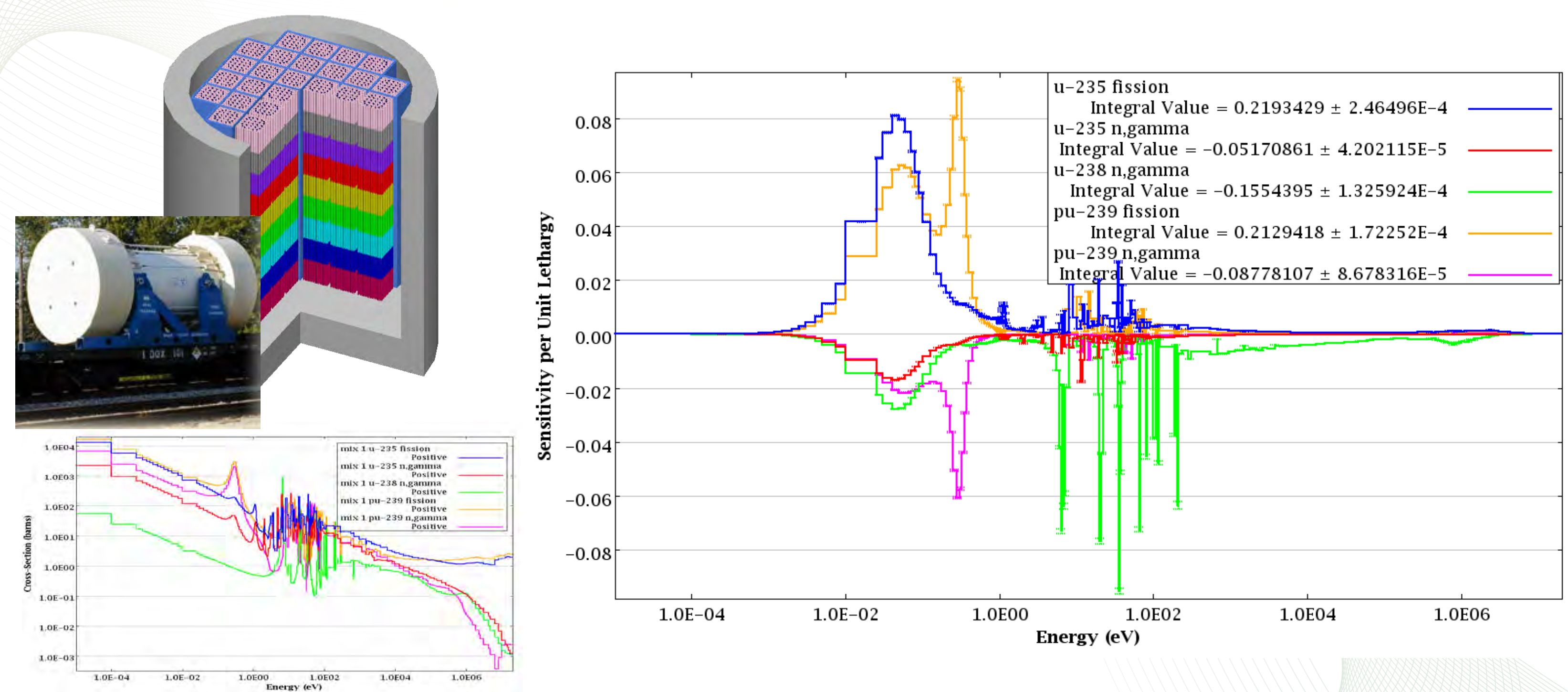


\section{Uncertainties in nuclear data}

SCALE 6.2 covariance library

- ENDF/B-VII.1 contains data for 187 isotopes.

- SCALE 6.1 data retained for $\sim 215$ missing nuclides.

- Modified ENDF/B-VII.1 ${ }^{239}$ Pu nubar, ${ }^{235} \mathrm{U}$ nubar, $\mathrm{H}$ capture, and several fission product uncertainties, with data contributed back to ENDF/A repository.

- Fission spectrum (chi) uncertainties processed from ENDF/B-VII.1 and from JENDL 4.0 (minor actinides).

- No uncertainties available for scattering secondary particle energy/angular distributions

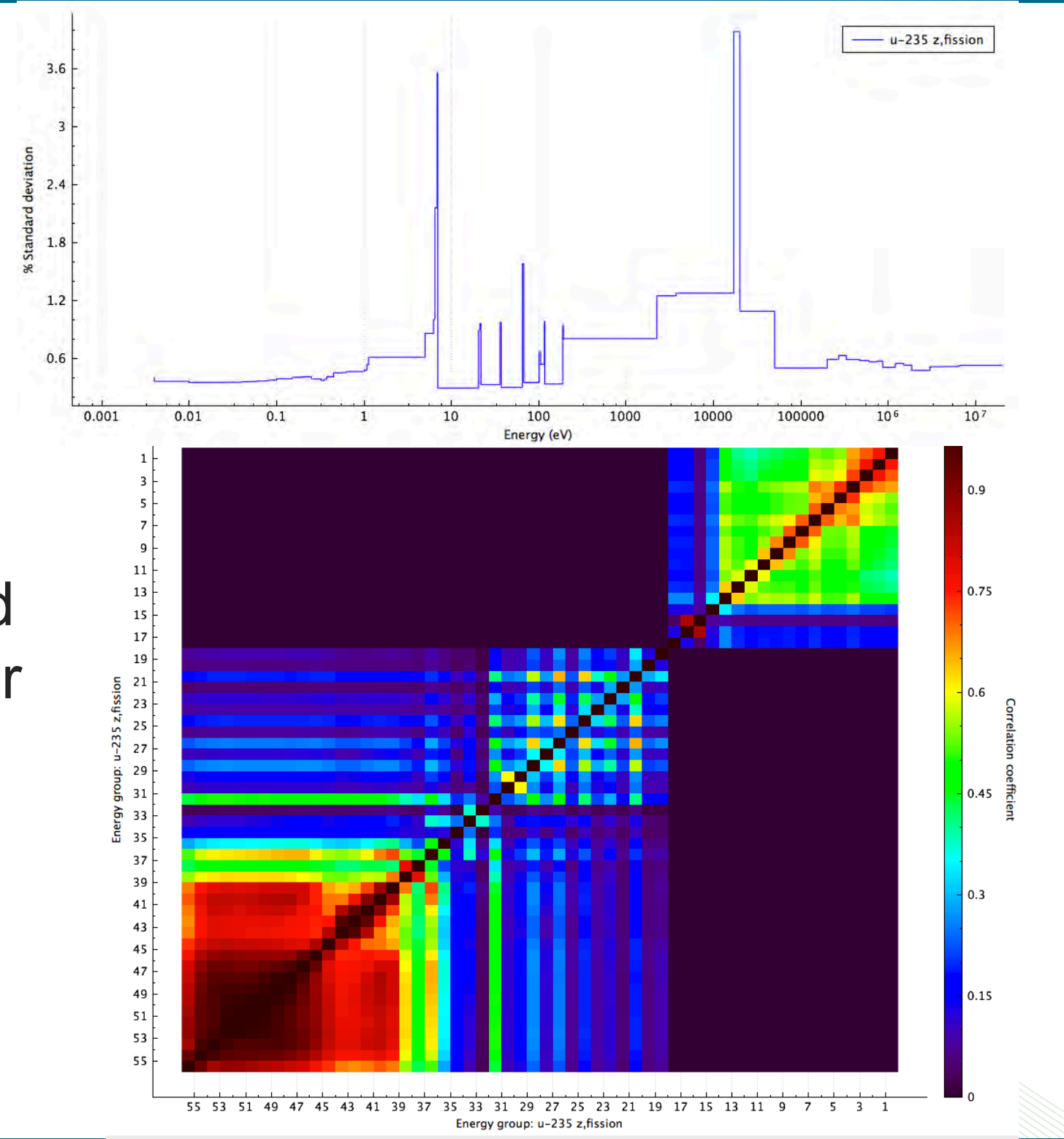




\section{S/U analysis to identify important processes}

\section{Application specific}

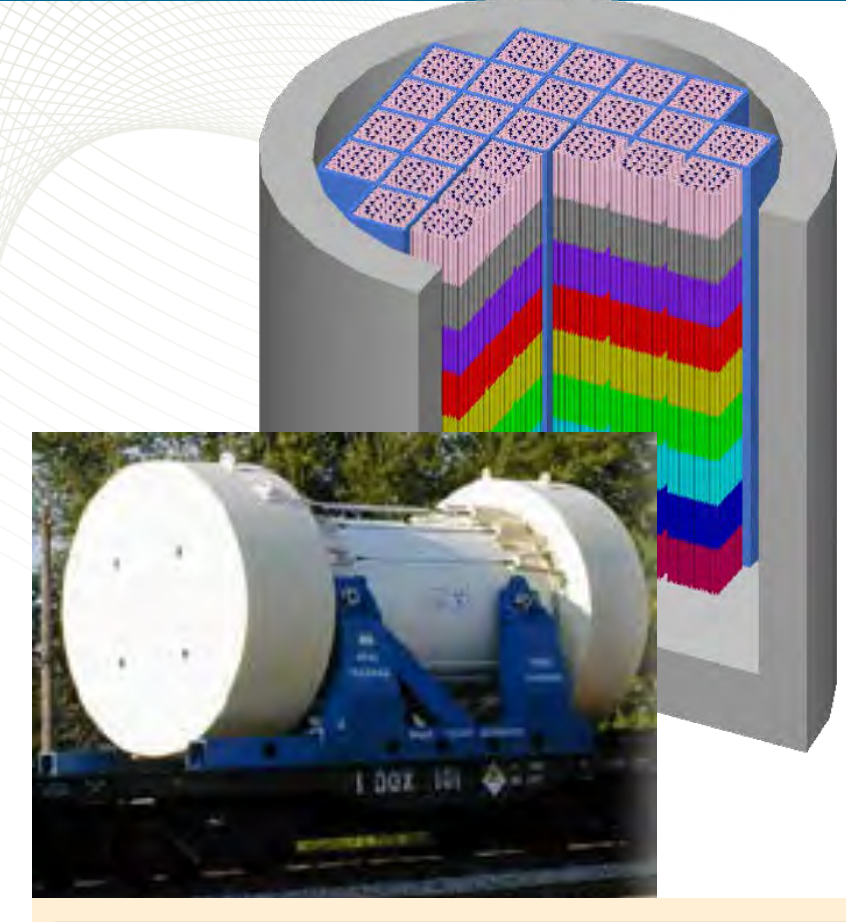

\begin{tabular}{||c|}
\hline \multicolumn{2}{|c|}{ Covarian } \\
\hline \hline Nuclide-Reaction \\
\hline \hline${ }^{239} \mathrm{Pu}$ nubar \\
\hline \hline${ }^{238} \mathrm{U}$ n,gamma \\
\hline \hline${ }^{239} \mathrm{Pu}$ fission \\
\hline \hline${ }^{235} \mathrm{U}$ nubar \\
\hline${ }^{239} \mathrm{Pu}$ fission \\
\hline \hline
\end{tabular}

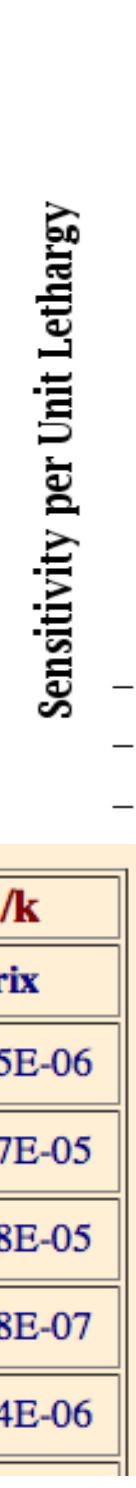

0.18 BUC Cask pu-239 nubar

0.16

0.14

0.12

0.10

0.08

0.06

0.04

0.02

0.00

0.04

$-0.06$

0.08
Unc. in \% $\mathbf{d k} / \mathbf{k}$

Due to this Matrix

4.0032E-01 $\pm 2.5625 \mathrm{E}-06$

$1.9457 \mathrm{E}-01 \pm 1.2387 \mathrm{E}-05$

$1.5501 \mathrm{E}-01 \pm 1.0838 \mathrm{E}-05$

$1.3981 \mathrm{E}-01 \pm 5.0038 \mathrm{E}-07$

$1.2261 \mathrm{E}-01 \pm 4.3564 \mathrm{E}-06$ 
Identify and analyze benchmark experiments to quantify bias in application
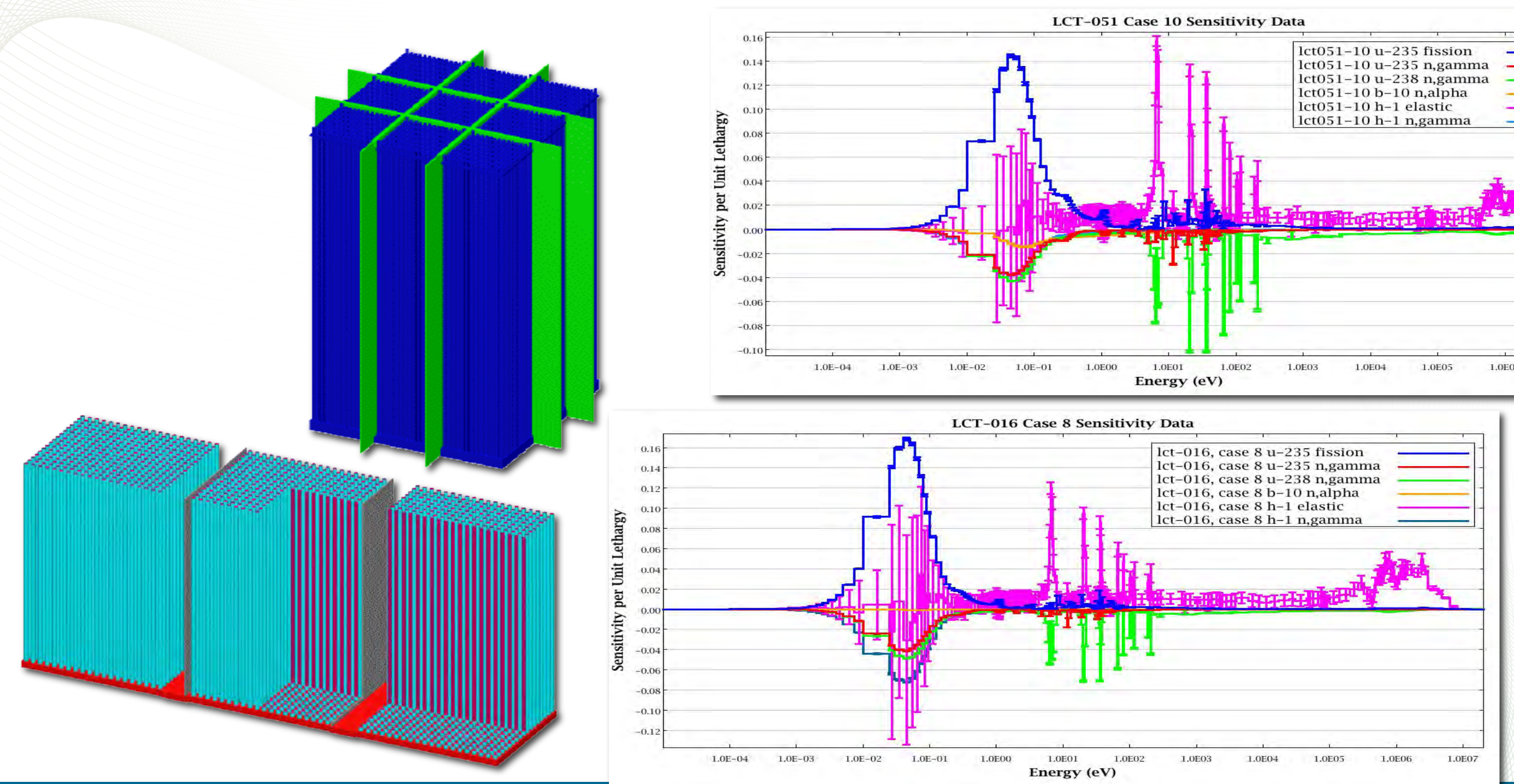
- Quantifies overall similarity potential sources of bias in $k_{\text {eff }}$ between design application and benchmark experiment.

$$
\begin{aligned}
& \text { Covariance between } \\
& \sigma_{a e}^{2} \longleftarrow \text { Experiment (e) and Application (a) } \\
& c_{k}=\frac{\sigma_{a e}}{\sigma_{a} \sigma_{e}} \quad \text { Standard deviations for } \\
& \text { Application (a) and Experiment (e) } \\
& \text { due to all nuclides and reactions }
\end{aligned}
$$


Code Validation: Identification of laboratory experiments that are similar to the targeted application

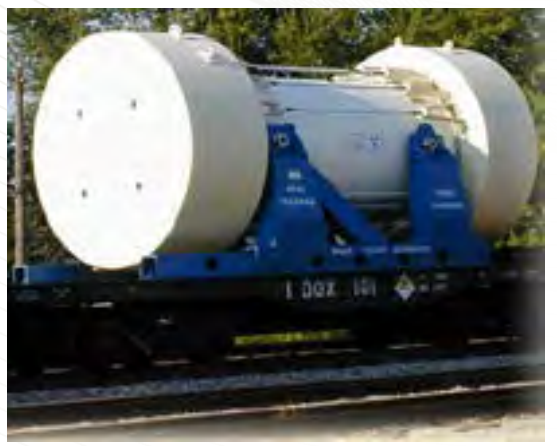

\section{APPLICATION}

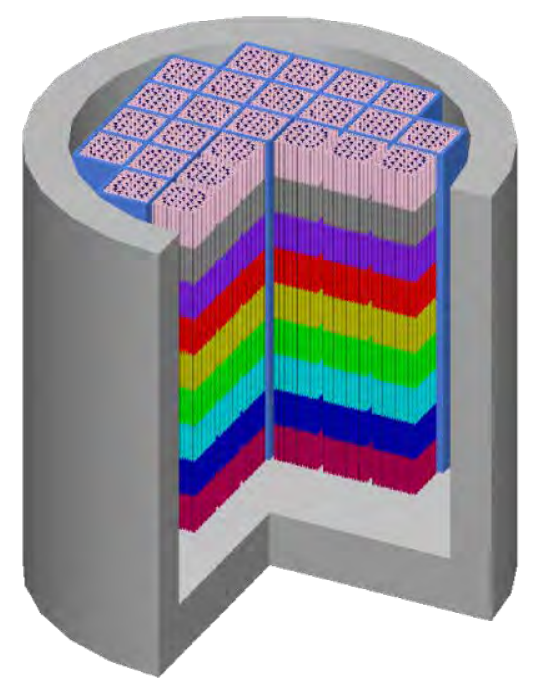

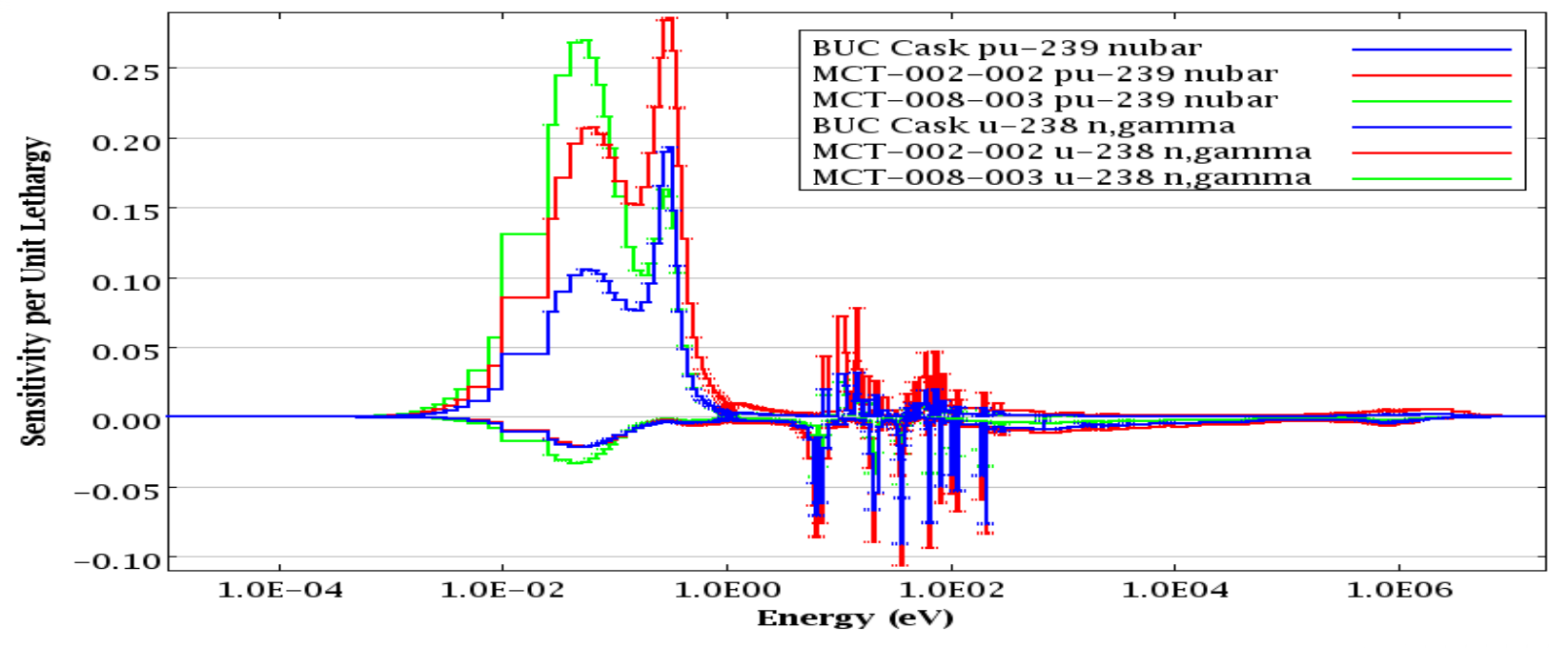

Applicability of 1,134 Critical Experiments to a PWR Burnup Credit Cask Model

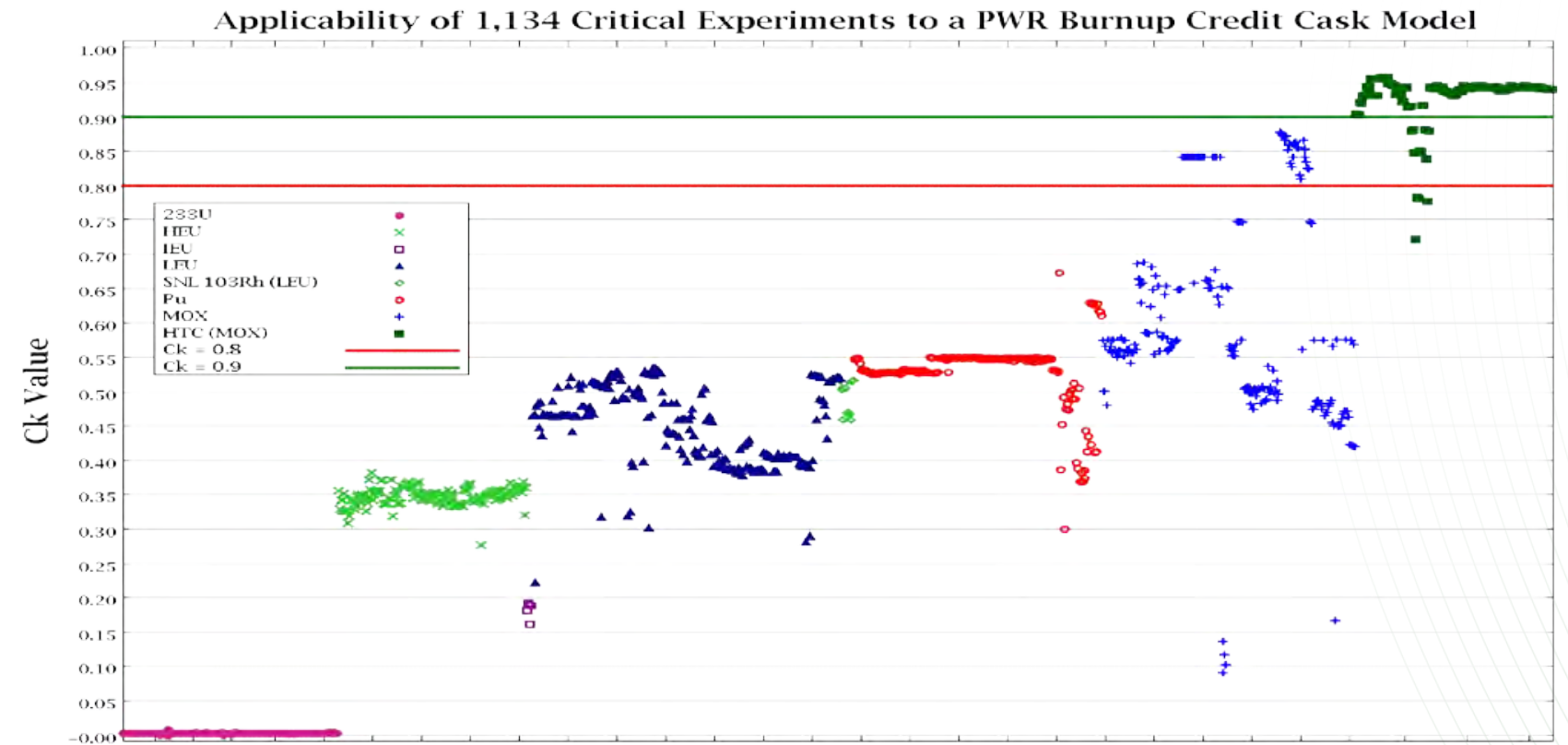

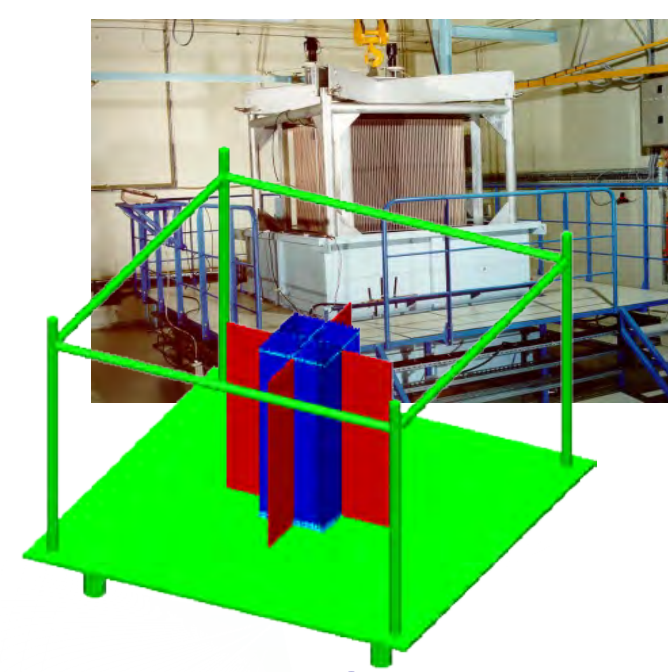

NUCLEAR CRITICALITY EXPERIMENTS 


\section{Similarity as independent parameter for trending analysis}

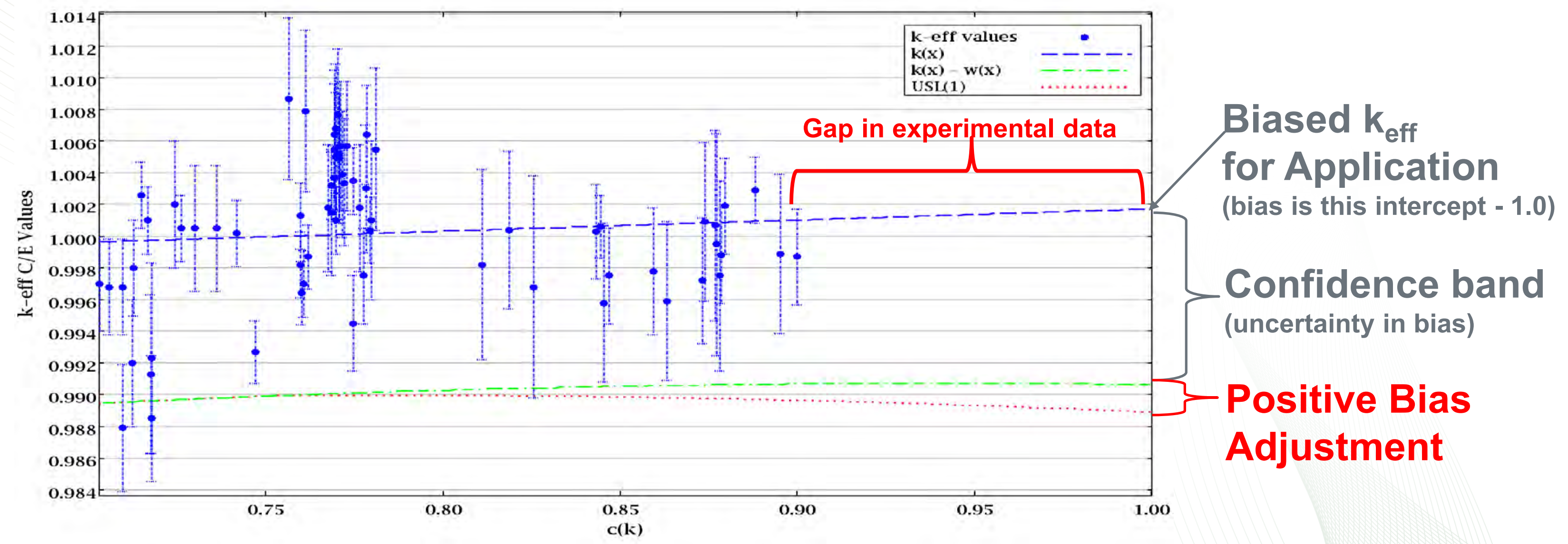




\section{Regulatory basis for validation applicability}

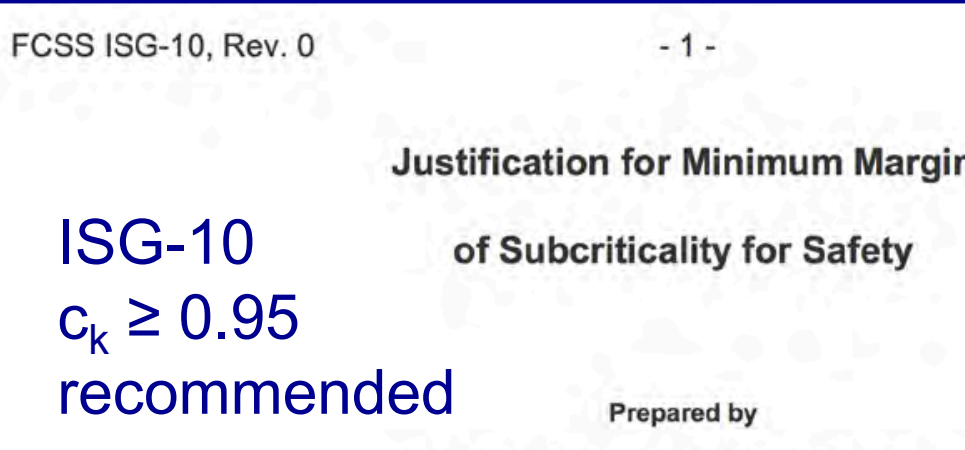

Division of Fuel Cycle Safety and Safeguards

Office of Nuclear Material Safety and Safeguards

Issue

Technical justification for the selection of the minimum margin of subcriticality for safety for fuel

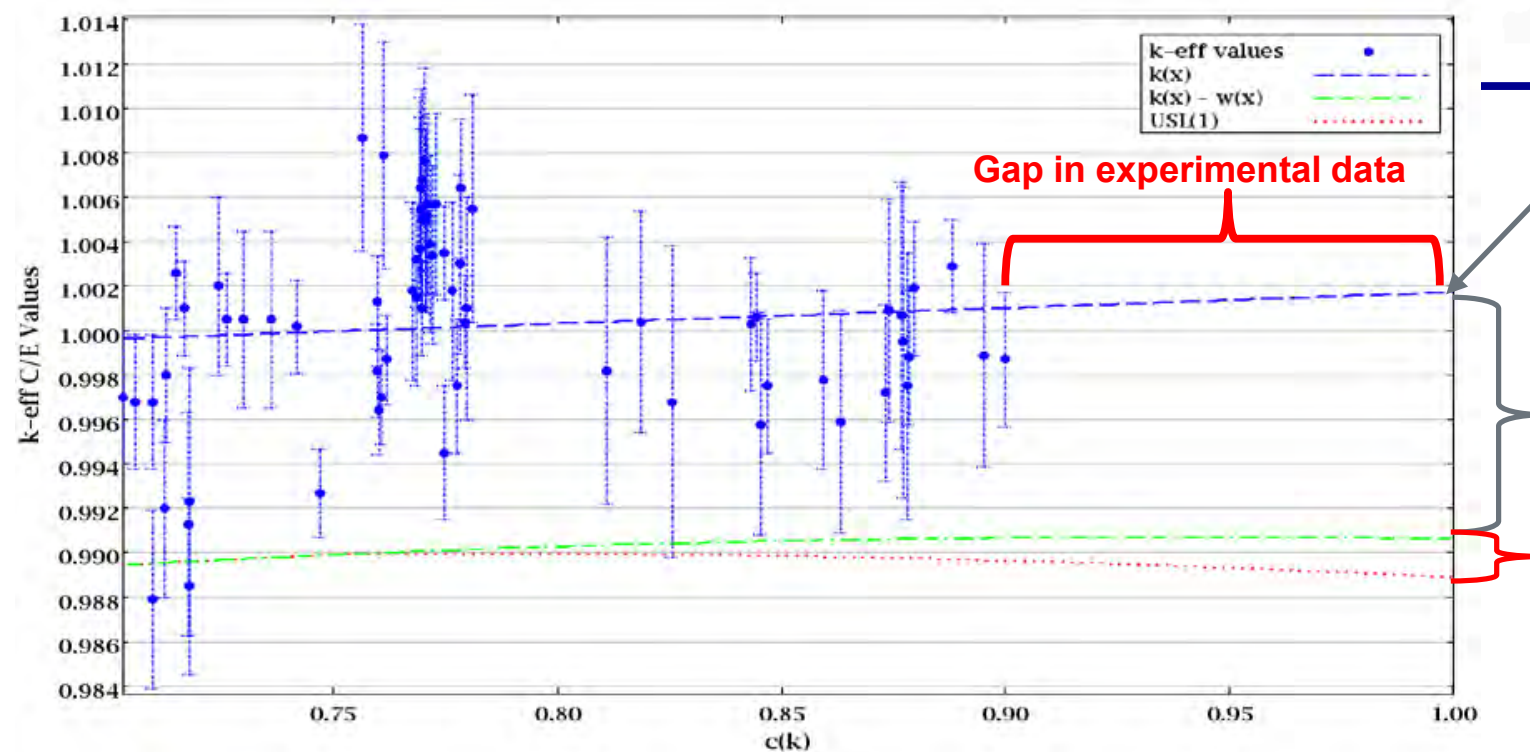

Sensitivity and Uncertainty

Analyses Applied to

Criticality Safety

Validation

Methods Development

Biased $\mathrm{k}_{\text {eff }}$

for Application

(bias is this intercept - 1.0)

Confidence band

(uncertainty in bias)

Positive Bias

Adjustment
NUREG/CR-6655,Vol.2
ORNL/TM-13692/V2

Sensitivity and Uncertainty

Analyses Applied to

Criticality Safety

Validation

Illustrative Applications and Initial Guidance

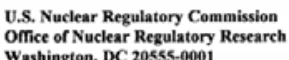


- Nuclear data and validation studies:

- Gap analysis for nonLWR (ORNL - Sobes/Bostelmann)

- Investigation of HA-LEU transportation validation basis (ORNL Rearden/Scaglione/Marshall/Clarity/Holcomb)

- Nuclear data generation:

- Investigation and generation of application driven covariance data (ORNL - Sobes)

- Improvements of nuclear data for depletion, activation, and decay (ORNL - Wieselquist)

- New measurement of ${ }^{238} \mathrm{U}$ (n,n') with associated uncertainties (LBNL - Bernstein)

- International benchmarking activities:

- Multi-Physics Experimental Data, Benchmark, and Validation (ORNL - Valentine)

- International Physics Benchmark Programs: ICSBEP and IRPhEP (INL - Bess)

- University projects:

- Generation of thermal scattering data for graphite (N.C. State, X-energy, ORNL)

- Generation of thermal scattering sensitivity/uncertainty capabilities (U. Michigan, ORNL) 


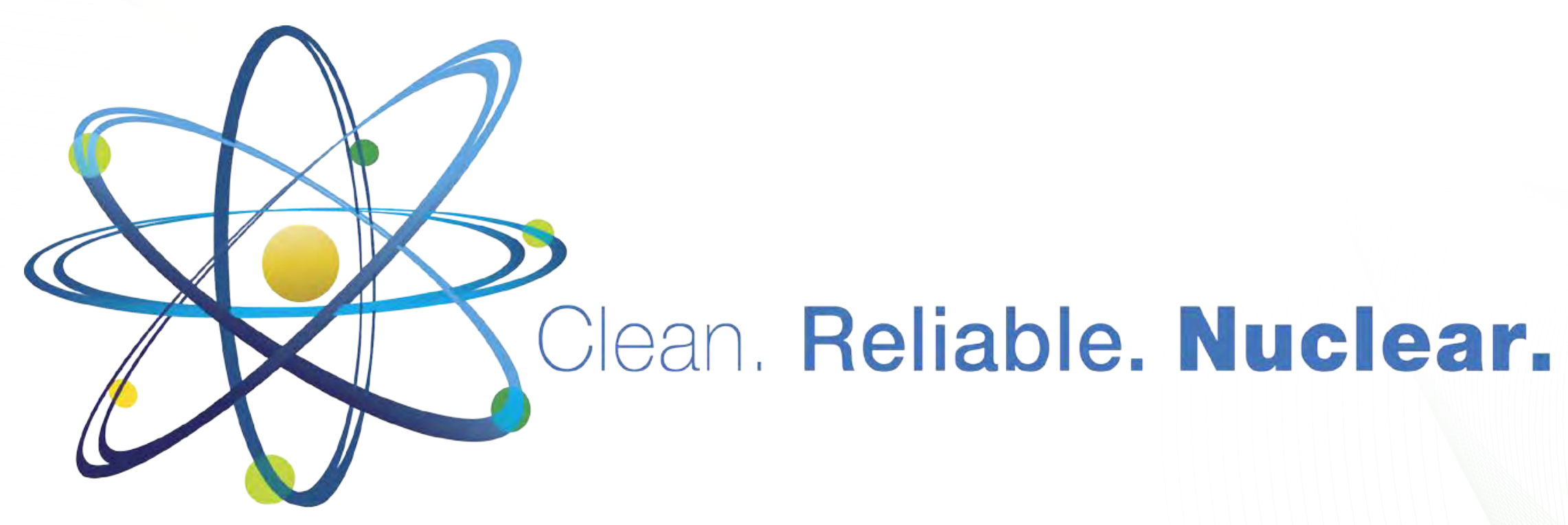




\section{INL-NEI Technical Workshop on Transportation of High Assay Low Enriched Uranium}

August 30-31, 2018

Melissa Mann

President, URENCO USA, Inc. 


\section{HALEU and the HALEU Community}

- High Assay Low Enriched Uranium (HALEU) refers to enrichments above $5.0 \%$ U235 and below $20.0 \%$ U235.

- A broad community of users may benefit from HALEU:

- Research and test reactors: including reactors fueled by DOE in the US/overseas and including those currently relying on HEU that may convert to HALEU

- Advanced reactors, including non-LWRs

- Advanced fuel designs

- Producers of targets for medical isotope production

- Operators of existing LWRs seeking improvements in fuel reliability and economics through higher burnup* and extended operating cycles

- As the enrichment levels needed by these users will vary, fuel solutions are needed across the full span of HALEU enrichments (although some "clumping" may develop in the ranges of $6.0 \%-8.0 \%$ U235 and $13.0-16.0 \%$ U235 and at $19.75 \%$ U235). 


\section{HALEU Fuel Cycle}

- A complete and sustainable HALEU fuel cycle includes three fundamental capabilities:

- A uranium enrichment facility to produce HALEU enrichments*: the material will be in the form of uranium hexafluoride (UF6)

- A conversion facility to (de)convert HALEU UF6 into metal, oxide and/or salts

- One or more fabrication facilities that can manufacture the specific fuel types required by the various reactor and fuel designs

*It is assumed that the "feed" material for HALEU enrichment is standard

low enriched uranium as UF6 at roughly $4.95 \%$ U235.

- Packaging and transportation solutions are needed between each of these processing steps and to the ultimate user (for the purposes of today's discussion, spent fuel packaging is not addressed). 


\section{Initial Observations}

- Fuel cycle facilities producing and utilizing higher enrichments can be licensed in the US: two NRC-licensed facilities currently fabricate HEU fuel (Category I sites)

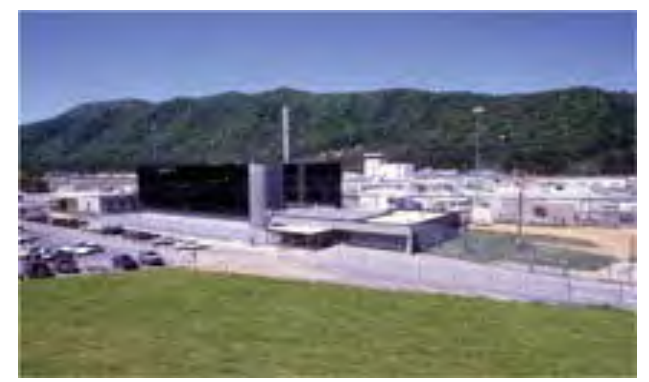

Nuclear Fuel Services (Erwin, TN)

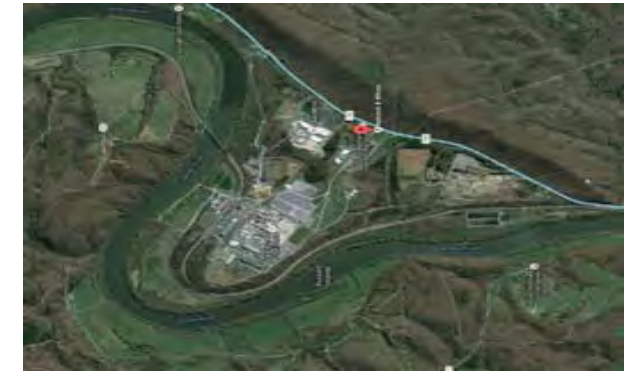

BWXT Nuclear Operations Group (Lynchburg, VA)

- It is imperative that the enrichment, conversion and fabrication facilities - and the concordant packaging solutions - be developed on concurrent schedules.

- The licensing framework needs to support development of a HALEU fuel cycle and regulator resources are needed.

- Companies making investments in HALEU facilities need to be sufficiently assured of an economic return. 


\section{Potential HALEU Enrichment at URENCO USA (UUSA)}
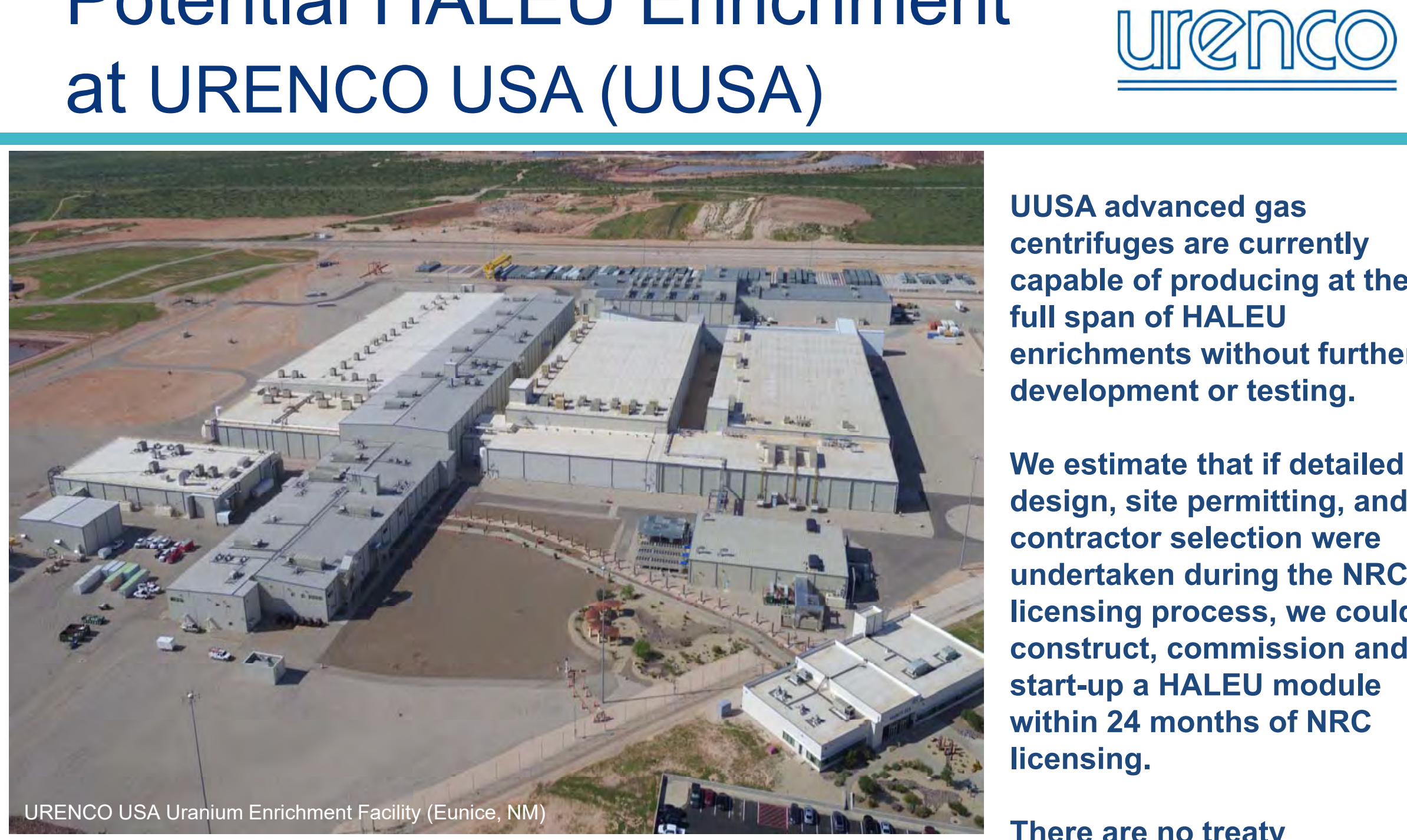

UUSA advanced gas centrifuges are currently capable of producing at the full span of HALEU enrichments without further development or testing.

We estimate that if detailed design, site permitting, and contractor selection were undertaken during the NRC licensing process, we could construct, commission and start-up a HALEU module within 24 months of NRC licensing.

There are no treaty

- $\quad 1^{\text {st }}$ facility licensed, constructed and operated under a COL

- Application submitted 12/12/2003 and issued on 6/23/2006 (2 years, 6 months)

- Operations started in 2010

- $\quad$ Licensed for 10,000 million SWU/a; currently producing $\sim 4.9$ million SWU/a at up considerations associated with HALEU production at UUSA to $5.0 \%$ U235 as UF6

- Utilizes advanced gas centrifuge technology 


\section{Licensing HALEU Enrichment}

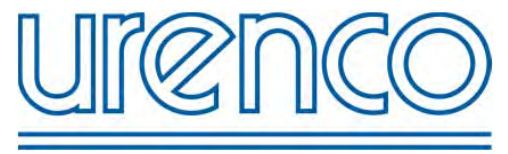

- UUSA is currently licensed as a Category III facility. The licensing approach for adding a HALEU module may differ by assay bands:

- For enrichments between $5.0 \%$ and $6.0 \%$ U235 - analytical approach?

- For other assays below $10.0 \%$ U235 - amended license as a Category III site

- For assays above $10.0 \%$ U235 and below $20.0 \%$ U235, Category II license

Decision point: Initiate a separate license for a Category II HALEU module or license entire site as a Category II facility?

- NRC has clear guidance on MC\&A/Fundamental Nuclear Material Control Plans for Category III (NUREG-1065) and Category I (NUREG-1280) facilities, but not for Category II sites.

- Physical protection appropriate to a Category II site and materials is required (as well as for transport).

- Additional criticality benchmark data will be required to support new licensing but questions also exist about how the NRC will approach criticality safety analyses. We would like to see a consistent and coordinated approach to criticality safety for all HALEU fuel cycle facilities. 


\section{Packagings for Fissile UF6}

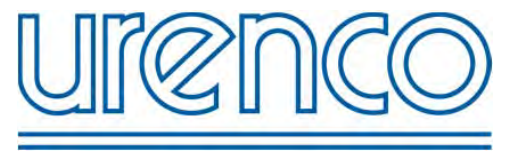

$\S 71.55$ General requirements for fissile material packages (excerpted)

b) Except as provided in paragraph (c) or ( $\mathrm{g}$ ) of this section, a package used for the shipment of fissile material must be so designed and constructed and its contents so limited that it would be subcritical if water were to leak into the containment system, or liquid contents were to leak out of the containment system so that, under the following conditions, maximum reactivity of the fissile material would be attained:

(1) The most reactive credible configuration consistent with the chemical and physical form of the material;

(2) Moderation by water to the most reactive credible extent; and

(3) Close full reflection of the containment system by water on all sides, or such greater reflection of the containment system as may additionally be provided by the surrounding material of the packaging.

(g) Packages containing uranium hexafluoride only are excepted from the requirements of paragraph (b) of this section provided that:

(1) Following the tests specified in $\S 71.73$ ("Hypothetical accident conditions"), there is no physical contact between the valve body and any other component of the packaging, other than at its original point of attachment, and the valve remains leak tight;

(2) There is an adequate quality control in the manufacture, maintenance, and repair of packagings;

(3) Each package is tested to demonstrate closure before each shipment; and

(4) The uranium is enriched to not more than 5 weight percent uranium-235.

- Approved packagings are needed for HALEU UF6, HALEU metal/oxide and for HALEU fabricated components

- Due to moderator exclusion requirements, packaging HALEU UF6 will likely be more complicated than packaging HALEU metals and oxides

- A rule change to 10 CFR Part 71.55 would be a lengthy process and likely unsuccessful

- Bespoke designs are likely required for different fabrication needs 


\section{UF6 Packaging Considerations}

- Are HALEU UF6 shipments limited to use of a small packaging?

\begin{tabular}{|c|c|c|c|}
\hline \multicolumn{2}{|c|}{ Existing UF6 Cylinders for Higher Assays } \\
\hline Cylinder Model & Diameter in inches & Maximum Enrichment & Maximum lb UF6* \\
\hline 1S & 1.5 & $100.00 \%$ & 1.0 \\
\hline 2S & 3.5 & $100.00 \%$ & 4.9 \\
\hline 5A & 5.0 & $100.00 \%$ & 54.9 \\
\hline 5B & 5.0 & $100.00 \%$ & 54.9 \\
\hline 8A & 8.0 & $12.5 \%$ & 255 \\
\hline
\end{tabular}

- Are moderator exclusion requirements met through the cylinder or through an overpack?

- Criticality benchmarking data is needed for HALEU assays. 


\section{The 2-Box Model}
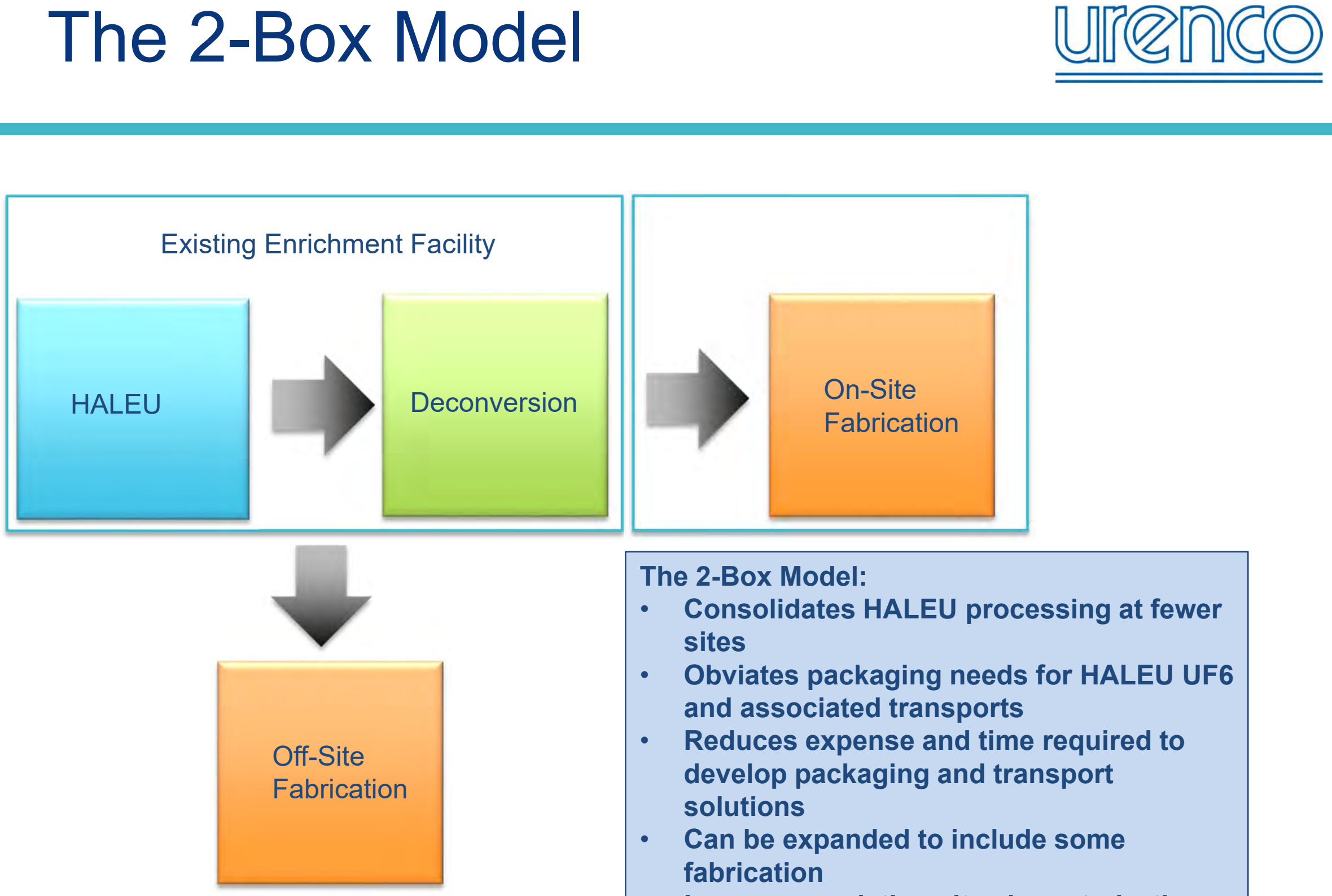

The 2-Box Model:

- Consolidates HALEU processing at fewer sites

- $\quad$ Obviates packaging needs for HALEU UF6 and associated transports

- Reduces expense and time required to develop packaging and transport solutions

- Can be expanded to include some fabrication

- Leverages existing site characterization data, site infrastructure, and regulator familiarity 


\section{Recommendations}

- HALEU users and fuel cycle participants should coordinate on packaging design and development of criticality benchmark data. This drives consistency, reduces duplication of effort, and provides for a consolidated voice with the regulators.

- DOE/National Laboratory involvement in development of new criticality data for HALEU facilities and packagings - and possibly packagings themselves - would support development of new technologies/designs and provide endorsement of underlying benchmarks.

- Industry should engage with DOT/NRC in the near-term on resource requirements, regulatory approach, anticipated time frames, testing requirements, etc.

- Industry should similarly engage with ANSI (and ISO) to ensure that incorporated standards are updated on a concurrent schedule.

- Get started soon - package development, testing and approval takes time! 
Global Nuclear Fuel

\section{HALEU Fuel Fabrication \& Transport: An Overview}

Lon Paulson

Senior Nuclear Engineer

GNFA

INL-NEI Technical Workshop on High Assay Low-Enriched Uranium August 30-31, 2018

Nuclear Energy Institute

Washington, DC
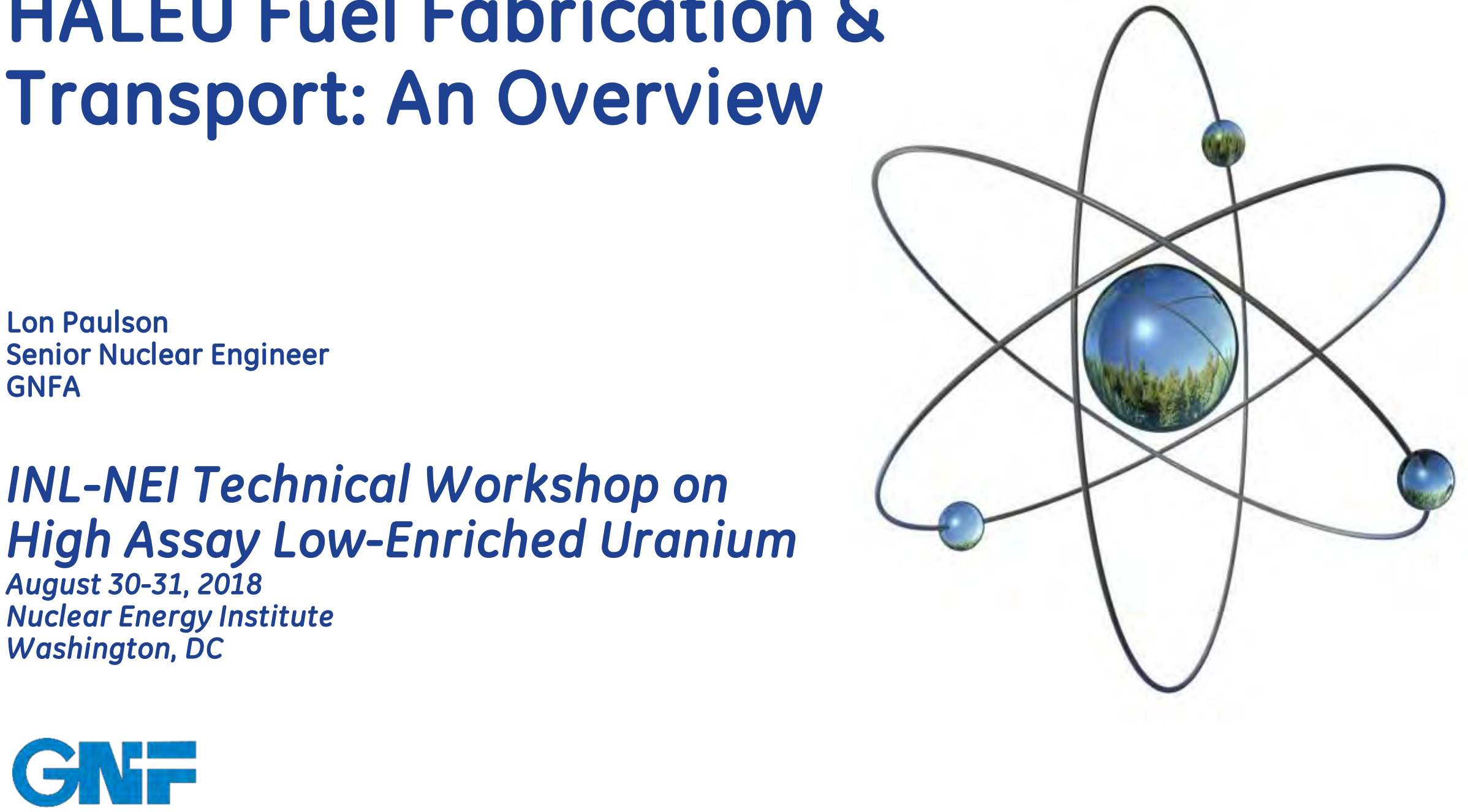


\section{HALUE Fuel Fabrication}

- Why HALEU?

- Fuel Form(s)

- Enrichment Facility*

- Feed Transport - 30B UF6 Cylinder / UX-30*

- Monte Carlo Methods

- Nuclear Criticality Safety Evaluations

- SNM-1097 License Amendment \& ISAS

- $\quad$ Factory Implementation: Nodal Basis

- NDA and RP Instrumentation

- Misc. Programs

- $\quad$ Product Transport - Model RAJ-II, NPC

- Example NRC Review Timeline

- Cost Elements

- Summary 


\section{Why Higher Assay LEU?}

- $\quad$ Existing LWR fuel cycle is currently limited to $5.0 \mathrm{wt} \% \mathrm{U} 235$ enrichment.

- The value to reactor utility is very high, as overall fuel cycle lengths could be increased in the existing fleet of Boiling Water Reactors (BWRs) or Pressurized Water Reactors (PWRs).

- Higher assay needed to reach +24-month cycle.

- $\quad$ Nearterm: BWRs/PWRs/SMRs utilizing $\mathrm{UO}_{2}$ Accident Tolerant Fuel (ATF) designs such as IronClad (FeCrAl cladding) or other cladding types would require higher enrichment to permit higher exposure lup to $~ 80 \mathrm{k}$ MWD/MTU). Anticipated peak assay is $<6.5 \mathrm{wt}$. \% U235.

- Longterm: Advanced reactors and novel SMR designs utilizing SFR technology with metallic uranium fuel may require assays up to 19.9 wt. \% U235. 


\section{Fuel Form(s)}

HALEU fuel forms being considered by GNFA in support of SMRs include:

UO2 fuel matrix $\rightarrow$ BWRX-300

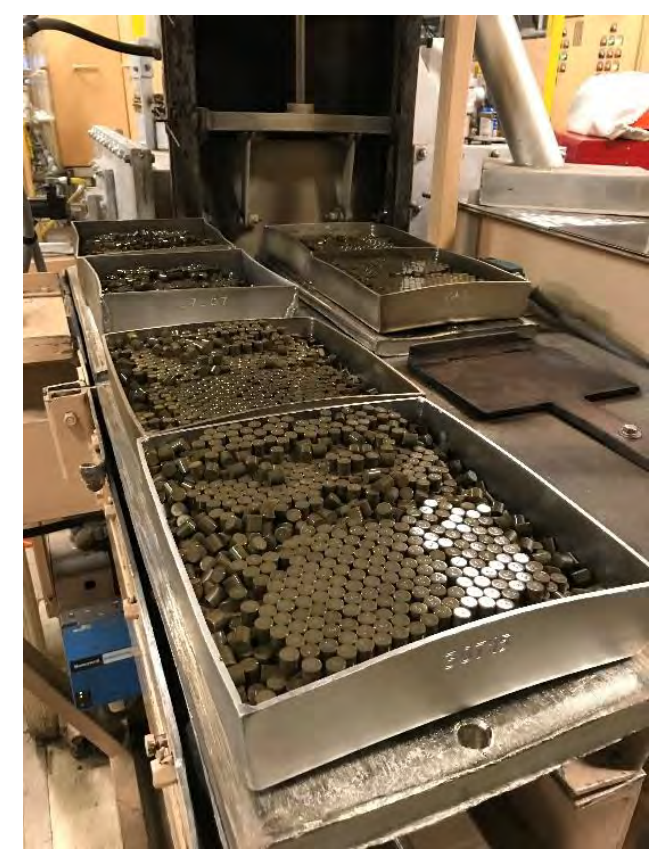

GN=
U Metal fuel matrix $\rightarrow$ PRISM, ARC, OKLO

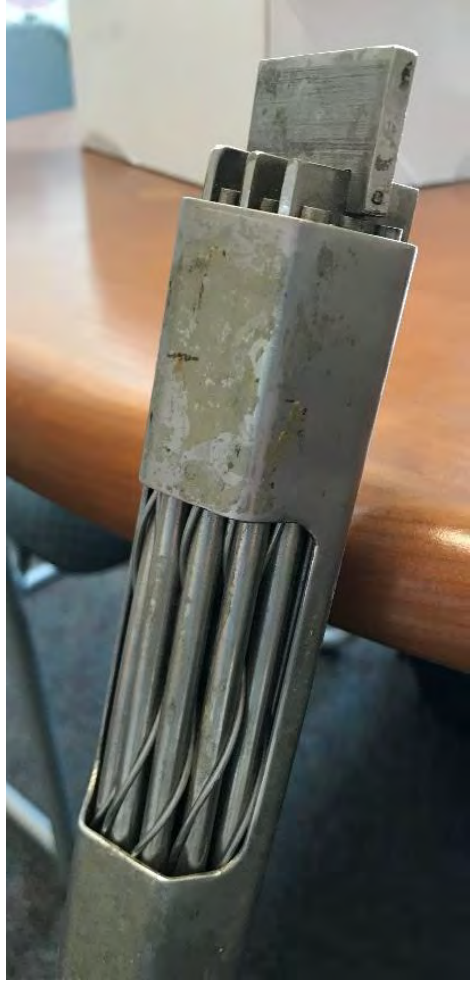

$U$ metal feed could be derived from national labs or converted from oxide....
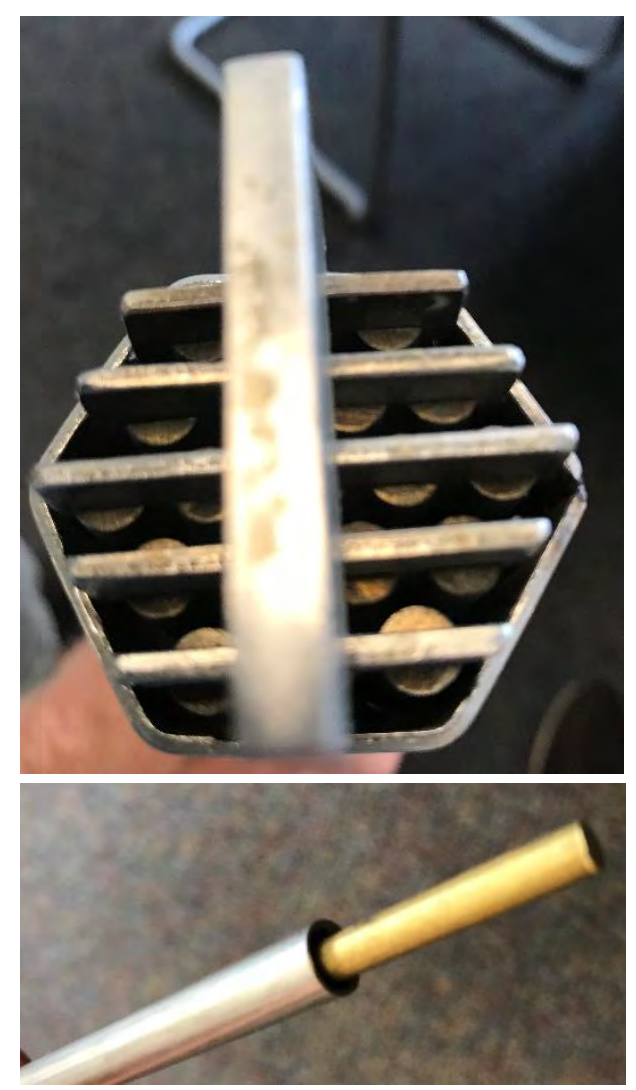


\section{ENR Facility}

- The enrichment facility must successfully produce, and deliver to the fabricator, $>5 \%$ assay in an approved UF6 cylinder.

- Technically feasible to configure cascade output to $>5 \%$ enr.

- Licensing, analysis, ISA Summary perturbations required.

- $\quad$ NOTE: GLE licensing bases evaluated 30-inch and 48-inch UF6 cylinders up to $10.0 \mathrm{wt}$.\% U235. 


\section{ENR Facility}

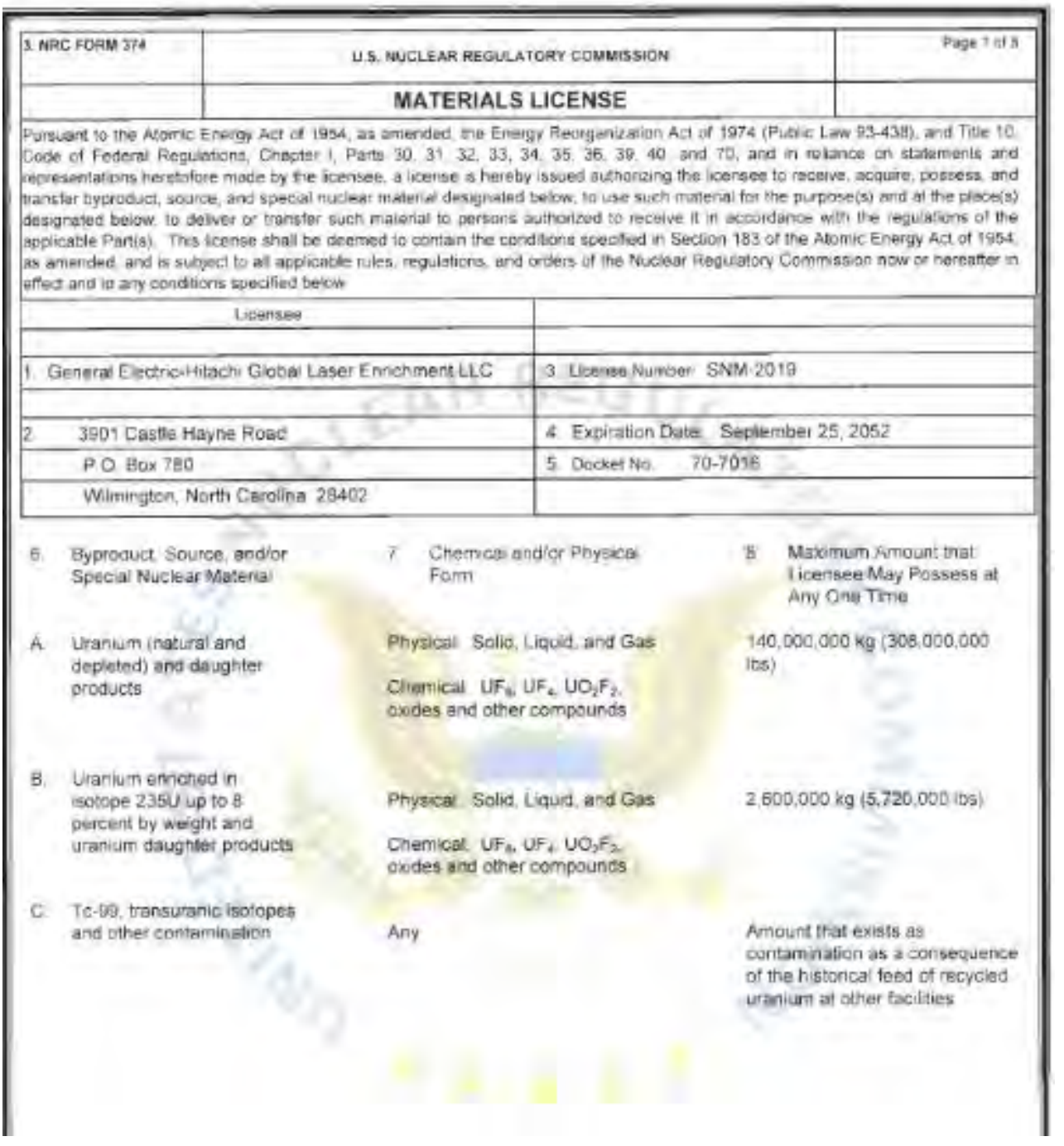

Under License SNM2019, GLE CF authorized to produce UF6 with material enrichments up to $8.0 \mathrm{wt} . \% \mathrm{U} 235$

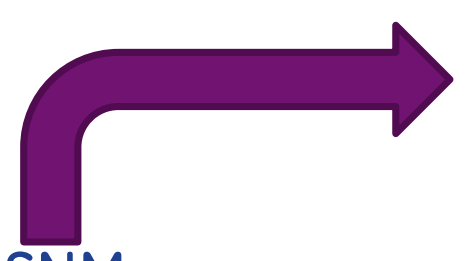




\section{Feed Transport: UF6 Cylinder / UX-30}

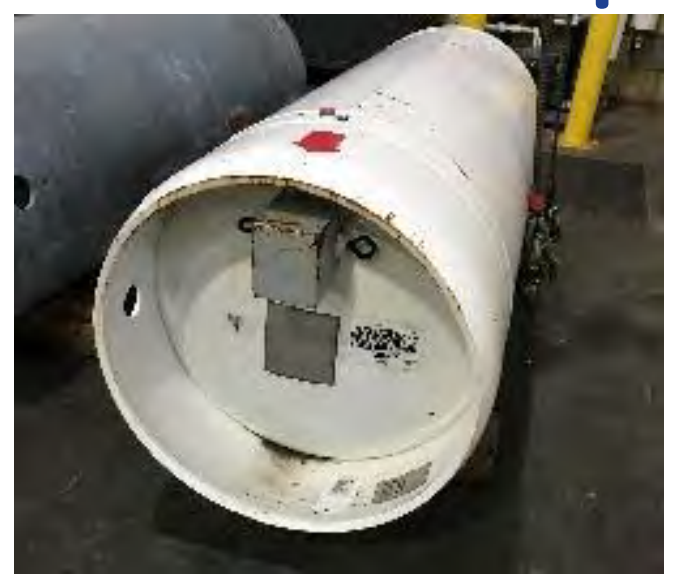

Model 30B UF6 Cylinder
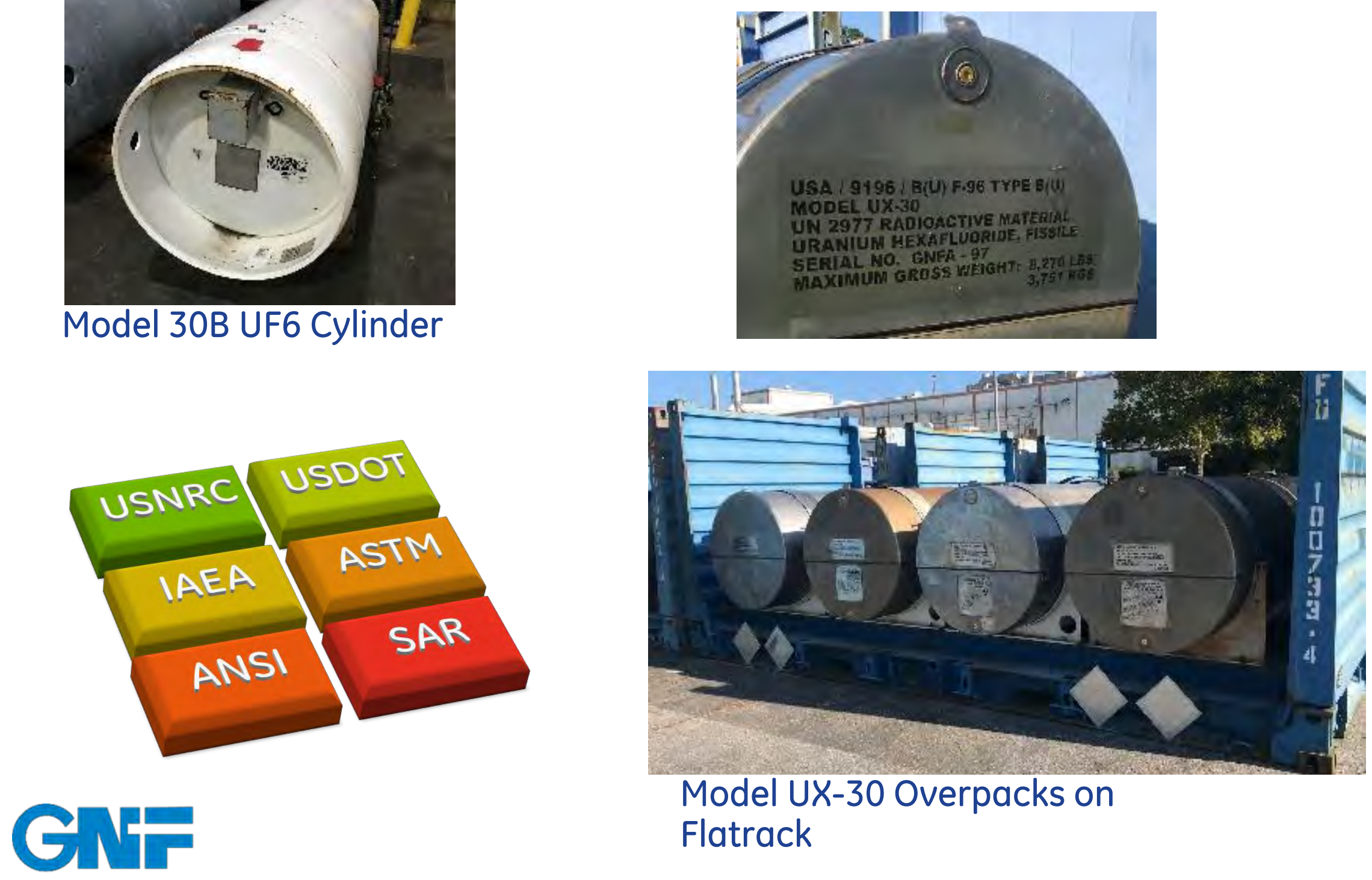

Model UX-30 Overpacks on Flatrack 


\section{Methods}

GNFA Monte Carlo validation report(s) now support a variety of AOAs:

\section{AOA-1: LEU Homogeneous Systems}

AOA-2: HEU Solution Systems

AOA-3: LEU Heterogeneous Compound Systems without Absorbers AOA-4: LEU Compound Systems with Cadmium

AOA-5: LEU Heterogeneous Compound Systems with Boron

AOA-6: Uranium Metal Systems

AOA-7: LEU Heterogeneous Compound System with Gadolinium

LEU systems: $\leq 10.0$ wt. \% U235

HEU soln systems: 89 - 93.2 wt.\% U235

U Metal systems: $\underbrace{9-97.6 \text { wt. \% U235 }}$
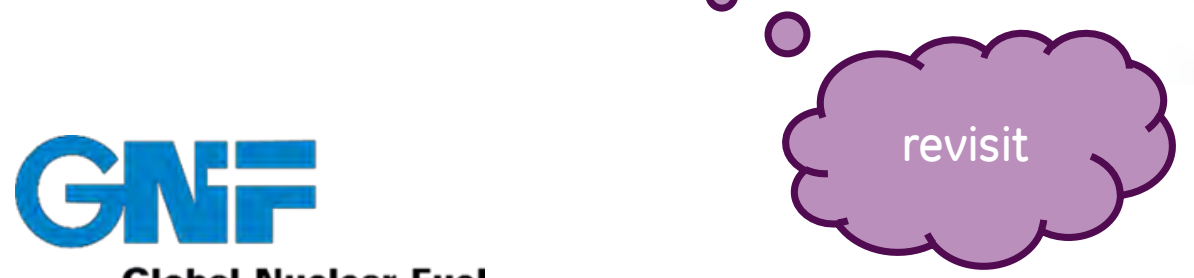

SCALE6.1/KENO-VI Monte Carlo Code Validation Report (Rev. 3)
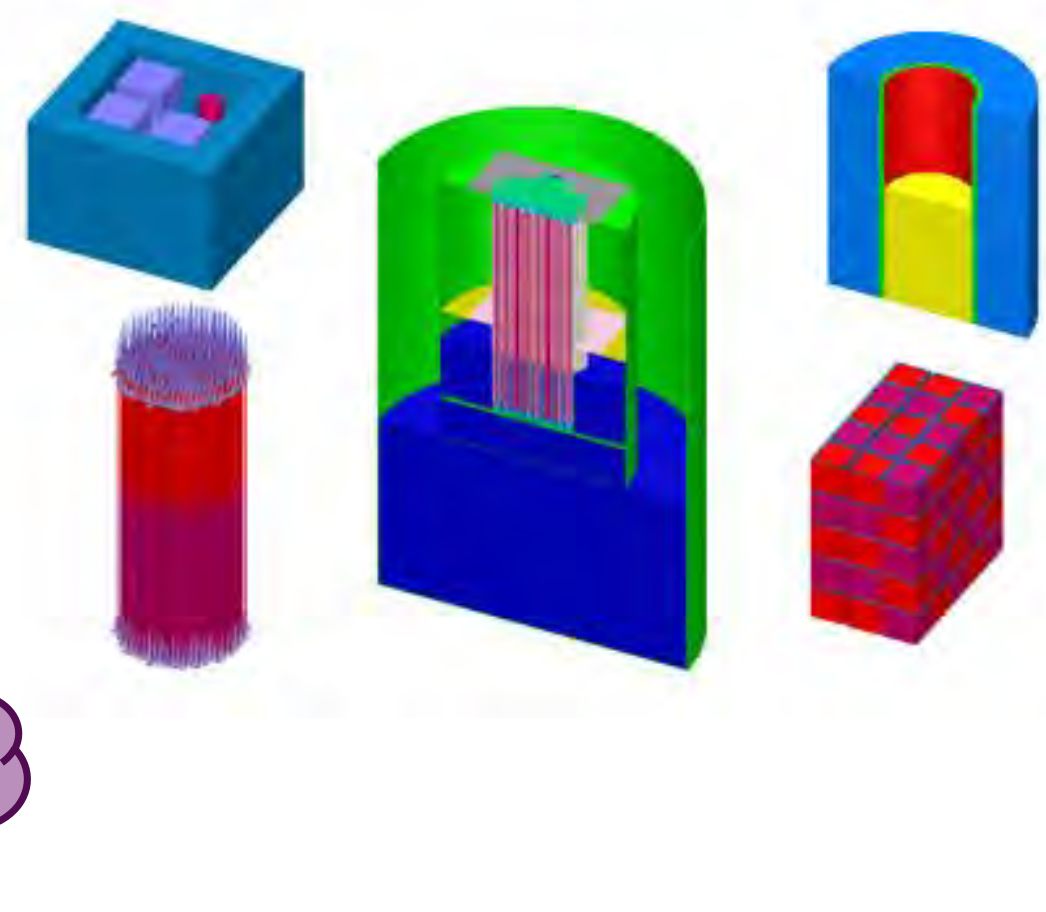


\section{Criticality Safety Analyses}

- The fabricator must re-evaluate the nuclear criticality safety bases associated with conversion of UF6 to UO2 and related ceramic processes to build LWR fuel bundles with a higher assay.

- Documented nuclear criticality safety evaluations (referred to herein as criticality safety analyses or CSAs) would be required to be re-baselined for the fuel manufacturing and support facilities on a node-by-node basis.

- $\quad$ Assay increase would result in low to intermediate impact on dry powder system(s), as well as on ceramics palletization, rod storage and bundle assembly, since the existing safety margins associated with non-uniform moderation safety limits / safe mass limits / safe rod quantity / etc. would be reduced with minor equipment modification required.

- $\quad$ Balance of plant systems are currently physically sized for favorable geometry classification (e.g., pipe tanks, annular vessels, containers, etc.) at $5 \%$; and would in most cases not qualify as such at a higher assay; thus, equipment modifications would be expected for liquid waste systems. 


\section{Licensing \& ISA}

- Commensurate with the SNM-1097 license [amendment] application, an integrated safety analysis summary (ISAS) for the GNFA Wilmington fuel fabrication facility must also be revised to demonstrate that high consequence accident sequences remain highly unlikely pursuant 10CFR70.

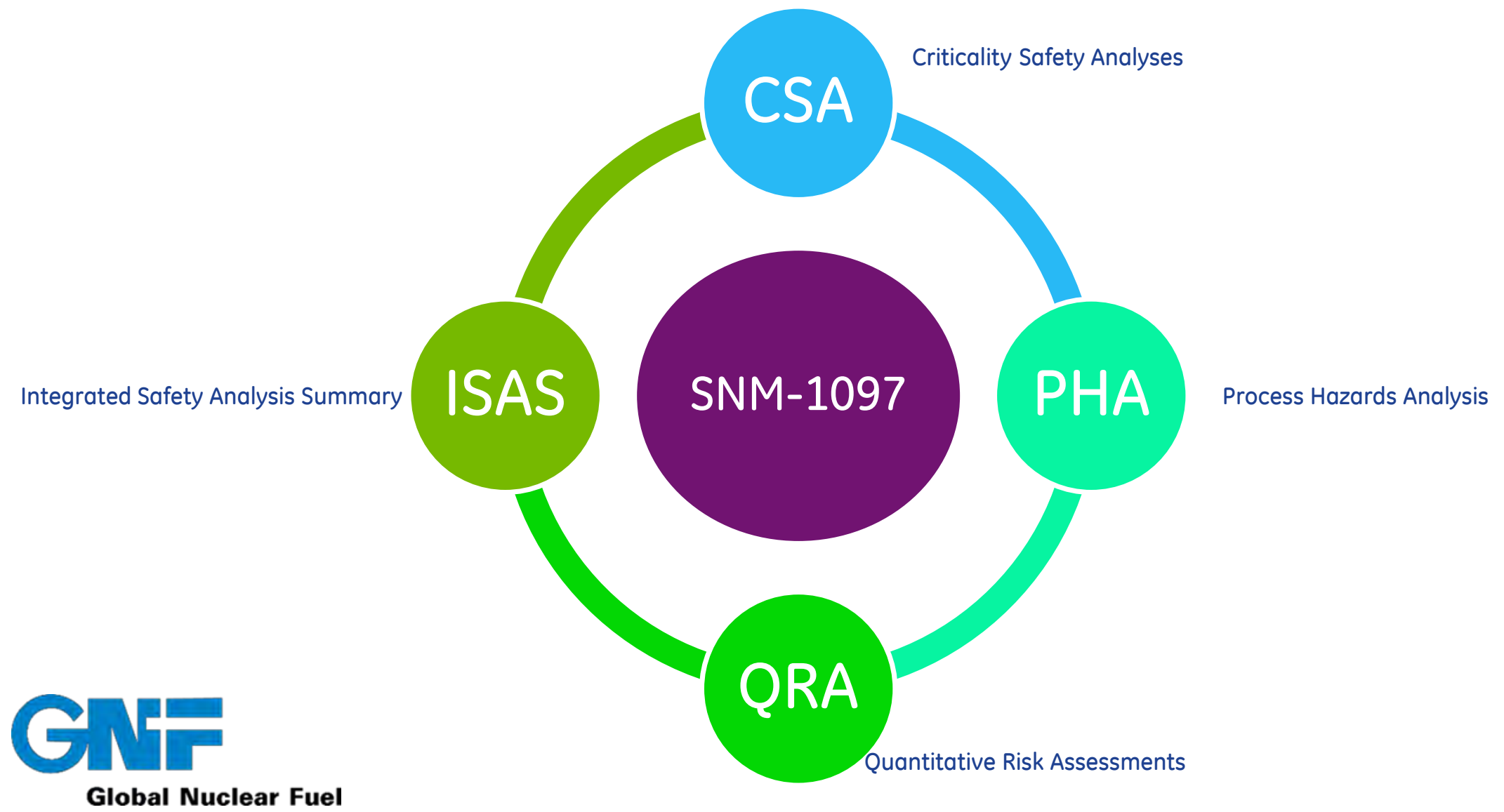




\section{Factory Implementation - Nodal Basis}

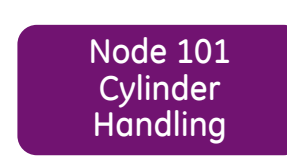

- Receipt, Handling, Storage, and UF6 Heel Cylinder Shipment

Node 201
Vaporization

- Vaporization and Cold Trap Processes

\section{Node 202 \\ Conversion}

Node 203
HF Recovery

- DCP Conversion ReactorKiln

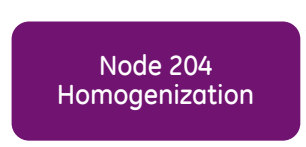

DCP HF Acid Recovery and HF Neutralization

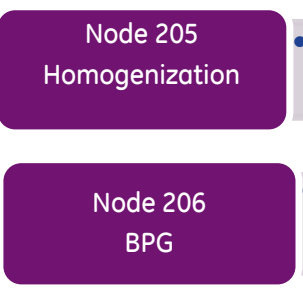

Homogenization

Node 207

Powder Pack / Receipt

Node 208

Miscellaneous
-DCP Homogenization

-DCP Powder Outlet

DCP Homogenization

DCP Blend, Precompact Granulate, Tumble

- DCP Powder Pack / Powder Receipt

-DCP MRA Facility and Powder Containers

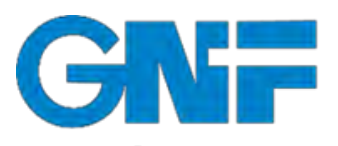

Global Nuclear Fuel

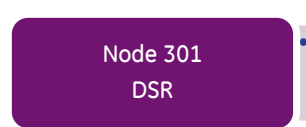
- Dry Scrap Recylcle Furnace Feed,
Blender, XFR Station, Furnace, Screene

\begin{tabular}{|c|l}
\hline $\begin{array}{c}\text { Node 401-503 } \\
\text { Fabrication Press }\end{array}$ & $\begin{array}{l}\text { Fabrication Rotary Press, Beaker } \\
\text { Storage }\end{array}$ \\
\hline $\begin{array}{c}\text { Node 405-504 } \\
\text { Fabrication Sinter }\end{array}$ & $\begin{array}{l}\text { Sintering Furnaces, Sinter Test, } \\
\text { Pellet Boats, Boat Conveyors, } \\
\text { Gamma Densitometer }\end{array}$ \\
\hline
\end{tabular}

Node 405a-504a
Fabrication Sinter
Hydrogen Gas Release $\cdot$ N/A

$\begin{array}{ll}\begin{array}{l}\text { Node 406-505 } \\ \text { Fabrication Grind }\end{array} & \begin{array}{l}\text { Pellet tray, Grind, Rod } \\ \text { Load, Ministacker, Rod } \\ \text { Storage }\end{array}\end{array}$

Fabrication Grind Storage

Node 407-506
Fabrication Rod
Processing

- Fabrication Rod

Processing

Node 501-502 Fabrication GAD Vibromil

- GAD MRA DM-10

Vibromill

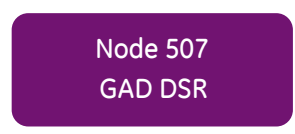

- GAD Dry Scrap Recycle -GDSR DM-10 Vibromill

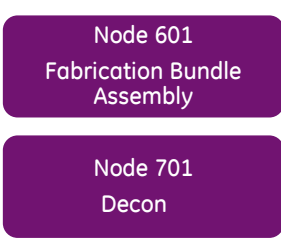

Node 702-703 Radwaste/WTF

Radwaste Processes, CAAS Node 705 FMO SPF

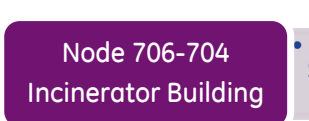

- Incinerator Building, Outside Storage Pads, CAAS Needs Evaluation - Wastebox

\begin{tabular}{|c|c|c|c|c|c|c|c|}
\hline $\begin{array}{c}\text { Node } 801-802 \\
\text { Auxiliary Operations }\end{array}$ & $\begin{array}{c}\text { General Can Storage, Scrap Hood } \\
\text { and Utility Hoods }\end{array}$ \\
\hline $\begin{array}{c}\text { Node } 803-804 \\
\text { HVAC }\end{array}$ & $\begin{array}{c}\text {-Primary and Secondary } \\
\text { HEPA Filter Systems }\end{array}$ \\
\hline $\begin{array}{c}\text { Node } 805 \\
\text { Laboratory }\end{array}$ & -Support Labs \\
\hline $\begin{array}{c}\text { Node } 805 a \\
\text { Hydrogen Gas Leak - } \\
\text { Chemet Lab }\end{array}$ \\
\hline $\begin{array}{c}\text { Node } 807 \\
\text { Utilities }\end{array}$ \\
\hline
\end{tabular}

Node 808
Adjacent Fire

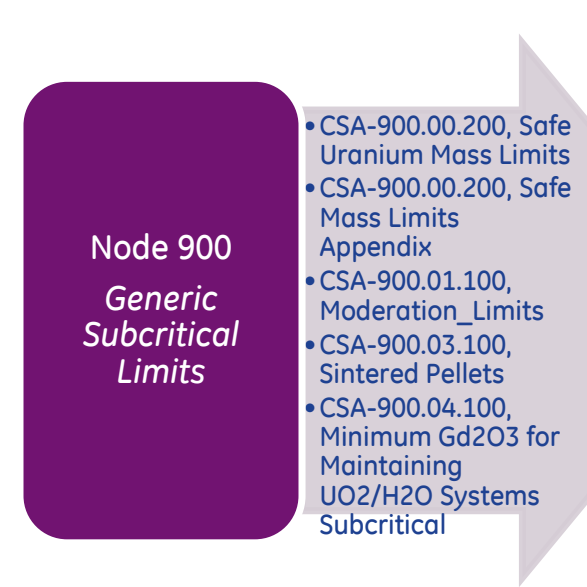




\section{NDA Systems and RP Instrumentation}

- $\quad$ To permit LWR fuel manufacture $>5 \%$ enrichment, select non-destructive assay (NDA) nuclear measurement systems must be requalified.

- NDA systems based on interrogation of U238 (or total U) should not be directly affected by ENR changes

$>$ DECON waste cart monitors, DECON box monitors, Elephant-Gun, Gad powder XRF, Gad pellet XRF, Gad/UO2 Pellet Densitometers, hand-held Scout-II gamma monitor for detecting uranium buildup

- NDA systems based on interrogation of U235 will be directly impacted by an ENR change

$>$ Fat Albert, MAPS, DCP HF and FMO Radwaste, Nal scintillation detectors (a.k.a., "pipe detectors"), and the UF6 cylinder enrichment verification system

- Radiation Protection (RP) instrumentation is a special case, the alpha/beta counters (tennelec counters, airborne sample filter counters, and personnel exit survey personnel contamination monitors or PCMs) will require review and assessment.

$>\quad$ When enrichment is changed, the expected uranium isotopic signature ratios (e.g., U234/U238) also change; and impact interpretation of the uranium content in a sample or deposit.

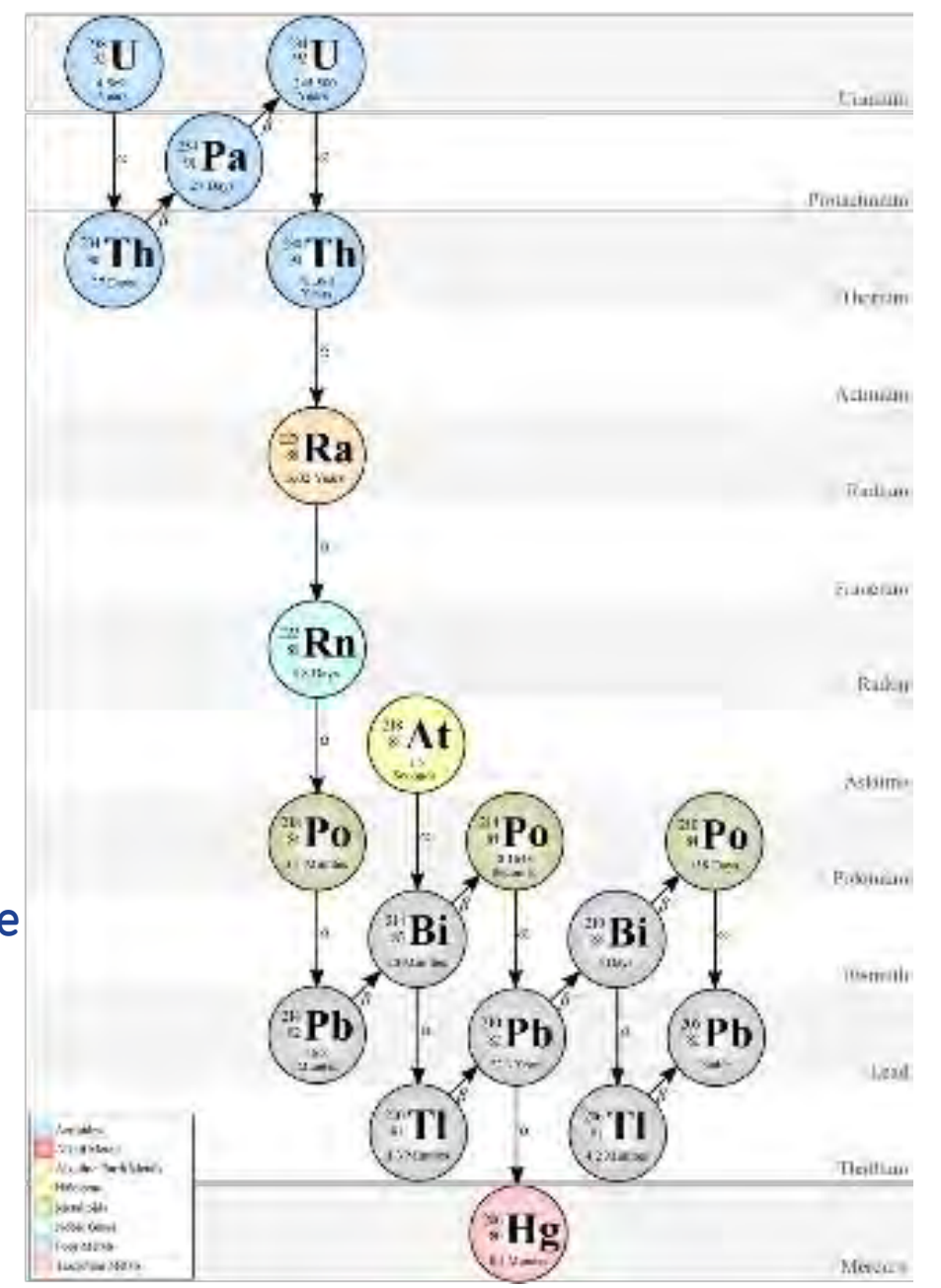




\section{Miscellaneous Program(s)}

- $\quad$ To permit LWR fuel manufacture $>5 \%$ enrichment the corresponding SNM1097 license must evaluate potential impacts on the following:

Decommissioning Funding Plan (DFP)

$\square$ Radiological Contingency and Emergency Plan (RC\&EP).

Physical Security Plan (10CFR73)

Note:

$>$ Category III, Special nuclear material of low strategic significance - GNFA fuel fabrication facility may continue under Category III classification for physical security programs.

$>$ Category II, Special nuclear material of moderate strategic significance - GNFA fuel fabrication facility may / may not require Category 2 designation to support $U$ metal fuel fab; depends on scale of pilot.

\begin{tabular}{|l|l|}
\hline Category & Qty. Permitted : Assay Range \\
\hline II & $\geq 10 \mathrm{~kg} \mathrm{U} 235: \geq 10 \%$ but $<20 \%$ \\
\hline III & $\geq 1 \mathrm{~kg}$ but $<10 \mathrm{~kg} \mathrm{U} 235: \geq 10 \%$ but $<20 \%$ \\
& $\geq 10 \mathrm{~kg} \mathrm{U} 235: \leq 10 \%$
\end{tabular}




\section{Product Transport: RAJ-II}

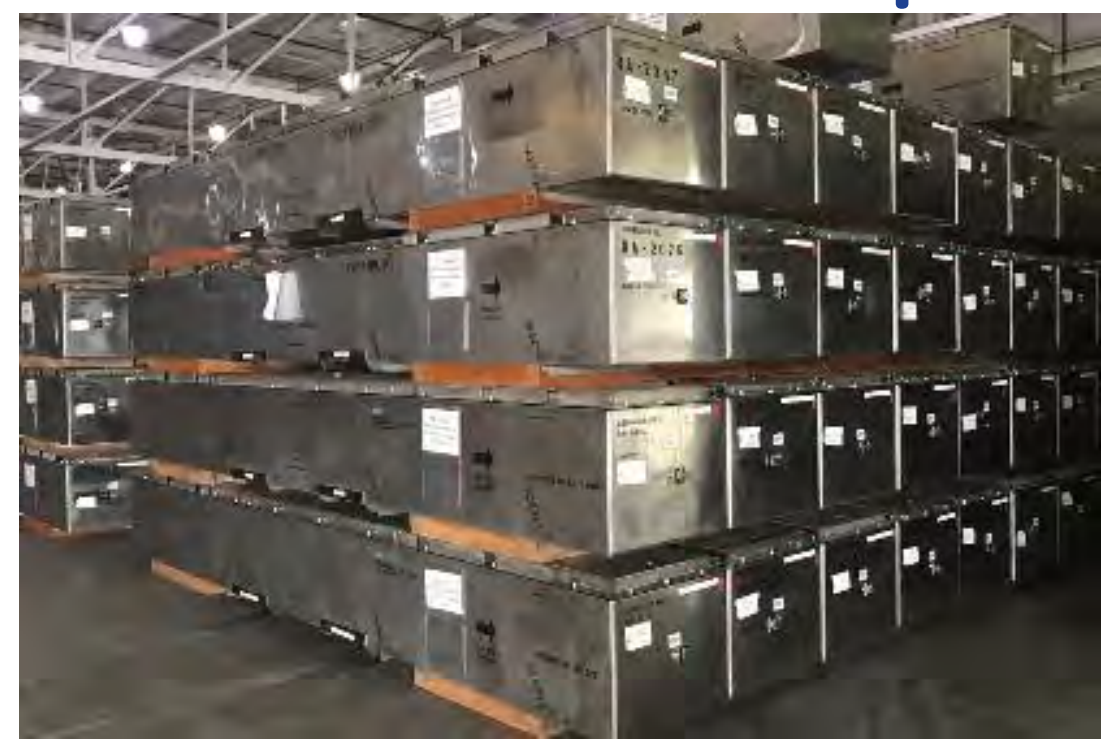

Model RAJ-II Type B Fissile Package [USA/9309/B(U)F-96]

$8 \times 8,9 \times 9,10 \times 10$ fuel assemblies

UO2 rods, UC rods, PWR rods

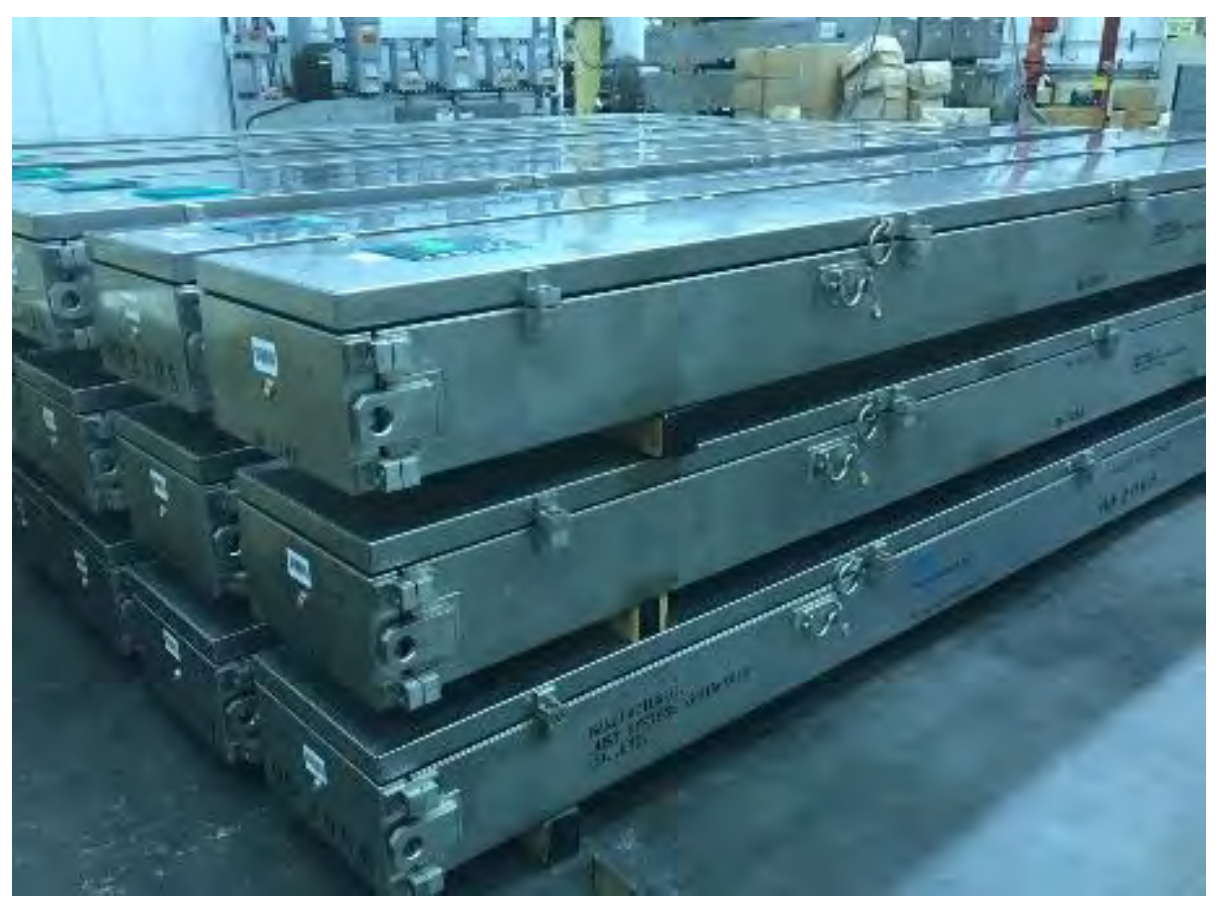

ECGU or RU per ASTM C996 material forms enriched to no more than $5.0 \mathrm{wt} \%$ U235

HALEU requires SAR update, corresponding CSI change

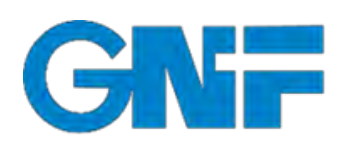




\section{Product Transport: NPC}

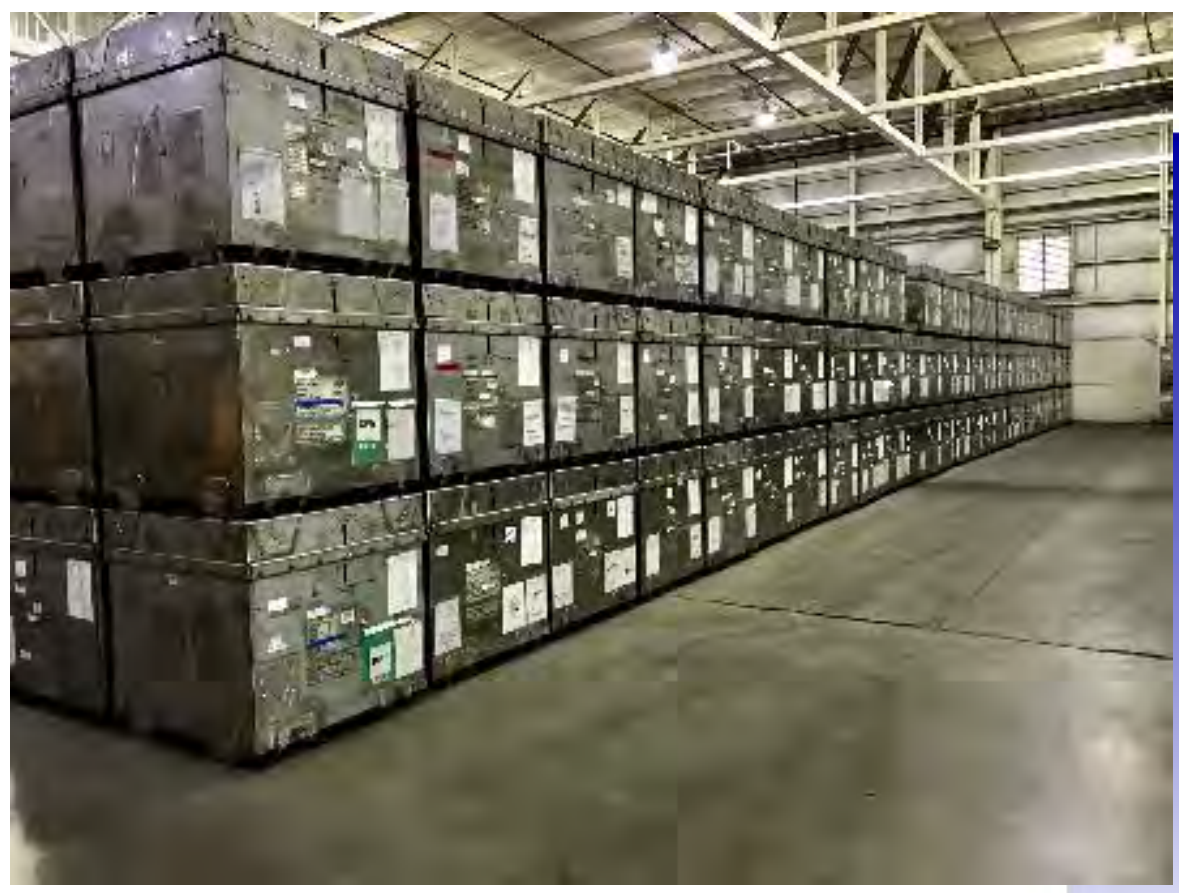

\section{GNF-A NPC Package}

\section{Model NPC Type A Fissile Package [USA/9294/AF-96]}

UO2 powder, U308, UOx, UNH, U-bearing ash, calcium containing sludges, etc. Heterogeneous UO2 pellets (BWR/PWR), Heterogeneous UO2, U308, UOX

Material forms enriched to no more than 5.0 wt\% U235

HALEU requires SAR update, corresponding CSI change

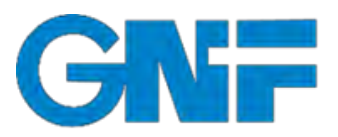




\section{NRC Review Timeline - An Example}

Below SNM-2019 License Application provides a recent real-world example timeline for full scope HALEU licensing.

\section{Timeline}

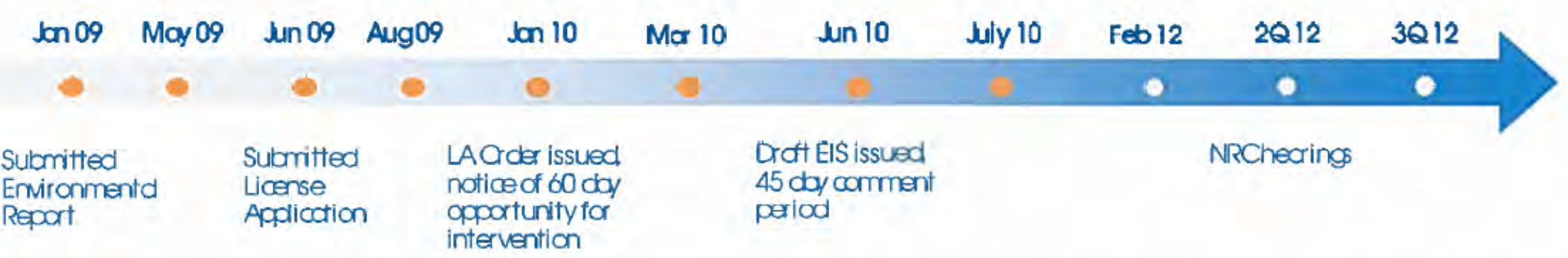

\begin{tabular}{|c|c|c|c|c|}
\hline $\begin{array}{l}\text { NRCheld } \\
\text { public } \\
\text { scoping } \\
\text { meeting }\end{array}$ & $\begin{array}{l}\text { ERcormment } \\
\text { periodends }\end{array}$ & $\begin{array}{l}60 \mathrm{dar} \\
\text { intervention } \\
\text { periodencs }\end{array}$ & $\begin{array}{l}\text { NRCholds } \\
\text { public } \\
\text { meting }\end{array}$ & $\begin{array}{l}\text { NRCissues } \\
\text { Find ElS } \\
\\
\text { NRCissues } \\
\text { Scfety } \\
\text { Evdudion } \\
\text { Report }\end{array}$ \\
\hline
\end{tabular}

Above time scale can be compressed in SNM-1097 License Amendment pursued. 


\section{GNF-A HALEU Cost Elements}

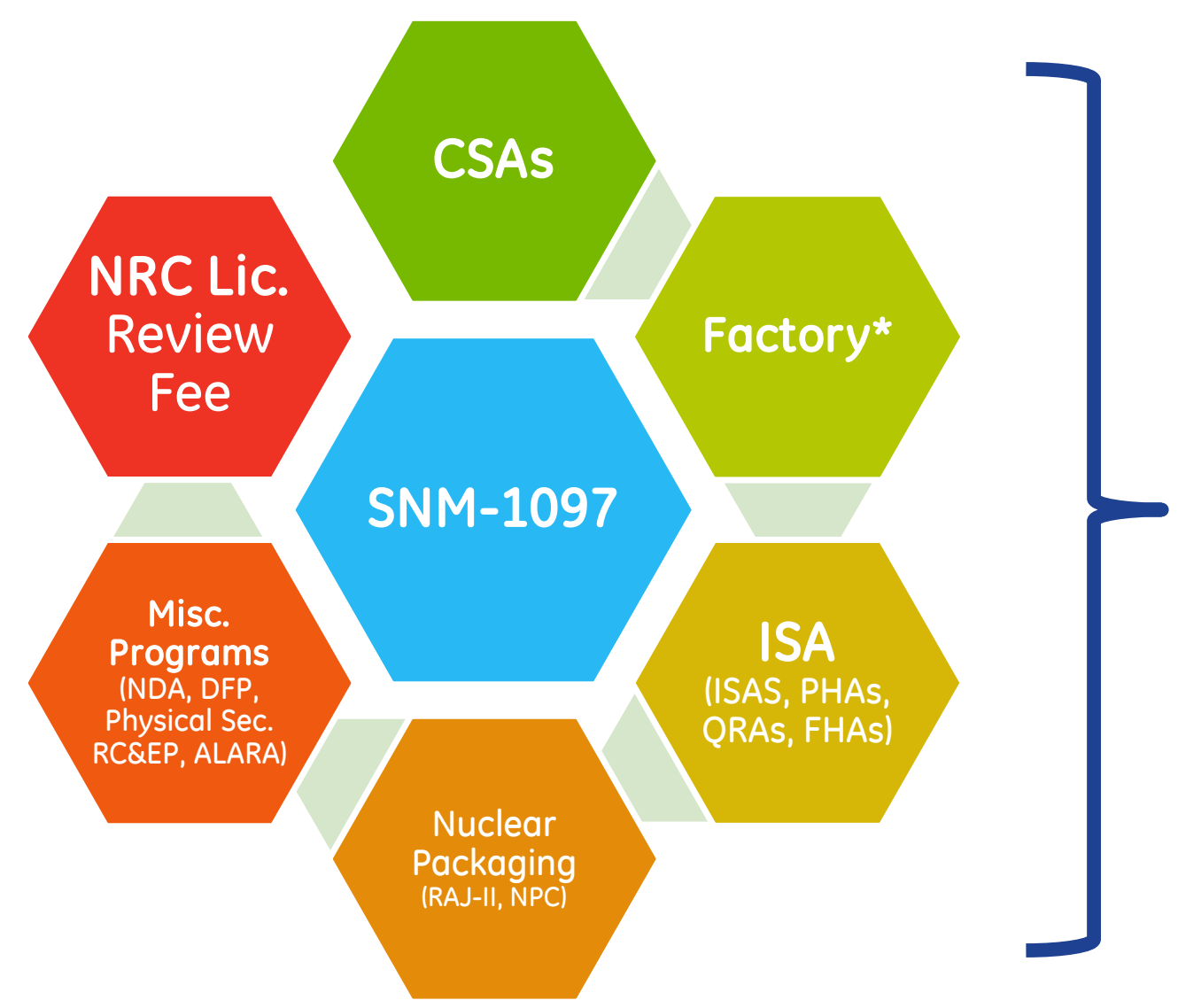

SNM-1097 License Amendment (LA) approach

* Extent of factory changes depends on fuel form, enrichment limit 


\section{Summary}

- $\quad$ Enrichment cascades can be licensed to produce higher assay UF6 feed; labs can support feed to u-metal pilot

- UF6 feed transport in 30B greater than $5 \%$ is technically feasible, but will create industry challenge to align regulations, standards, and certificate; u-metal transport can be authorized.

- $\quad$ Product transport will require SAR revisions/CSI change

- GNFA has proven experience in higher assay LEU licensing; fuel form selected will ultimately dictate cost.

- $\quad$ For u-metal, demonstration facility can capitalize on (i) existing environmental permits, (ii) NRC licensed facility, (iii) site security and infrastructure, (iv) established NRC/DOT nuclear packaging program, and (v) existing DFP. 


\section{DAHER-TLI}

\section{Packages for Shipping 20\% Enriched Materials}

Author:

Andy Langston

INL-NEI Technical Workshop on Transportation of High Assay Low-Enriched Uranium, August 30-31, 2018 


\section{DAHER-TLI}

Currently Available Packages

- Majority of $20 \%$ shipped in DOE complex using drum type packages

- Example the Versa-Pac

- Currently under NRC Amendment Application for $1 \mathrm{~S} / 2 \mathrm{~S}$ cylinder transport

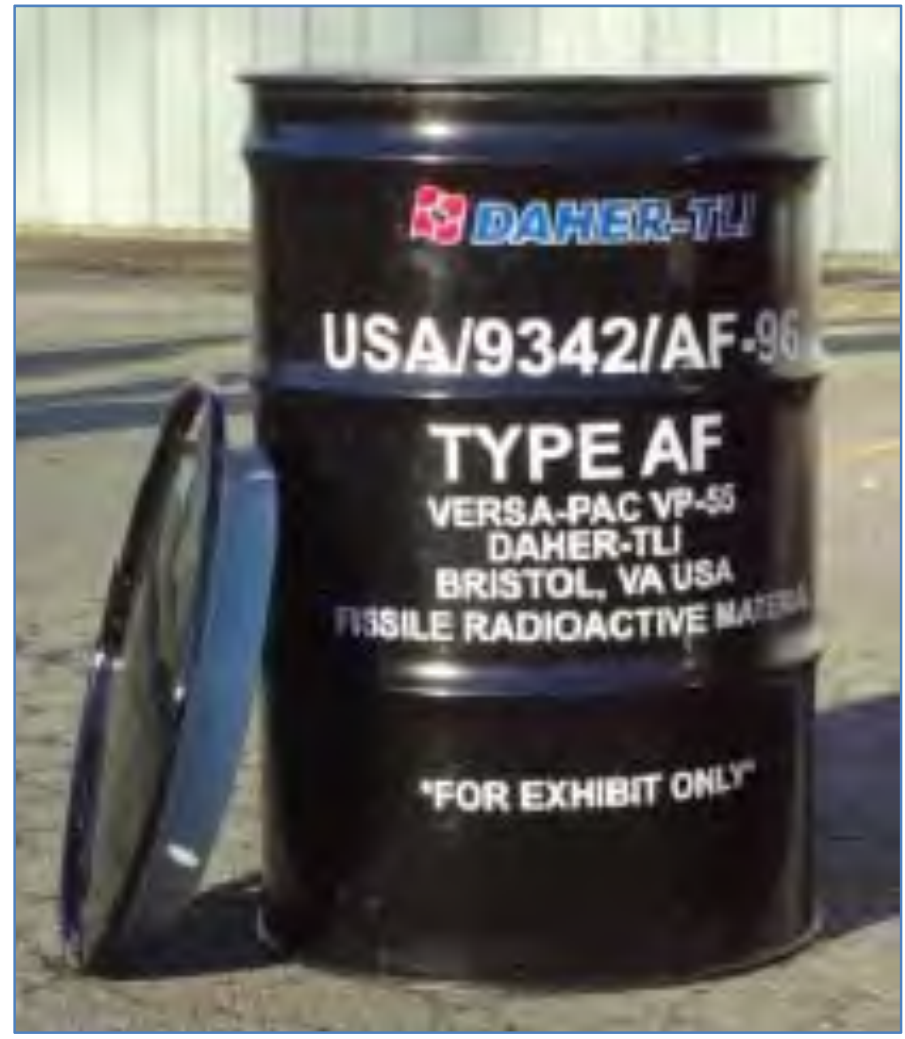




\section{DAHER-TLI}

\section{General Design}
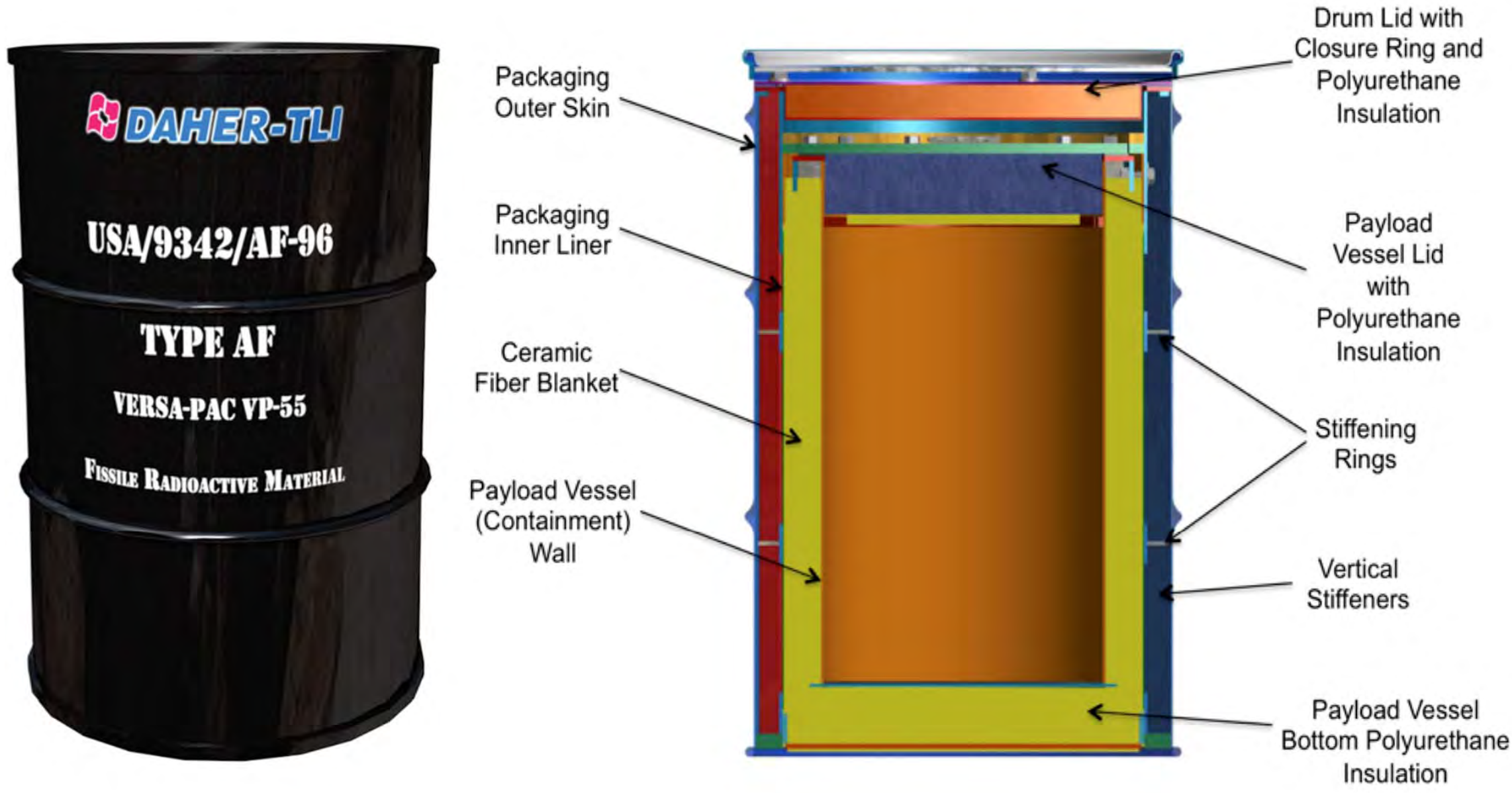


\section{DAHER-TLI}

\section{Current Contents}

- Contents limits based on uranium metal to bound likely contents

- uranium oxides, uranium metal, uranyl nitrate crystals and other uranium compounds, e.g., uranium carbides, uranyl fluorides and uranyl carbonates, and thorium 232 as TRISO fuel

- 11.4 kw content limit

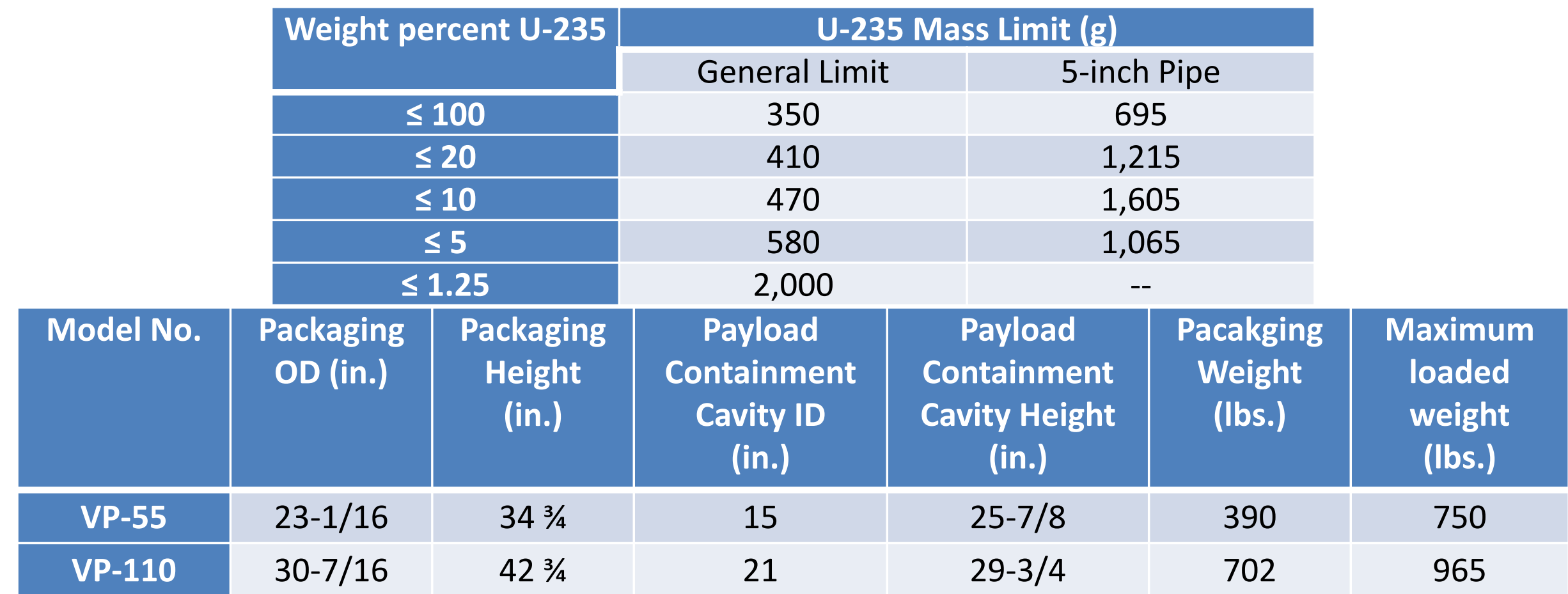




\section{DAHER-TLI}

Content Addition - UF 6 1S and 2S Cylinders

- ANSI N14.1-compliant 1S and 2S cylinders

- Criticality safety HAC evaluation assumes cylinders do not survive, NCT evaluations credit cylinder geometry

- Criticality results limit the quantity and type of $\mathrm{UF}_{6}$ cylinders

- 100 wt.\% limited by fit of pipes in the cavity

- Thermal evaluation requires a 2 inch thick foam liner in the cavity

TABLE. Summary Table of 1S/2S Cylinder Modeling Configuration

\begin{tabular}{|c|c|c|c|c|}
\hline \multirow{2}{*}{ Content } & \multicolumn{4}{|c|}{ Configuration } \\
\cline { 2 - 5 } & \multicolumn{2}{|c|}{20 wt.\% } & \multicolumn{2}{c|}{100 wt.\% } \\
\hline $\begin{array}{c}\text { Quantity of } \\
\text { cylinders }\end{array}$ & 7 cylinders & 2 cylinders & $\begin{array}{c}1 \text { cylinders * } \\
\text { in } \\
\text { 5-inch pipe }\end{array}$ & $\begin{array}{c}1 \text { cylinder * } \\
\text { in } \\
5 \text { 5-inch pipe }\end{array}$ \\
\hline
\end{tabular}

*operation limit 


\section{DAHER-TLI}

Content Addition Air Transport (criticality)

- Air transport - 1 package - packaging assumed to not survive

Allowable Payloads by Enrichment, Versa-Pac Configuration

\begin{tabular}{|c|c|c|c|c|}
\hline \multirow{4}{*}{$\begin{array}{l}\text { wt.\% } \\
235 \mathrm{U}\end{array}$} & \multicolumn{4}{|c|}{ Configuration } \\
\hline & \multicolumn{2}{|c|}{ VP-55 / VP-110 } & \multicolumn{2}{|c|}{ VP-55 (5-inch Pipe) } \\
\hline & \multicolumn{2}{|c|}{ Mass ${ }^{235} \mathrm{U}(\mathrm{g})$} & \multicolumn{2}{|c|}{ Mass ${ }^{235} \mathrm{U}(\mathrm{g})$} \\
\hline & General & Air transport & General & Air Transport \\
\hline$\leq 100$ & 350 & 350 & 695 & 395 \\
\hline$\leq 20$ & 410 & 410 & 1,215 & 495 \\
\hline$\leq 10$ & 470 & 470 & 1,605 & 590 \\
\hline$\leq 5$ & 580 & 580 & $1,065^{*}$ & 790 \\
\hline$\leq 1.25$ & 2000 & -- & -- & -- \\
\hline
\end{tabular}




\section{DAHER-TLI}

Under Development - 30B cylinder designs up to $20 \%$ enrichment

The 30B-20 cylinder is designed based on the 30B cylinder as per the ISO 7195/ANSI N14.1 standards. Thanks to its state-of-the-art confinement system for criticality control, it can safely accommodate up to $20 \%$ enriched $1600 \mathrm{~kg}$ of UF6 which represents a tremendous increase in transport capacities.

The 30B-20 cylinder can be operated and handled the same way as a 30B cylinder and does not require any special retrofitting for already existing plants. This efficiently reduces costs for plantrelated adjustments and additional staff training.

The cylinder will have to be licensed as part of a package system.

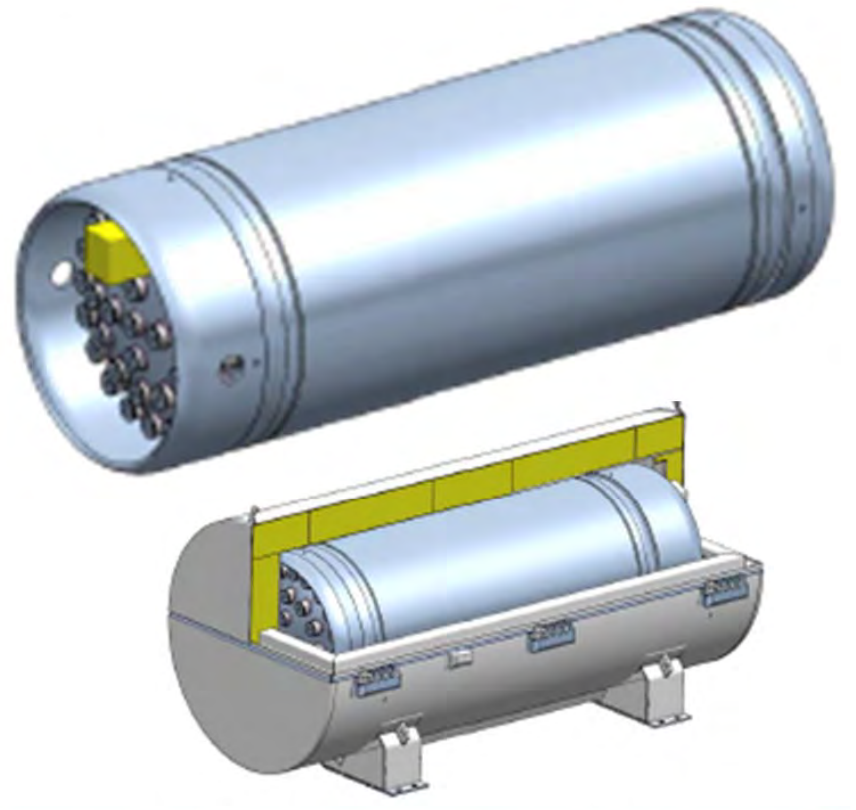

30B-20 cylinder Technical Data

\begin{tabular}{|c|c|}
\hline Nominal Diameter $(\mathrm{mm})$ & 762 \\
\hline Nominal Length $(\mathrm{mm})$ & 2060 \\
\hline Max. Net UF $_{6}$ Weight $(\mathrm{kg})$ & 1600 \\
\hline Max. Gross Weight $(\mathrm{kg})$ & 2710 \\
\hline Enrichtment $\left(\right.$ wt. $\left.\%{ }^{235} \mathrm{U}\right)$ & $\max .20$ \\
\hline
\end{tabular}




\section{DAHER-TLI}

Under Development - Package for 5B/A Cylinders and TRIGA Fuel

- VP-55XL is an enhanced version of the TLI's NRC approved VP-55 (55-gal Type A package).

- In addition to the increased height the VP-55XL design includes an added thermal insulation.

\begin{tabular}{|l|l|l|}
\hline & Dimensions \\
\hline & VP-55 & VP-55XL \\
\hline Overall height & $34.8 \mathrm{in}$ & $55.92 \mathrm{in}$ \\
\hline Outer diameter & $22.5 \mathrm{in}$ & $22.5 \mathrm{in}$ \\
\hline Cavity height & $26 \mathrm{in}$ & $36.6 \mathrm{in}$ \\
\hline Cavity diameter & $15 \mathrm{in}$ & $15 \mathrm{in}$ \\
\hline Tare weight & $390 \mathrm{lb}$ & $780 \mathrm{lb}$ \\
\hline Gross weight & $640 \mathrm{lb}$ & $1170 \mathrm{lb}$ \\
\hline
\end{tabular}

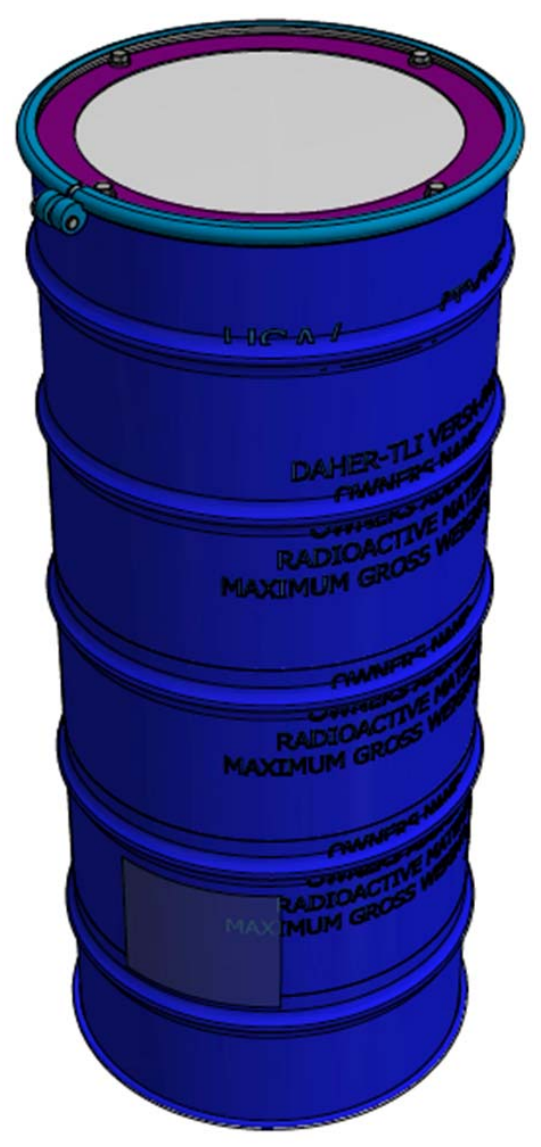




\section{DAHER-TLI}

\section{VP-55XL Contents}

- Contents of the package include, but not limited to, 5B/A cylinders and TRIGA fuel bundles to transport fissile radioactive material.

- 5B/A dimensions are:

- Gross weight $=110 \mathrm{lb}$

- Overall height $=35.625$ in

- Outer diameter $=5.563$ in

- Temperature range is $-40^{\circ} \mathrm{F}$ to $250^{\circ} \mathrm{F}$.

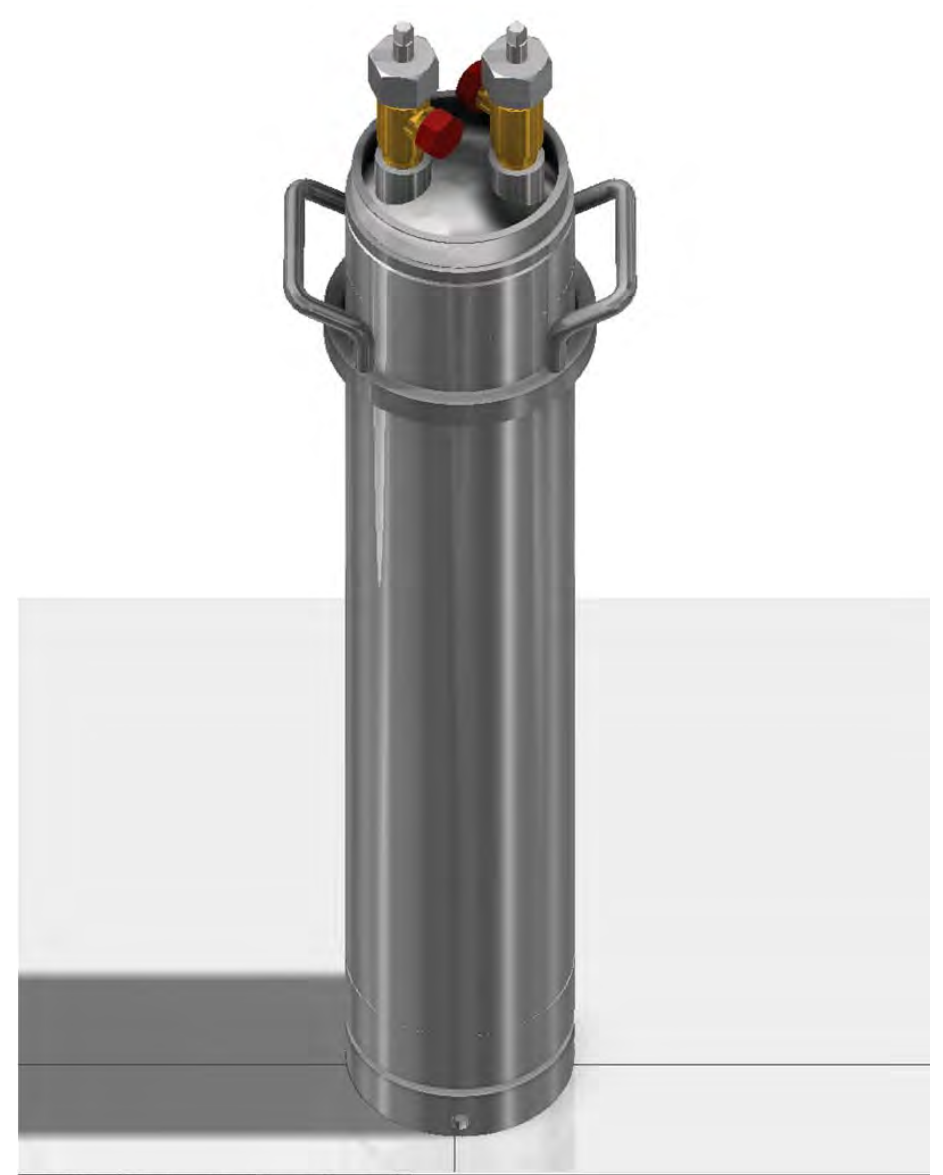




\section{DAHER-TLI}

\section{VP-55XL Components}
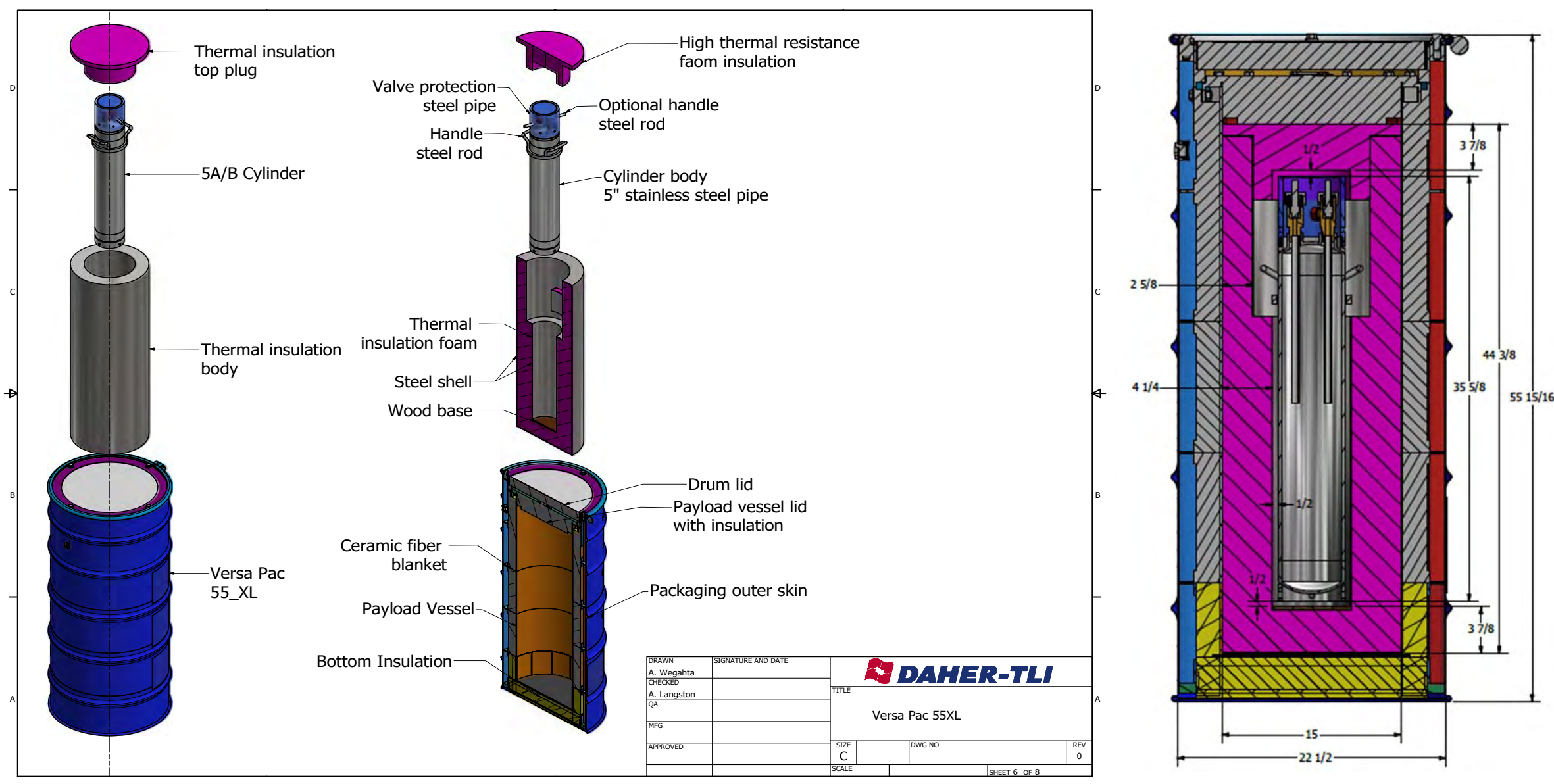


\section{DAHER-TLI}

QUESTIONS? 


\section{Criticality Sensitivity Analysis}

Presented by:

Bradley T. Rearden, Ph.D.

National Technical Director

Nuclear Data and Benchmarking Program

\section{Presented to:}

INL-NEI Technical Workshop on Transportation of High Assay Low-Enriched Uranium August 30-31, 2018

Nuclear Energy Institute

August 30, 2018 


\section{Knowledge Management}

"There are known knowns; there are things we know that we know. There are known unknowns; that is to say, there are things that we now know we don't know. But there are also unknown unknowns - there are things we do not know we don't know." -United States Secretary of Defense, Donald Rumsfeld, 2002

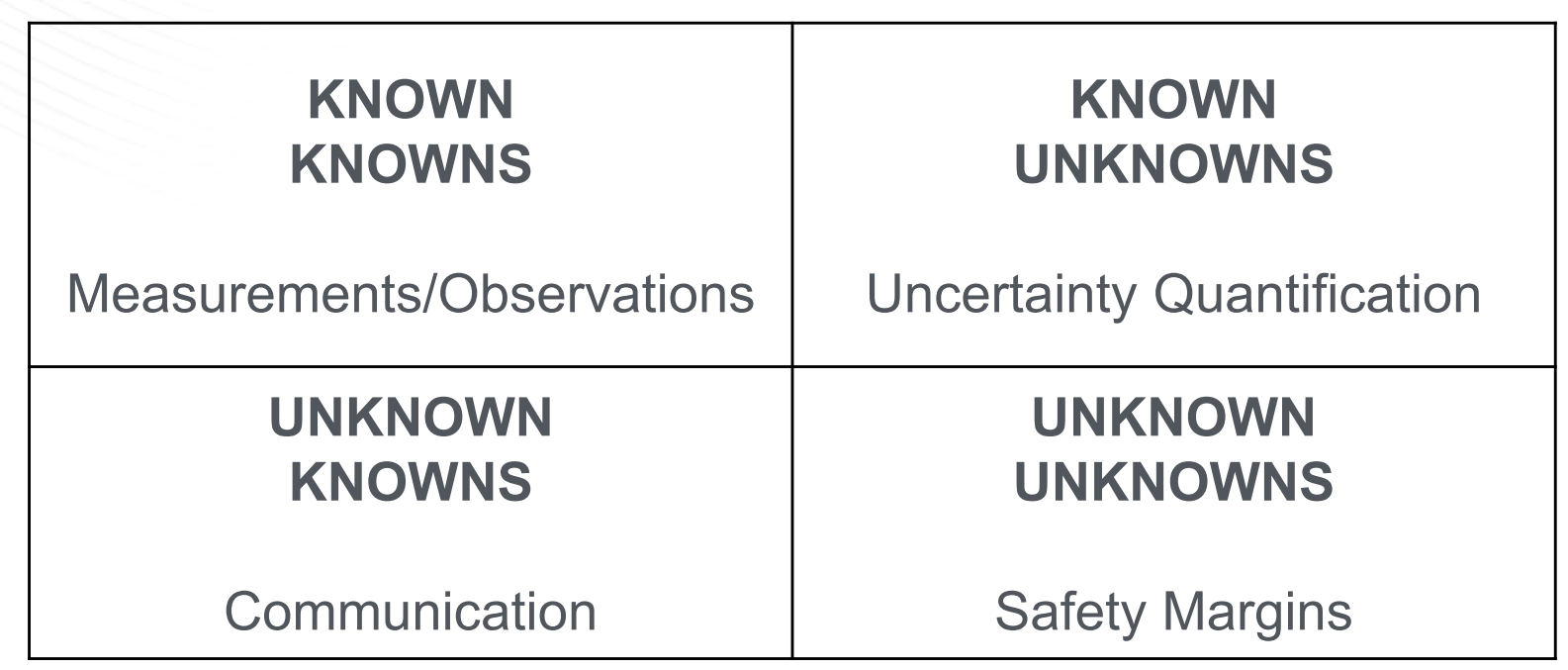

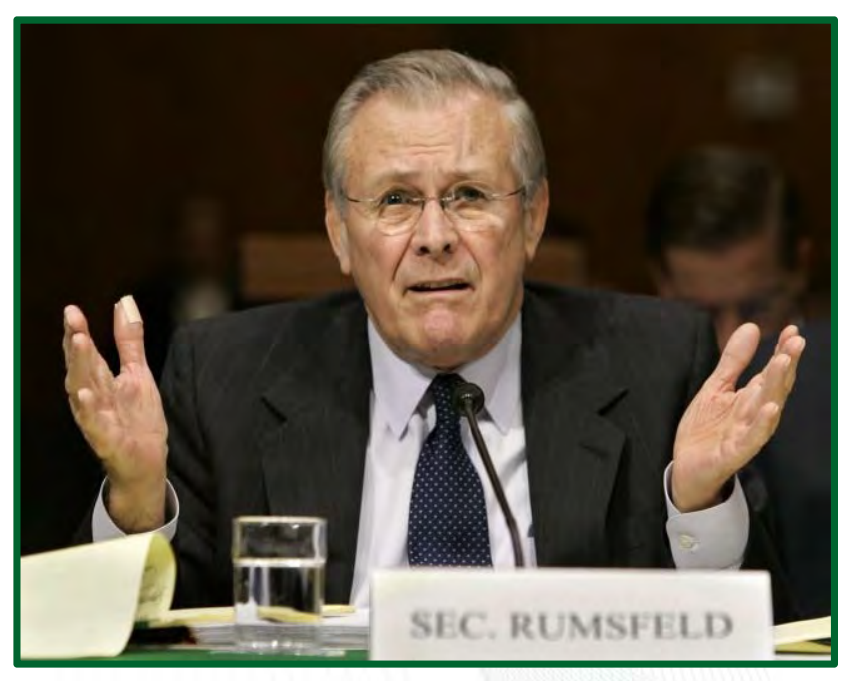

"All models are wrong, some are useful."

-George E. P. Box - Statistician, Professor, Univ. of Wisconsin 


\section{Reminder: Sensitivity of $k_{\text {eff }}$ to nuclear data for LEU, HEU and IEU benchmarks}

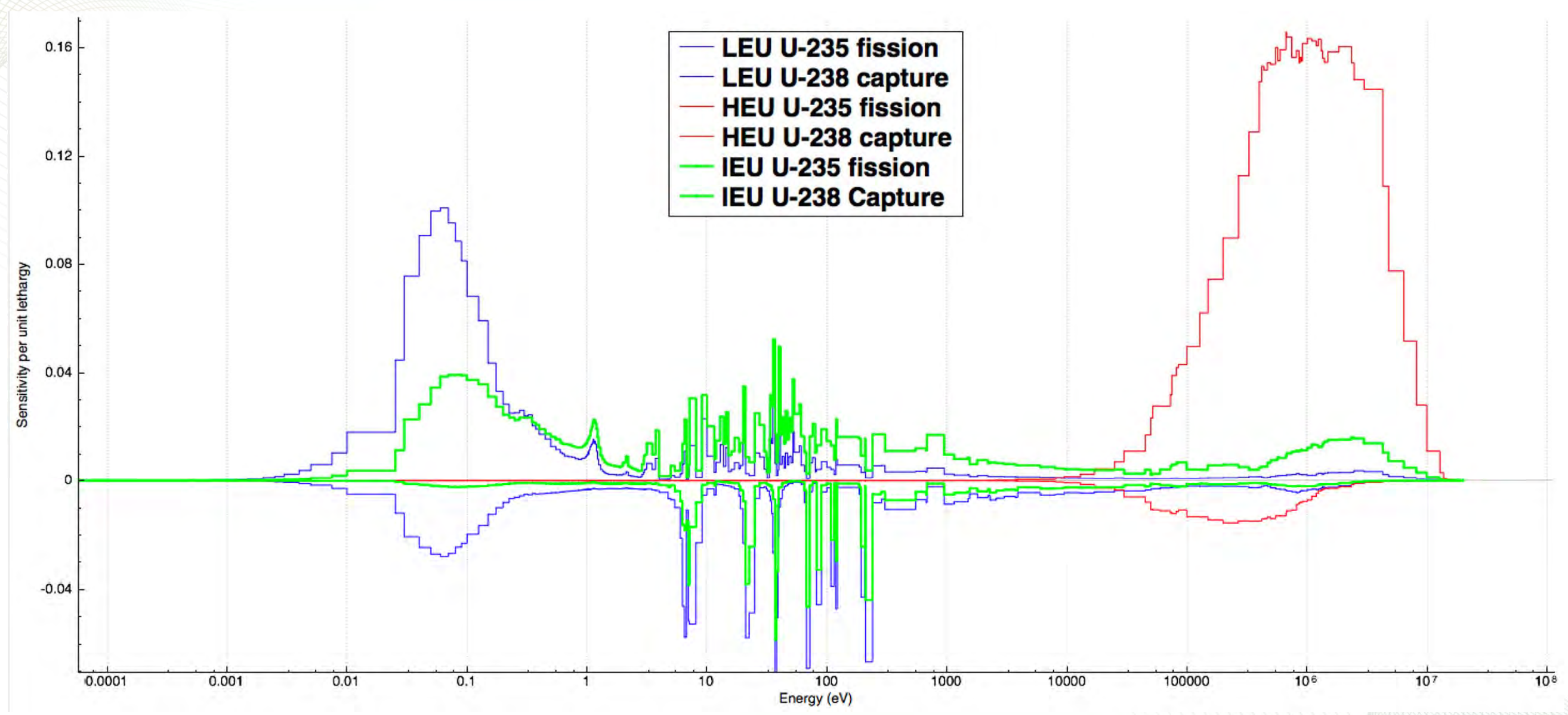




\section{Reminder: Cross section similarity as independent parameter for trending analysis}

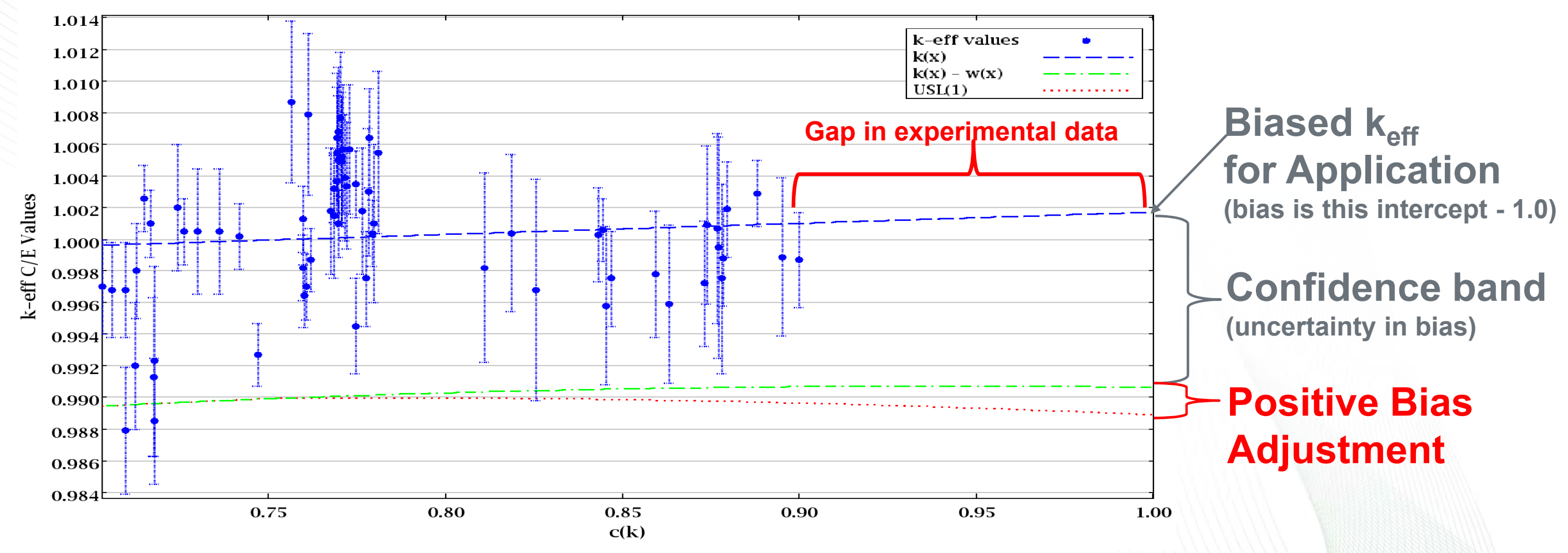




\section{ICSBEP experiments with $5 \%<235 \mathrm{U} w t \%<25 \%$}

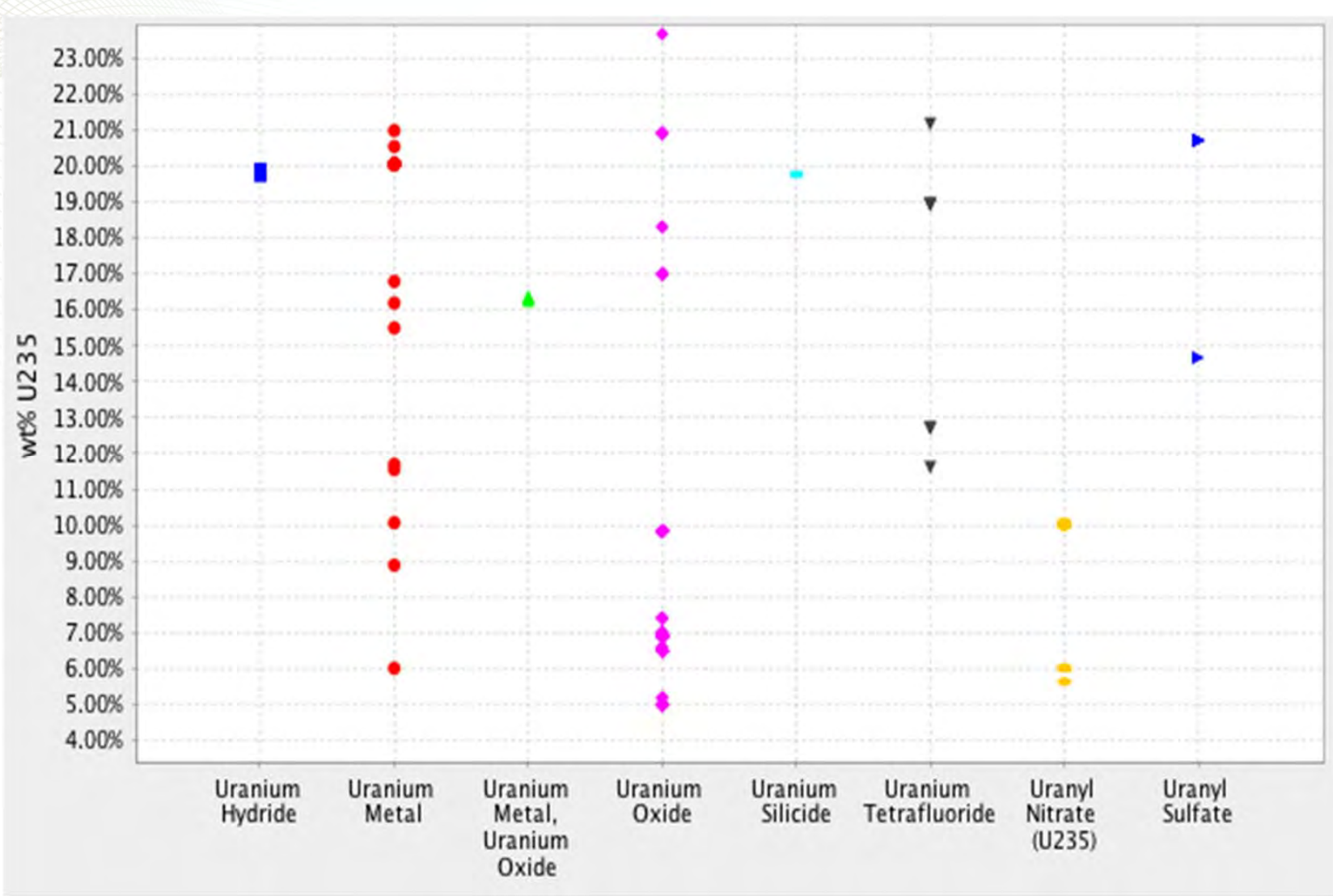

- Many legacy experiments for metallic cores

- IRPhEP has a few experiments for HTGR (HTR-10, HTTR)

- No experiments for molten salt (limited new measurements in Czech republic for non-fueled FLiBe)

- No data for FHR 


\section{Design of optimized experiments}

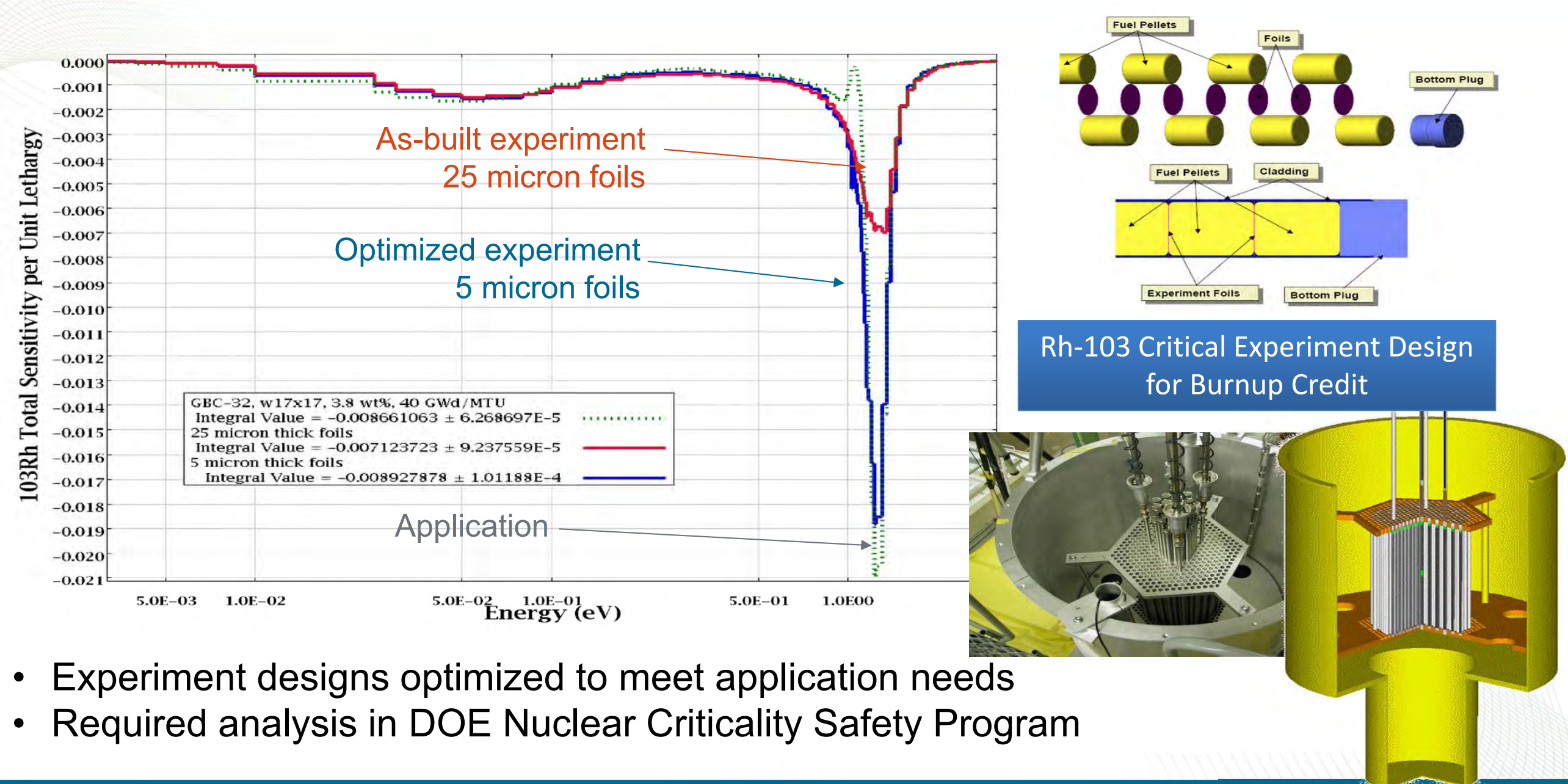




\section{Design of MIRTE reference experiments}

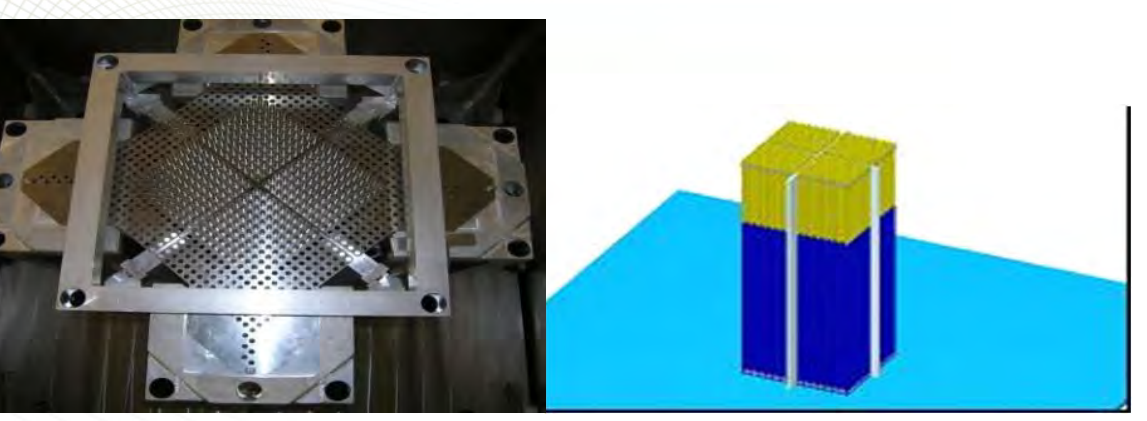

- Design of reference experiments (without material)

$\stackrel{\leftrightarrow}{\leftrightarrow}$ Need to optimize the number of reference experiments

(to perform reproducibility exp. for uncertainty treatment)

- Studies performed with SCALE
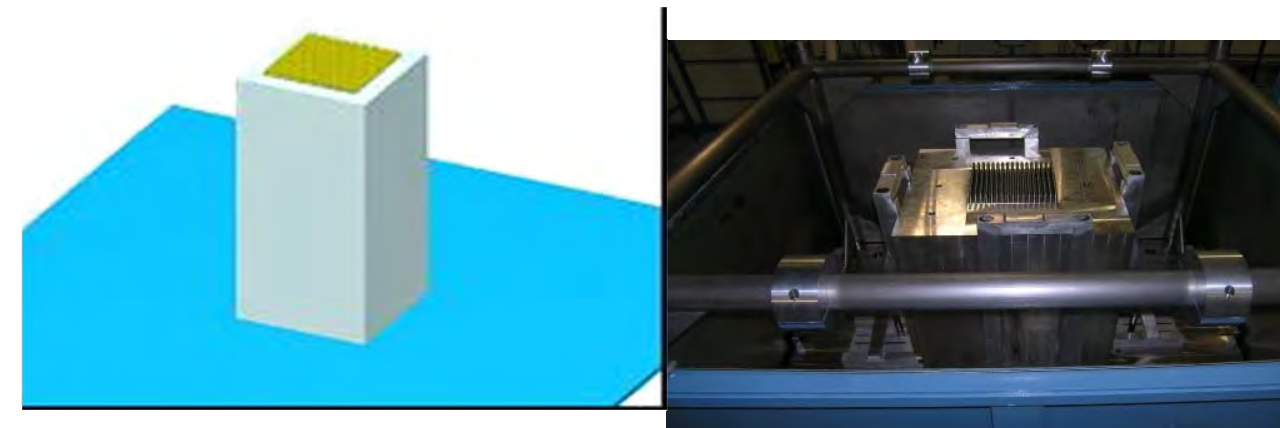

- KENO V.A calculations for reference experiments design (criticality)

- Keep lattices dimensions and reduce critical water height

- Keep critical water height and reduce lattices dimensions

- TSUNAMI calculations to obtain sensitivity coefficients

- Comparison of sensitivity profiles for Uranium cross sections between experiments with and without material 


\section{Comments on Use of S/U in Validation}

- Provides advanced methods for challenging validation scenarios.

- Allows for combining information from many diverse experiments.

- Extracts and projects bias information from replacement experiments.

- Surrogate for validation to fill gaps where experiments are not available.

- Design of new experiments targeted to meet application needs.

- Data and tools readily available for production use. 


\section{Reminder:}

Knowledge Management

\begin{tabular}{|c|c|}
\hline KNOWN & KNOWN \\
KNOWNS & UNKNOWNS \\
Measurements/Observations & Uncertainty Quantification \\
\hline UNKNOWN & UNKNOWN \\
KNOWNS & UNKNOWNS \\
Communication & Safety Margins \\
\hline
\end{tabular}

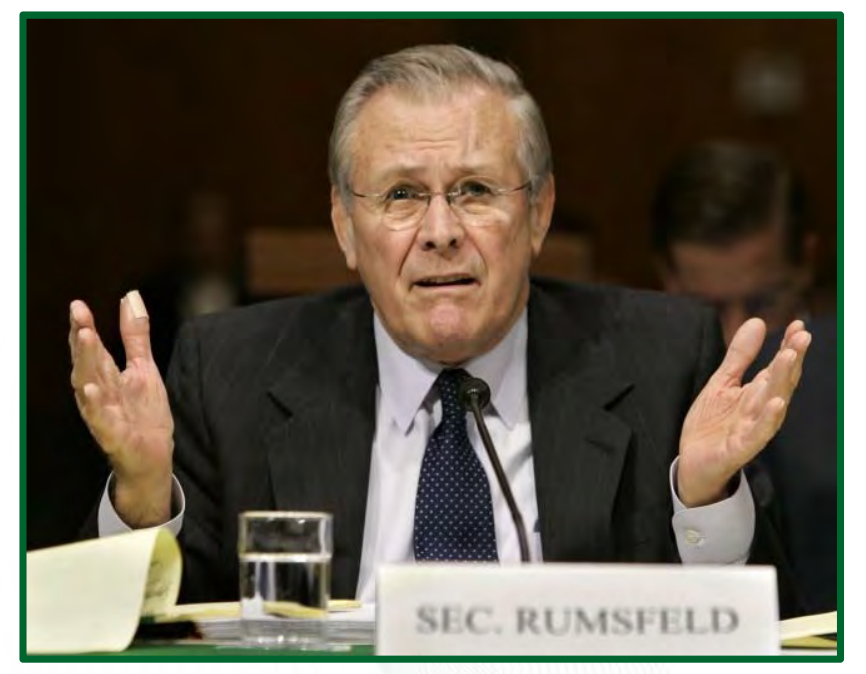




\section{Identifying important processes and uncertainties}

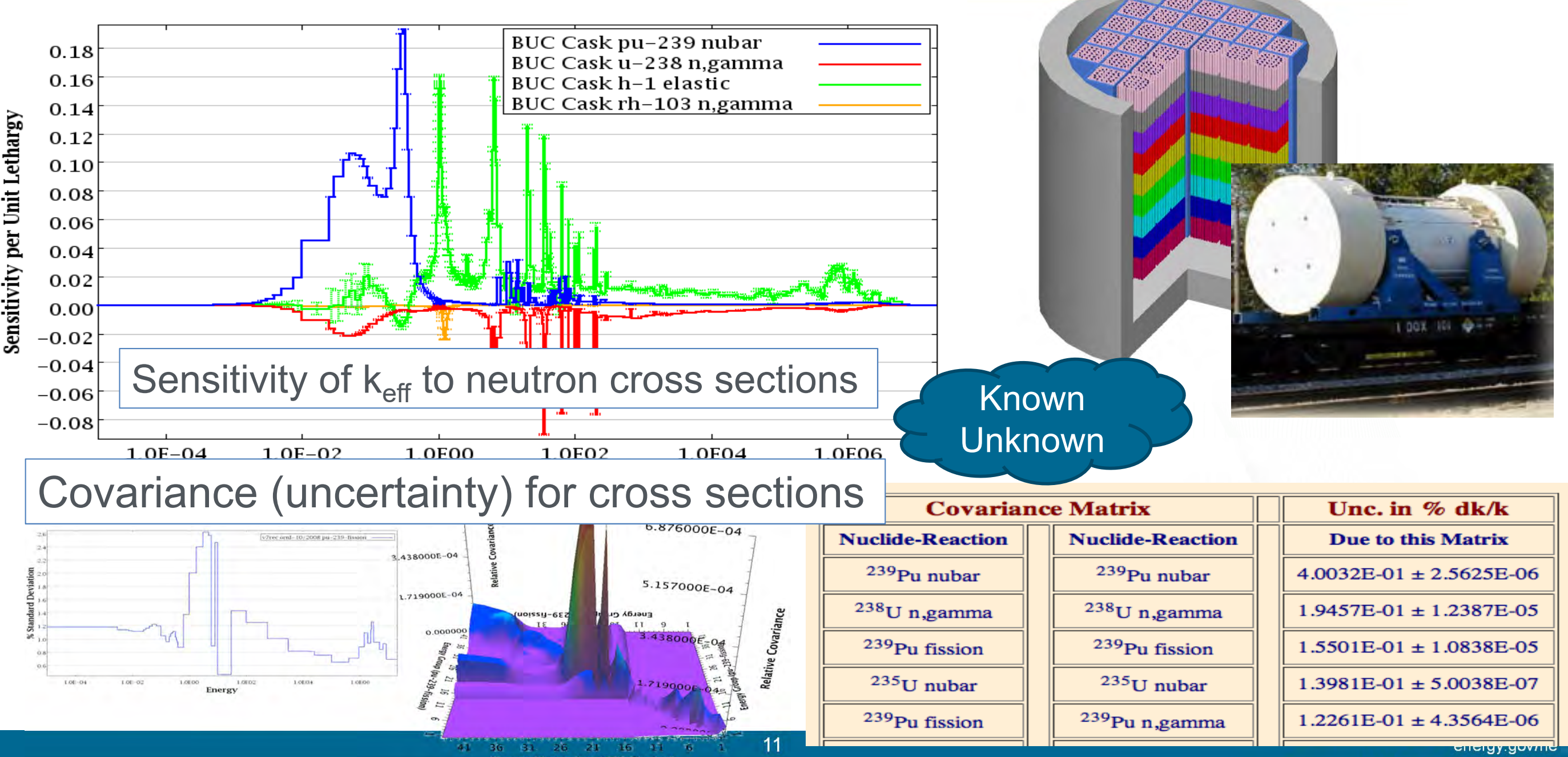




\section{Code Validation: Identification of Laboratory Experiments that}

are Similar to the Targeted Application

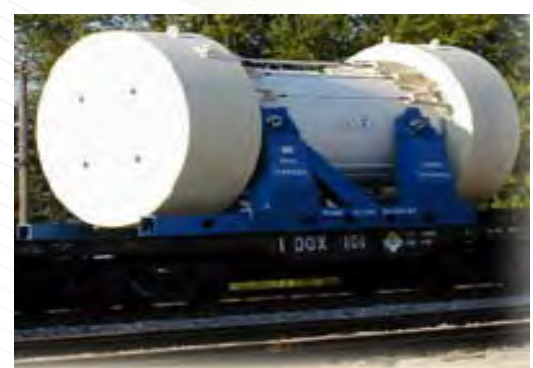

APPLICATION

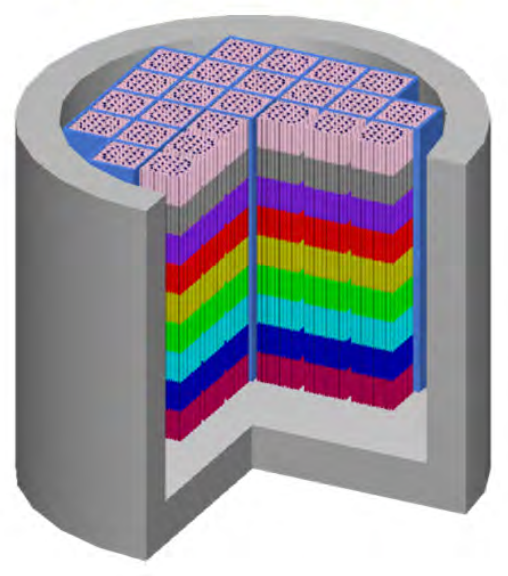

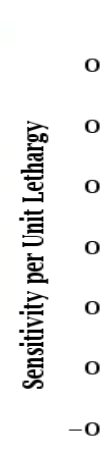

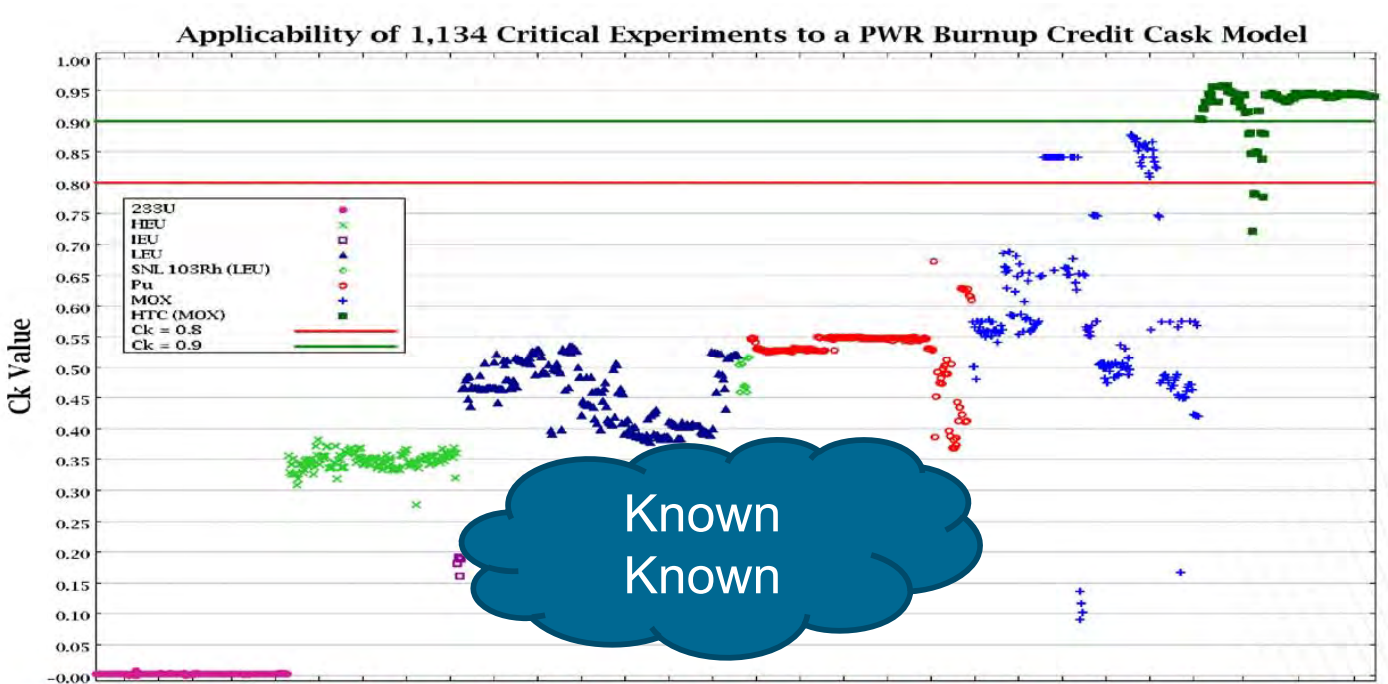

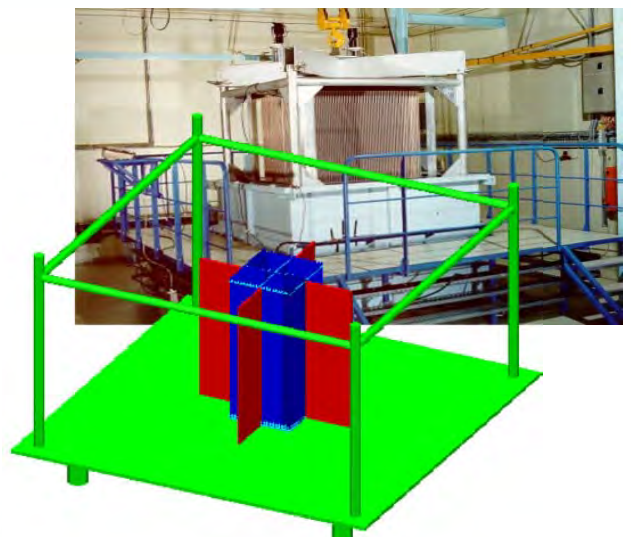

NUCLEAR CRITICALITY EXPERIMENTS

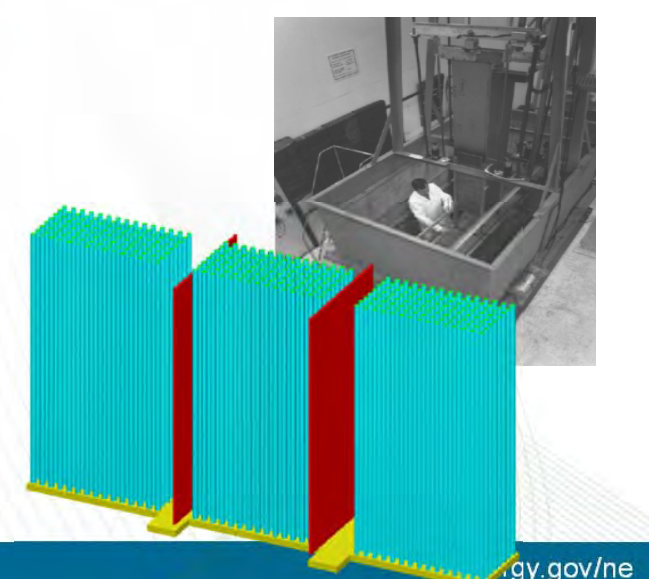




\section{Design of optimized experiments in US and abroad}

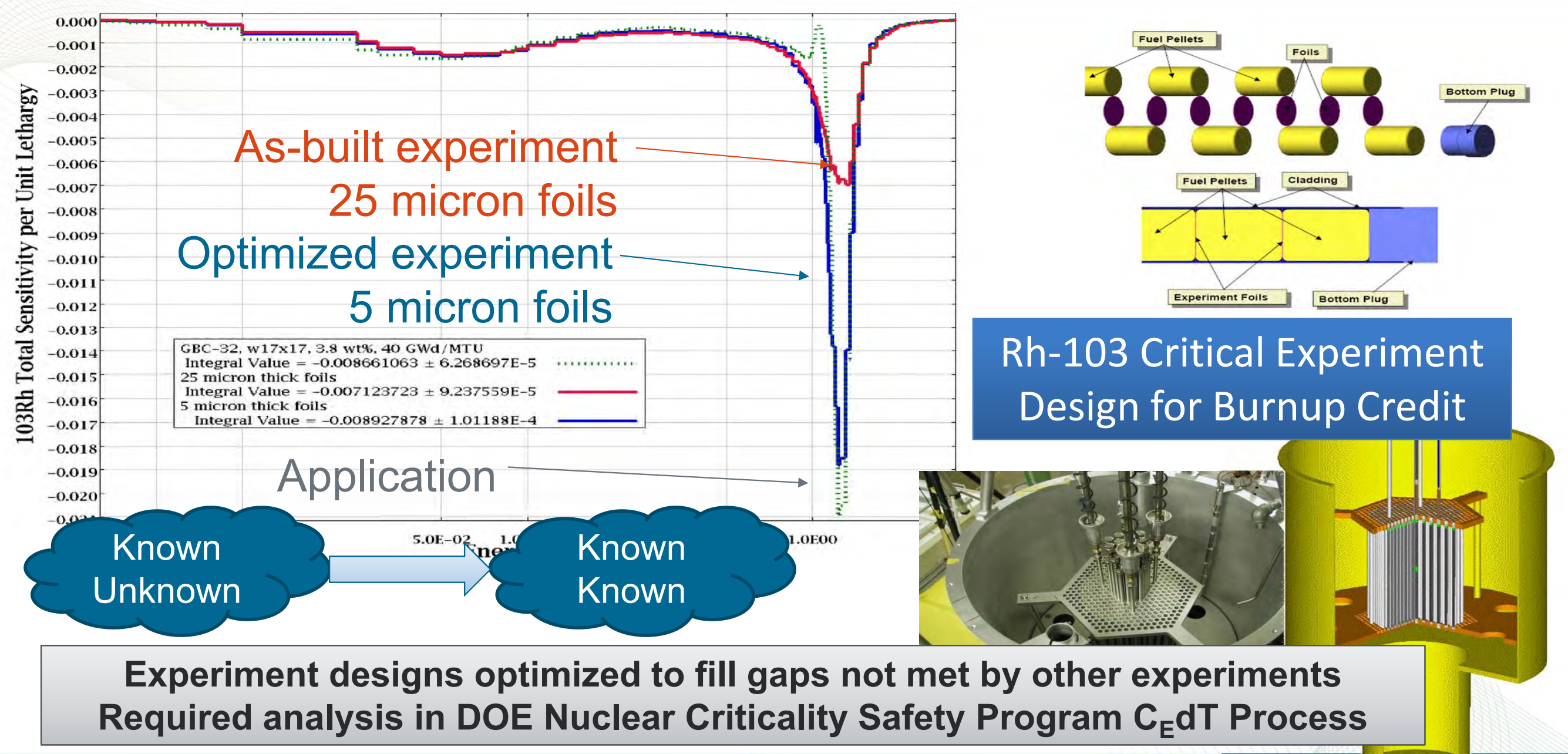




\section{Setting safety limits}

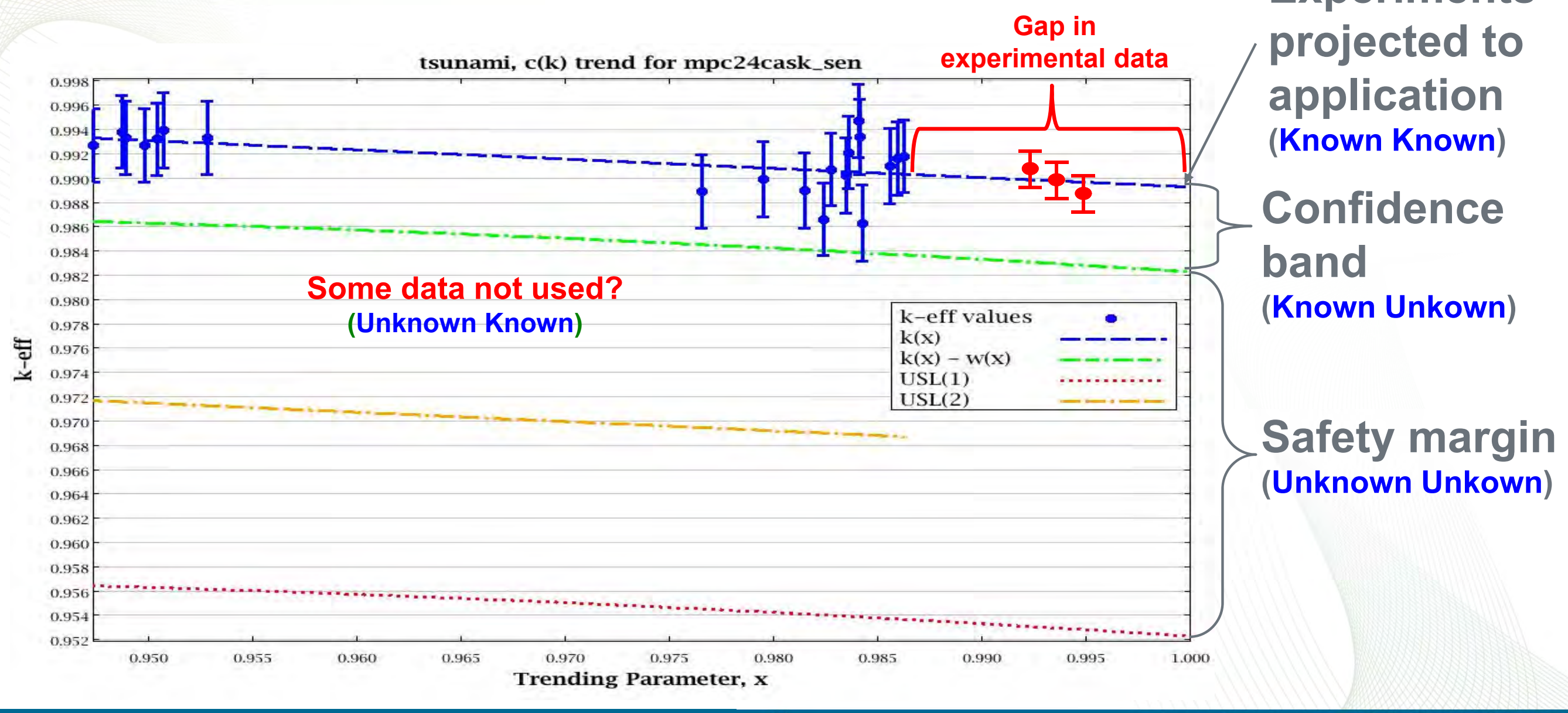




\section{Sensitivity/uncertainty analysis methods in practice}

- U.S. Nuclear Regulatory Commission

- Nuclear Materials Safety and Safeguards, Nuclear Reactor Regulation, Office of New Reactors

- U.S. DOE / Areva / Duke Energy

- Mixed Oxide Fuel Fabrication Facility

- Candu Energy

- ACR-1000 Design Validation

- NRC / Atomic Energy of Canada, Ltd.

- ACR-700 NRC Review/PIRT

- U.S. DOE

- Yucca Mountain post-closure criticality safety

- Global Nuclear Fuels

- Transportation package licensing

- Svensk Kärnbränslehantering AB (SKB)

- Swedish used fuel repository

- Organization for Economic Cooperation and Development, Nuclear Energy Agency / International Atomic Energy Agency

- International Expert Groups

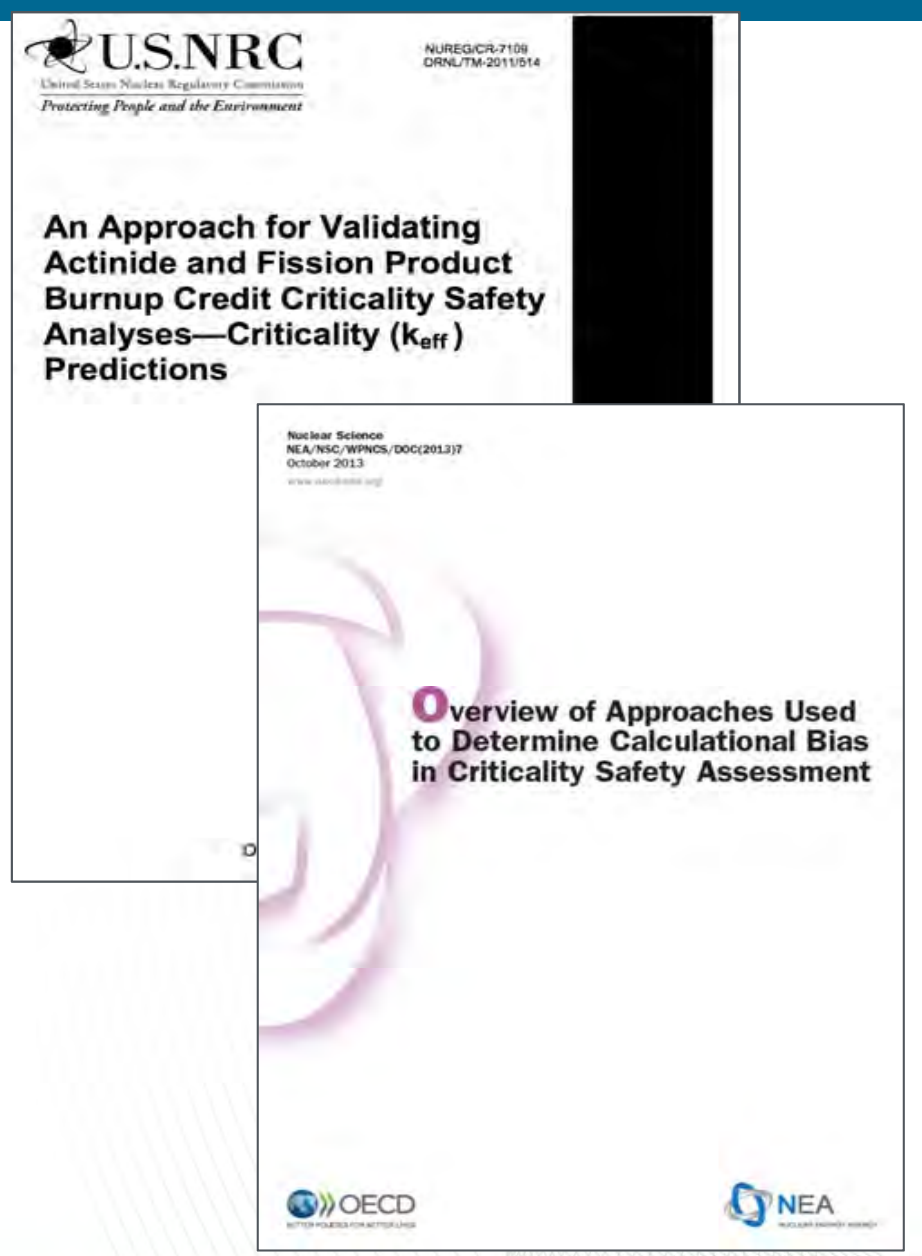

Actinide and Fission Product

Burnup Credit Criticality Safety Analyses-Criticality ( $k_{\text {eff }}$ )

Predictions to Determine Calculational Bias 
Fission nuclear data programs and prioritization 


\section{OECD Nuclear Energy Agency high priority request list}

\section{NEA Nuclear Data High Priority Request List}

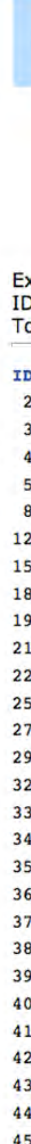

HPRL Main

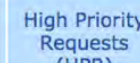

General
Requests (GR)

Purpose
Quantities
New Request

SGC/HPRL Documents

Results of your search in the request list

Requests are shown from the following list(s):

\section{High Priority (H)}

Explanations of each column can be found in the table heads. To view the details of a request, please click on the link symbol after the request To send a comment on a particular entry, please view the request, and click on the 'letter' symbol there.

\begin{tabular}{|c|c|c|c|c|c|c|c|c|c|}
\hline ID & view & Target & Reaction & Quantity & Energy range & Sec.E/Angle & Accuracy & Cov Field & Date \\
\hline $2 \mathrm{H}$ & $\theta$ & $8-0-16$ & $(n, a),(n, a b s)$ & SIG & $2 \mathrm{MeV}-20 \mathrm{MeV}$ & & See details & Y Fission & 12 -SEP- 08 \\
\hline 3日 & $\theta$ & 94-PU-239 & $(n, f)$ & prompt $g$ & Therma1-Fast & $\mathrm{Eg}=0-10 \mathrm{MeV}$ & 7.5 & Y Fission & $12-$ MAY- 06 \\
\hline $4 \mathrm{H}$ & Q & $92-U-235$ & $(n, f)$ & prompt $g$ & Therma1-Fast & $E g=0-10 \mathrm{MeV}$ & 7.5 & $\mathrm{Y}$ Fission & 12-MAY-06 \\
\hline $5 \mathrm{H}$ & $\theta$ & $72-\mathrm{HF}-0$ & $(n, g)$ & SIG & $0.5-5.0 \mathrm{kev}$ & & 4 & Y Fission & 16-APR- 07 \\
\hline $8 \mathrm{H}$ & 0 & 1-H-2 & $(\mathrm{n}, \mathrm{e} 1)$ & $\mathrm{DA} / \mathrm{DE}$ & $0.1 \mathrm{MeV}-1 \mathrm{MeV}$ & 0-180 Deg & 5 & Y Fission & 16-APR-07 \\
\hline $12 \mathrm{H}$ & - & $92-U-235$ & $(n, g)$ & SIG, RP & $100 \mathrm{eV}-1 \mathrm{MeV}$ & & 3 & Y Fission & 06-Nov-07 \\
\hline $15 \mathrm{H}$ & $\theta$ & 95-AM-241 & $(n, g),(n, t o t)$ & SIG & Thermal & & See details & Fission & 10 -SEP- 08 \\
\hline $18 \mathrm{H}$ & - & $92-U-238$ & $(n$, inl $)$ & SIG & $65 \mathrm{keV}-20 \mathrm{MeV}$ & Emis spec. & See details & Y Fission & 11 -SEP-08 \\
\hline $19 \mathrm{H}$ & 0 & $94-\mathrm{PU}-238$ & $(n, f)$ & SIG & $9 \mathrm{keV}-6 \mathrm{MeV}$ & & See details & Y Fission & 11 -SEP- 08 \\
\hline 21H & $\theta$ & 95-AM-241 & $(n, f)$ & SIG & $180 \mathrm{keV}-20 \mathrm{MeV}$ & & See details & Y Fission & 11 -SEP- 08 \\
\hline $22 \mathrm{H}$ & - & $95-\mathrm{AM}-242$ & $(n, f)$ & SIG & $0.5 \mathrm{keV}-6 \mathrm{MeV}$ & & See details & Y Fission & 11 -SEP-08 \\
\hline $25 \mathrm{H}$ & 0 & $96-\mathrm{CM}-244$ & $(n, f)$ & SIG & $65 \mathrm{keV}-6 \mathrm{MeV}$ & & See details & Y Fission & 12 -SEP- 08 \\
\hline 27в & 0 & $96-\mathrm{CM}-245$ & $(n, f)$ & SIG & $0.5 \mathrm{keV}-6 \mathrm{MeV}$ & & See details & Y Fission & 12 -SEP- 08 \\
\hline $29 \mathrm{H}$ & 0 & $11-\mathrm{NA}-23$ & $(n, i n 1)$ & SIG & $0.5 \mathrm{MeV}-1.3 \mathrm{MeV}$ & Emis spec. & See details & Y Fission & 12 -SEP- 08 \\
\hline $32 \mathrm{H}$ & Q & $94-\mathrm{PU}-239$ & $(n, g)$ & SIG & $0.1 \mathrm{eV}-1.35 \mathrm{MeV}$ & & See details & Y Fission & 12 -SEP- 08 \\
\hline 33н & $\theta$ & 94-PU-241 & $(n, g)$ & SIG & $0.1 \mathrm{eV}-1.35 \mathrm{MeV}$ & & See details & Y Fission & 12 -SEP- 08 \\
\hline 34H & 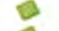 & $26-\mathrm{PE}-56$ & $(n, i n 1)$ & SIG & $0.5 \mathrm{MeV}-20 \mathrm{MeV}$ & Emis spec. & See details & Y Fission & 12 -SEP- 08 \\
\hline 35H & 0 & $94-\mathrm{PU}-241$ & $(n, f)$ & SIG & $0.5 \mathrm{eV}-1.35 \mathrm{MeV}$ & & See details & Y Fission & 12 -SEP- 08 \\
\hline $36 \mathrm{H}$ & 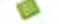 & 92-U-238 & $(n, g)$ & SIG & $20 \mathrm{eV}-25 \mathrm{keV}$ & & See details & Y Fission & 15-SEP-08 \\
\hline 37H & - & $94-\mathrm{PU}-240$ & $(n, f)$ & SIG & $0.5 \mathrm{keV}-5 \mathrm{MeV}$ & & See details & Y Fission & 15 -SEP- 08 \\
\hline 38H & 2 & $94-\mathrm{PU}-240$ & $(n, f)$ & nubar & $200 \mathrm{keV}-2 \mathrm{MeV}$ & & See details & Y Fission & 15 -SEP- 08 \\
\hline 39н & 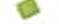 & 94-PU-242 & $(n, f)$ & SIG & $200 \mathrm{keV}-20 \mathrm{MeV}$ & & See details & Y Fission & 15-SEP-08 \\
\hline $40 \mathrm{H}$ & Q & $14-S I-28$ & $(n$, inl $)$ & SIG & $1.4 \mathrm{MeV}-6 \mathrm{MeV}$ & & See details & Y Fission & 15 -SEP- 08 \\
\hline $41 \mathrm{H}$ & - & $82-\mathrm{PB}-206$ & $(n, i n 1)$ & SIG & $0.5 \mathrm{MeV}-6 \mathrm{MeV}$ & & See details & Y Fission & 15 -SEP- 08 \\
\hline $42 \mathrm{H}$ & 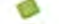 & 82-PB-207 & $(\mathrm{n}$, in 1$)$ & SIG & $0.5 \mathrm{MeV}-6 \mathrm{MeV}$ & & See details & Y Fission & 15 -SEP- 08 \\
\hline $43 \mathrm{H}$ & 0 & $1-\mathrm{H}-1$ & $(\mathrm{n}, \mathrm{el})$ & SIG,DA & $10 \mathrm{MeV}-20 \mathrm{MeV}$ & $4 \mathrm{pi}$ & $1-2$ & Y Standard & 13-MAY-11 \\
\hline $44 \mathrm{H}$ & - & 93-NP-237 & $(n, f)$ & SIG,DE & $200 \mathrm{keV}-20 \mathrm{MeV}$ & & & Y Fission & 18-MAY-15 \\
\hline 45B & e & $19-\mathrm{K}-39$ & $(n, p),(n, n p)$ & SIG & $10 \mathrm{MeV}-20 \mathrm{MeV}$ & & 10 & y Fusion & 11-JUL-17 \\
\hline
\end{tabular}

Number of requests found: 28 (out of a total of 89 requests)

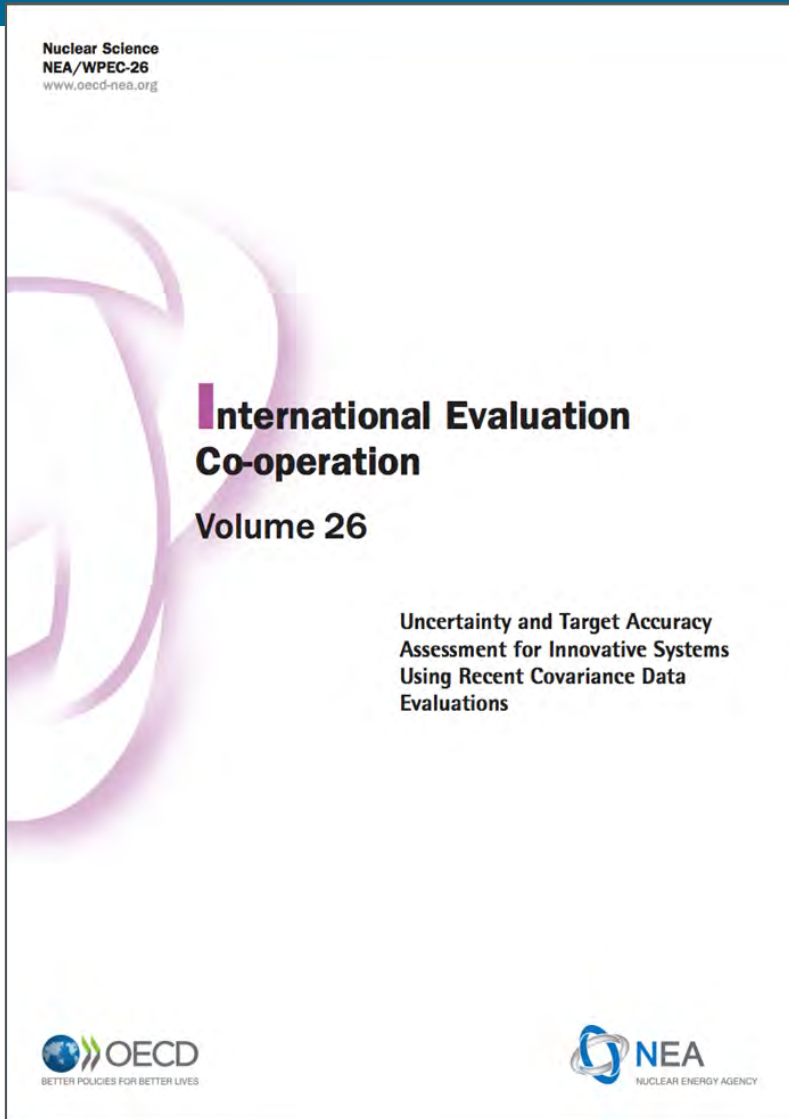

https://www.oecd-nea.org/dbdata/hprl/ 


\section{Next steps}

\section{Now}

- Identify candidate materials and transportation packages

- Perform nuclear data / benchmarking needs assessment and gap analysis

- Proceed with defensible safety margin (possibly at cost of efficiency)

\section{Ongoing R\&D}

- Extend use of existing data with advanced validation methods and training

- Nuclear data gaps

- Generate improved evaluations

- \$1-2M,3-5 years per nuclide

- Benchmark experiment gaps

- Mine existing experiments for information and document as archival benchmarks

- \$500k, 1-2 years per benchmark series

- Build new critical experiments

- Generate optimized experiment designs

- Survey available facilities and materials and supplement as needed

- \$2-5M+++, 2-5 years for measurement

- $\$ 500 \mathrm{k}, 1-2$ years to generate archival benchmark 


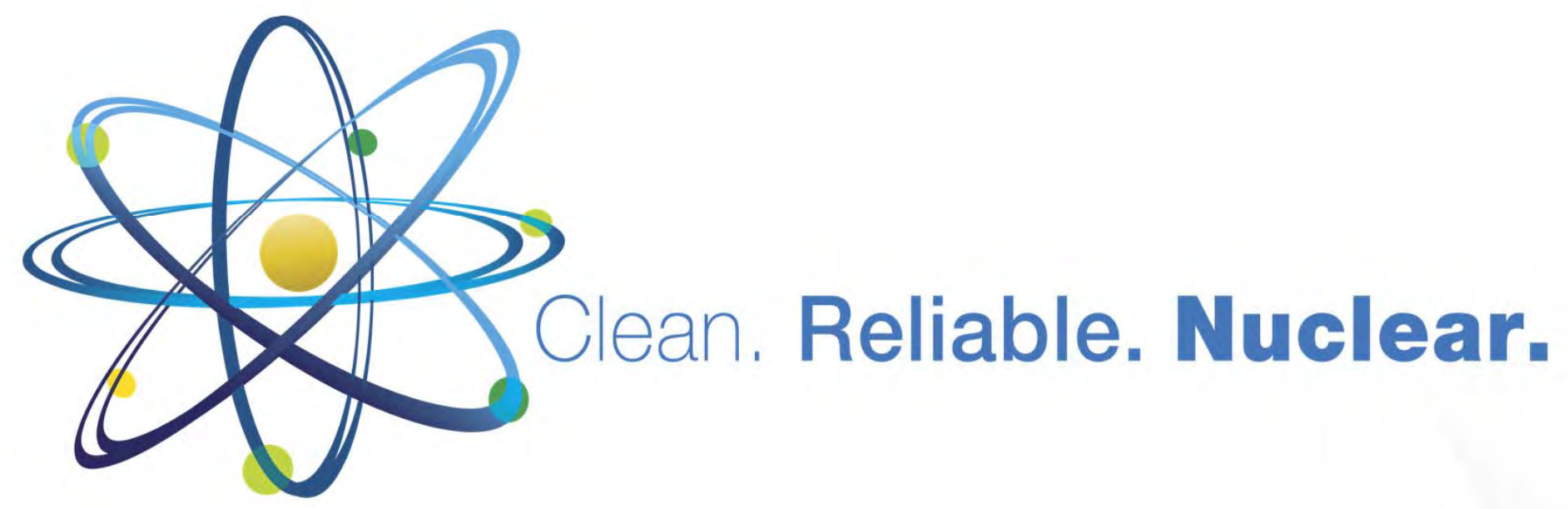




\section{$>$ 5.0 Weight Percent}

\section{Code Validation:}

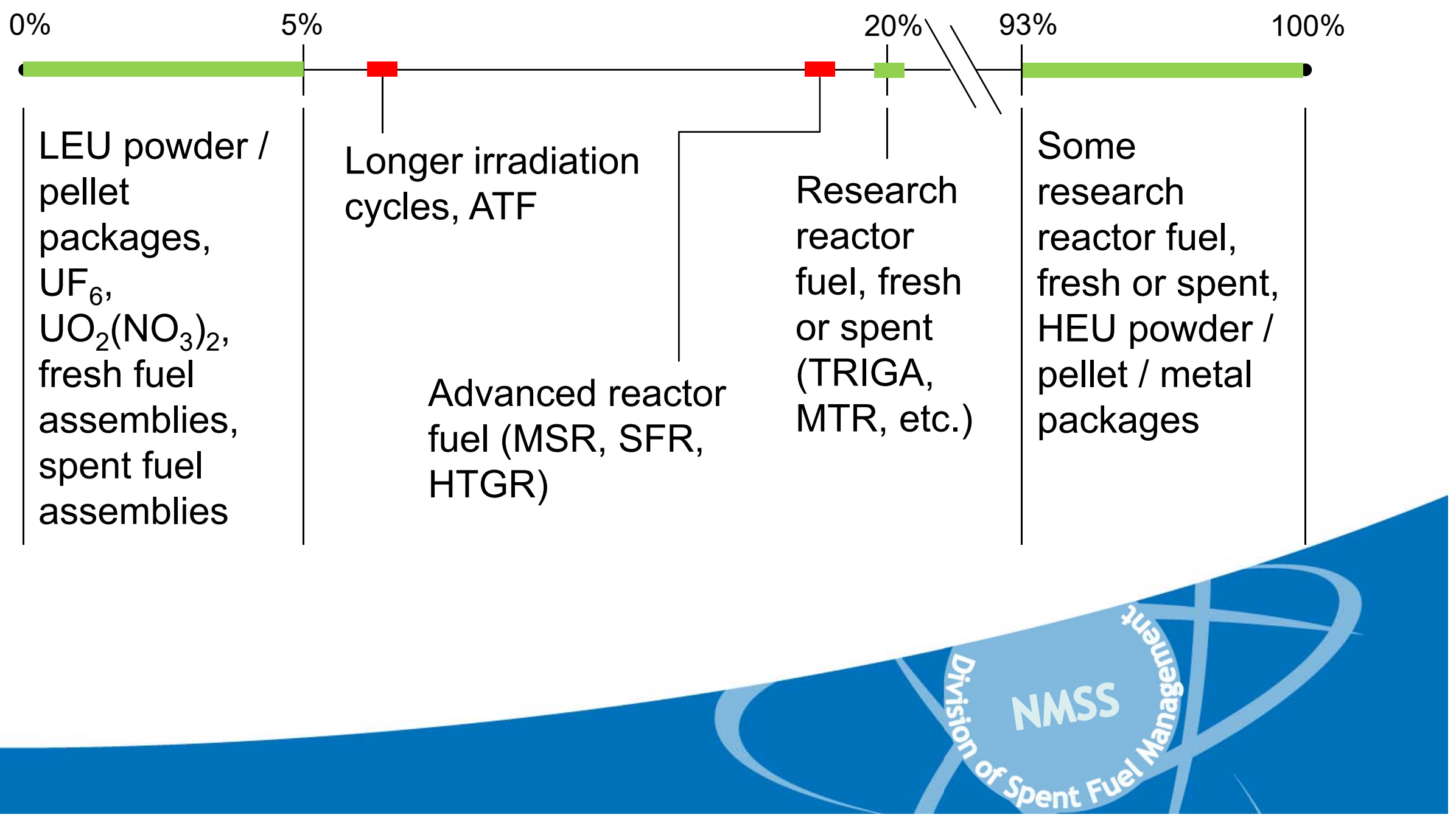




\section{$\mathrm{UF}_{6}$}

- 10 CFR $71.55(\mathrm{~g})(4)$ - The uranium is enriched to not more than 5 weight percent uranium-235.

- 49 CFR 173.417(a)(2) - "Heel" requirements: less than 5 weight percent in a 30-inch cylinder

- IAEA SSR-6 p. 680(a) - relief from water in-leakage requirement for $U F_{6}$ packages if enrichment is less than 5 weight percent

- ANSI N14.1 -

- 30B/C, 12A/B enrichment limit: 5 weight percent

- 8A: 12.5 weight percent

- 5A/B: 100 weight percent

- ISO 7195 - similar to ANSI N14.1 


\section{Integral Experiments in the United States -} Cost and Process

Douglas G. Bowen, Ph.D.

Nuclear Data and Criticality Safety Group Leader Reactor and Nuclear Systems Division

Oak Ridge National Laboratory

Nuclear Criticality Safety Program Execution Manager:

INL-NEl Technical Workshop on Transportation of HALEU August 31, 2018 


\section{Background / History}

- Defense Nuclear Facilities Safety Board (DNFSB) Recommendations 93-2 and 97-2:

- 93-2 (3/23/1993): Need for a general-purpose critical experiment capability that will ensure safety in handling and storage of fissionable material.

- 97-2 (5/19/1997): Need for improved criticality safety practices and programs to alleviate potential adverse impacts on safety and productivity of DOE operations.

- 97-2 encompassed ongoing DOE activities of 93-2 while broadening scope to address important cross-cutting safety activities needed to ensure NCS throughout the Complex.

- DOE Implementation Plan for Board Recommendation 93-2 and 97-2 resulted in establishment of the US Nuclear Criticality Safety Program (NCSP)
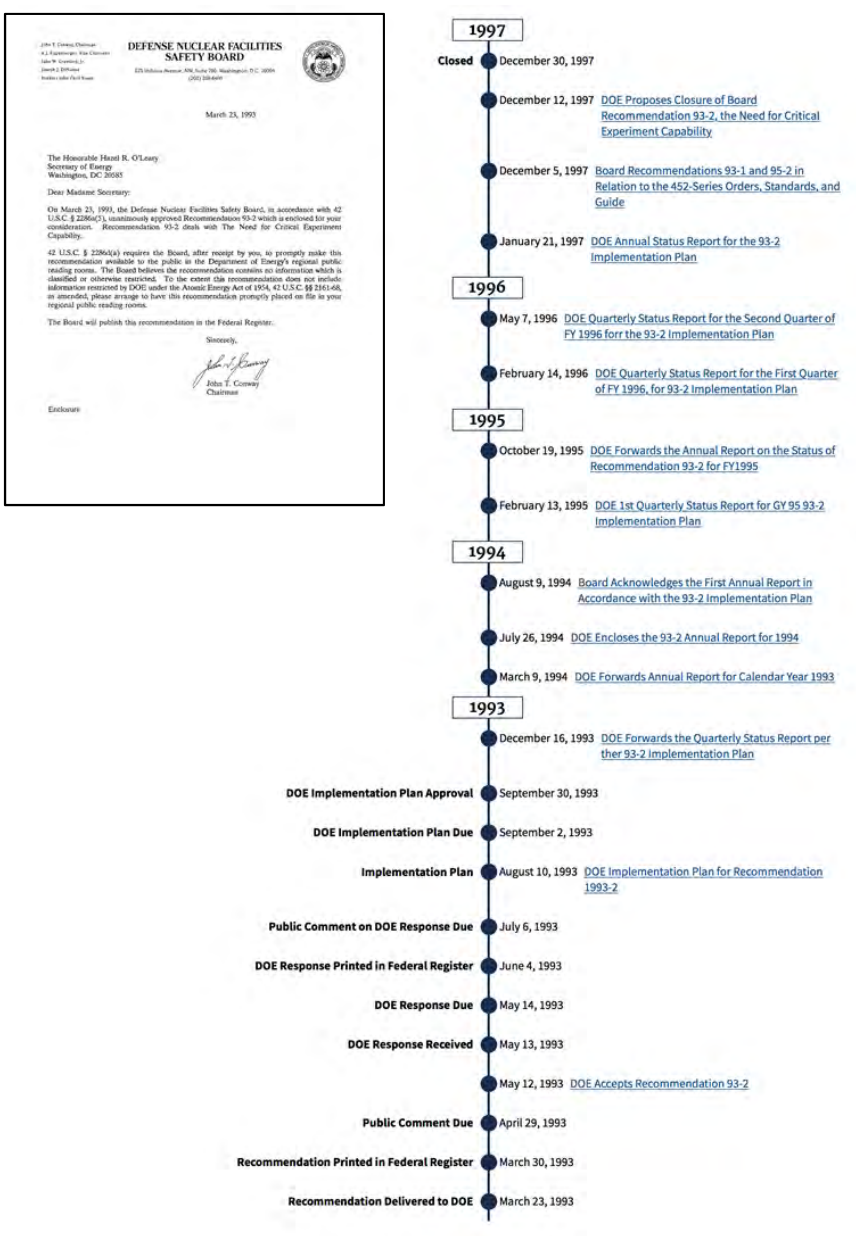


\section{NCSP Organization and Overview}

- Mission

- Provide sustainable expert leadership, direction and the technical infrastructure necessary to develop, maintain and disseminate the essential technical tools, training and data required to support safe, efficient fissionable material operations within the Department of Energy.

- Vision

- Continually improving, adaptable and transparent program that communicates and collaborates globally to incorporate technology, practices and programs to be responsive to the essential technical needs of those responsible for developing, implementing and maintaining nuclear criticality safety.
10 Year Mission \& Vision

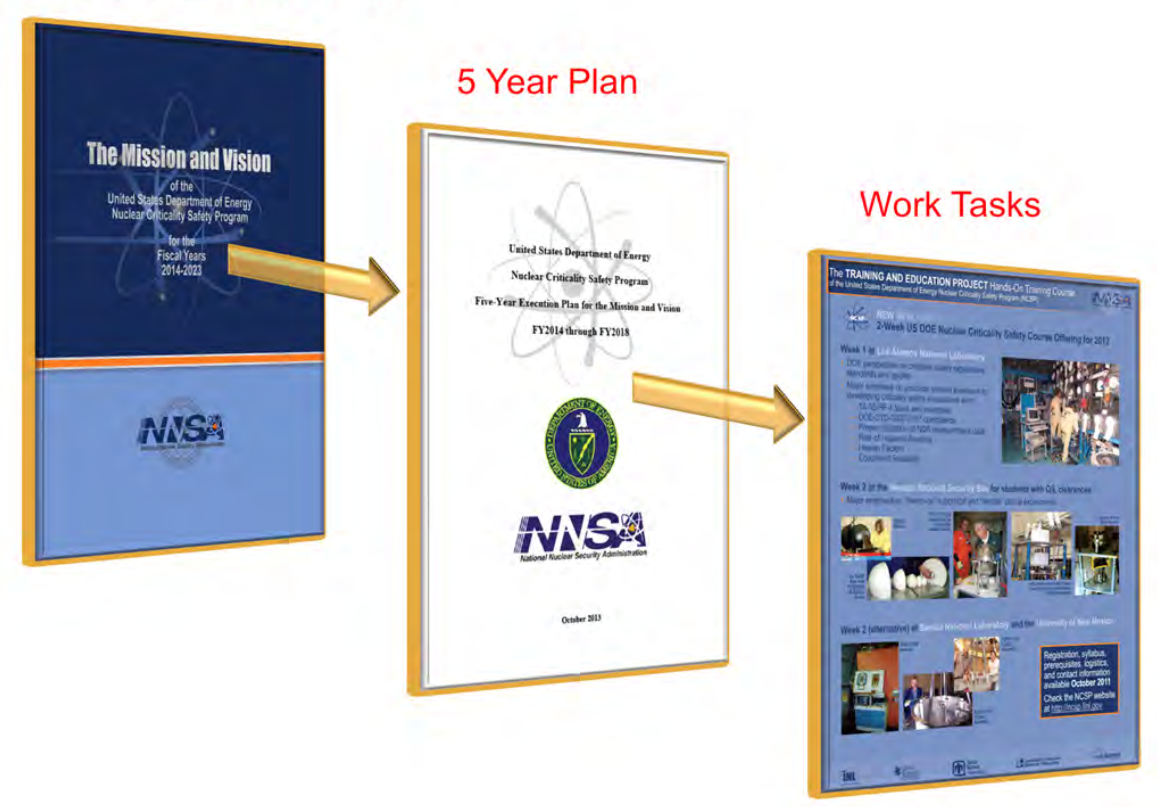




\section{NCSP Technical Program Elements}

- Analytical Methods (AM) $-15 \%$ of budget

- Maintain and improve the Production Codes and Methods for Criticality Safety Engineers (MCNP/SCALE, NJOY/AMPX)

- Nuclear Data (ND) - $13 \%$ of budget

- Perform Measurements of Basic Nuclear (Neutron) Physics Cross-Sections and Generate New Evaluated Cross-Section Libraries and Covariance Data for Use in Production Criticality Safety Codes

- Information Preservation and Dissemination (IPD) - 4\% of budget

- Protects Valuable Analyses and Information Related to Criticality Safety (includes ICSBEP)

- Integral Experiments (IE) $-\mathbf{5 2 \%}$ of budget

- Critical and Subcritical Experiments at the Critical Experiments Facility (CEF) at the Device Assembly Facility (DAF) in Nevada and Sandia National Laboratory Pulse Reactor Facility- provides integral tests of codes and data

\section{- Training and Education (TE) $-6 \%$ of budget}

- Web-based training modules and 1- \& 2-week Hands-On Criticality Safety courses for Criticality Safety Engineers, Line Management, and Oversight Personnel

\section{- Technical Support (TS) $-10 \%$ of budget}

- Managerial and technical support

TMs - Task managers

CSSG - Criticality Safety Support Group

CSCT - Criticality Safety Coordinating Team NDAG - Nuclear Data Advisory Group

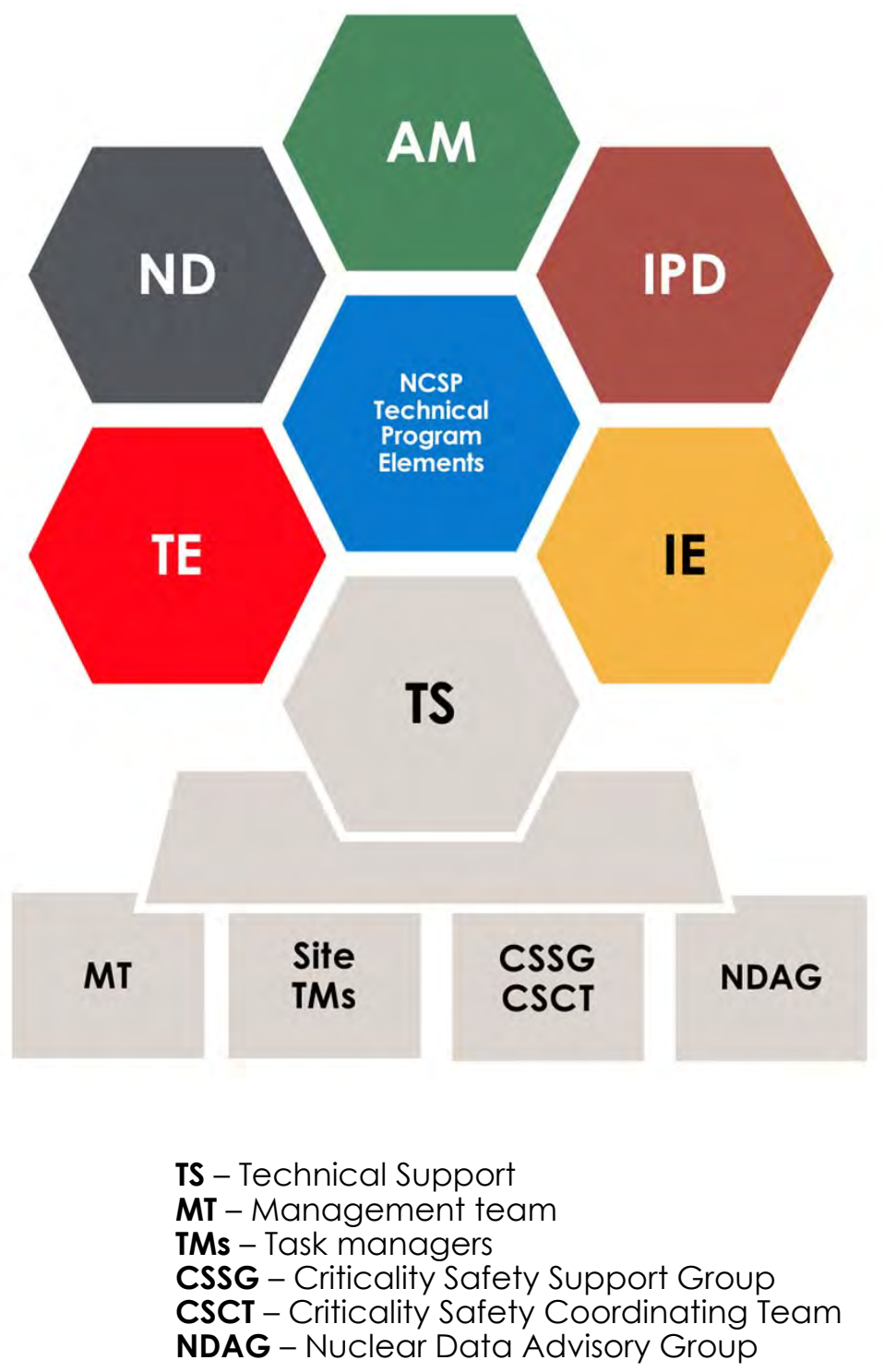




\section{Current NCSP Work Sites}

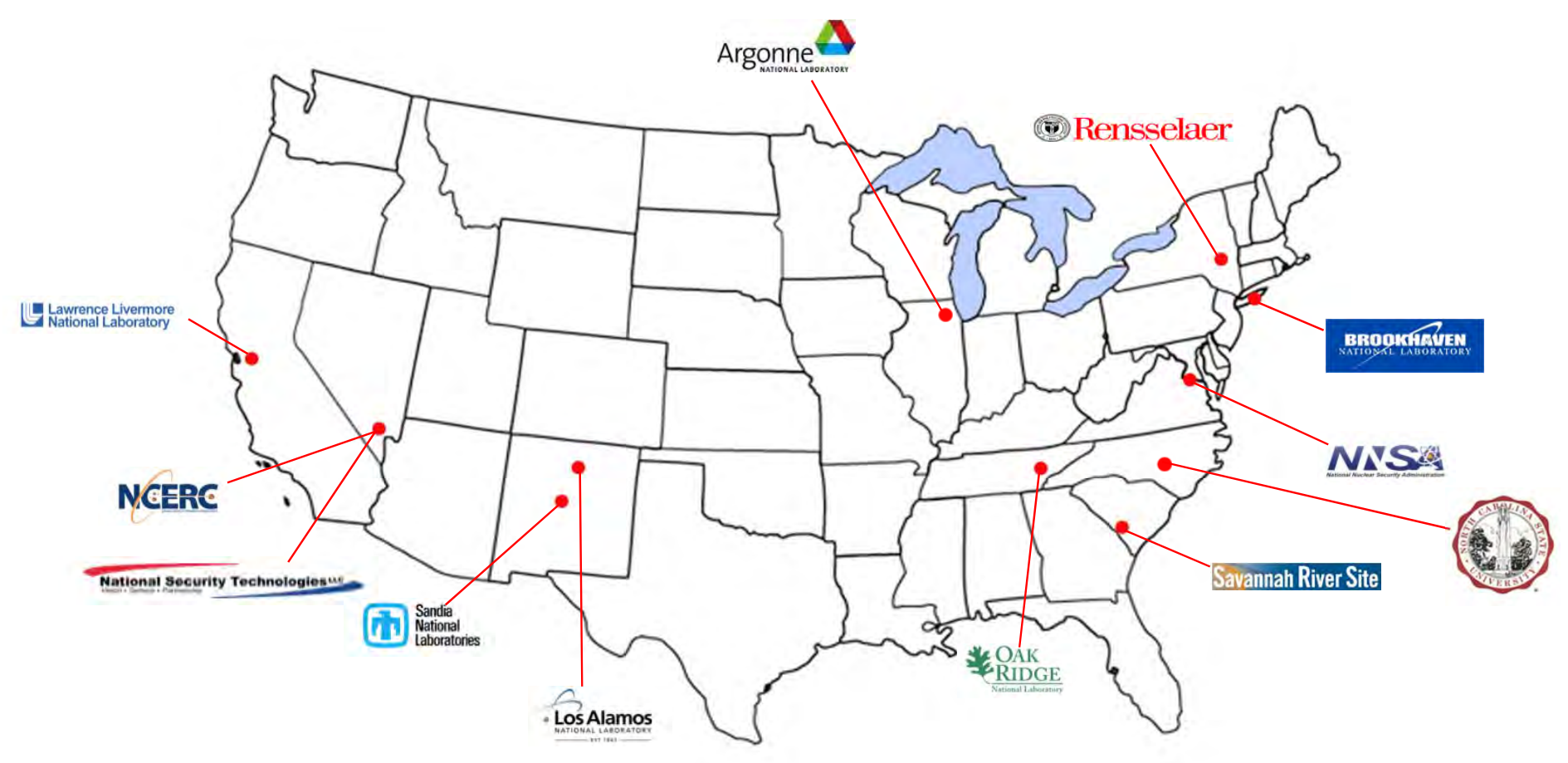

FY2019 NCSP Budget: \$26.8 million

National Laboratory 


\section{US DOE NCSP Contributors}

\section{US Contributors}

- National Laboratories

- Argonne (ANL)

- Brookhaven (BNL)

- Lawrence Livermore (LLNL)

- Los Alamos (LANL)

- Oak Ridge (ORNL)

- Pacific Northwest (PNNL)

- Sandia (SNL)

- Sites

- Nevada National Security Site (NNSS)

- Savannah River (SRNL)

- Y-12

- Universities

- Rensselaer Polytechnic Institute (RPI)

- Georgia Institute of Technology (Ga Tech)

- North Carolina State University (NCSU)

- Massachusetts Institute of Technology (MIT)

- University of Florida (Gainesville) (UF)

- University of Tennessee (Knoxville) (UTK)

\section{International Partners}

- U.K.: AWE (JOWOG-30)

- France:

- IRSN (Formal MOU with NCSP)

- CEA (Nuclear Data)

- Belgium: Institute for Reference Materials and Measurements (IRMM) differential nuclear data measurements

- OECD/NEA

- ICSBEP

- WPEC

- WPNCS 


\section{NCSP Integral Experiments}

- NCSP integral measurements are performed at

- Sandia National Laboratories (SNL) and

- National Criticality Experiments Research Center (NCERC), currently operated by Los Alamos National Laboratory

- NCERC is located at the Nevada National Security Site (NNSS) inside the Device Assembly Facility (DAF)

- Types of experiments that can be performed

- Subcritical

- Rocky Flats shells, BeRP ball, Np-237 sphere, TACS shells, etc.

- Critical/Delayed Supercritical

- NCERC: Planet, Comet, Godiva IV, Flattop

- Sandia: Sandia Pulse Reactor critical assembly (2 fuel types, currently)

- Prompt Supercritical

- NCERC: Godiva IV (<300 deg. C pulse)
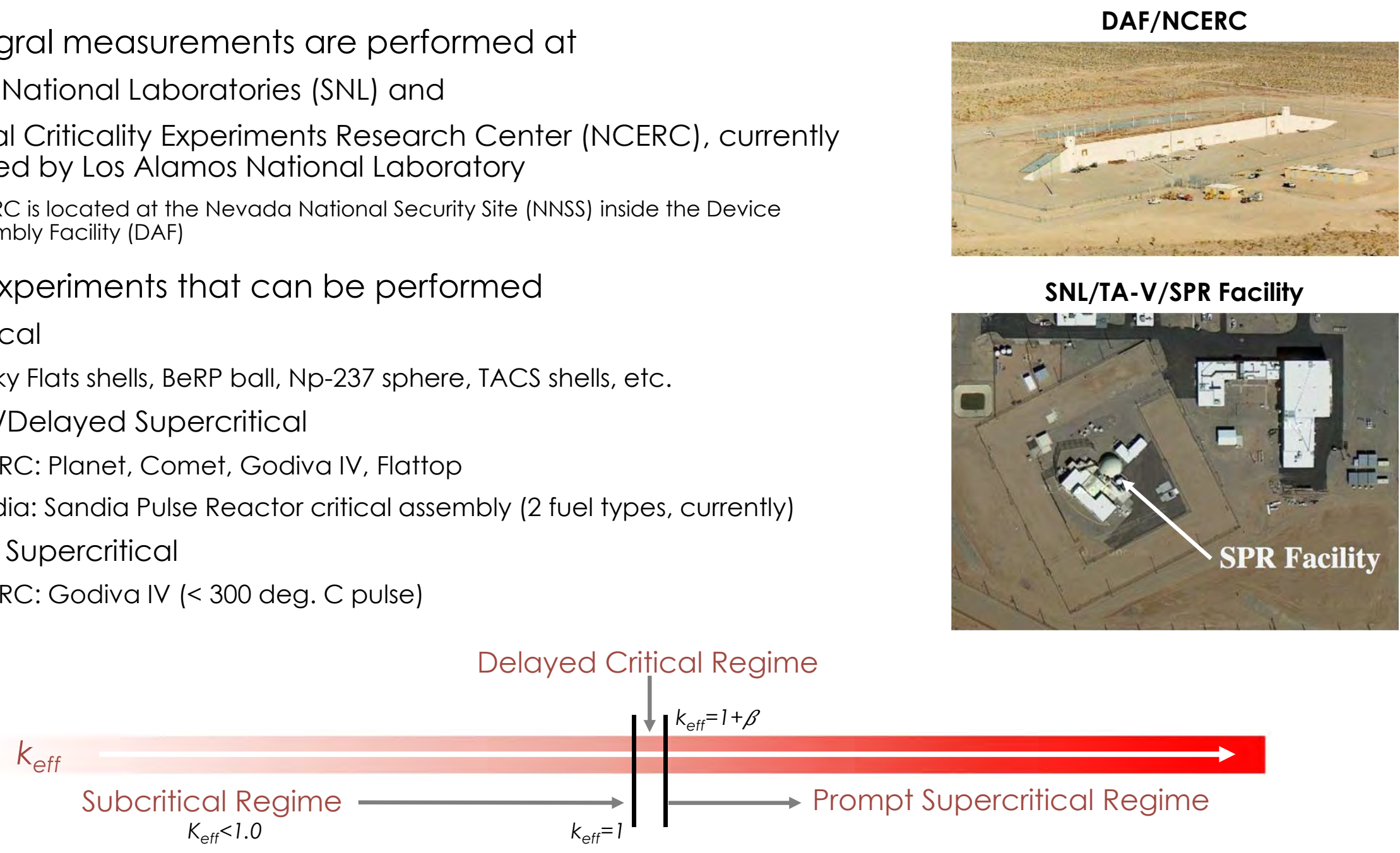


\section{NCSP Critical Assemblies}
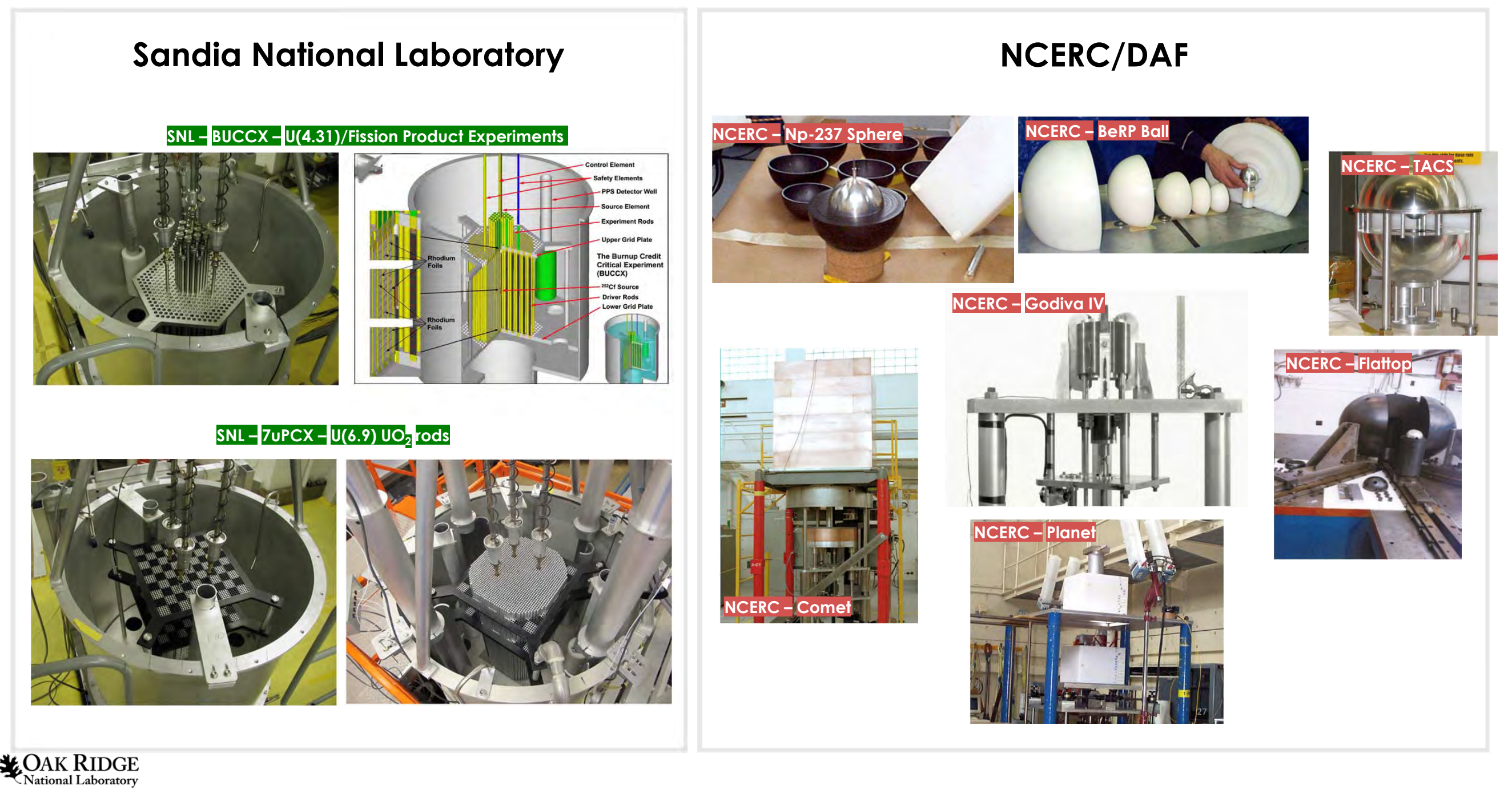


\section{Overview of the NCSP $C_{E}$ dT Process}

- Experimental phases

- CED-0 - experiment proposal is submitted

- CED-1 - preliminary design of the experiment

- CED-2 - final design of the experiment

- CED-3

- CED-3a-Schedule/cost/procurement/installations/etc.

- CED-3b-experiment execution

- CED-4

- CED-4a-summary of experimental data collected during the experiment to ensure it met requirements

- CED-4b - publish final laboratory report or formal critical experiment benchmark report

- Each experiment is assigned a team of experts to provide support

- The experiments take years to complete and are dependent upon the regulatory environment, critical experiment assembly availability, availability of trained operators, etc.

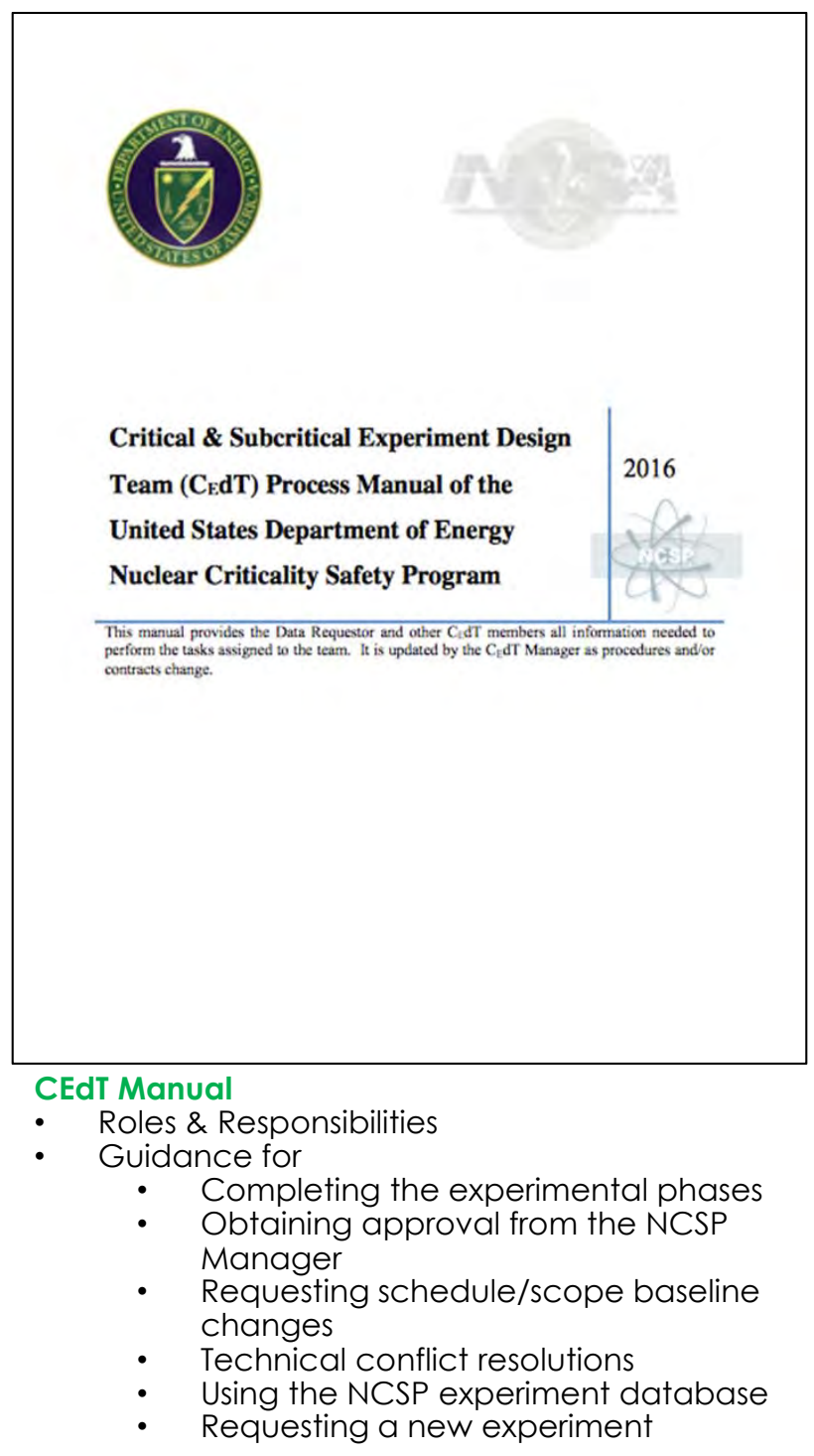




\section{Costs to Design and Perform Critical Experiments}

\begin{tabular}{|c|c|c|c|c|c|c|c|c|}
\hline \multirow{2}{*}{\multicolumn{2}{|c|}{$\begin{array}{c}\text { CEdT Phase } \\
\text { Gate } \\
\text { CED-1 }\end{array}$}} & \multirow{2}{*}{$\begin{array}{l}\text { Description } \\
\text { Preliminary Design }\end{array}$} & \multicolumn{2}{|c|}{$\begin{array}{c}\text { Cost (k\$) } \\
\text { (low) }\end{array}$} & \multicolumn{2}{|c|}{$\begin{array}{c}\text { Cost (k\$) } \\
\text { (high) }\end{array}$} & \multirow{2}{*}{$\begin{array}{l}\text { Duration } \\
\text { 3-12 months }\end{array}$} & \multirow{3}{*}{\begin{tabular}{l}
\multicolumn{1}{c}{ Comments } \\
Depends significantly on the \\
complexity of the experiment
\end{tabular}} \\
\hline & & & $\$$ & 75 & $\$$ & 150 & & \\
\hline & E-2 & Final Design & $\$$ & 100 & $\$$ & 250 & 6-12 months & \\
\hline \multirow[t]{2}{*}{ CED-3 } & CED-3a & $\begin{array}{l}\text { Costs estimated for procurements and } \\
\text { procedure development; resource } \\
\text { loaded schedule developed; } \\
\text { component fabrication }\end{array}$ & $\$$ & 50 & $\$$ & 300 & 3-6 months & $\begin{array}{l}\text { Material procurements, reactor } \\
\text { safety committee approvals, } \\
\text { safety basis changes, and } \\
\text { procedure reviews can be } \\
\text { expensive }\end{array}$ \\
\hline & CED-3b & Experiment execution & $\$$ & 100 & $\$$ & 1,000 & 3-6 months & $\begin{array}{l}\text { Approximate costs per site: } \\
\text { SNL - \$45k/week; NCERC - } \\
\$ 75 \text { k /week }\end{array}$ \\
\hline \multirow{3}{*}{ CED-4 } & CED-4a & $\begin{array}{l}\text { Process experimental data; Begin to } \\
\text { document final report }\end{array}$ & $\$$ & 50 & $\$$ & 250 & 3-6 months & \\
\hline & CED-4b & Publish final report & $\$$ & 50 & $\$$ & 150 & 6-12 months & $\begin{array}{l}\text { Sponsor report or an evaluation } \\
\text { for the International Handbook } \\
\text { of Evaluated Criticality Safety } \\
\text { Benchmark Experiments }\end{array}$ \\
\hline & & Total Estimated Cost & $\$$ & 425 & $\$$ & 2,100 & 24-54 months & \\
\hline
\end{tabular}




\section{Experimental Cost Discussion}

- Sandia Example (6.9\% Fuel Benchmark)

- Experiments for ICSBEP handbook

- Series of 19 configurations

- Experimental duration and costs

\begin{tabular}{|c|c|c|}
\hline Phase & Date/Duration & Cost $(\mathbf{x} \mathbf{1 , 0 0 0})$ \\
\hline CED-0 & Late 2012 & - \\
\hline CED-1 & $3 / 2013$ & 80 \\
\hline CED-2 & $9 / 2013$ & 75 \\
\hline CED-3a & $1 / 2014$ & 200 \\
\hline CED-3b & $9 / 2014$ & 195 \\
\hline CED-4a & $9 / 2015$ & 243 \\
\hline CED-4b & & \\
\hline Total Cost & Duration $\mathbf{3} \mathbf{y r}$ & $\mathbf{7 9 3}$ \\
\hline
\end{tabular}
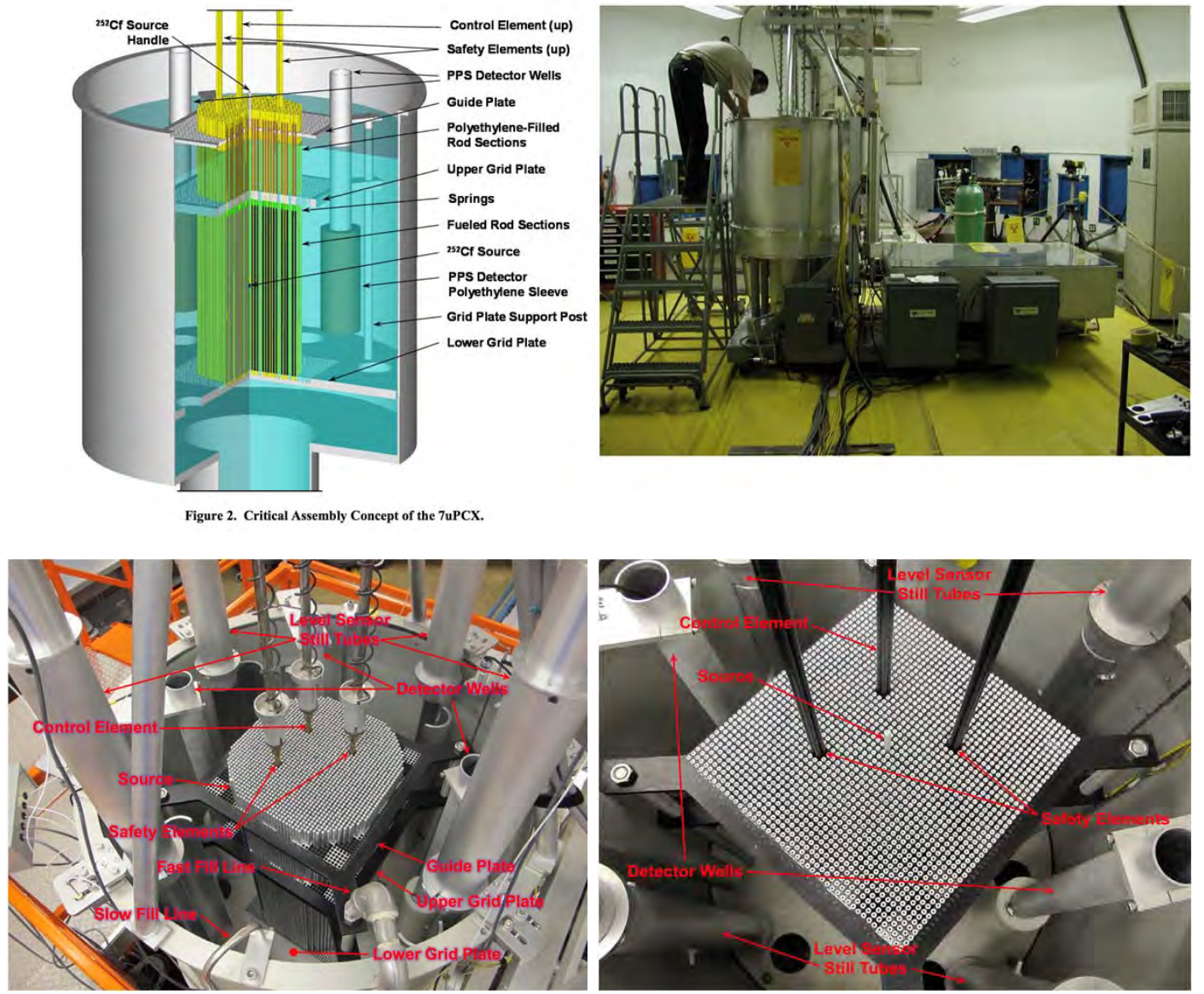


\section{Experimental Cost Discussion}

- NCERC Example (LLNL PU TEX Experiments)

- Experiments for ICSBEP handbook

- Series of 10 experiments

- Five baseline thermal, intermediate, and fast experiments

- Five with a tantalum layer to test cross sections

- Experimental duration and costs

\begin{tabular}{|c|c|c|}
\hline Phase & Date/Duration & Cost $(x \$ 1,000)$ \\
\hline CED-O & $5 / 2011$ & - \\
\hline CED-1 & $9 / 2012$ & 100 \\
\hline CED-2 & $11 / 2014$ & 150 \\
\hline CED-3a & $10 / 2017$ & $\begin{array}{c}200 \\
-65 \text { (Component Fabrication) } \\
-125 \text { (Procedure Dev.) }\end{array}$ \\
\hline CED-3b & $\begin{array}{c}\text { In progress } \\
(2018)\end{array}$ & 600 (est.) \\
\hline CED-4a & \multirow{2}{*}{ TBD } & \multirow{2}{*}{250 (est.) } \\
\hline CED-4b & & \\
\hline Total Cost & $\begin{array}{l}7+\text { years } \\
\text { so far }\end{array}$ & 1,300 \\
\hline
\end{tabular}
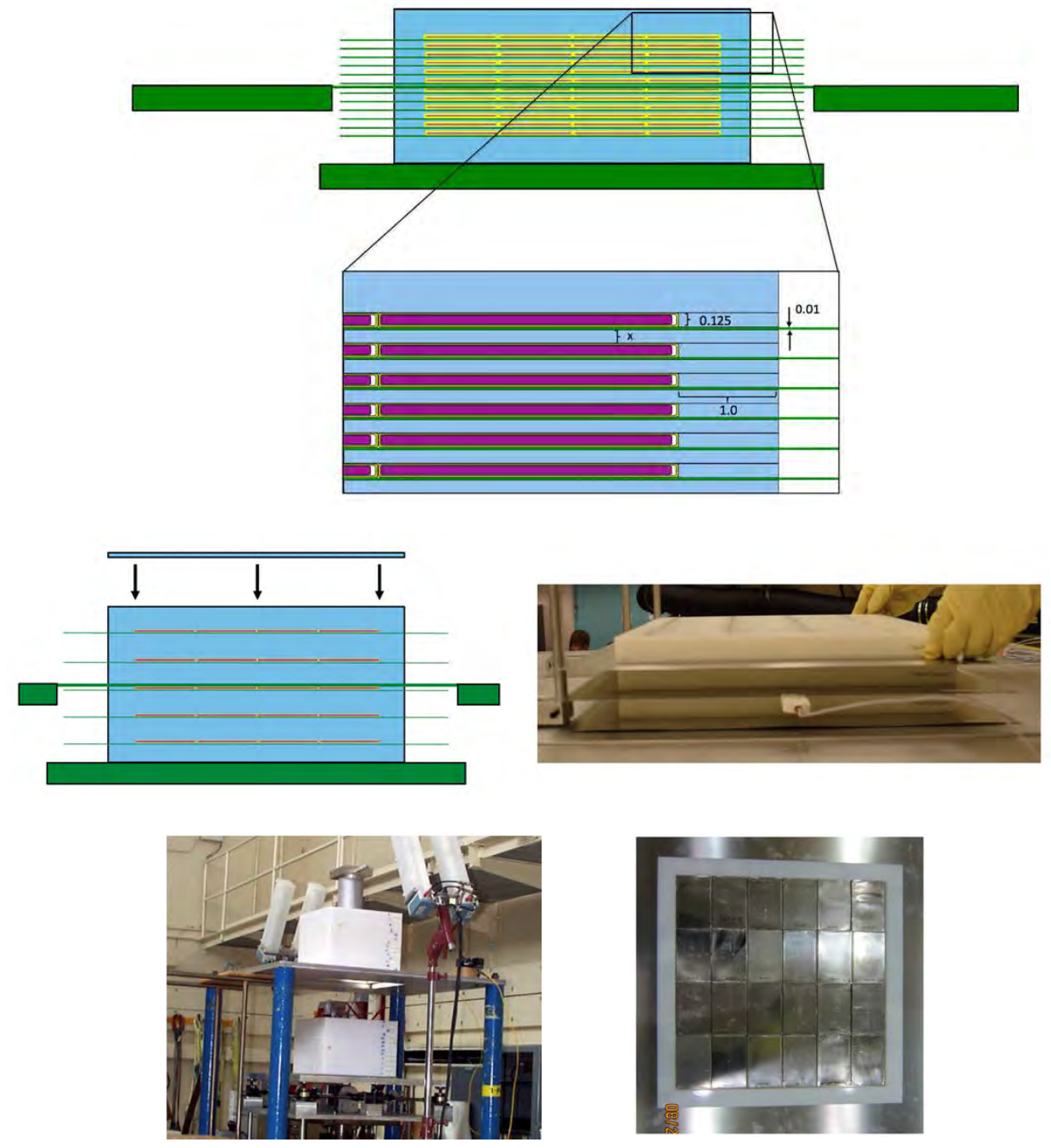


\section{Experimental Cost Discussion}

- NCERC Example (Extreme)

- KRUSTY Critical Experiment

- NNSA/NASA collaboration

- $C_{E}$ dT Team consisted of LANL personnel and the NNSS M\&O operator

- Phase Durations and Costs

\begin{tabular}{|c|c|}
\hline Phase & Duration \\
\hline CED-1 & $1 \mathrm{yr}$. \\
\hline CED-2 & $1.5 \mathrm{yr}$. \\
\hline CED-3a & $7 \mathrm{mo}$. \\
\hline CED-3b & $3 \mathrm{mo}$. \\
\hline CED-4a & $\begin{array}{r}1.5 \mathrm{yr} . \\
\text { expected }\end{array}$ \\
\hline CED-4b & Duration $\mathbf{3} \mathbf{y r}$. \\
\hline Total Cost & \\
\hline
\end{tabular}

- KRUSTY Funding

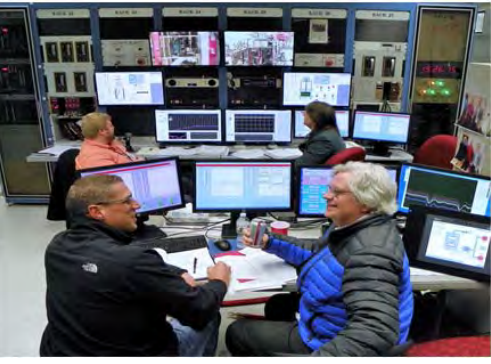

\begin{tabular}{|l|l|l|}
\hline Year & NASA & NNSA \\
\hline FY15 & $\$ 3.6 \mathrm{M}$ & $\$ 0$ \\
\hline FY16 & $\$ 3.9 \mathrm{M}$ & $\$ 0.5 \mathrm{M}$ \\
\hline FY17 & $\$ 4.0 \mathrm{M}$ & $\$ 2.9 \mathrm{M}$ \\
\hline FY18 & $\$ 0.8 \mathrm{M}^{*}$ & $\$ 2.5 \mathrm{M}$ \\
\hline FY19 & $\$ 0 \mathrm{M}$ & $\$ 0.2 \mathrm{M}$ \\
\hline Total & $\$ \mathbf{1 2 . 3 M}$ & $\$ \mathbf{6 . 1 M}$ \\
\hline
\end{tabular}

*estimate provide by NASA based upon currently available data
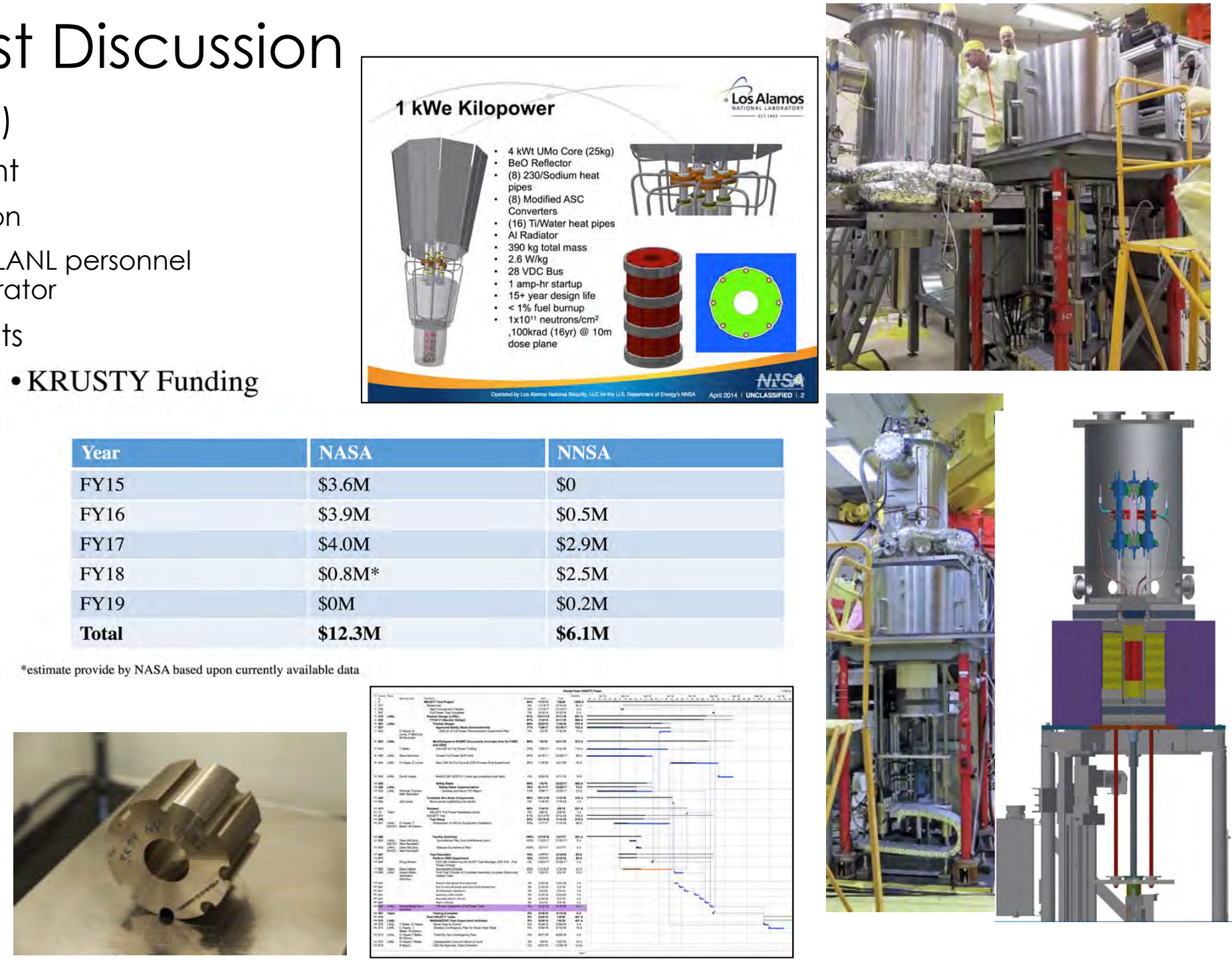


\section{Questions}

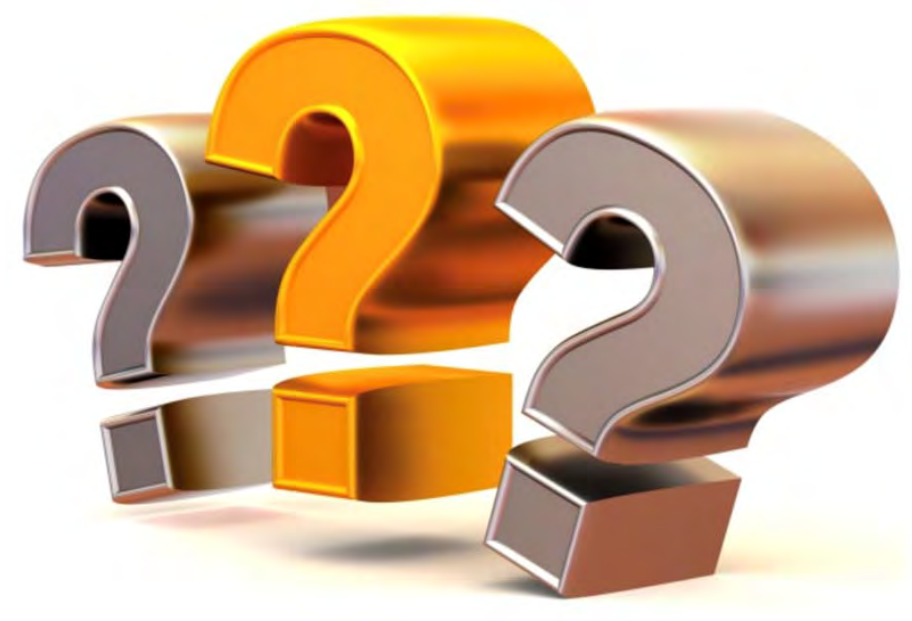




\section{Overview of Criticality Analysis Validation}

Presented by:

John M. Scaglione

Reactor and Nuclear Systems Division

Oak Ridge National Laboratory 
Methods using sensitivity and uncertainty (S/U) analysis to assess similarity of models are available in existing computer codes

- The International Handbook of Evaluated Criticality Safety Benchmark Experiments (IHECSBE) contains 5,000 laboratory critical experiments performed at various critical facilities around the world

- Computational tools are available to survey the critical experiments and use a mathematics-based approach to select benchmarks that are applicable to the application model of interest (e.g., transportation package model)

- Techniques are available to fill in gaps using cross section data uncertainty (NUREG/CR-7109) 


\section{Performance of criticality calculations requires detailed knowledge of the application system (package and contents) and modes for reconfiguration}

- Parameters important for nuclear criticality safety control include materials, mass, geometry, density, enrichment, reflection, moderation, concentration, interaction, neutron absorption, and volume

- Fuel forms to focus on

- Powder

- Pellets

- Rods

- Fuel assemblies

- Configuration development considers both normal conditions of transport and hypothetical accident conditions

- Demonstrate under all credible transport conditions that the system is subcritical

\begin{tabular}{l|l}
\hline Traditional & \multicolumn{1}{|c}{ Advanced reactors } \\
\hline $\mathrm{UO}_{3}$ & Triso \\
$\mathrm{UO}_{2}$ & Metal \\
$\mathrm{UF}_{6}$ & Oxide \\
& Molten salt
\end{tabular}

NAK RIDGE 


\section{Criticality safety analyses are performed to show that a}

proposed fuel transport configuration meets applicable requirements

- 10 CFR 71.55 general requirements for fissile material packages:

... a package used for the shipment of fissile material must be so designed and constructed and its contents so limited that it would be subcritical if water were to leak into the containment system, or liquid contents were to leak out of the containment system so that, under the following conditions, maximum reactivity of the fissile material would be attained:

1) The most reactive credible configuration consistent with the chemical and physical form of the material;

2) Moderation by water to the most reactive credible extent; and

3) Close full reflection of the containment system by water on all sides, or such greater reflection of the containment system as may additionally be provided by the surrounding material of the packaging. 


\section{Calculated results frequently do not exhibit exact agreement with expectations}

- The computational method is the combination of the computer code, the data used by the computer code, and the calculational options selected by the user

- Criticality safety evaluations require validation of the calculational method with critical experiments that are as similar as possible to the safety analysis models and for which the $k_{\text {eff }}$ values are known

- The goal of this validation is to establish a predictable relationship between calculated results and reality

- A quantitative understanding of the difference or "bias" between calculated and expected results

- Uncertainty in this difference (bias uncertainty) 
The traditional approach to criticality validation is to compute bias and bias uncertainty values through comparisons with critical experiments

- Trending analyses are typically used in these comparisons

- The difference between the expected and calculated values of the effective neutron multiplication factor, $k_{\text {eff }}$ of a critical experiment is considered the computational bias for that experiment

- The uncertainty in the bias is established through a statistical analysis of the trend 


\section{Criticality analysis process}

- Develop application model and identify metrics that define it

- Select appropriate benchmark experiments

- Calculate bias and uncertainty

- Process is agnostic to application model

RCA $=$ Radiochemical assay

LCE = laboratory critical experiment

*OAK RIDGE

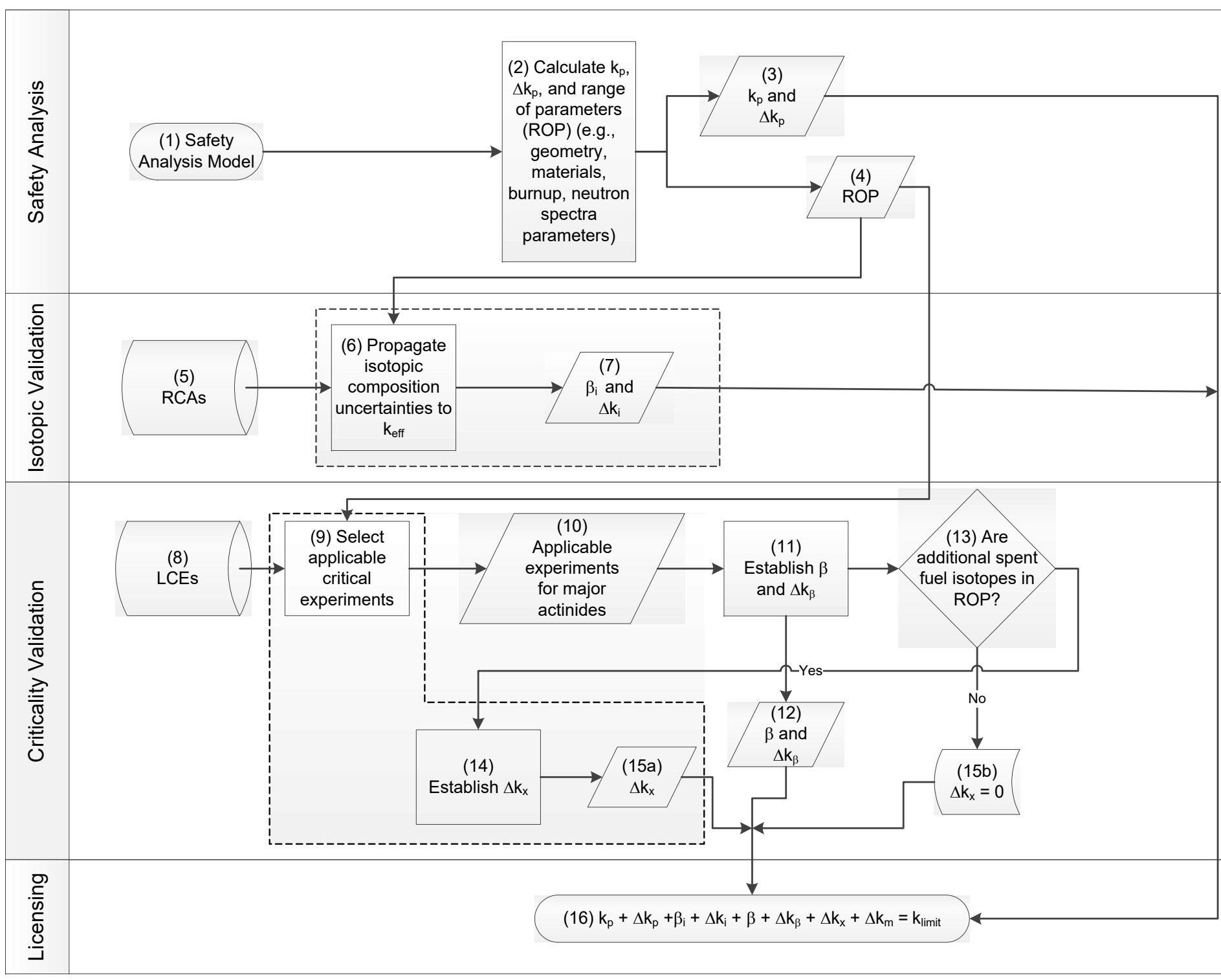

Methodology illustrated from NUREG/CR-7109 


\section{Acceptance criterion}

$\mathrm{k}_{\mathrm{p}}+\Delta \mathrm{k}_{\mathrm{p}}+\beta_{\mathrm{i}}+\Delta \mathrm{k}_{\mathrm{i}}+\beta+\Delta \mathrm{k}_{\beta}+\Delta \mathrm{k}_{\mathrm{x}}+\Delta \mathrm{k}_{\mathrm{m}} \leq \mathrm{k}_{\text {limit }}$

$\mathbf{k}_{\mathrm{p}}$ is the calculated multiplication factor of the model for the system being evaluated

$\Delta \mathbf{k}_{\mathrm{p}}$ is an allowance for statistical or convergence uncertainties, or both, in the determination of $k_{p}$ material and fabrication tolerances, uncertainties due to geometric or material representation limitations of the models used in the determination of $k_{p}$

$\boldsymbol{\beta}$ is the bias that results from the calculation of the benchmark criticality experiments using a particular calculation method and nuclear cross section data

$\Delta \mathbf{k}_{\boldsymbol{\beta}}$ is bias uncertainty that includes

- statistical or convergence uncertainties, or both, in the computation of $\beta$,

- uncertainties in the benchmark criticality experiments,

- uncertainty in the bias resulting from application of the linear least-squares fitting technique to the critical experiment results, and

- a tolerance interval multiplier to yield a single-sided $95 \%$ probability and $95 \%$ confidence level $\Delta \mathbf{k}_{\mathbf{x}}$ is a supplement to $\beta$ and $\Delta \mathrm{k}_{\beta}$ that may be included to provide an allowance for the bias and uncertainty from nuclide cross section data that might not be adequately accounted for in the benchmark criticality experiments used for calculating $\beta$

$\Delta \mathbf{k}_{\mathbf{m}}$ is a margin for unknown uncertainties and is deemed adequate to ensure subcriticality of the physical system being modeled. This term is typically referred to as an administrative margin

$\mathbf{k}_{\text {limit }}$ is the upper limit on the $k_{\text {eff }}$ value for which the system is considered acceptable

* OAK RIDGE 


\section{Selection of critical experiments}

- The critical experiments and the safety basis model need to use the nuclear data in a similar energy-dependent manner; otherwise, an incorrect bias could be generated

- Historically, similarity has been left largely to professional judgment using qualitative and integral quantitative comparisons to select critical experiments

- Qualitative parameters considered might include

- fissionable, moderating, and neutron-absorbing materials present;

- type of geometry (e.g., fuel pin lattices);

- type of neutron reflection (i.e., bare, water reflected, steel reflected, etc.);

- qualitative characterization of the energy dependence of the neutron flux as thermal, intermediate, or fast

- Quantitative parameters include

- Energy of average lethargy of a neutron causing fission (EALF)

- ratio of moderating nuclei to fissile nuclei (e.g., H/X)

- fuel enrichment

- lattice fuel pitch 


\section{Sensitivity/uncertainty ( $S / U$ ) tools can be used to assess application and critical experiment model similarity with a quantifiable metric}

- Uncertainty analysis is performed for the safety analysis (application) model and for each candidate critical experiment model

- Uncertainty analysis results rely heavily on the cross-section uncertainty data in the covariance data file

- Sensitivity is the fractional change in $k_{\text {eff }}$ due to a fractional change in a nuclear data value or $S \equiv(\Delta \mathrm{k} / \mathrm{k}) /(\Delta \sigma / \sigma)$

- Energy-dependent $k_{\text {eff }}$ uncertainties for each application model and each critical experiment are compared, producing a correlation coefficient (ck) for each application/experiment model pair

- A high ck value of near 1 for an application/critical experiment pair indicates that both models have similar sensitivities to the same nuclear data and consequently should have similar biases

- Low ck values indicate that the two systems differ significantly and may have significantly different biases 


\section{In many instances there are nuclides in the application model for which there are few or no appropriate critical experiments available}

- Historically, when a particular material could not be evaluated in a safety analysis model, the material was either removed or a $\Delta \mathrm{k}$ penalty was used based on engineering judgment

- NUREG/CR-7109 provides a validation approach for nuclides that lack experimental data (e.g., minor actinides and structural materials) for criticality safety evaluations

- The approach is based on the uncertainty in $k_{\text {eff }}$ due to nuclear data uncertainties

- Model-specific sensitivity data, which are in units of $(\Delta k / k) /(\Delta \sigma / \sigma)$, can be used to translate nuclear data uncertainties, which are in units of $\Delta \sigma / \sigma$, into uncertainty in the model $k_{\text {eff }}$ value 


\section{Plots of computational and experimental uncertainty \\ Comparison of calculated biases and experiment-specific nuclear data uncertainty in $\mathrm{k}_{\text {eff }}$ for LEU experiments}

- The plot suggests that the nuclear data uncertainties are overestimated

- It also demonstrates the relative merits of analytical techniques that can be used to address validation gaps using nuclear data uncertainties

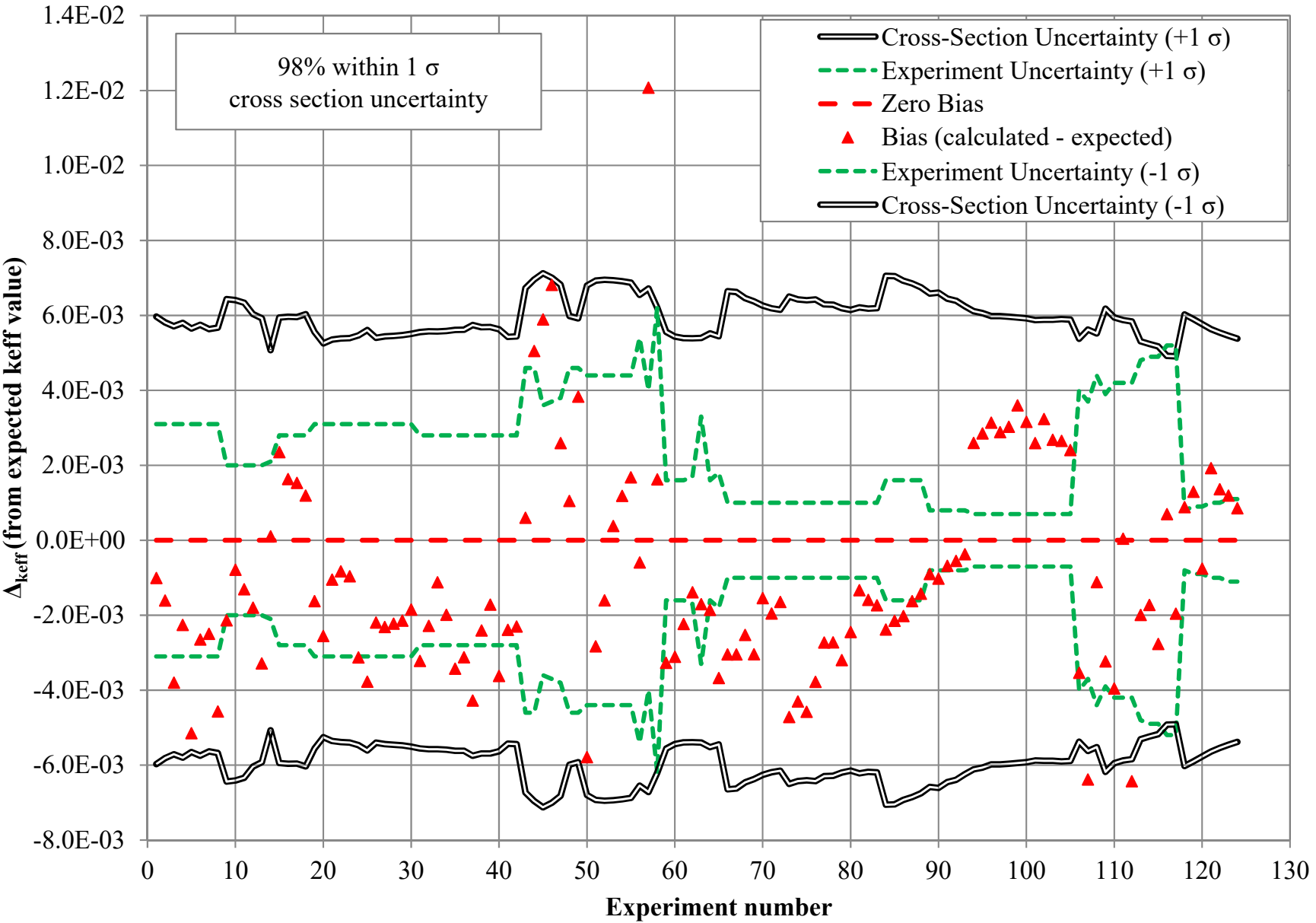
Credit Criticality Safety Analyses: Criticality (keff) Predictions, Nuclear Technology, 188:3, 266-279, DOI: 10.13182/NT13-151 


\section{Example application of process}




\section{Standard UF 6 cylinder data}

\begin{tabular}{|c|c|c|c|c|c|c|c|}
\hline Model \# & $\begin{array}{l}\text { Nominal } \\
\text { diameter } \\
\text { (in.) }\end{array}$ & $\begin{array}{c}\text { Maximum } \\
\text { enrichment } \\
\left(w^{\prime} \%{ }^{235} \mathrm{U}\right)\end{array}$ & $\begin{array}{l}\text { Fill limił } \\
\text { (lb. UF })\end{array}$ & Model \# & $\begin{array}{l}\text { Nominal } \\
\text { diameter } \\
\text { (in.) }\end{array}$ & $\begin{array}{l}\text { Maximum } \\
\text { enrichment } \\
\left.\text { (wł\% }{ }^{235} \mathrm{U}\right)\end{array}$ & $\begin{array}{l}\text { Fill limit } \\
\text { (lb. UF })\end{array}$ \\
\hline $1 S$ & 1.5 & 100.0 & 1.0 & $48 \mathrm{~F}$ & 48 & 4.5 & 27,030 \\
\hline $2 S$ & 3.5 & 100.0 & 4.9 & $48 Y$ & 48 & 4.5 & 27,560 \\
\hline $5 A$ & 5.0 & 100.0 & 54.9 & $48 \mathrm{~T}$ & 48 & 1.0 & 20,700 \\
\hline $5 B$ & 5.0 & 100.0 & 54.9 & 480 & 48 & 1.0 & 26,070 \\
\hline $8 \mathrm{~A}$ & 8.0 & 12.5 & 255.0 & 480M Allied & 48 & 1.0 & 27,030 \\
\hline $12 \mathrm{~A}$ & 12.0 & 5.0 & 460.0 & $480 \mathrm{M}$ & 48 & 1.0 & 26,070 \\
\hline $12 B$ & 12.0 & 5.0 & 460.0 & $48 \mathrm{H}, 48 \mathrm{HX}$ & 48 & 1.0 & 27,030 \\
\hline $30 B, 30 C$ & 30.0 & 5.0 & $5,020.0$ & $48 G$ & 48 & 1.0 & 26,840 \\
\hline $48 \mathrm{~A}, 48 \mathrm{X}$ & 48.0 & 4.5 & $21,030.0$ & & & & \\
\hline
\end{tabular}




\section{Kaolite-insulated packages}

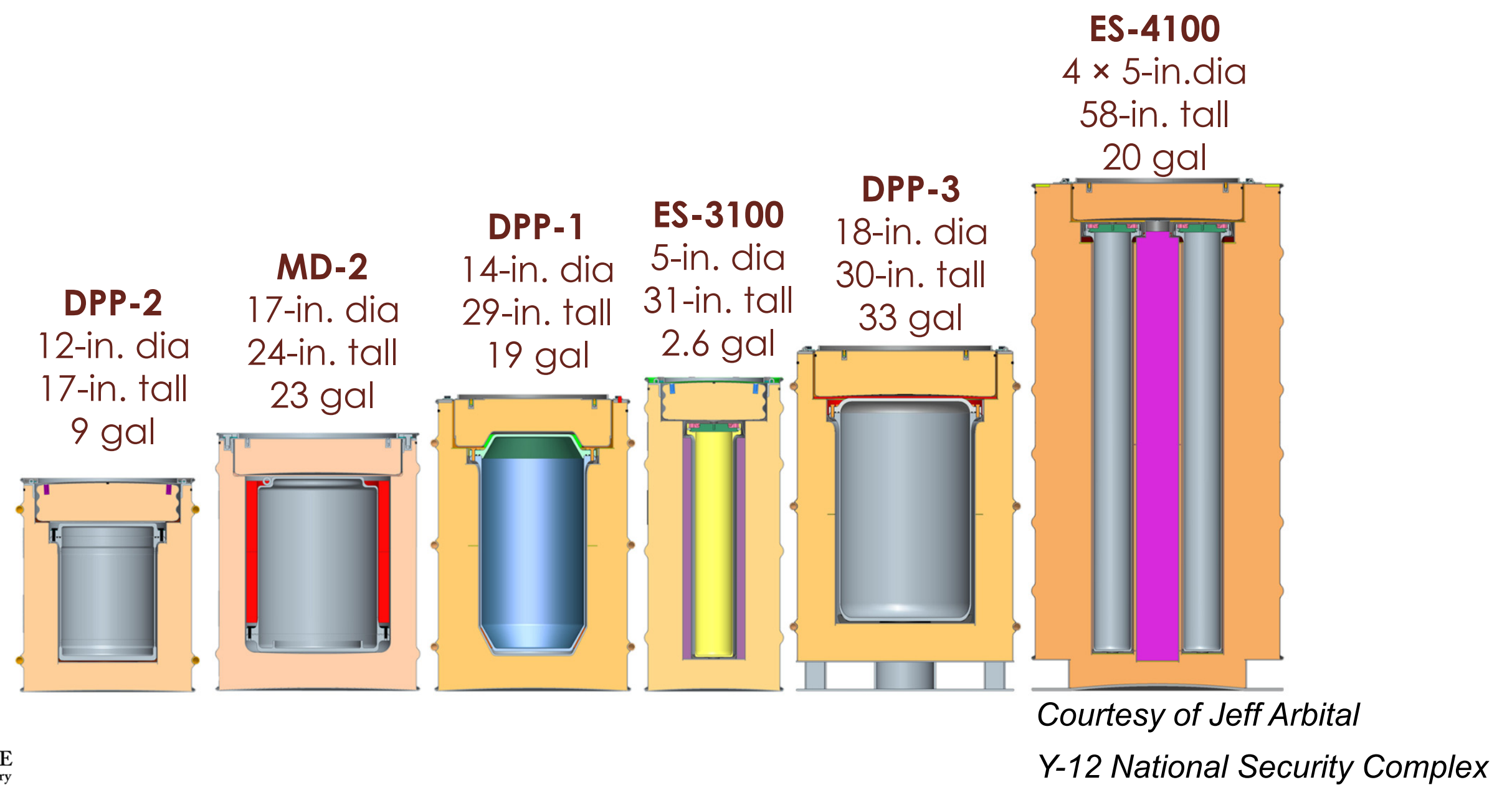




\section{Example criticality validation process using the}

ES-4100 package

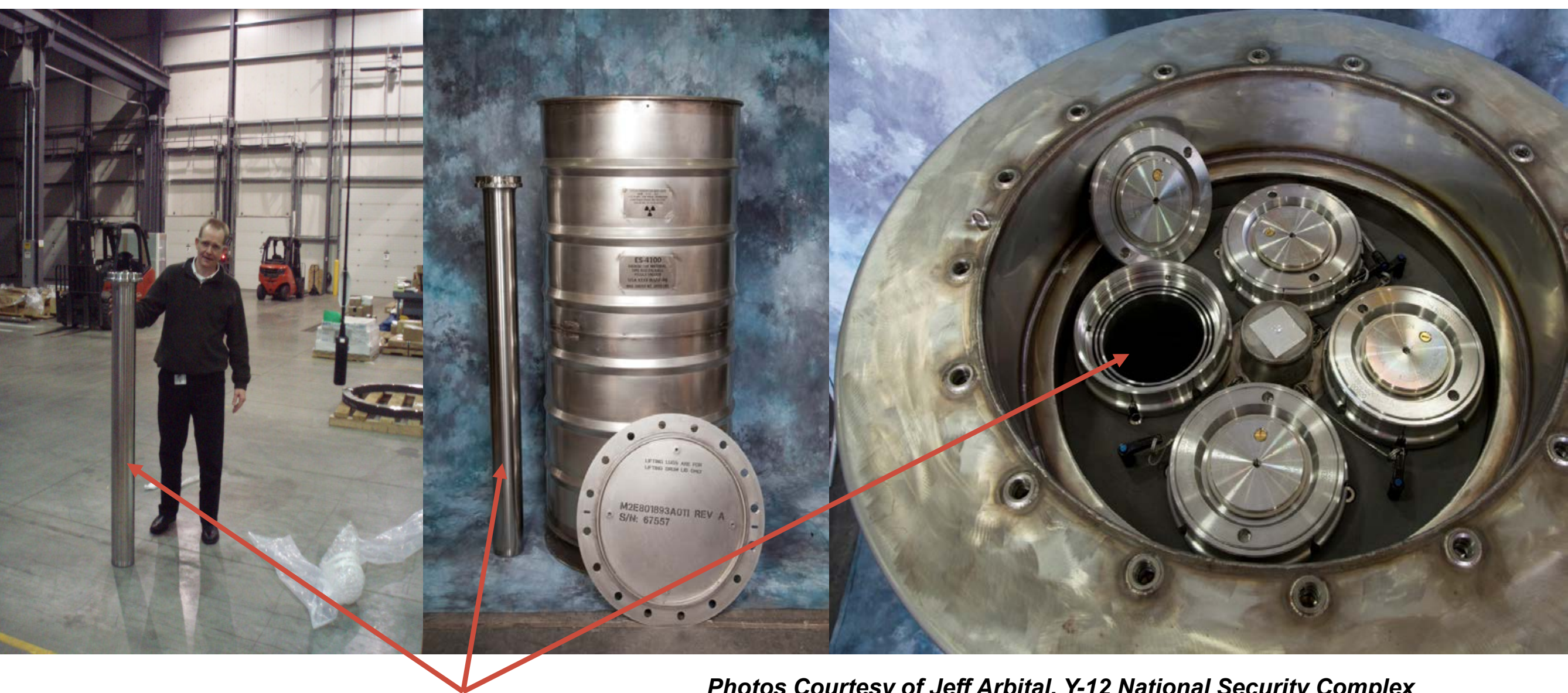

NaAK RIDGE Containment vessel 


\section{ES-4100 design features}

\section{ES-4100}

- Multi-pack: 4 containment vessels (CVs) per drum

- CV inner dimensions: 5.0-in. dia $\times 58$ in. tall

- Outer drum size: 34.0-in. dia $\times 71$ in. tall

- Insulation: Kaolite 1600

- Neutron absorber: 277-4 cast ceramic w/B ${ }_{4} \mathrm{C}$

- Gross weight: approximately 2,000 lb

- Less than gross weight of four $6 \mathrm{M}-110 \mathrm{~s}$

- Content weight allowance: $4 \times 88 \mathrm{lb}$

- Over $350 \mathrm{lb}$ of content weight 


\section{Allowable contents}

- University of Missouri Research Reactor (MURR) fuel

- Massachusetts Institute of Technology (MIT) reactor fuel

- Loose Advanced Test Reactor (ATR) fuel rods

- Materials Test Reactor (MTR)-type fuel elements and components

- Foreign Research Reactor (FRR) fuels

- Other fuels

- 1,000 g 235 $\mathrm{U}$ per CV limit

- Typical US pressurized water reactor (PWR) fuel assembly has $\sim 23,000 \mathrm{~g}^{235} \mathrm{U}$

- Typical US boiling water reactor (BWR) fuel assembly has $\sim 8,700 \mathrm{~g} 235 \mathrm{U}$ 


\section{Selection of applicable critical experiments using similarity assessment}

$\mathrm{Ck}_{\mathrm{is}}$ a correlation coefficient indicating how similar an experiment is to an application model

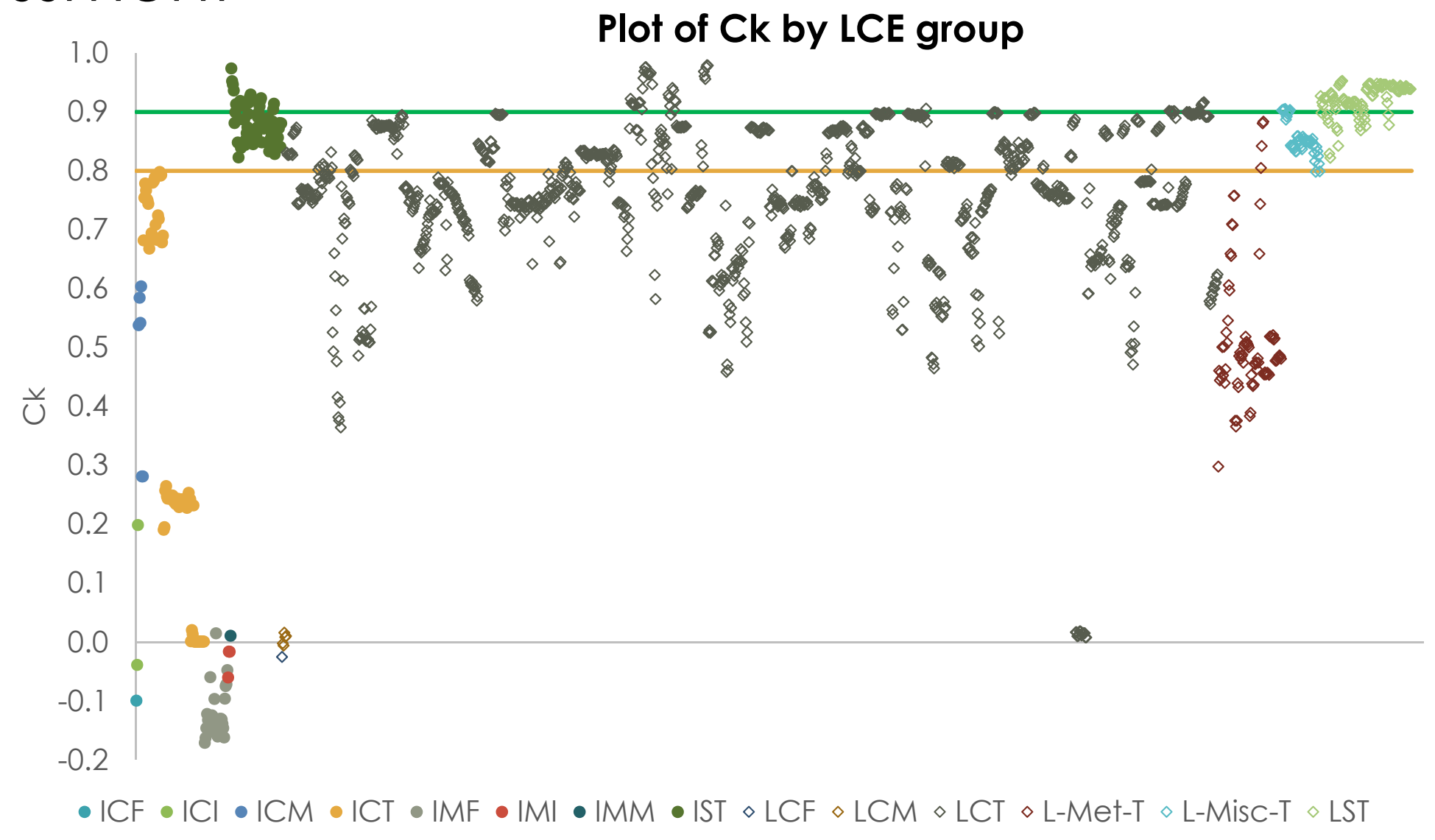




\section{Ck trended with enrichment}

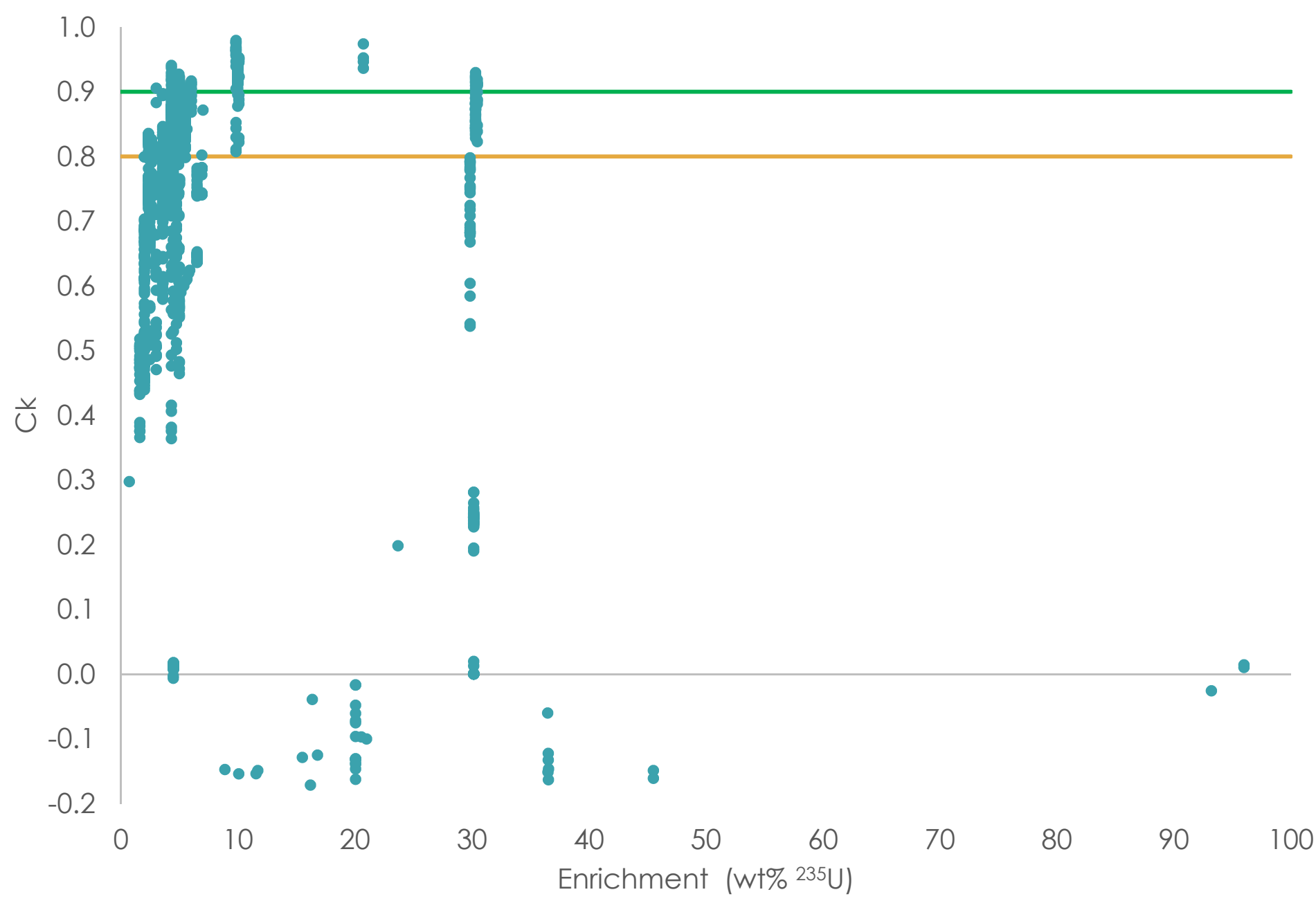




\title{
Summary of applicable critical benchmarks
}

\author{
LCEs by group
}

\begin{tabular}{|c|c|c|c|c|c|c|c|c|c|c|c|c|c|c|c|c|}
\hline \multicolumn{2}{|c|}{ Application system } & \multicolumn{15}{|c|}{ Number of applicable critical experiments } \\
\hline Package & $\begin{array}{c}\text { Enrichment } \\
\text { / BU }\end{array}$ & $\underline{U}$ & $\underline{\bar{U}}$ & $\underline{\underline{U}}$ & $\underline{\underline{U}}$ & $\stackrel{u}{\Sigma}$ & $\underline{\Sigma}$ & $\sum$ & $\underline{5}$ & U & $\sum_{U}$ & 巳一 & $\sum_{i}^{\frac{1}{10}}$ & $\begin{array}{l}\underbrace{\prime}_{j} \\
\sum_{i}^{.0} \\
\end{array}$ & 5 & Total \\
\hline \multirow[t]{3}{*}{ ES4100 } & Evaluated & 1 & 2 & 6 & 76 & 29 & 3 & 1 & 63 & 1 & 5 & 1,157 & 79 & 48 & 113 & 1,584 \\
\hline & $C k>0.9$ & 0 & 0 & 0 & 0 & 0 & 0 & 0 & 19 & 0 & 0 & 52 & 0 & 7 & 95 & 173 \\
\hline & $C k>0.8$ & 0 & 0 & 0 & 0 & 0 & 0 & 0 & 63 & 0 & 0 & 472 & 4 & 46 & 113 & 698 \\
\hline
\end{tabular}




\section{Trend analysis using initial enrichment}

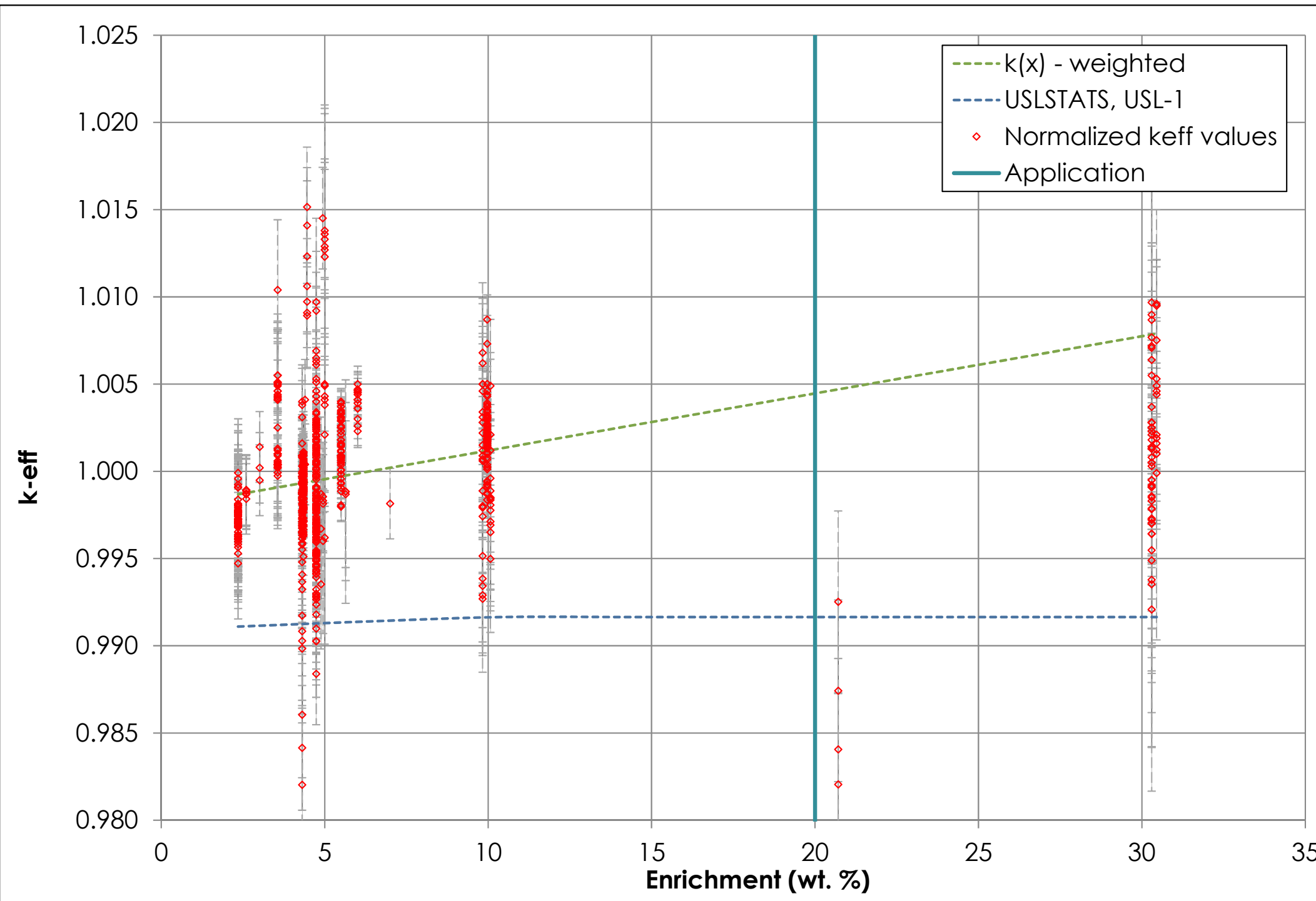




\section{Trend analysis using EALF}

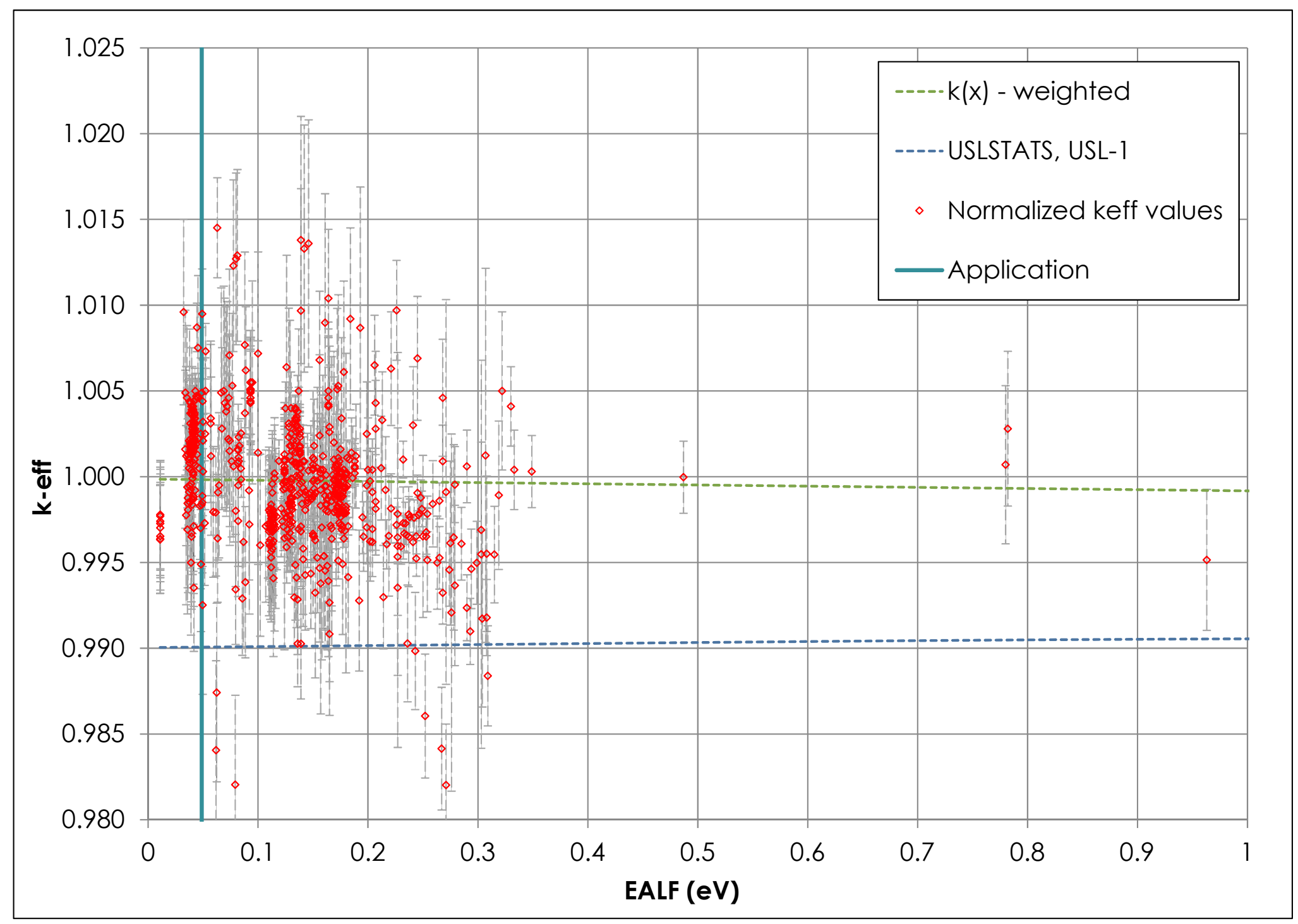




\section{Trend analysis using ck similarity coefficient}

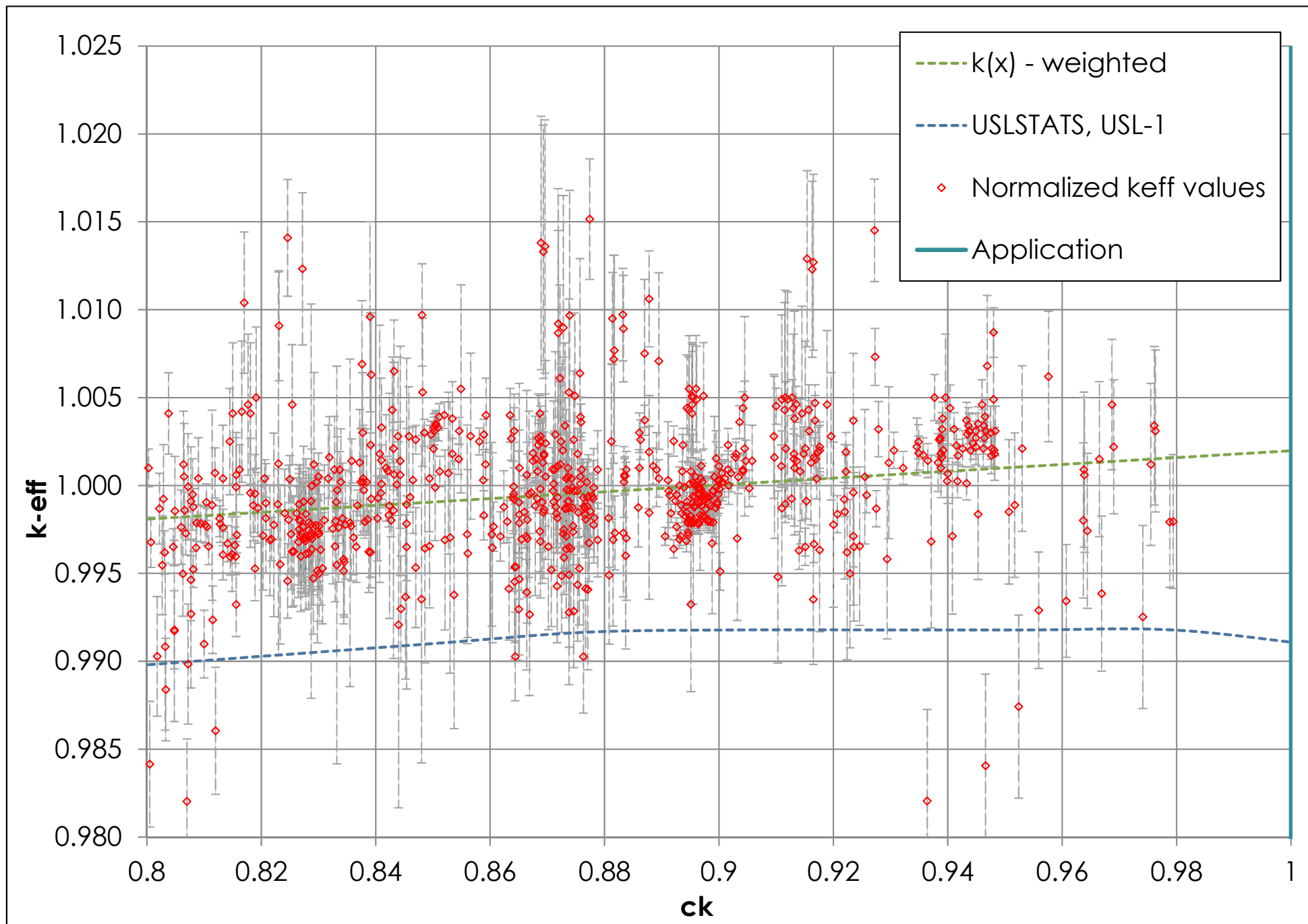




\section{Criticality ( $\left.k_{\text {eff }}\right)$ validation summary}

- Validate criticality calculational method using available critical experiment data and appropriate statistical analysis techniques

- Uncertainty in $k_{\text {eff }}$ due to nuclear data uncertainties can be used to cover validation gaps

- If new critical experiments are needed, a process exists to ensure that the critical experiment is designed to fill the gaps using existing computational tools

- The fuel form and the package's internal design are important for development of appropriate design basis configurations and selection of applicable benchmarks

- Note that it is also required to demonstrate that the fuel can be stored safely after use in the reactor (10 CFR 50)

- The same criticality experiments may or may not be applicable

- Any new experiment design should also consider storage conditions to maximize range of applicability 


\section{BACKUP}

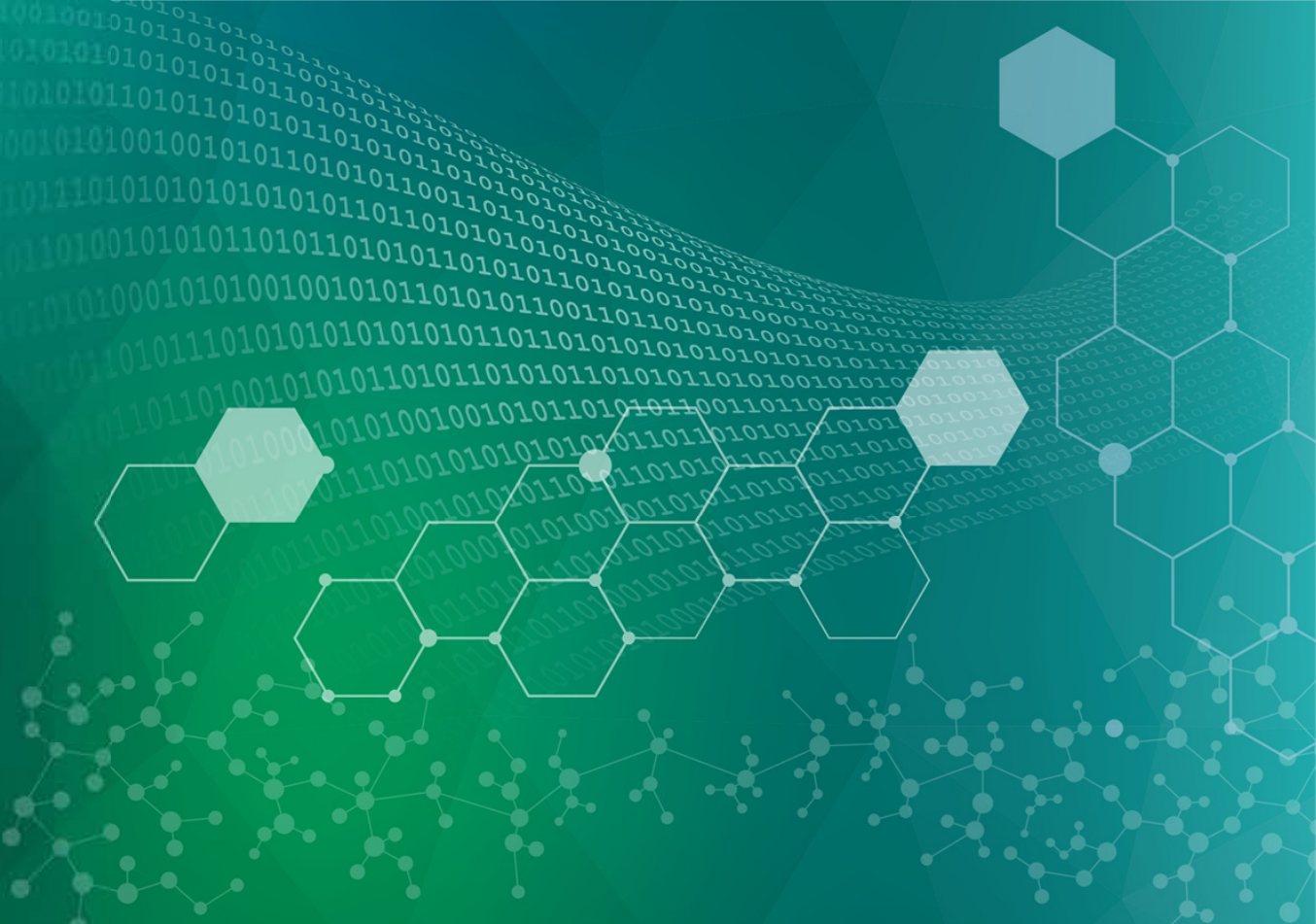

(1) ENERYY 


\section{All nuclear data used in criticality calculations have some error}

- Sources of error include

- the type of data

- the experimental apparatus and procedure used to measure the data

- the quality and amount of measured data

- nuclear models used to fill in data gaps

- the evaluation technique used to combine measured and modeled data and resolve conflicting data

- conversion of the data into formats suitable for use in the computational method 